NISTIR 7379

\title{
Building Retrofits for Increased Protection Against Airborne Chemical and Biological Releases
}

\author{
Andrew Persily \\ Robert E. Chapman \\ Steven J. Emmerich \\ W. Stuart Dols \\ Heather Davis \\ Priya Lavappa \\ Amy Rushing
}


NISTIR 7379

\title{
Building Retrofits for Increased Protection Against Airborne Chemical and Biological Releases
}

\author{
Andrew Persily \\ Robert E. Chapman \\ Steven J. Emmerich \\ W. Stuart Dols \\ Heather Davis \\ Priya Lavappa \\ Amy Rushing \\ Building and Fire Research Laboratory
}

Prepared for: U.S. Environmental Protection Agency Research Triangle Park, NC

Funded under IAG DW-13-93010301-0 by the U.S. EPA National Homeland Security Research Center (NHSRC), Decontamination and Consequence Management Division (DCMD)

March 2007

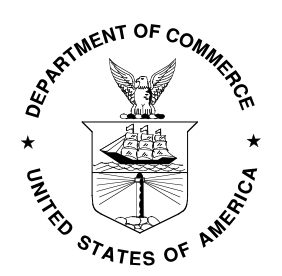

U.S. Department of Commerce Carlos M. Gutierrez, Secretary

Technology Administration Robert Cresanti, Undersecretary of Commerce for Technology National Institute of Standards and Technology William A. Jeffrey, Director 



\section{ABSTRACT}

Due to concerns about potential airborne chemical and biological (chembio) releases in or near buildings, building owners and managers and other decision makers are considering retrofitting buildings to provide some degree of protection against such events. A wide range of technologies and approaches are being proposed with varying levels of efficacy and cost, as well as varying degrees of applicability to particular buildings and ventilation systems. This document presents the results of an effort to evaluate chembio retrofit options for buildings. A number of retrofit options are identified, and their potential to protect building occupants from a number of generic contaminant releases is evaluated using building airflow and contaminant transport modeling. In addition, a case study is presented in which specific retrofit options were considered for two actual buildings and pre-installation designs and cost estimates were developed. Based on the analyses performed, the results of the case study and other available information, guidance on the application and effectiveness of various retrofits are presented. An economic analysis software tool employing life cycle cost analysis techniques was developed as part of this project, and its use is described in an appendix to this report.

The retrofit options considered fall into two categories, the first being stand-alone technologies or devices such as enhanced particulate filtration that are installed and implemented as purchased. The second category includes retrofit approaches that employ operational strategies or building modifications to increase building protection, such as outdoor air purging or building envelope airtightening. The guidance section describes each retrofit technology and approach in some detail, presenting relevant performance data and the level of protection that might be expected from the retrofit. Potential disadvantages and knowledge gaps are also discussed for each technology. The retrofit technologies considered include enhanced particle filtration, sorbent based gaseous air cleaning, ultraviolet germicidal irradiation, photocatalytic oxidative air cleaning, and work area air capture and filtration equipment such as mail handling tables. The approaches include ventilation system recommissioning, building envelope airtightening, building pressurization, relocation of outdoor air intakes, shelter-in-place (SIP), isolation of vulnerable spaces such as lobbies, system shutdown and purge cycles, and automated heating, ventilating and air-conditioning (HVAC) operational changes in response to contaminant sensing. The filtration and air cleaning options are noted to have an advantage of always being operational, which is an advantage as long as the systems are properly designed, installed and maintained. However, the lack of standard test methods for sorbent-based gaseous air cleaning and other air cleaning approaches is identified as a critical issue in the application of these technologies. Building envelope air sealing and pressurization can be quite effective in protecting against outdoor releases as long as effective filtration against the contaminant of concern is also in place. The protection provided by operational changes such as system shutdown and purging are shown to be very dependent on the timing of their implementation, with the possibility of increasing occupant exposure if the timing is inappropriate. Isolating vulnerable zones and other system related modifications are highly dependent on the building layout and system design, and their implementation must be well conceived to be effective under the range of conditions that exist in buildings. Finally, many retrofits are noted as also providing additional benefits of increased energy efficiency and improved indoor air quality, which should be included in the life-cycle cost comparison of different options to the degree possible.

Keywords: air cleaning, building protection, CBR, chembio, filtration, indoor air quality, lifecycle costs, terrorism 


\section{Use of Non-SI Units in a NIST Publication}

The policy of the National Institute of Standards and Technology is to use the International System of Units (SI units) in all its publications. However, in the North American construction and heating, ventilating and air-conditioning (HVAC) industries, certain non-SI units are so widely used instead of SI units that it is more practical and less confusing to include values in non-SI units in portions of this publication. 


\section{TABLE OF CONTENTS}

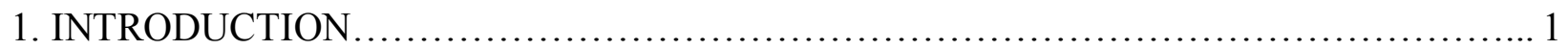

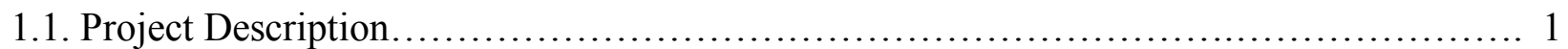

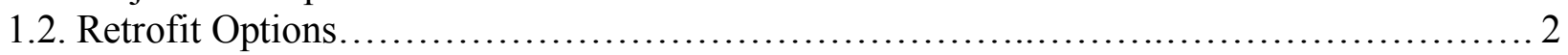

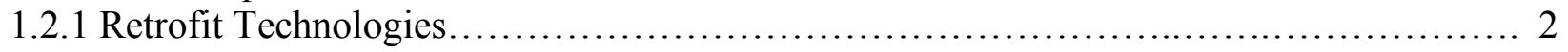

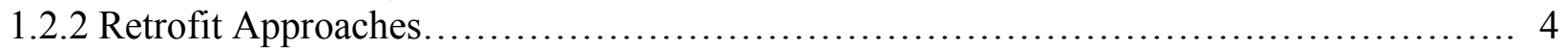

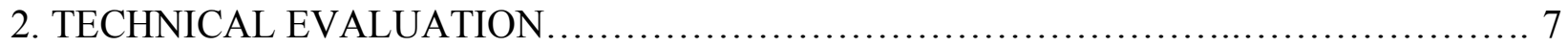

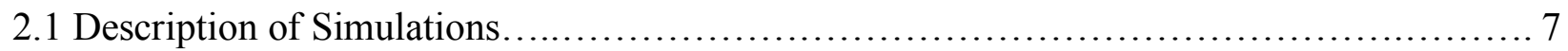

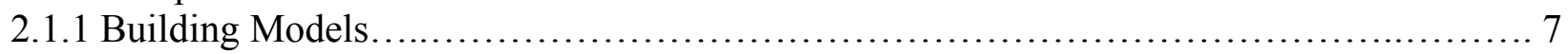

2.1.2 Contaminants and Release Scenarios.............................................. 10

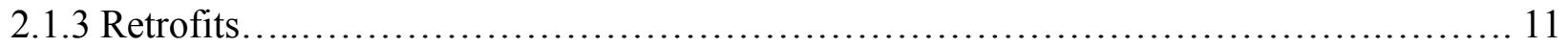

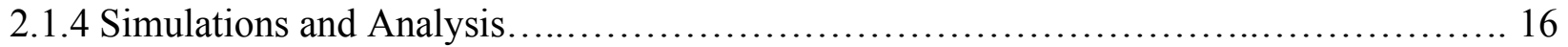

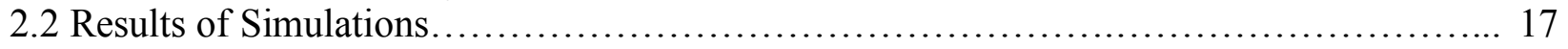

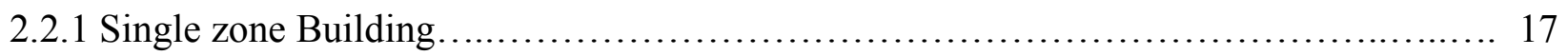

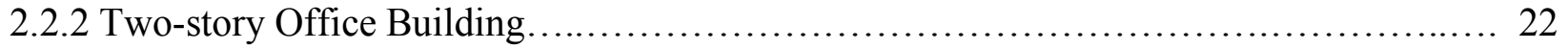

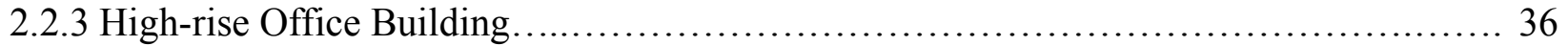

2.3 Summary of Simulation Results..................................................... 43

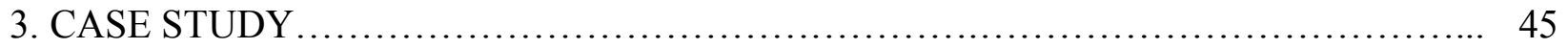

3.1 Description of Buildings and Retrofits Considered................................ 45

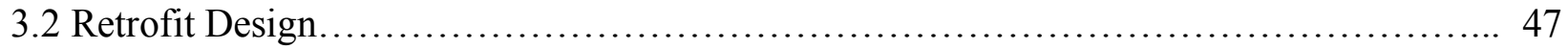

3.3 Economic Evaluation ............................................................. 50

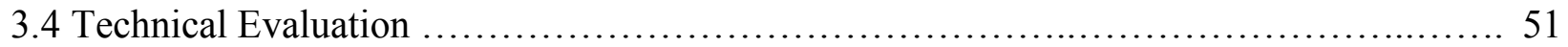

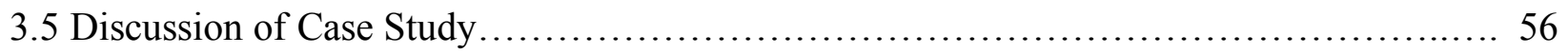

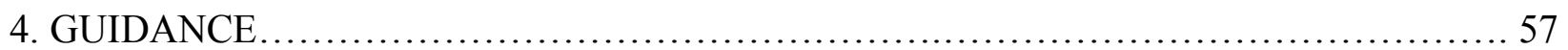

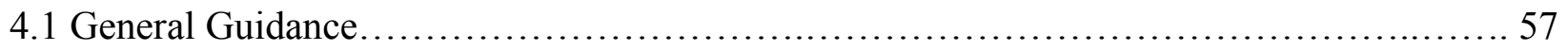

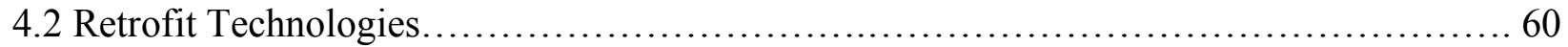

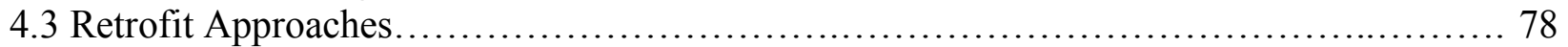

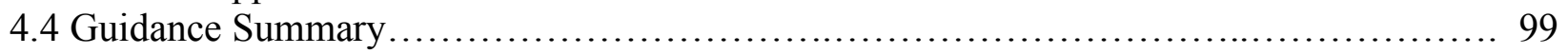

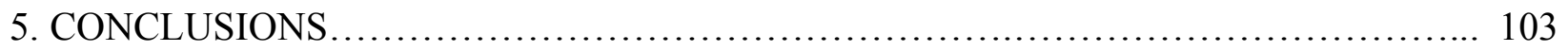

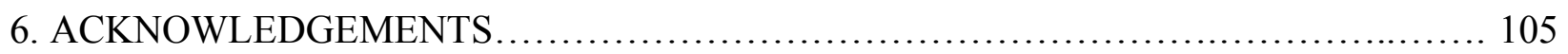

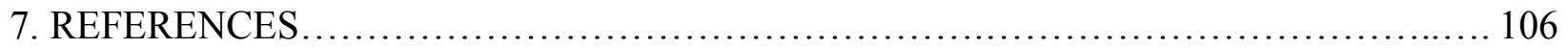

APPENDICES
A. Life-Cycle Cost Analysis Tool for Chem/Bio Protection of Buildings: Software Primer.... 111

B. Case Study Retrofit Design Documentation.................................................. 143

C. Case Study Retrofit Costs Per Unit of Floor Area....................................... 157 


\section{LIST OF ACRONYMS}

A\&E: architectural and engineering, with reference to firms that do both types of design work ASHRAE: American Society of Heating, Refrigerating and Air-Conditioning Engineers ASZM-TEDA: military grade carbon sorbent, impregnated with copper, silver, zinc, molybdenum and triethylenediamine

BASE: Building Assessment, Survey and Evaluation (EPA study of 100 U.S. office buildings)

BFRL: Building and Fire Research Laboratory (part of NIST)

CMU: concrete masonry unit (type of wall construction block)

CONTAM: NIST-developed multizone airflow and contaminant dispersal simulation program

CSEPP: Chemical Stockpile Emergency Preparedness Program (FEMA program)

ELA: effective leakage area

EPA: Environmental Protection Agency

FEMA: Federal Emergency Management Agency

GPAC: gas-phase air cleaning

HEPA: high-efficiency particulate air filters

HVAC: heating, ventilating and air-conditioning

IAQ: indoor air quality

LCAT: Life-Cycle Cost Analysis Tool, NIST-developed software for comparing retrofit options

LCC: life-cycle cost, method for economic comparison of retrofit options

MERV: minimum efficiency reporting value, metric of particle filtration efficiency based on ASHRAE Standard 52.2

NIST: National Institute of Standards and Technology

OAE: Office of Applied Economics (part of BFRL)

PCO: photocatalytic oxidation

PVNS: present value of net savings, method for economic comparison of retrofit options

SIP: shelter-in-place

TAB: testing, adjusting and balancing; procedure for confirming ventilation system operation relative to design

ULPA: ultra low-penetration air filters

UV: ultraviolet

UVC: C-band wavelength of UV radiation, generally less than $280 \mathrm{~nm}$

UVR: UVGI rating value

UVGI: ultraviolet germicidal irradiation 


\section{INTRODUCTION}

Due to concerns about potential airborne chemical and biological (chembio) releases in or near buildings, building owners and managers and other decision makers are considering retrofitting buildings to increase protection against such events. A range of technologies and approaches are being proposed with varying levels of efficacy and cost, as well as varying degrees of applicability to particular buildings and ventilation systems. While a number of useful guidance documents have been published (ASHRAE 1993, NIOSH 2002 and 2003), most of these do not the address the selection of appropriate and cost-effective retrofits for specific buildings. In order to address this need for better guidance on building retrofits to increase protection against chembio releases, the Building and Fire Research Laboratory (BFRL) at the National Institute of Standards and Technology (NIST) undertook the project described in this report.

\subsection{Project Description}

The purpose of the project is to provide building owners, managers, engineers, and other decision makers with information about retrofit options to improve the safety of buildings against airborne hazards and with economic analysis tools for use in selecting cost-effective approaches to mitigating those hazards. This project was organized around a number of tasks, the first two of which were to identify the retrofit options to be considered in the project, and to establish the methods to use in the technical and economic evaluations of the retrofit options. The next task was to conduct a technical evaluation of the protection impacts of the retrofits using building airflow and contaminant transport modeling. This evaluation is described in Section 2 of the report. These simulations involved the analysis of three buildings subjected to generic particle and gaseous releases to determine the reduction in occupant exposure as a result of implementing the various retrofits. Section 3 of the report presents a case study in which specific retrofit options were investigated for two buildings and pre-installation designs and cost estimates were developed. Finally, guidance on the application and effectiveness of various retrofits is presented in Section 4.

A key effort within the project was to formulate methods for economic analysis that provide lifecycle cost (LCC) information about retrofit options to assist decision makers in choosing how to improve the safety of their buildings. An economic analysis software tool was developed (available for download at www2.bfrl.nist.gov/software/LCCchembio/index.htm), with a software primer included in Appendix A to this report The economic analysis methodology includes the following considerations: the assumptions and information requirements necessary to compute the costs of each retrofit option; the methodology for combining information about first costs with operations, maintenance, and repair costs and with other costs to compute the life-cycle costs of the retrofit options; and specifying the appropriate circumstances for applying this methodology to cost analyses of retrofit options. The economic analysis methodology includes two metrics of the cost effectiveness of alternative investments, life-cycle cost and present value of net savings.

It is important to note that every building and its ventilation systems and every contaminant release scenario are unique. Therefore the information presented here must be considered in the context of a specific building's characteristics, including layout, system type and design, and occupancy. The level of protection in a given situation is highly dependent on these characteristics and the nature of the contaminant release, and it is extremely difficult to make general statements about what strategies will be effective in a given situation and to what degree. Nevertheless, this project is based on the philosophy that better protection is a worthy goal, even if the degree of protection cannot be characterized in general terms. 


\subsection{Retrofit Options}

The first task in this project was to identify candidate retrofit options for consideration in the technical evaluations of the study and for potential inclusion in the resultant guidance itself. These options are divided into two basic categories, specific technologies, such as filtration and air cleaning devices, and more generic approaches to increasing building protection such as building pressurization strategies and isolation of areas of potential concern (e.g. mail rooms). These options have been identified based on information in the published literature, information from vendors, and interactions with researchers, consultants, government agencies, building contractors, HVAC experts, and other knowledgeable individuals. The options that are considered are limited to engineering-based retrofits as opposed to building and personnel management options such as building security and evacuation. Obviously, building management practices can play a major role in increasing building protection, but they are not within the scope of this project. In addition, the options considered are restricted to those that are "off-theshelf" or commercially available today. While much research and development is currently in progress that will result in more options in the future, only currently available technologies are being considered.

This section presents the technologies and approaches that have been identified, including a discussion of the performance data that is relevant to the simulations planned for the project and a summary of other issues related to the retrofit that are relevant to the study.

\subsubsection{Retrofit Technologies}

A number of technologies have the potential to increase building protection against chembio agent releases. Most of these are in the particle filtration and gaseous air cleaning categories. Other technologies for building protection include systems for use in mail rooms, and other spaces that may be more vulnerable to agent releases, to capture and remove the agents before they are able to migrate to other portions of the building.

\section{Enhanced particle filtration}

Particle filtration is currently employed in most commercial and institutional buildings, primarily to limit dirt buildup on cooling coils and other wetted surfaces in order to reduce the potential for microbial growth and to maintain good heat transfer between the air and the coil surfaces. However, typical levels of filtration are not always very effective in removing particles of the sizes associated with many biological agents, i.e., on the order of $1 \mu \mathrm{m}$. Nevertheless, dramatic increases in removal rates can still be achieved through enhanced filtration without the use of very high levels of efficiency (NIOSH 2003). Particle removal efficiencies are fairly well established based on the use of ASHRAE Standard 52.2 (ASHRAE 1999), which provides a rating method referred to as Minimum Efficiency Reporting Value (MERV).

The implementation of enhanced filtration involves a number of important issues. First, the particle size of interest must be considered. Biological agents vary in size, but the bacteria and spores of most interest are generally on the order of $1 \mu \mathrm{m}$ to $10 \mu \mathrm{m}$. In addition, the installation of more efficient filters will generally result in an increase in the pressure drop across the filter. Depending on the increase in filter efficiency and the type of filter installed, the increase in pressure drop may or may not be particularly large. In some cases, the air handling equipment will need to be modified due to the increased pressure drop. 
Sorption based gaseous air cleaning

Sorption based gaseous air cleaning is currently employed in a number of applications to control odorous, corrosive or otherwise undesirable gases generated within or outside of buildings. A variety of sorbents are employed including activated carbon, alumina and sorbents impregnated with compounds to enhance their ability to remove specific contaminants (NIOSH 2003, ASHRAE 2003). These sorbents have varying degrees of removal effectiveness depending on the particular sorbent-contaminant combination, and they capture contaminants through either physical adsorption or chemisorption. Some sorbents employing the former mechanism can be regenerated through heating or other processes. Adsorbents using a chemisorption process generally rely on catalytic (continuously self-regenerating) reactions that chemically decompose the threat gases into less toxic or non-toxic gases. The effectiveness of sorbent-based air cleaners also depends on temperature, humidity, the concentrations of the contaminant of interest as well as other contaminants, and the residence time of the airstream in the air cleaning unit. Gaseous air cleaning devices are not typically employed in commercial and institutional buildings but are seeing increasing use in a number of applications. There are no standard test methods for determining the contaminant removal efficiency of gaseous air cleaning equipment for use in selecting and sizing these systems. Manufacturers have performance data and experience that can be useful, but efforts to develop the equivalent of a MERV rating for gaseous air cleaning are still being pursued.

In general, gaseous air cleaning systems are associated with a more significant pressure drop than particle filtration devices and require more space than typical filtration equipment. These increased pressure drops can in turn affect system airflow rates and may require significant system modifications. These devices must be changed at intervals that depend on their capacity, the concentrations to which they are exposed, and the degree of temperature and humidity control in the system.

Ultraviolet germicidal irradiation (UVGI):

UVGI systems have been used for many years to kill airborne infectious agents in healthcare facilities and other venues, primarily to control the transmission of tuberculosis. These devices use ultraviolet irradiation in the $250 \mathrm{~nm}$ to $260 \mathrm{~nm}$ wavelength range and are generally installed in the upper portions of a room with shielding to protect the occupants or in ductwork where such shielding is not required. This application is distinct from the use of UVGI to kill biological contamination on exposed cooling coils resulting from dirt accumulation and condensation.

The effectiveness of these devices is primarily a function of device geometry, intensity of the light source, microbial resistance and residence time of the agents of concern. Inactivation or "kill" rates can be predicted with a fair level of reliability based on these parameters (VanOsdell and Foarde 2002). However, there is no standard test method for determining the effectiveness of these devices and they are not generally supplied with the performance data to determine kill rates. These devices are associated with electrical energy consumption and require some level of maintenance to keep them operating effectively.

Photocatalytic oxidation air cleaning (PCO)

PCO is an air cleaning approach in which titanium dioxide $\left(\mathrm{TiO}_{2}\right)$ acts as a photocatalyst when irradiated by UV light, removing organic chemicals including both chemical and biological agents. If the photocatalytic reaction is $100 \%$ complete, the byproducts include water and carbon dioxide, but complete conversion is difficult to achieve in practice. 
Various PCO devices are available as either portable, stand-alone units or in-duct devices. However, the lack of test methods for gas or biological removal limits the availability of performance data.

PCO systems generally have low pressure drops in comparison to particle filters and sorption based gaseous air cleaning. However, questions exist as to the useful life of the catalysts in practice and the production of undesirable byproducts associated with incomplete photochemical reactions.

\section{Work area treatment}

A variety of devices are available for capturing and removing particulates from work areas, e.g. mail opening stations. These devices are essentially air capture hoods combined with highefficiency filtration systems. Some of these devices also incorporate anti-microbial elements, gaseous air cleaning components and UVGI.

The performance of these devices is generally expressed as a filter efficiency at a specific particle size and an airflow rate. Units with anti-microbial or gaseous air cleaning capabilities are impacted by the lack of standard test methods noted earlier. Another important parameter is the contaminant capture effectiveness, but this is not generally covered in the product specifications.

\subsubsection{Retrofit Approaches}

In addition to the specific technologies described above, there are a number of retrofit options that also have the potential to increase building protection against chembio releases. This section describes options that do not involve a specific technology but rather a general strategy for building and system design or operation.

\section{System recommissioning}

Assessing the vulnerability of a building to a chembio release and using the ventilation system as part of a protective strategy require that the system design be understood and that the system be operated as intended. Ventilation system recommissioning is a process by which a system's operation is brought into line with its design intent. Depending on the system, recommissioning can involve a number of items including the following: airflow testing and balancing; calibration of temperature, humidity and other sensors used to control system operation; checking dampers for proper operation; reviewing system operating schedules; and confirming system capacity relative to current loads.

The impacts of a recommissioning effort will depend on the design of the ventilation system and the degree to which the system has "drifted" away from its design specifications. In addition to increasing building protection, building recommissioning can also increase energy efficiency, improve indoor air quality and extend equipment life.

\section{Envelope tightening}

Based on the available data, the exterior envelopes of U.S. commercial and institutional buildings are fairly leaky (Emmerich and Persily 2005). This leakage in combination with indoor-outdoor pressure differences caused by weather and system operation can lead to significant infiltration rates and the entry of exterior chembio agents without the possibility of removing them through filtration or air cleaning. Therefore, tightening of building envelopes has the potential to increase building protection.

Envelope tightening can also improve building energy efficiency by reducing heating and cooling loads due to infiltration (Emmerich et al., 2005a and 2005b, Emmerich and Persily 
1998). In addition, building indoor air quality can improve due to the reduction in unfiltered and uncontrolled infiltration.

\section{Building pressurization}

This approach involves protecting a building against outdoor chembio releases through the overpressure of the building interior relative to outdoors and the removal of the outdoor agent from the intake air via filtration or air cleaning. The idea behind this strategy is for the building to be pressurized continuously under normal operation, not as a response strategy in the event of a release. To be effective, the amount of air must be sufficient to overcome negative pressures that can be induced by weather and the operation of other systems. This approach is more likely to be effective in a building with a tight envelope than a leaky one.

This approach is characterized by the net amount of outdoor air intake relative to exhaust or spill air, the envelope airtightness, the weather conditions and the filter/air cleaner removal efficiency. The cost and maintenance issues associated with filtration are also relevant to this approach. In addition, ventilation system airflow rates and controls may need to be modified to achieve the desired levels of pressurization. As with envelope tightening, this approach can have a positive impact on indoor air quality (IAQ) by reducing infiltration of contaminated air.

\section{$\underline{\text { Relocation of outdoor air intakes }}$}

Unless otherwise protected, ground level air intakes are more likely to be exposed to the intentional release of a chembio agent relative to more inaccessible intakes. One potential solution is to relocate the intake to a higher elevation that will presumably be harder to access.

There is no quantity that characterizes the degree of accessibility of an air intake, but presumably an intake that is located at a higher elevation is less likely to be subject to a ground level release. Locating outdoor air intakes well above ground level also reduces the entry of contaminants associated with landscaping and other activities. There is clearly a cost associated with relocating air intakes, which in some cases can be quite significant. In addition, the relocation may modify the airflow resistance associated with the intake, thereby requiring other modifications to the air handling system.

\section{Shelter-in-place (SIP)}

In the event of an exterior release, and in some cases an interior release, the building occupants can move to a designated space that is isolated from the rest of the building and offers protection from the airborne agent. The degree of protection will increase if the space is well isolated in terms of airflow by having tight boundaries and even more if it is equipped with a filtration and air cleaning system to remove contaminants that have entered the space. Self-contained filtration and air cleaning system for use in SIP spaces are currently commercially available.

The primary variables describing this approach include the airtightness of the interior partitions and, if filtration or air cleaning is employed, the supply airflow rate to the space and the filter/air cleaner removal efficiency. There is some cost involved in setting up such an arrangement, particularly in terms of any airtightening involved and the equipment costs for an oversupply and cleaning system. The system will also require some maintenance to ensure it will function properly in the event it is needed. 
Isolation of special-use spaces

Due to the potential vulnerability of mail rooms, loading docks and lobbies to chembio releases, keeping these spaces at a lower pressure than adjacent portions of the building can provide some protection. Such isolation can be achieved through ventilation airflow control, e.g., exhaust fans, and will generally be easier to achieve if these spaces are served by a dedicated system. This approach is more likely to be successful if the boundaries between the vulnerable space and the rest of the building are tight.

There may be some initial costs associated with airtightening or with modifications of system airflow rates to achieve the desired pressure relationships. The latter will require maintenance in terms of periodically checking the system balancing to verify that these pressure relationships are still in effect. In some cases a new air handling system may need to be installed, as well as controls to modulate the system airflows in response to the real-time pressure monitoring between the space and an adjacent space.

\section{System shutdown and purging}

In some circumstances, shutting down a building ventilation system or operating it at $100 \%$ outdoor air intake (purging) may help protect the building occupants from exposure to a chembio release. However, realizing these benefits requires knowledge that the release has occurred, that one of these options is the appropriate response, and switching to the desired ventilation mode quickly. A dedicated control that implements the operational strategy is one means of making the change relatively quickly, though a fast shutdown requires quick-acting and tight-sealing dampers, fan braking mechanisms and specially-constructed ductwork to prevent ducts from collapsing, all of which are not typically employed in commercial building ventilation systems. Also, running a building in a purge mode can result in pressure differences that make it difficult for building occupants to open and close doors.

\section{Automated HVAC response}

Given a timely and reliable signal from a contaminant sensor, or perhaps an occupant generated signal, a building's automated control system could modify the ventilation system operation in a manner that contains the contaminant in the zone of release, or prevents it from entering a building in the case of an outdoor release, and maintains the rest of the building and egress paths at low contaminant concentrations. These modifications could include stopping and starting fans, repositioning dampers, or securely closing doorways. This is the concept behind automated smoke control systems that have been used for many years (Klote and Milke 2002) to contain smoke in the fire zone and provide a safe evacuation route for the building occupants. The manner in which a system's configuration and operation should be modified depends on the building and system design and layout, and the nature of the contaminant release.

In theory, if the sensors and system capabilities were available, and the building and system airflow dynamics were well understood, this approach would be able to provide a high level of protection. However, sensors that are fast, reliable and inexpensive enough are not currently available for any applications other than very high security buildings where the costs are justified. 


\section{TECHNICAL EVALUATION}

In order to support the guidance to be developed as part of this project, technical evaluations of the retrofit options were conducted to estimate the impacts of the retrofits on occupant exposure. These evaluations employed simulations of generic building and system configurations, with contaminants intended to represent generic chembio agents, as described below.

\subsection{Description of simulations}

The technical evaluations of the retrofits involved simulations of airflow, contaminant transport and occupant exposure in selected buildings using the multizone airflow and indoor air quality model CONTAM (Walton and Dols 2005). The general concept of the evaluations is to simulate generic contaminant releases within or outside a building and calculate the occupant exposure, and then to repeat the process for the same building and release scenario with one or more retrofits in place. The cases without the retrofits are referred to as the baseline cases. The measure of retrofit performance is based on the change in occupant exposure, i.e., the retrofit exposure as a percentage of the baseline exposure.

The CONTAM simulation program was used based on its demonstrated ability to model multizone airflow and contaminant transport in building systems, as well as the project team's familiarity with the program. CONTAM considers a building as a system of interconnected volumes or zones, each at a uniform temperature and contaminant concentration. These zones can be rooms, hallways, floors of a building, stairwell shafts, etc. Airflow paths between zones, and between zones and the outdoors, are specified in the building model along with other relevant information such as ventilation system airflows, weather, and wind pressure coefficients on exterior surfaces. Using these inputs, CONTAM calculates airflow rates between each zone, under either steady state or transient weather and system operation conditions, based on a simultaneous mass balance of air in each zone. Given additional information on contaminant sources and removal mechanisms and outdoor contaminant concentrations, CONTAM determines contaminant concentrations in the zones based on the calculated airflow rates and contaminant-specific information.

\subsubsection{Building Models}

The project focus on commercial and institutional buildings served to define the buildings studied in the simulations, which are described in Table 1.

\begin{tabular}{|c|c|c|l|}
\hline & \# of stories & Floor area, $\mathbf{~ m}^{\mathbf{2}}\left(\mathbf{f t}^{\mathbf{2}}\right)$ & \multicolumn{1}{|c|}{ System Type } \\
\hline 1, Single-zone & 1 & $1000(10800)$ & Simple air handler \\
\hline 2, Office & 2 & $2600(28000)$ & Single air handling system \\
\hline 3, Office & 14 & $11,900(128000)$ & Central air handling systems \\
\hline
\end{tabular}

Table 1 Simulated Buildings

Building \#1 is a simple, single-zone model of a building included to examine first order effects of ventilation, filtration, and infiltration without the complexities of weather, interior zoning, etc. The various airflow rates are input to the model, rather than calculated as in the other building models. Only some of the retrofits apply in this building, but its simplicity makes it easier to understand the impacts of each option. The 2-story office building model is more detailed, including some interior zoning such as stair and elevator shafts and ceiling return plenums, a more realistic ventilation system, and the calculation of weather-driven infiltration associated 
with envelope leakage. Building \#3 contains a lobby, mail room and loading dock, and is modeled with central air handling systems.

In order to create CONTAM models of these buildings, a number of factors need to be defined, including the building zoning, occupancy levels, airtightness of the exterior and interior walls, and ventilation systems. The manner in which these factors are handled in each of the buildings is described below.

\section{$\underline{\text { Zones }}$}

While the number of stories of each building is listed in Table 1, the subdivision of these stories into zones in the CONTAM representation of each building must also be defined. In addition, some of the simulations involve lobbies, mail rooms and loading docks, which must also be specified in each building model. The buildings are zoned as described below:

1-zone building: single zone, with no lobby, mail room or loading dock.

2-story office: two levels per floor, the occupied space and the return plenum above the suspended ceiling; two toilet rooms with exhaust airflow on each floor; an elevator and a stair shaft in the building core, both of which are two stories tall; a lobby zone and loading dock door on the first floor, but no mail room; and, a conference room on the second floor.

High-rise office: two levels per floor, the occupied space and the return plenum above the suspended ceiling; two toilet rooms with exhaust airflow on each floor; two elevator shafts and two stair shafts, all of which extend from the basement to the $11^{\text {th }}$ floor and one stairway which extends through the $13^{\text {th }}$ floor; a Mezzanine level that houses the mechanical ventilation systems between the $1^{\text {st }}$ and $2^{\text {nd }}$ floors; a $12^{\text {th }}$ floor mechanical room and $13^{\text {th }}$ floor elevator room; a main lobby on the $1^{\text {st }}$ floor, a mail room with a loading dock door on the basement level; and, conference rooms on all occupied floors from the basement through the $11^{\text {th }}$ floor.

\section{Airtightness}

Values for the baseline airtightness of the exterior walls are based on an existing database of airtightness values obtained from building fan pressurization testing (Emmerich and Persily 2005, Persily 1999). While there is less information on the airtightness of interior partitions, the available data were used as a basis for the values in the models (Ivy and Persily 2001). In the analysis, the exterior wall leakage (effective leakage area at $4 \mathrm{~Pa}$ reference pressure normalized by wall area) value in the model of the two-story office was $5 \mathrm{~cm}^{2} / \mathrm{m}^{2}$ of wall area $\left(0.07 \mathrm{in}^{2} / \mathrm{ft}^{2}\right)$. For the high-rise building, the exterior wall leakage area was $8.7 \mathrm{~cm}^{2} / \mathrm{m}^{2}\left(0.13 \mathrm{in}^{2} / \mathrm{ft}^{2}\right)$. These leakage values are fairly typical for office buildings based on the limited measurements that have been made. Interior partitions are assumed to be leakier, with an effective leakage area of $20 \mathrm{~cm}^{2} / \mathrm{m}^{2}\left(0.29 \mathrm{in}^{2} / \mathrm{ft}^{2}\right)$. For the one-zone building model, all airflow rates are defined, so no airtightness values are employed to calculate pressure-driven airflows.

\section{Occupancy}

The number of people in each occupied zone was based on the default occupant density values in ASHRAE Standard 62.1-2004, i.e., 5 people per $100 \mathrm{~m}^{2}\left(1000 \mathrm{ft}^{2}\right)$ in office space (ASHRAE 2004). The corresponding number of people is located in each CONTAM zone for the duration of each simulation, except in cases where shelter-in-place strategies are evaluated and the people move during the simulation period. 
Systems and system models

While the system types in each building are generically identified in Table 1, the details of the system airflows are based on current ASHRAE Standards (ASHRAE 2004), the results of the EPA BASE ventilation data analysis (Persily and Gorfain 2004), and actual design values in the case of the high-rise office building. CONTAM has three options for modeling ventilation systems (constant airflows to or from the outdoors; simple air handling systems that allow for recirculation; and full duct models that include all the details of duct resistance and fan performance curves). Simple air handling system models were determined to be sufficient for these simulations based on their ability to adequately handle system filtration and their ease of use relative to complete duct models.

The single-zone building model has constant airflow rates, with the outdoor air intake rate equal to $20 \%$ of an assumed supply airflow rate per unit floor area of $5 \mathrm{~L} / \mathrm{s} \bullet \mathrm{m}^{2}$ (roughly $1 \mathrm{cfm} / \mathrm{ft}^{2}$ ). These values correspond to typical office building system designs, consistent with those seen in the EPA BASE buildings (Persily and Gorfain 2004). The envelope infiltration rate is also modeled as a constant airflow corresponding to an air change rate of $0.2 \mathrm{~h}^{-1}$. The baseline system is assumed to have a MERV 6 particle filter in the outdoor air intake and in the recirculated airstream (equivalent to the filter being in the mixed airstream), with a particle removal efficiency of $16.4 \%$ for particle diameters of $1 \mu \mathrm{m}$, but no gaseous air cleaning capability. The MERV ratings throughout this report are Minimum Efficiency Reporting Values as defined by ASHRAE Standard 52.2 (ASHRAE 1999).

The two-story office building model was developed to be more realistic than the single-zone case, with envelope infiltration rates calculated by CONTAM based on weather and system induced pressure differences and envelope leakage areas. The outdoor air intake rate of the system was about $10 \%$ of the supply airflow rate, which corresponds to about $9.2 \mathrm{~L} / \mathrm{s}(19 \mathrm{cfm})$ per person for the 130 occupants assumed to occupy the building. The supply airflow rate to the building zones is based on roughly $5 \mathrm{~L} / \mathrm{s}^{2} \mathrm{~m}^{2}\left(1 \mathrm{cfm} / \mathrm{ft}^{2}\right)$ of floor area. The baseline building model has a MERV 6 filter in the mixed airstream impacting both the outdoor air intake and recirculation air.

The high-rise building model is based on, though not identical to, a portion of an actual office building. The system outdoor and supply airflow rates are based on the design specifications for that building, with a minimum outdoor air intake of approximately $23 \%$ of the supply airflow rate of $4.9 \mathrm{~L} / \mathrm{s}^{\bullet} \mathrm{m}^{2}\left(0.96 \mathrm{cfm} / \mathrm{ft}^{2}\right)$ of floor area. The systems are assumed to have MERV 6 filters in the mixed airstream, with no gaseous air cleaning.

\footnotetext{
${ }^{*} \mathrm{cfm}$ is the conventional non-SI unit for volumetric airflow rate and refers to cubic feet per minute.
} 


\subsubsection{Contaminants and Release Scenarios}

The simulated contaminants include generic particulate and gaseous contaminants rather than any specific chembio agents. The particular and gaseous contaminants are referred to as agent $\mathrm{P}$ and $\mathrm{G}$ respectively. The particle is modeled as monodispersed with a diameter of $1 \mu \mathrm{m}$, and the gaseous contaminant is assumed to be nonreactive. Particle removal by deposition on surfaces, including filtration of infiltrating air by the building walls, is not included in the analysis.

Release locations both inside and outside the building are considered, including the following:

Exterior release distant from building

Exterior release at outdoor air intake(s)

Interior release in lobby

Interior release in mail room

Interior release into ventilation system return

Exterior release in vicinity of loading dock, with loading dock door closed.

The simulated releases are described in Table 2 . The outdoor release is represented by a constant, elevated outdoor concentration for a period of $60 \mathrm{~s}$. The release at the intake and the loading dock are modeled as a localized increase in the outdoor concentration at that specific location, again lasting $60 \mathrm{~s}$. The indoor releases are expressed as contaminant release rates per unit time, and once again last for $60 \mathrm{~s}$ in the designated location.

\begin{tabular}{|l|c|c|c|}
\hline Contaminant & Outdoor general & $\begin{array}{c}\text { Outdoor air intake and } \\
\text { loading dock }\end{array}$ & Interior \\
\hline G, gas & $1 \mathrm{mg} / \mathrm{m}^{3}$ & $10 \mathrm{~g} / \mathrm{m}^{3}$ & $16.7 \mathrm{~g} / \mathrm{s}$ \\
\hline $\mathbf{P}$, particle & $10^{9} \mathrm{particles} / \mathrm{m}^{3}$ & $10^{9} \mathrm{particles} / \mathrm{m}^{3}$ & $10^{9} \mathrm{particles} / \mathrm{min}$ \\
\hline
\end{tabular}

Table 2 Contaminant release rates

Only two release scenarios are used for the single-zone building model, indoor and outdoor. There are more release scenarios for the two-story office building, given its more detailed representation. In addition to the outdoor general release, there is also a release at the outdoor air intake and the loading dock door. Indoor releases occur in the lobby and into a ventilation system return vent on the first floor. In addition to these releases, the high-rise office building simulations include a release in the mail room instead of the loading dock.

The calculated concentrations and the assumed release rates have no significance in relation to any particular chembio agent but were chosen to yield indoor concentrations in a reasonable range of interest. Given the generic nature of these contaminants and releases, and in keeping with the purpose of the project, the calculated concentrations cannot be used to estimate health impacts. As a result, the simulation results in terms of the relative concentration or exposure between the various simulated cases are of far more relevance than the absolute concentration and exposure values themselves. Also, while radiological contaminants are not specifically considered in this study, the results for the particulate contaminant can be considered to represent the impacts on radiological agents of the same particle size. 


\subsubsection{Retrofits}

Like the contaminant releases, the retrofits and the manner in which they are implemented in the simulations depend on the building in question. The list of retrofits considered in the simulations is as follows:

1 Air cleaning and filtration options: Separate analyses are performance for these systems located in the outdoor air intake and in the mixed air (downstream of where the outdoor and recirculation airstream merge).

a Enhanced particle filtration: increase from baseline MERV value to retrofit value.

b Gaseous or gas-phase air cleaning (GPAC): include a gaseous air cleaner in ventilation system with none assumed present in the baseline case; since there is no standard method of test for these devices or values provided by manufacturers, the contaminant removal efficiency is only an estimate for the purposes of the simulations.

2 HVAC System options: The following retrofits include changes in HVAC operation.

a System shut down: model by turning off all ventilation systems including exhausts, thereby reducing outdoor air intake to zero; include different initiation times to account for varying degrees of warning based on automatic, visual or other means of detection; note that when the system is shut down envelope infiltration continues to occur based on weather effects.

b Purging: model by running the ventilation systems with $100 \%$ outdoor air intake; include different initiation times to account for varying degrees of warning.

c Ventilation system recommissioning: assume the baseline case is consistent with design intent and model condition(s) that are "off-design" including the following: reduce the outdoor air intake by $50 \%$ (referred to as $5 \%$ intake since the "design" value is assumed to be $10 \%$ ), increase the return airflow relative to the supply such that there is $5 \%$ less supply to the building than return (referred to as $5 \%$ undersupply), increase the return airflow from the ventilated space to $100 \%$ of the supply, i.e. $100 \%$ recirculation, and allow $10 \%$ of the airflow intended to pass through the filter to bypass around the filter (10\% filter bypass). Note that recommissioning cases are only applied to the two-story building.

d Relocation of outdoor air intakes: simply assume that the contaminant does not enter the building if the intake is moved and all exposures are zero; applies only to release at the intake.

3 Envelope and pressurization options:

a Envelope tightening: tighten the building envelope, but do not modify the ventilation system operation.

b Envelope tightening/filtration: combine the envelope tightening and enhanced particle filter in the outdoor air intake.

c Envelope tightening/GPAC: combine the envelope tightening and outdoor air intake GPAC retrofit.

d Envelope tightening/filtration/pressurization: combine envelope tightening and enhanced particle filter retrofit in the air intake with attempt to pressurize the building by doubling the outdoor air intake relative to the minimum design value.

e Envelope tightening/GPAC/pressurization: combine envelope tightening and air intake GPAC retrofit with attempt to pressurize the building. 
4 Local options:

a Shelter in place: move occupants from office space to selected shelter locations in each building and turn off all ventilation systems at a specified time; shelters have tighter interior partition; after a two-hour sheltering period, the occupants leave the building and the systems are operated with $100 \%$ outdoor air.

b Shelter in place with air cleaning: same as shelter in place, but with a recirculating filtration and air cleaning system operating in the shelter during the sheltering period.

c Lobby and mail room isolation: isolate these spaces through combinations of interior partition tightening and using ventilation systems to induce lower pressures in these spaces relative to the rest of the building; only applied to high-rise building.

The manner in which these retrofits were implemented in each of the building models is described below.

Single zone model

Table 3 presents the retrofits applied to each of the release scenarios for the single zone model. Almost all of the retrofits were applied to both the outdoor and indoor releases, even though not all of them are expected to have a beneficial impact. For example, shutting down a system in the event of an indoor release would be expected to increase rather than to reduce exposure. Nevertheless, all possible cases were analyzed to explore the impacts of both "good" and potentially "bad" actions.

\begin{tabular}{|l|c|c|}
\hline & \multicolumn{2}{|c|}{ Release Scenario } \\
\hline Retrofit & Outdoor & Indoor \\
\hline Enhanced outdoor air filtration & $\mathrm{X}$ & -- \\
\hline Enhanced mixed air filtration & $\mathrm{X}$ & $\mathrm{X}$ \\
\hline System shutdown & $\mathrm{X}$ & $\mathrm{X}$ \\
\hline Purging & $\mathrm{X}$ & $\mathrm{X}$ \\
\hline Envelope tightening & $\mathrm{X}$ & $\mathrm{X}$ \\
\hline Envelope tightening and outdoor air filtration & $\mathrm{X}$ & $\mathrm{X}$ \\
\hline
\end{tabular}

Table 3 Retrofit and release scenarios for single zone model

Enhanced Outdoor Air Filtration: The MERV 6 particulate filter on the outdoor air intake is replaced with a more efficient filter, specifically a MERV 13 filter. This change is reflected in an increase in the particle removal efficiency at $1 \mu \mathrm{m}$ from $16.4 \%$ to $89.6 \%$. In addition, a gaseous air cleaner with a removal efficiency of $95 \%$ is located in the outdoor air intake; in the base case there was no gaseous air cleaning. Note that this retrofit does not account for the existence of any bypass around the filter.

Mixed Air Filtration: The MERV 6 particulate filter in the mixed airstream is replaced with a MERV 13 filter, again with no bypass. In addition, a gaseous air cleaner with a removal efficiency of $95 \%$ is added to the mixed airstream.

System Shutdown: The outdoor air intake is reduced to zero for $2 \mathrm{~h}$ starting $6 \mathrm{~s}, 30 \mathrm{~s}, 1 \mathrm{~min}$ and $5 \mathrm{~min}$ after the start of the contaminant release. At the end of the $2 \mathrm{~h}$ shutdown period, the system operates at $100 \%$ outdoor air intake. 
Outdoor Air Purge: The outdoor air intake is increased from the minimum value of $10 \%$ outdoor air intake to $100 \%$ intake, beginning $30 \mathrm{~s}$ prior, $30 \mathrm{~s}$ after, $1 \mathrm{~min}$ after and $5 \mathrm{~min}$ after the start of the release and continuing for the remainder of the simulation.

Envelope Tightening: The constant envelope infiltration rate is reduced from $0.20 \mathrm{~h}^{-1}$ to $0.01 \mathrm{~h}^{-1}$. Envelope Tightening and Enhanced Filtration: The reduced infiltration rate and the enhanced outdoor air filtration are combined.

Two-story office model

Table 4 presents the retrofits applied in the two-story office building simulations.

\begin{tabular}{|l|c|c|c|c|c|}
\hline & \multicolumn{5}{|c|}{ Release Scenario } \\
\hline Retrofit & $\begin{array}{c}\text { Outdoor } \\
\text { general }\end{array}$ & $\begin{array}{c}\text { Outdoor } \\
\text { intake }\end{array}$ & $\begin{array}{c}\text { Indoor, } \\
\text { lobby }\end{array}$ & $\begin{array}{c}\text { Indoor, } \\
\text { return }\end{array}$ & $\begin{array}{c}\text { Loading } \\
\text { dock }\end{array}$ \\
\hline Enhanced outdoor air filtration & $\mathrm{X}$ & $\mathrm{X}$ & -- & -- & -- \\
\hline Mixed air filtration & $\mathrm{X}$ & $\mathrm{X}$ & $\mathrm{X}$ & $\mathrm{X}$ & $\mathrm{X}$ \\
\hline System shutdown & $\mathrm{X}$ & $\mathrm{X}$ & $\mathrm{X}$ & $\mathrm{X}$ & $\mathrm{X}$ \\
\hline Purging & $\mathrm{X}$ & $\mathrm{X}$ & $\mathrm{X}$ & $\mathrm{X}$ & $\mathrm{X}$ \\
\hline Envelope tightening & $\mathrm{X}$ & $\mathrm{X}$ & $\mathrm{X}$ & $\mathrm{X}$ & $\mathrm{X}$ \\
\hline Tightening and enhanced outdoor air filtration & $\mathrm{X}$ & $\mathrm{X}$ & -- & -- & -- \\
\hline Tightening, OA filtration and pressurization & $\mathrm{X}$ & $\mathrm{X}$ & $\mathrm{X}$ & $\mathrm{X}$ & $\mathrm{X}$ \\
\hline Tightening and enhanced mixed air filtration & $\mathrm{X}$ & $\mathrm{X}$ & $\mathrm{X}$ & $\mathrm{X}$ & $\mathrm{X}$ \\
\hline Tightening, MA filtration and pressurization & $\mathrm{X}$ & $\mathrm{X}$ & $\mathrm{X}$ & $\mathrm{X}$ & $\mathrm{X}$ \\
\hline Shelter-in-place & $\mathrm{X}$ & $\mathrm{X}$ & $\mathrm{X}$ & $\mathrm{X}$ & $\mathrm{X}$ \\
\hline Shelter-in-place with filtration & $\mathrm{X}$ & $\mathrm{X}$ & $\mathrm{X}$ & $\mathrm{X}$ & $\mathrm{X}$ \\
\hline Recommissioning & & & & & \\
\hline $100 \%$ recirculation & $\mathrm{X}$ & -- & $\mathrm{X}$ & $\mathrm{X}$ & $\mathrm{X}$ \\
\hline $5 \%$ outdoor air intake & $\mathrm{X}$ & $\mathrm{X}$ & $\mathrm{X}$ & $\mathrm{X}$ & $\mathrm{X}$ \\
\hline $5 \%$ undersupply & $\mathrm{X}$ & $\mathrm{X}$ & $\mathrm{X}$ & $\mathrm{X}$ & $\mathrm{X}$ \\
\hline $10 \%$ bypass of baseline filter & $\mathrm{X}$ & $\mathrm{X}$ & $\mathrm{X}$ & $\mathrm{X}$ & $\mathrm{X}$ \\
\hline $10 \%$ bypass of enhanced mixed air filter & $\mathrm{X}$ & $\mathrm{X}$ & $\mathrm{X}$ & $\mathrm{X}$ & $\mathrm{X}$ \\
\hline
\end{tabular}

Table 4 Retrofit and release scenarios for two-story office building model

Enhanced Outdoor Air Filtration: The MERV 6 particulate filter on the outdoor air intake is replaced with a MERV 13 filter, and a gas phase air cleaner (removal efficiency of $95 \%$ ) is added to the air intake. This retrofit was not applied to the indoor releases since it would not impact the resulting exposure.

Mixed Air Filtration: A MERV 13 particle filter replaces the baseline MERV 6 filter in the mixed airstream. and a $95 \%$ efficient gaseous air cleaner is added to that airstream as well.

System Shutdown: The outdoor air intake is reduced to zero for $2 \mathrm{~h}$ starting $6 \mathrm{~s}, 30 \mathrm{~s}, 1 \mathrm{~min}$ and 5 min after the start of the exterior contaminant release. However, envelope infiltration still continues during the shutdown, as determined by the outdoor weather conditions. At the end of the $2 \mathrm{~h}$ shutdown period, the system operates at $100 \%$ outdoor air intake.

Outdoor Air Purge: The outdoor air intake is increased from the minimum value to $100 \%$ outdoor air intake, beginning $30 \mathrm{~s}$ prior, $30 \mathrm{~s}$ after, $1 \mathrm{~min}$ after and $5 \mathrm{~min}$ after the start of the release and continuing for the remainder of the simulation. 
Envelope Tightening: The exterior wall leakage is reduced from $5 \mathrm{~cm}^{2} / \mathrm{m}^{2}\left(0.07 \mathrm{in}^{2} / \mathrm{ft}^{2}\right)$ to $0.7 \mathrm{~cm}^{2} / \mathrm{m}^{2}\left(0.01 \mathrm{in}^{2} / \mathrm{ft}^{2}\right)$.

Envelope Tightening and Enhanced Outdoor Air Filtration: The improved envelope airtightness and the enhanced outdoor air filtration are combined. Applies only to the general outdoor release and the release at the intake, since the results for the indoor releases are no different from the envelope tightening retrofit alone.

Envelope Tightening, Enhanced Outdoor Air Filtration and Building Pressurization: The increased envelope airtightness and the enhanced outdoor air filtration are combined with a doubling of the outdoor air intake fraction to $20 \%$ in order to pressurize the building and reduce infiltration of outdoor releases.

Envelope Tightening and Enhanced Mixed Air Filtration: The improved envelope airtightness and the enhanced mixed air filtration are combined.

Envelope Tightening, Enhanced Mixed Air Filtration and Building Pressurization: The increased envelope airtightness and the enhanced mixed air filtration are combined with a doubling of the outdoor air intake fraction to $20 \%$.

Shelter-in-place: Occupants are moved to a shelter-in-place zone in the second floor conference room. Four different cases are included corresponding to different times at which the occupants move to the shelter: $30 \mathrm{~s}$ before the release, and $30 \mathrm{~s}, 1 \mathrm{~min}$ and $5 \mathrm{~min}$ after the release starts. During the sheltering period, the shelter-in-place zones are "sealed" by reducing plenum and door leakage, and all ventilation systems are turned off. Two hours after the start of the release, all occupants are moved out of the building, i.e., they are no longer exposed to the contaminants, and the systems are run at $100 \%$ outdoor air.

Shelter-in-place with Air Cleaning: This is the same as the shelter-in-place case with the addition of an air cleaner to each shelter zone. The air cleaners recirculate air within the room and have an airflow rate of roughly $5 \mathrm{~L} / \mathrm{s} \bullet \mathrm{m}^{2}\left(1 \mathrm{cfm} / \mathrm{ft}^{2}\right)$ of floor area with MERV 15 particle filters $(99.75 \%$ removal efficiency for $1 \mu \mathrm{m}$ particles) and a removal efficiency of $95 \%$ for the gaseous agent.

Recommissioning: Five cases represent a system that isn't operating properly in order to estimate the potential benefit from a recommissioning effort. These cases include the following: $100 \%$ recirculation (no outdoor air intake); reduction of the outdoor air intake to $5 \%$ from the baseline value of $10 \%$; an unbalanced system with $5 \%$ more return air from the space than supply air to the space; $10 \%$ of the supply air bypassing the baseline mixed air filters; and $10 \%$ of the supply air bypassing the enhanced mixed air filters. 
High-rise model

Table 5 presents the retrofits applied to each the five release scenarios for the high-rise model. As this is a relatively complex model, not all retrofits were applied to all the releases.

\begin{tabular}{|c|c|c|c|c|c|}
\hline \multirow[b]{2}{*}{ Retrofit } & \multicolumn{5}{|c|}{ Release Scenario } \\
\hline & $\begin{array}{l}\text { Outdoor } \\
\text { general }\end{array}$ & $\begin{array}{l}\text { Outdoor } \\
\text { intake }\end{array}$ & $\begin{array}{l}\text { Indoor, } \\
\text { Lobby }\end{array}$ & $\begin{array}{l}\text { Indoor, } \\
\text { return }\end{array}$ & $\begin{array}{l}\text { Mail } \\
\text { room }\end{array}$ \\
\hline Enhanced outdoor air filtration & $\mathrm{X}$ & $\mathrm{X}$ & -- & -- & -- \\
\hline Mixed air filtration & $\mathrm{X}$ & $\mathrm{X}$ & $\mathrm{X}$ & $\mathrm{X}$ & $\mathrm{X}$ \\
\hline System shutdown & $\mathrm{X}$ & $\mathrm{X}$ & -- & -- & -- \\
\hline Purging & $\mathrm{X}$ & -- & $\mathrm{X}$ & $\mathrm{X}$ & \\
\hline Envelope tightening & $\mathrm{X}$ & $\mathrm{X}$ & -- & $\mathrm{X}$ & -- \\
\hline Envelope tightening and OA filtration & $\mathrm{X}$ & $\mathrm{X}$ & -- & -- & -- \\
\hline Tightening, filtration and pressurization & $\mathrm{X}$ & -- & -- & -- & -- \\
\hline Shelter-in-place & $\mathrm{X}$ & -- & -- & -- & -- \\
\hline Shelter-in-place with filtration & $\mathrm{X}$ & -- & -- & -- & -- \\
\hline Lobby partitions & -- & -- & $\mathrm{X}$ & -- & -- \\
\hline Lobby partitions and HVAC isolation & -- & -- & $\mathrm{X}$ & -- & -- \\
\hline Mail room under-supply & -- & -- & -- & -- & $\mathrm{X}$ \\
\hline $\begin{array}{l}\text { Mail room undersupply \& return air } \\
\text { filtration }\end{array}$ & -- & -- & -- & -- & $\mathrm{X}$ \\
\hline
\end{tabular}

Table 5 Retrofit and release scenarios for high-rise office building model

Enhanced Outdoor Air Filtration: As in the single zone and two-story models, the MERV 6 particulate filters on the outdoor air intakes of all three air handling systems are replaced with MERV 13 filters. Gaseous air cleaners having removal efficiencies of $95 \%$ are also installed in the intake. Again, this retrofit was not applied to the indoor release cases.

Mixed Air Filtration: A MERV 13 particle filter replaces the MERV 6 baseline filter in the mixed airstream, and a $95 \%$ efficient gaseous air cleaner is added to that airstream as well

System Shutdown: Four different shutdown scenarios are considered. All systems are turned off starting $6 \mathrm{~s}, 30 \mathrm{~s}, 1 \mathrm{~min}$ and $5 \mathrm{~min}$ after the start of the exterior contaminant release. Two hours after the release begins, the systems are turned back on and operated at $100 \%$ outdoor air intake for the remainder of the simulation. The occupants are assumed to remain in the building throughout the changes in system operation. Note that envelope infiltration continues during the shutdown, as driven by the outdoor weather conditions.

Outdoor Air Purge: The outdoor air intake of all three systems is increased from the minimum value to $100 \%$ outdoor air intake, beginning one minute after the start of the release and continuing for the remainder of the simulation.

Envelope Tightening: The exterior wall leakage is reduced from $8.7 \mathrm{~cm}^{2} / \mathrm{m}^{2}\left(0.13 \mathrm{in}^{2} / \mathrm{ft}^{2}\right)$ to $0.7 \mathrm{~cm}^{2} / \mathrm{m}^{2}\left(0.01 \mathrm{in}^{2} / \mathrm{ft}^{2}\right)$.

Envelope Tightening and Enhanced Outdoor Air Filtration: The improved envelope airtightness and the enhanced outdoor air filtration are combined. This retrofit is applied only to the general outdoor release and the release at the intake, since the results for the three indoor releases are no different from the envelope tightening retrofit alone. 
Envelope Tightening, Enhanced Outdoor Air Filtration and Building Pressurization: The increased envelope airtightness and the enhanced outdoor air filtration are combined with an increase in the outdoor airflow rate.

Shelter-in-place: Occupants are moved to shelter-in-place zones on their respective floors of the building. Four different cases are included corresponding to different times at which the occupants move to the shelter: $30 \mathrm{~s}$ before the release, and $30 \mathrm{~s}, 1 \mathrm{~min}$ and $5 \mathrm{~min}$ after the release starts. During the sheltering period, the shelter-in-place zones are "sealed" by reducing plenum and door leakage, and all ventilation systems are turned off. Two hours after the start of the release, all occupants are moved out of the building, i.e., they are no longer exposed to the contaminants, and the systems are run at $100 \%$ outdoor air.

Shelter-in-place with Air Cleaning: This is the same as the shelter-in-place case with the addition of an air cleaner to each shelter zone. The air cleaners recirculate air within the room and have an airflow rate of roughly $5 \mathrm{~L} / \mathrm{s} \bullet \mathrm{m}^{2}\left(1 \mathrm{cfm} / \mathrm{ft}^{2}\right)$ of floor area with MERV 15 particle filters $(99.75 \%$ removal efficiency for $1 \mu \mathrm{m}$ particles) and a removal efficiency of $95 \%$ for gas $\mathrm{G}$.

Lobby Partitions: The lobby is partitioned off from the rest of the first floor with walls having the same leakage rate as the rest of the interior walls and two doors. The lobby is still served by the same ventilation system that serves the rest of the first floor.

Lobby Partitions and HVAC Isolation: In addition to a separate lobby, this retrofit includes an air handling system dedicated to the lobby. The lobby system has approximately $10 \%$ more return airflow than supply in an attempt to depressurize this zone relative to the rest of the building.

Mailroom Under-supply: Adjust the mail room return airflow to be $10 \%$ greater than the supply, in an attempt to depressurize this zone relative to the adjacent zones.

Mailroom Under-supply and Enhanced Return Air Filtration: In addition to the under-supply, filter the mail room return air with a MERV 15 particle filter and a $95 \%$ gas filter.

\subsubsection{Simulations and Analysis}

Simulations were performed for the building models and retrofits described above. These simulations were run for $12 \mathrm{~h}$ with a $5 \mathrm{~s}$ time step. For the two-story and high-rise buildings, cases were run with no wind speed or indoor-outdoor temperature difference, i.e., no weatherinduced envelope infiltration. To study infiltration effects, additional cases were run with a wind speed of $5 \mathrm{~m} / \mathrm{s}(11 \mathrm{mi} / \mathrm{h})$ and an indoor-outdoor temperature difference of $20^{\circ} \mathrm{C}\left(36^{\circ} \mathrm{F}\right)$.

The simulations yield contaminant concentrations as a function of time in each building zone, which were subsequently used to determine occupant exposures. The exposure of an individual building occupant is the average contaminant concentration to which they are exposed over the simulation period in units of $\mathrm{mg}-\mathrm{min} / \mathrm{m}^{3}$ for the gaseous contaminant $\mathrm{G}$ and number-min $/ \mathrm{m}^{3}$ for the particulate contaminant $\mathrm{P}$. In the shelter-in-place cases, the exposure is based on the occupants' initial location in the building and then their exposure after moving to the shelter. They are assumed to leave the building $2 \mathrm{~h}$ after the release, at which point there is no additional contribution to their exposure. The two-story office building is assumed to have 130 occupants, evenly split between the two floors. The high-rise office building has a total of 285 occupants distributed among the various floors.

The average exposure for all occupants of the building is then determined from the individual occupant exposures. These exposures are calculated over $6 \mathrm{~h}$, starting $1 \mathrm{~h}$ before the release and continuing $5 \mathrm{~h}$ after. For each retrofit simulation, the average building exposure is compared with the baseline exposure to determine the exposure as a percentage of the baseline exposure. 


\subsection{Results of Simulations}

The simulation results for each of the building models are presented in this section in terms of the exposure reduction for each retrofit case relative to the baseline exposure without any of the retrofits included. In addition, representative plots of concentration versus time are included for selected cases to help explain the impacts of the retrofits.

\subsubsection{Single zone model}

Figure 1 is a plot of the calculated concentrations for the single zone baseline and retrofit cases subject to the outdoor particle release. As described earlier, this release corresponds to an increase in the outdoor concentration from $\left(0\right.$ to $\left.10^{9}\right)$ particles $/ \mathrm{m}^{3}$ occurring at $\mathrm{t}=1 \mathrm{~h}$ and lasting for $1 \mathrm{~min}$. Therefore, all the concentrations are zero for the first hour. The baseline case is the solid line with a peak concentration of $2 \times 10^{4}$ particles $/ \mathrm{m}^{3}$. The other lines show the impacts of selected retrofits, with the combination of enhanced outdoor air filtration and envelope tightening resulting in the lowest peak concentration. Envelope tightening alone has a less significant impact due to the low baseline infiltration rate relative to the outdoor air intake rate and the low baseline filter efficiency. Less contaminant enters the building at the lower infiltration rate, so the initial concentration is slightly lower than the baseline case. However, the lower air change rate causes the contaminant to remain in the building for a longer time, resulting in similar concentrations to the baseline case after about $45 \mathrm{~min}$. The enhanced outdoor air filter significantly reduces contaminant entry and therefore concentration, while the enhanced mixed air filter reduces concentration even further due to the continued filtration of the recirculation airstream.

The four shutdown cases show the importance of timing, with timely implementation of the shutdown having a much more significant impact than a delayed shutdown. (Note that the shutdown cases all exhibit a discontinuity at a time of 3:00 when the system resumes operation at $100 \%$ outdoor air intake.) The $6 \mathrm{~s}$ and $30 \mathrm{~s}$ shutdowns reduce contaminant entry and the initial concentrations, but the lower ventilation rate during the shutdown leads to higher contaminant concentrations than the baseline case later on during the shutdown. The two late shutdown cases, $1 \mathrm{~min}$ and $5 \mathrm{~min}$, result in significantly higher concentrations than the baseline case because the ventilation rate is reduced after the agent has entered the building. The purge retrofit doesn't reduce the initial concentration, but the increased ventilation rate the contaminant at a relatively high rate. The timing of the purge cycle also impacts the concentrations, but only the $1 \mathrm{~min}$ purge results are displayed in this figure; the other results are presented below in Table 6 . Analogous transient concentration data exist for the gaseous contaminant $\mathrm{G}$ and for the indoor release scenarios, and these results are also summarized in Table 6.

The single zone exposure reductions, relative to the baseline case, for the indoor and outdoor particle releases are presented in Table 6 and plotted in Figures 2 and 3. The exposures are presented as a percentage of the baseline exposure; therefore, a retrofit that does not change the exposure corresponds to a value of $100 \%$. Lower percentages correspond to a reduction in exposure. As noted in the discussion of Figure 1, the combination of outdoor air filtration and decreased infiltration results in the lowest initial concentrations for the outdoor release, but the mixed-air filtration retrofit results in the lowest exposure. Envelope tightening alone increases exposure to the indoor release due to the lower dilution rate, but has only a small impact on exposure to the outdoor release. Retrofits that are particularly effective, i.e., decreasing exposure to about one-third or less of the baseline, include outdoor air filtration (for the outdoor release), mixed air filtration, envelope tightening with outdoor air filtration (outdoor release), outdoor air purge for an indoor release, and purging after the release is complete. 
The $6 \mathrm{~s}$ shutdown reduces exposure to the outdoor releases by about one third, but the later shutdowns actually increase exposure to the outdoor release. These results indicate that unless a shutdown can be implemented very early in response to an outdoor release, it may be better to leave the system running. All the shutdowns increase the exposure to an indoor release, as would be expected, pointing out the importance of reacting to an event based on good awareness of the circumstances. The change in exposure for the purge cycle given an indoor source is not strongly dependent on timing, but it is for an outdoor release. Of course, purging is not a reasonable response to an outdoor release, but it could conceivably happen given poor awareness. After an outdoor release is over, however, purging is an effective means of removing the contaminant that did enter the building. Figures 2 and 3 display the relative exposures for the gaseous and particulate contaminants respectively. The results are similar in the two figures, with the only differences resulting from the lack of a gaseous air cleaner in the baseline case and differences in the removal efficiencies for the particulate and gaseous filter retrofits.

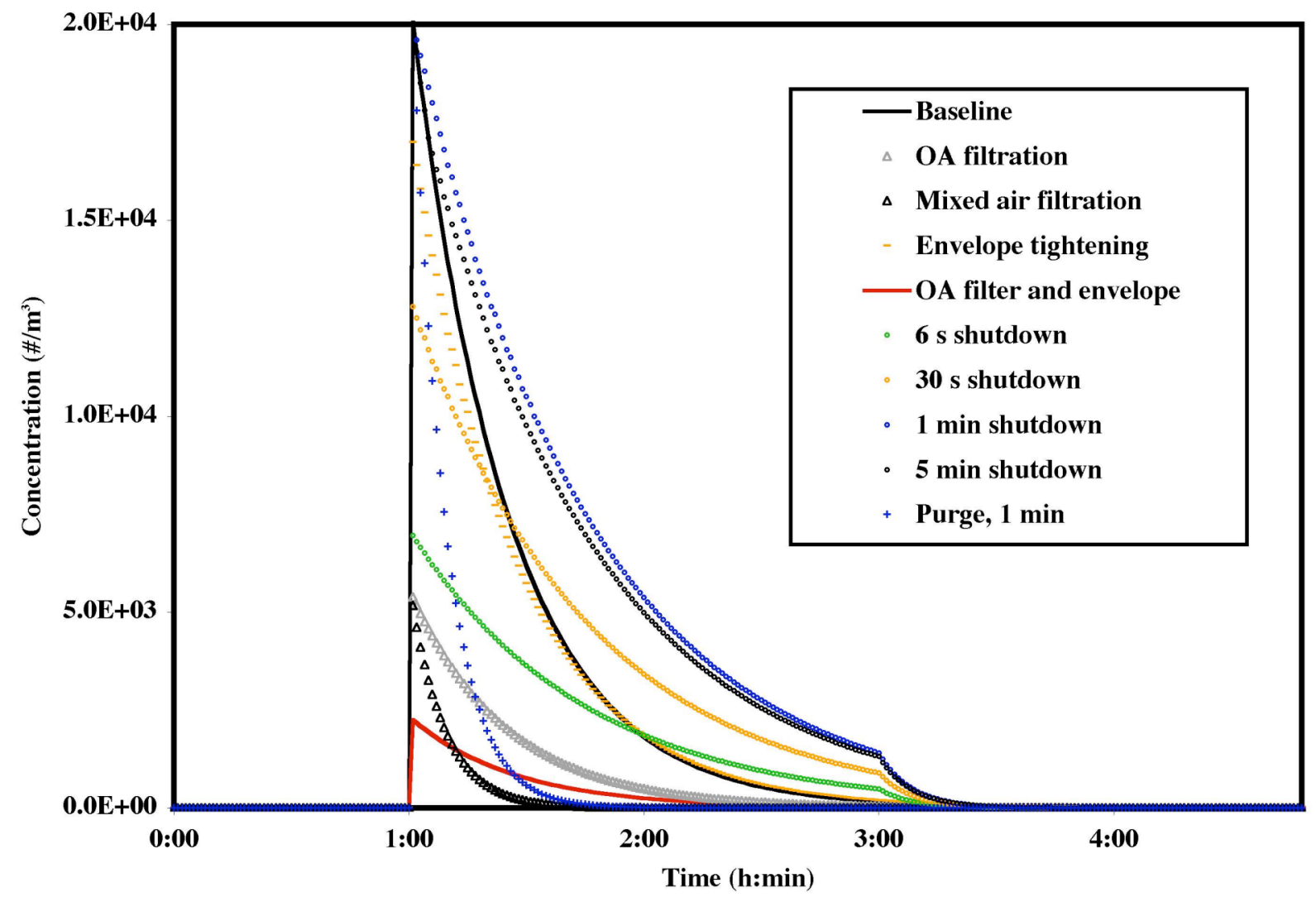

Figure 1 Single-zone simulation results for an outdoor particulate release 


\begin{tabular}{|c|c|c|c|c|}
\hline \multirow{2}{*}{ Case } & \multicolumn{3}{|c|}{ Exposure Relative to Baseline (\%) } \\
\cline { 2 - 5 } & \multicolumn{2}{|c|}{ Gas G } & \multicolumn{2}{c|}{ Particle P } \\
\hline OA filtration & $\begin{array}{c}\text { Indoor } \\
\text { source }\end{array}$ & $\begin{array}{c}\text { Outdoor } \\
\text { source }\end{array}$ & $\begin{array}{c}\text { Indoor } \\
\text { source }\end{array}$ & $\begin{array}{c}\text { Outdoor } \\
\text { source }\end{array}$ \\
\hline Mixed air filtration & 100.0 & 18.4 & 100.0 & 26.8 \\
\hline Shutdown (6 s) & 19.7 & 3.6 & 35.2 & 9.4 \\
\hline Shutdown (30 s) & 220.7 & 68.1 & 171.9 & 58.8 \\
\hline Shutdown (1 min) & 220.6 & 135.5 & 171.5 & 108.3 \\
\hline Shutdown (5 min) & 219.7 & 219.6 & 170.0 & 170.0 \\
\hline Purge (30 sec prior) & 208.7 & 208.8 & 158.7 & 158.8 \\
\hline Purge (30 sec after) & 22.6 & 100.1 & 33.2 & 144.0 \\
\hline Purge (1 min after) & 22.8 & 62.6 & 33.6 & 90.6 \\
\hline Purge (5 min after) & 23.6 & 23.6 & 34.7 & 34.6 \\
\hline Envelope tightening & 115.3 & 99.9 & 108.5 & 91.7 \\
\hline Envelope + OA Filtration & 115.3 & 5.8 & 108.5 & 12.1 \\
\hline
\end{tabular}

Table 6 Single zone retrofit effectiveness values

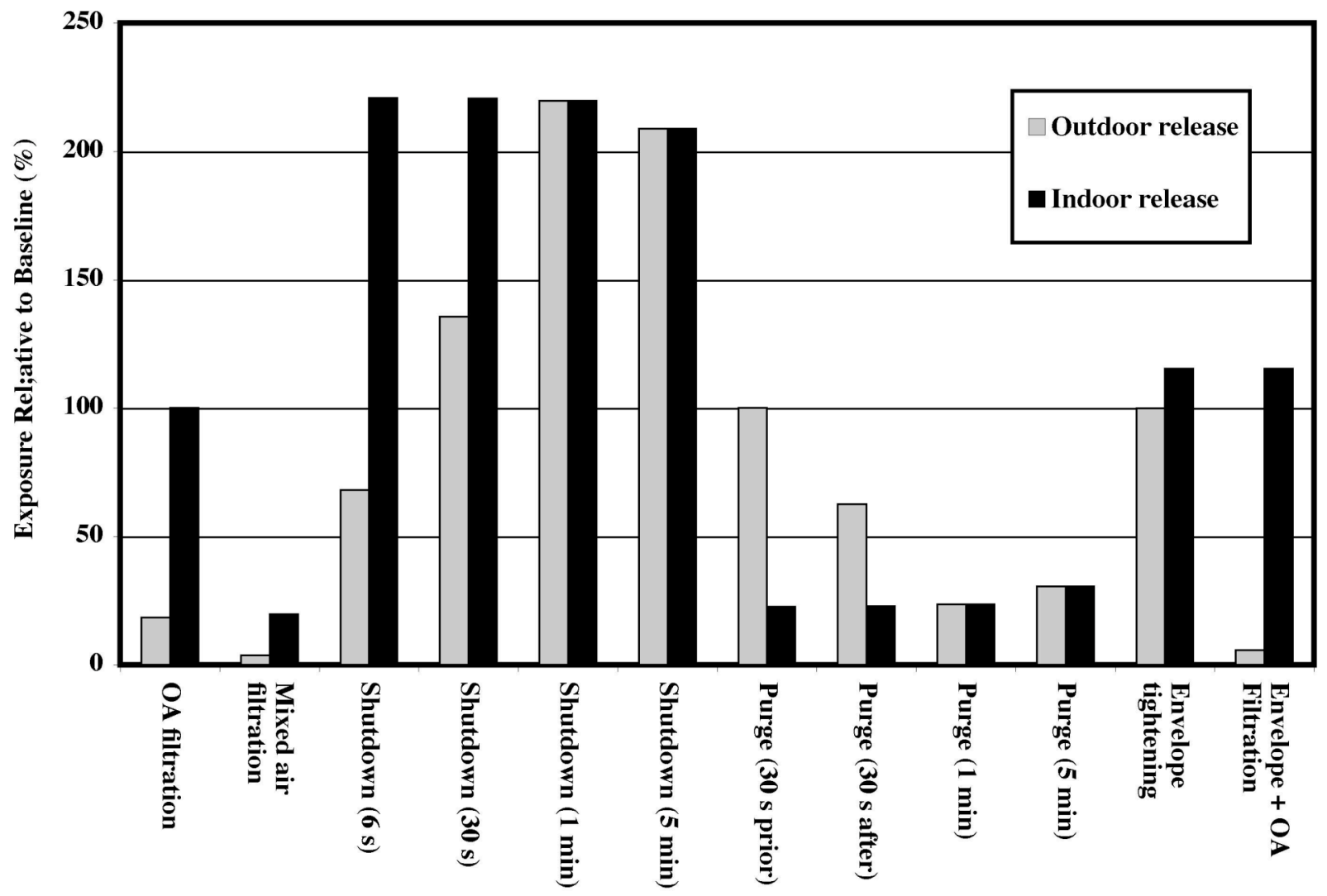

Figure 2 Single-zone exposure results for gaseous contaminant $\mathrm{G}$ 


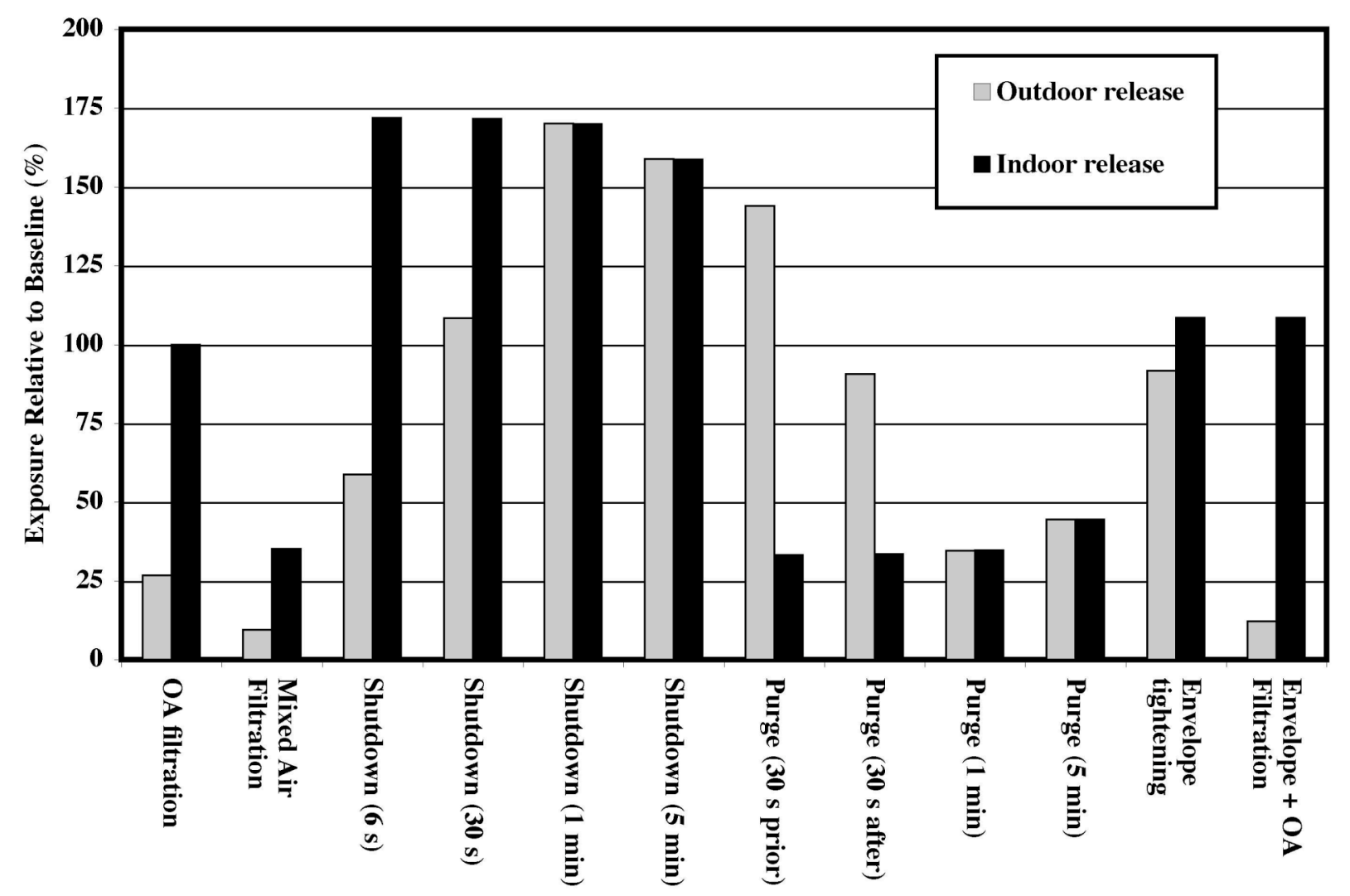

Figure 3 Single-zone exposure results for particulate contaminant $\mathrm{P}$

In order to determine the importance of the input parameters in the single-zone simulations, a simple sensitivity analysis was performed in which the baseline and retrofit simulations were repeated with selected inputs varied (decreased) by $10 \%$. The results of that analysis are presented in Table 7, with the impacts on the baseline case exposures in the upper portion of the table and the impacts on the retrofits in the lower portion. In the latter cases, the parameters associated with the retrofit (e.g. filter efficiency) were decreased by $10 \%$ and the value in the table is the change in exposure relative to the retrofit case. Most cases show either essentially no impact of the variation or an approximately linear (i.e., about $10 \%$ ) impact. For example, varying the zone volume has no impact since it increases both the contaminant concentrations and the air change rate, resulting in no change in exposure. Larger differences are seen for the filter efficiency retrofits, for example a $44 \%$ increase in exposure for the gaseous contaminant and a $33 \%$ increase for the particulate contaminant for an outdoor release in the case of the outdoor air filter retrofit. This "amplified" sensitivity occurs because the exposure is impacted by 1 minus the removal efficiency, and therefore a $10 \%$ change in the efficiency is a larger change in one minus the efficiency. 


\begin{tabular}{|c|c|c|c|c|}
\hline \multirow{2}{*}{} & \multicolumn{3}{|c|}{ Exposure Relative to Case without Input Varied (\%) } \\
\cline { 2 - 5 } & \multicolumn{2}{|c|}{ Gas G } & \multicolumn{2}{c|}{ Particle P } \\
\hline \multirow{2}{*}{ Parameter varied } & $\begin{array}{c}\text { Indoor } \\
\text { release }\end{array}$ & $\begin{array}{c}\text { Outdoor } \\
\text { release }\end{array}$ & $\begin{array}{c}\text { Indoor } \\
\text { release }\end{array}$ & $\begin{array}{c}\text { Outdoor } \\
\text { release }\end{array}$ \\
\hline \multicolumn{5}{|c|}{ Baseline } \\
\hline Zone volume & 0 & 0 & 0 & 0 \\
\hline OA intake rate & 9 & 0 & 5 & -3 \\
\hline Infiltration rate & 1 & 0 & 1 & -1 \\
\hline Filter efficiency & -- & -- & 4 & 6 \\
\hline Release amount & -10 & -10 & -10 & -10 \\
\hline Release duration & -10 & -10 & -10 & -10 \\
\hline \multicolumn{7}{|c|}{ Retrofits } & 44 & -- & 33 \\
\hline Outdoor air filter efficiency & -- & 57 & 9 & 45 \\
\hline Mixed air filter efficiency & 30 & 0 & 0 & 0 \\
\hline Reduced infiltration rate & 0 & & & \\
\hline
\end{tabular}

Table 7 Single zone sensitivity analysis results 


\subsubsection{Two-story office building}

Figure 4 is a plot of the calculated concentrations for the two-story office building subject to the outdoor particle release with no weather effects (i.e., zero wind speed and no indoor-outdoor temperature difference). As described earlier, the outdoor release corresponds to a $60 \mathrm{~s}$ increase in the outdoor concentration from $\left(0\right.$ to $\left.10^{9}\right)$ particles $/ \mathrm{m}^{3}$ at $\mathrm{t}=1 \mathrm{~h}$. The concentrations for the baseline case are shown by the solid black line with a peak concentration just below $7.5 \times 10^{6}$ particles $/ \mathrm{m}^{3}$, which begins to decay immediately after reaching that peak. The concentrations for the envelope tightening case are identical to the baseline case because there is no infiltration under no-weather conditions. The lack of weather-induced pressures in combination with the building being positively pressurized (i.e., supply airflow greater than return plus exhaust) leads to no infiltration through the envelope. The other lines in the plot show the impacts of selected retrofits, with the mixed air filtration retrofit (open black triangles) resulting in the lowest concentrations. Combining envelope tightening with outdoor air or mixed air filtration yields identical results to enhanced filtration alone, again because there is no envelope infiltration. Therefore these two cases are not shown in the figure. Tightening the envelope and increasing the outdoor air intake to induce pressurization increases the concentration for both filtration cases, because the additional outdoor air brings more contaminant into the building. Given that the building is already pressurized and there is no infiltration, there is no reduction in contaminant entry due to reduced envelope leakage.

The four shutdown cases show the importance of timing such actions. (Note that the shutdown cases in Figure 4 all exhibit a discontinuity at a time of 3:00 when the system resumes operation at $100 \%$ outdoor air.) The contaminant concentration is constant during the shutdown period because there is no air change under no-weather conditions. The 6-s shutdown significantly reduces contaminant entry, and once the purge begins the contaminant is quickly removed from the building. The $30 \mathrm{~s}$ shutdown also reduces contaminant entry and the initial concentration relative to the baseline case, but the contaminant concentrations are higher than the baseline later during the shutdown. The two late shutdown cases, 1 min and $5 \mathrm{~min}$, result in significantly higher concentrations than the baseline because the shutdown retains the contaminant in the building. Only the results for the purge case starting $1 \mathrm{~min}$ after the release are shown, and these exhibit a quick reduction in the contaminant concentration as expected. Analogous concentration data exist for the gaseous contaminant $\mathrm{G}$, and for the indoor releases.

Figure 5 is a plot of the two-story office building concentrations subject to the outdoor particle release with weather effects included, i.e., a nonzero infiltration rate. The concentration for the baseline case is the solid black line that peaks around $1.25 \times 10^{7}$ particles $/ \mathrm{m}^{3}$. Note first that this peak is higher than in the no weather case because more contaminant enters the building due to infiltration. The building air change rate for the no weather case is $0.38 \mathrm{~h}^{-1}$, while it is $0.60 \mathrm{~h}^{-1}$ with weather-induced infiltration. The roughly $60 \%$ increase in air change rate is close to the increase in the peak concentration. Upgrading the outdoor air filtration efficiency from MERV 6 to MERV 13 reduces the concentrations by about one half relative to the baseline case, while upgrading the filtration in the mixed airstream reduces the concentration even further. Tightening the envelope, which reduces the building air change rate from $0.60 \mathrm{~h}^{-1}$ to $0.39 \mathrm{~h}^{-1}$, decreases the concentrations somewhat but not as much as filtration. The combination of enhanced outdoor air filtration and envelope tightening (solid red line) significantly reduces the concentration, while locating the filter in the mixed air (solid blue line) reduces them even more. While not shown in the figure, increasing the outdoor air intake in an attempt to induce pressurization increases the concentration relative to the other outdoor air filtration cases, because the additional outdoor air brings more contaminant into the building. The four shutdown cases once again show the 
importance of the timing of the shutdown. However, the existence of significant envelope infiltration reduces the effectiveness of shutdown strategies relative to that seen in Figure 4 with no weather because contaminant continues to enter the building during the shutdown. Again, only the purge case starting 1 min after the release is shown, which exhibit a quick reduction in the contaminant concentration after the release. Analogous transient concentration data exist for the gaseous contaminant $\mathrm{G}$ and for the indoor release scenarios.

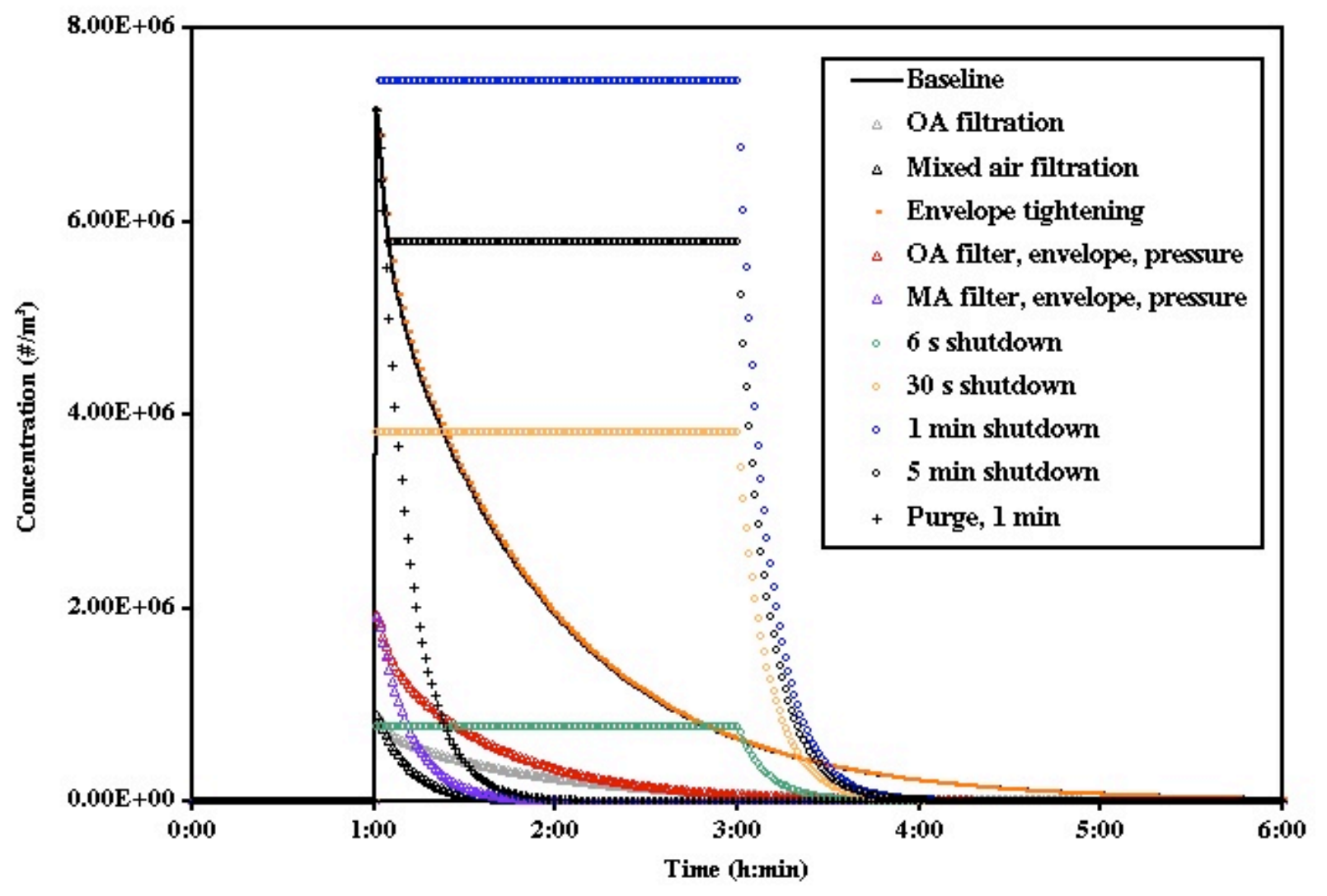

Figure 4 Two-story simulation results for an outdoor particle release (no weather)

Tables 8 through 11 present the exposure reductions for all the retrofit cases for the two-story building, with the first two covering contaminant $P$ (particle) and the second two covering $G$ (gas). Each value in the table is the change in occupant exposure over $6 \mathrm{~h}$ relative to the baseline case. Therefore, a value below $100 \%$ corresponds to an exposure reduction, which a value greater than $100 \%$ means the retrofit actually increases exposure. Table 8 contains the relative exposure for contaminant $\mathrm{P}$ with no weather effects, i.e., no envelope infiltration. There are no entries in the loading dock column (with one exception noted below) because with the outdoor air intake rate exceeding the exhaust airflow rate and no weather to drive air into the building, no contaminant enters at the loading dock door. Upgrading the outdoor air filtration from MERV 6 to MERV 13 reduces occupant exposure by almost $90 \%$ for the outdoor releases. The results for the general and intake releases are identical since there is no envelope infiltration. This filter upgrade has no impact on exposure to the two indoor sources, and therefore these cases were not run. Using a MERV 13 filter in the recirculation airstream is more effective in reducing exposure, with the retrofit exposure less than $5 \%$ of the baseline. The mixed air filter has a larger impact than the intake filter on the outdoor sources because now the recirculation air is 
filtered on each pass through the air handler. The upgraded mixed air filter also results in similar exposure reductions for the indoor sources.

Envelope tightening has almost no impact on exposure for any of the sources given the lack of any weather-induced driving pressures. Combining enhanced outdoor air filtration with envelope tightening is therefore identical to the filtration retrofit alone, as is the case for enhanced mixed air filtration plus tightening with only a minor exception for the lobby release. As noted in the discussion of Figure 4, supplementing these retrofits with increased outdoor air intake in an attempt to pressurize the building increases exposure to outdoor sources. However, combining outdoor filter enhancement and pressurization reduces exposure to the indoor sources by roughly one third due to the increased air change rate. Adding pressurization to the mixed air and envelope retrofit roughly doubles the exposure relative to these combined retrofits with no pressurization for the outdoor sources, but has little effect for the indoor sources.

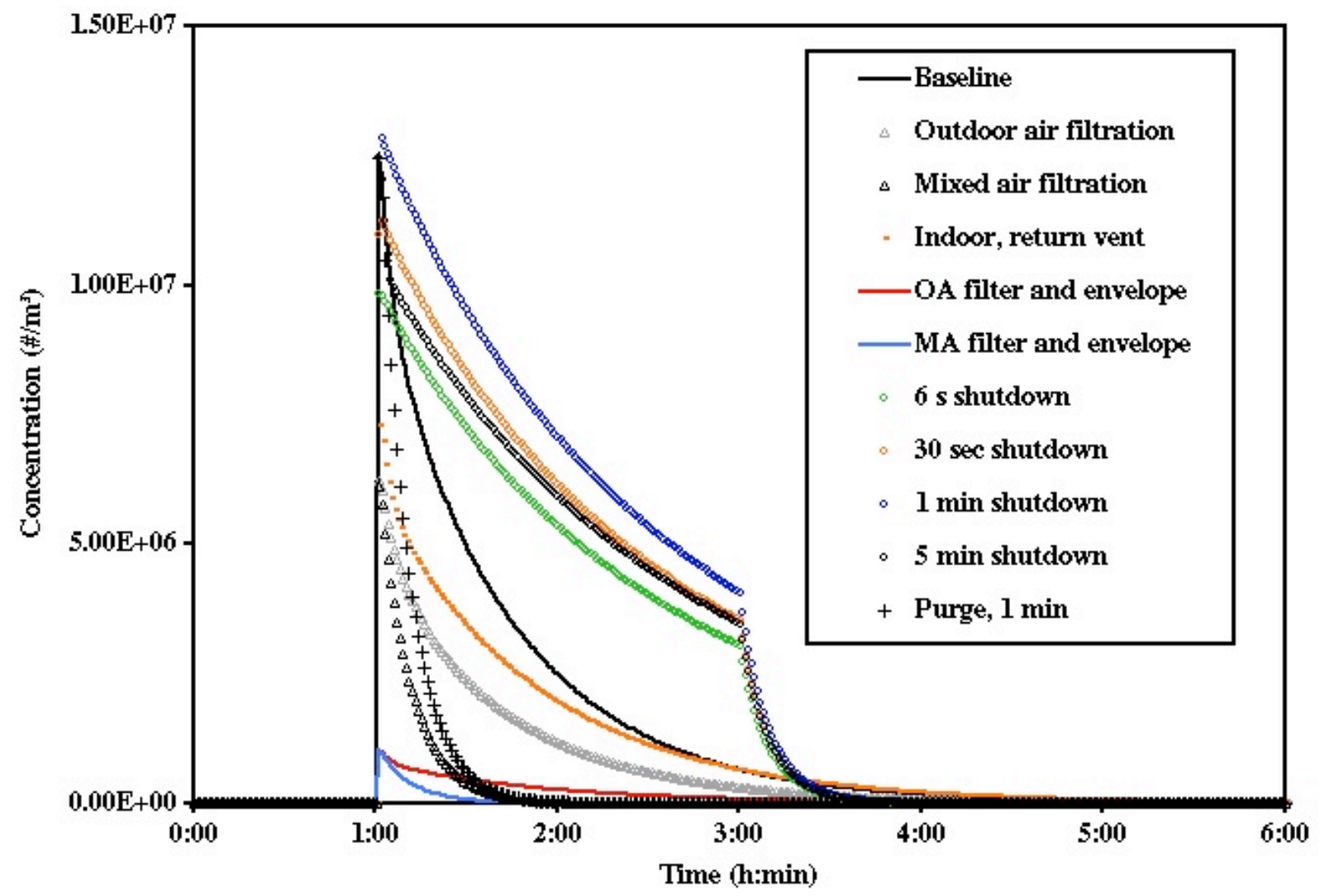

Figure 5 Two-story simulation results for an outdoor particle release (with weather effects)

The five "recommissioning" cases appear in Table 8 after the various "envelope" retrofits. The $100 \%$ recirculation case has roughly $20 \%$ higher exposures for the two indoor releases due to the lower total air change rate. There is a roughly one-third reduction for the outdoor general case because the reduced contaminant entry has a larger impact than the lower dilution rate. The situation is similar for the $5 \%$ outdoor air intake case for both the general outdoor release and the intake release, i.e., less entry is more significant than less dilution leading to a decrease in exposure. The indoor sources have somewhat higher exposures due to the decrease in the building air change rate. When there is $5 \%$ less supply than return, the infiltration rate increases from $0.0 \mathrm{~h}^{-1}$ to $0.40 \mathrm{~h}^{-1}$, and the total air change rate roughly doubles. In this case, the outdoor general exposure increases because of the increased contaminant entry, but the exposure 
decreases for the intake and two indoor source cases due to the higher dilution rate. Because the building is now depressurized, contaminant enters at the loading dock, which results in nonzero exposure even with no weather. In this case, the $9.1 \%$ exposure metric is relative to the baseline intake source case since there is no baseline loading exposure for comparison. Assuming $10 \%$ bypass around the baseline filter increases exposure by about $10 \%$ in all cases. If the same bypass fraction is assumed for the mixed air filtration retrofit, the exposure relative to the baseline is still low, but the exposure relative to the mixed air retrofit itself roughly doubles.

\begin{tabular}{|c|c|c|c|c|c|}
\hline \multirow[b]{2}{*}{ Retrofit } & \multicolumn{5}{|c|}{ Exposure Relative to Baseline (\%) } \\
\hline & $\begin{array}{c}\text { Outdoor, } \\
\text { General }\end{array}$ & $\begin{array}{c}\text { Outdoor } \\
\text { Air Intake }\end{array}$ & $\begin{array}{c}\text { Indoor, } \\
\text { Lobby }\end{array}$ & $\begin{array}{l}\text { Indoor, } \\
\text { return vent }\end{array}$ & $\begin{array}{c}\text { Loading } \\
\text { Dock }\end{array}$ \\
\hline Outdoor air (OA) filtration & 12.4 & 12.4 & & & \\
\hline Mixed air (MA) filtration & 3.3 & 3.3 & 4.2 & 3.3 & \\
\hline Envelope tightening & 100.0 & 100.0 & 98.3 & 100.0 & \\
\hline Envelope, OA filtration & 12.4 & 12.4 & & & \\
\hline Envelope, OA filter, pressure & 19.7 & 19.7 & 63.4 & 73.1 & \\
\hline Envelope, MA filtration & 3.3 & 3.3 & 3.8 & 3.3 & \\
\hline Envelope, MA filter, pressure & 7.1 & 7.1 & 3.3 & 3.3 & \\
\hline $100 \%$ recirculation & 65.7 & & 120.9 & 115.5 & \\
\hline $5 \%$ OA intake & 85.8 & 53.2 & 108.8 & 106.4 & \\
\hline $5 \%$ Undersupply & 151.0 & 76.6 & 69.9 & 66.1 & $9.1^{*}$ \\
\hline $10 \%$ baseline filter bypass & 108.5 & 108.5 & 108.3 & 108.5 & \\
\hline $10 \%$ MA filter bypass & 6.8 & 6.8 & 7.6 & 6.8 & \\
\hline 6 s Shutdown & 31.7 & 31.7 & 0.9 & 30.7 & \\
\hline 30 s Shutdown & 155.0 & 155.0 & 1.2 & 154.1 & \\
\hline 1 min Shutdown & 303.0 & 303.0 & 2.9 & 302.1 & \\
\hline 5 min Shutdown & 236.2 & 236.2 & 46.5 & 236.2 & \\
\hline Purge -30 s prior & 262.8 & 262.8 & 0.9 & 0.0 & \\
\hline Purge $-30 \mathrm{~s}$ after & 146.0 & 146.0 & 0.9 & 11.8 & \\
\hline Purge -1 min after & 24.3 & 24.3 & 1.0 & 24.3 & \\
\hline Purge -5 min after & 27.3 & 27.3 & 4.8 & 27.3 & \\
\hline $\mathrm{SIP}-30 \mathrm{~s}$ prior & 0.1 & 0.0 & 0.0 & 0.0 & \\
\hline SIP - $30 \mathrm{~s}$ after & 137.6 & 137.5 & 1.2 & 136.7 & \\
\hline SIP - 1 min after & 269.5 & 269.5 & 4.3 & 268.7 & \\
\hline SIP - 5 min after & 215.2 & 215.2 & 49.8 & 215.3 & \\
\hline SIP AC - 30 s prior & 0.0 & 0.0 & 0.0 & 0.0 & \\
\hline SIPAC - $30 \mathrm{~s}$ after & 12.2 & 12.2 & 0.3 & 12.1 & \\
\hline SIP AC - 1 min after & 24.9 & 24.9 & 0.6 & 24.9 & \\
\hline SIP AC - 5 min after & 28.4 & 28.4 & 5.9 & 28.4 & \\
\hline
\end{tabular}

* Exposure relative to the baseline outdoor air intake case.

Table 8 Two-story retrofit effectiveness values (Contaminant $\mathrm{P}$, no weather) 
As noted in the discussion of Figure 4, the earlier shutdowns are more effective than those that are delayed. In fact, only the $6 \mathrm{~s}$ shutdown reduces the exposure below the baseline case for all but the lobby source. The later shutdowns for the other sources actually increase the relative exposure, with the 1 min shutdown exposure being three times the baseline value. In this particular case, the system shuts down after the contaminant has entered the building and the dilution rate reduces to essentially zero. The 5 min shutdown is also not very timely, but there are 4 min of ventilation and filtration after the release ends and before the shutdown begins. The indoor lobby releases have much lower exposure because there are no occupants in the lobby when the release occurs, and the contaminant is not as effectively transported to the rest of the building from the lobby as it is from the return.

The impacts of the purge cycle are also a strong function of timing. Early purges are more effective for the indoor releases. However, as expected, purging is not effective for the outdoor releases when done before or during the release, as such timing brings more contaminant into the building. Later purging does help clear the outdoor contaminant from the building and reduces exposure by about $75 \%$. Again, less contaminant spreads from the lobby to the rest of the building when the purge cycle begins, and therefore the purge is more effective in removing the contaminant for this case. Note that purging reduces exposure more than system shutdown for the interior releases.

The shelter-in-place cases, like the shutdown and purge cases, show the importance of timing. For all sources, moving the occupants to the shelter $30 \mathrm{~s}$ before the release occurs eliminates essentially all exposure due to the lack of weather-driven air movement in the building. Instigating the shelter strategy halfway through the release increases exposure by about $40 \%$, with the exception of the lobby source, because of the contaminant that enters the shelter space and then remains there during the low air change sheltering conditions. In the lobby case, the source is not transported effectively to the shelter, and therefore the exposure decreases for that case. The $1 \mathrm{~min}$ and $5 \mathrm{~min}$ cases also increase exposures for other than the lobby source. However, adding a recirculating air cleaner to the shelter reduces exposure significantly in all cases, with later initiation of sheltering, resulting in greater exposure.

Table 9 contains the exposure relative to baseline for contaminant $P$ with weather included, i.e. a wind speed of $5 \mathrm{~m} / \mathrm{s}$ and an indoor-outdoor temperature difference of $20{ }^{\circ} \mathrm{C}$. The existence of weather-driven pressure differences results in an envelope infiltration rate of $0.22 \mathrm{~h}^{-1}$, which when added to the outdoor air intake rate of $0.38 \mathrm{~h}^{-1}$ yields a total air change rate of $0.60 \mathrm{~h}^{-1}$. With the existence of infiltration, contaminant from the loading dock source now enters the building, and the rightmost column of the table contains results. The existence of infiltration results in a difference between the impacts for the outdoor general and outdoor air intake sources for the outdoor air filtration retrofit. The former case has less of an exposure reduction because contaminant entering the building via envelope leakage is not filtered, while the reduction for the intake source is identical to the no-weather case. Adding a MERV 13 filter to the mixed airstream is again quite effective in reducing exposure, with similar reduction values as those seen in the no-weather cases. However the reductions are smaller for the outdoor general release because of unfiltered contaminant entry due to infiltration. The reduction for the loading dock release is smaller because of the exposure that occurs before the contaminant gets to the mixed air filter. 


\begin{tabular}{|c|c|c|c|c|c|}
\hline \multirow[b]{2}{*}{ Retrofit } & \multicolumn{5}{|c|}{ Exposure Relative to Baseline (\%) } \\
\hline & $\begin{array}{c}\text { Outdoor, } \\
\text { General }\end{array}$ & $\begin{array}{c}\text { Outdoor } \\
\text { Air Intake }\end{array}$ & $\begin{array}{l}\text { Indoor, } \\
\text { Lobby }\end{array}$ & $\begin{array}{c}\text { Indoor, } \\
\text { return vent }\end{array}$ & $\begin{array}{c}\text { Loading } \\
\text { Dock }\end{array}$ \\
\hline Outdoor air (OA) filtration & 48.6 & 12.4 & & & \\
\hline Mixed air (MA) filtration & 15.4 & 3.8 & 4.9 & 3.8 & 35.7 \\
\hline Envelope tightening & 72.4 & 121.8 & 120.3 & 121.6 & 4.3 \\
\hline Envelope, OA filtration & 9.9 & 15.1 & & & \\
\hline Envelope, OA filter, pressure & 14.1 & 24.0 & 78.4 & 89.3 & 0.0 \\
\hline Envelope, MA filtration & 2.7 & 4.1 & 4.7 & 4.0 & 1.3 \\
\hline Envelope, MA filter, pressure & 5.1 & 8.7 & 4.2 & 4.0 & 0.0 \\
\hline $100 \%$ recirculation & 75.8 & & 124.8 & 118.9 & 180.6 \\
\hline $5 \%$ OA intake & 88.3 & 54.5 & 112.5 & 109.2 & 125.0 \\
\hline $5 \%$ Undersupply & 118.4 & 85.4 & 78.1 & 73.7 & 83.0 \\
\hline $10 \%$ baseline filter bypass & 106.4 & 107.3 & 107.2 & 107.3 & 104.9 \\
\hline $10 \%$ MA filter bypass & 18.9 & 7.8 & 8.8 & 7.8 & 38.3 \\
\hline 6 s Shutdown & 160.5 & 21.4 & 13.0 & 20.5 & 391.7 \\
\hline 30 s Shutdown & 184.5 & 105.2 & 14.1 & 103.6 & 343.3 \\
\hline 1 min Shutdown & 211.7 & 207.0 & 17.2 & 204.5 & 278.2 \\
\hline 5 min Shutdown & 177.3 & 171.5 & 55.3 & 170.0 & 220.8 \\
\hline Purge $-30 \mathrm{~s}$ prior & 190.3 & 304.0 & 1.1 & 0.0 & 33.4 \\
\hline Purge $-30 \mathrm{~s}$ after & 111.3 & 169.1 & 1.2 & 13.6 & 33.4 \\
\hline Purge -1 min after & 28.8 & 28.2 & 1.3 & 28.0 & 33.5 \\
\hline Purge -5 min after & 33.0 & 31.7 & 5.8 & 31.7 & 36.7 \\
\hline SIP $-30 \mathrm{~s}$ prior & 16.5 & 0.0 & 24.2 & 0.0 & 42.2 \\
\hline SIP - $30 \mathrm{~s}$ after & 106.1 & 156.9 & 26.6 & 155.8 & 35.6 \\
\hline SIP - 1 min after & 196.5 & 308.5 & 33.4 & 307.3 & 40.8 \\
\hline SIP - 5 min after & 187.5 & 255.7 & 97.9 & 255.4 & 75.3 \\
\hline SIP AC - 30 s prior & 2.7 & 0.0 & 4.8 & 0.0 & 7.9 \\
\hline SIPAC - $30 \mathrm{~s}$ after & 11.4 & 15.6 & 5.1 & 15.5 & 6.8 \\
\hline SIP AC - 1 min after & 22.2 & 32.1 & 5.9 & 32.0 & 12.4 \\
\hline SIP AC - 5 min after & 30.8 & 36.8 & 13.6 & 36.7 & 10.8 \\
\hline
\end{tabular}

Table 9 Two-story retrofit effectiveness values (Contaminant $\mathrm{P}$, with weather)

Envelope tightening now reduces the exposure for the outdoor general source because less contaminant enters via infiltration. However, for the intake case, the same amount of contaminant enters the building as in the baseline case, but the dilution rate is lower with the tighter envelope and the exposure therefore increases. The situation for the two indoor sources is similar, and the exposure also increases by about $20 \%$. Because tightening the envelope increases the level of building pressurization, less contaminant enters at the loading dock door and there is a large exposure reduction for that case. Combining enhanced outdoor air filtration with envelope tightening increases the exposure reduction for the outdoor general source relative to the no-weather condition due to the reduced contaminant entry. There is less reduction for the 
intake source because of the lower dilution rate. Increasing the outdoor air intake in an attempt to pressurize the building increases the relative exposure for both the outdoor general and intake sources, relative to tightening and filtration alone, because more contaminant enters. Increasing outdoor air to pressurize the building eliminates all contaminant entry at the loading dock door, resulting in zero exposure. Combining envelope tightness with enhanced mixed air filtration reduces exposure for the outdoor general and loading dock cases relative to enhanced filtration alone, and has little impact on the other three cases. The exposure reductions for these combined retrofits are much more significant that for envelope tightening alone. Increasing outdoor air intake for pressurization again increases exposure for the two outdoor sources, relative to tightening and enhanced mixed air filtration alone. The combination of these three retrofits has little impact on the two indoor sources, but the addition of pressurization does eliminate contaminant entry at the loading dock.

The results for the first two of the five "recommissioning" cases, $100 \%$ recirculation and $5 \%$ outdoor air intake, are similar to those for the no-weather cases. The $100 \%$ recirculation case has roughly $20 \%$ higher exposures for the two indoor releases, and there is a roughly $25 \%$ reduction for the outdoor general case. The loading dock exposure increases significantly because the building is at a lower pressure with no outdoor air intake. Under $5 \%$ outdoor air intake for the general outdoor release and the intake release, the decrease in contaminant entry is more significant than the decrease in ventilation, leading to a decrease in exposure. The indoor and loading dock sources have somewhat higher exposures due to the decrease in the building air change rate. When there is $5 \%$ less supply than return, the infiltration rate roughly doubles, and the total air change rate increases by about one third. In this case, the outdoor general exposure increases because of the higher entry, but the exposure decreases for the other cases due to the higher dilution rate. Assuming $10 \%$ bypass around the baseline filter increases exposure by somewhat less than $10 \%$ in all cases. If the same bypass fraction is assumed for the mixed air filtration retrofit, the exposure is still reduced relative to the baseline, but the exposure relative to the mixed air retrofit itself increases by as much as $100 \%$.

The shutdown cases again show the impact of timing. However, the early shutdown does not reduce exposure for the outdoor general and loading dock sources because contaminant enters the building at a higher rate after the shutdown starts. The contaminant entry increases with the system off because the system flows tend to pressurize the building relative to outdoors. The reductions for the $6 \mathrm{~s}$ shutdown are similar for the intake, lobby and return vent sources relative to the no weather cases. The two later shutdowns have less relative exposure than the no weather case for all but the lobby source given the higher post-release dilution rates due to the extra infiltration airflow. Again, the indoor lobby releases have lower relative exposures under shutdown because there are no occupants in the lobby and the contaminant is not effectively transported to the rest of the building.

The two early purge cycles increase exposure for the outdoor sources because more contaminant enters the building. The exposure reductions for the later purge cycles are similar to those seen in the no-weather cases. It is interesting to note that the reductions for the loading dock source are relatively independent of timing. The exposure changes and timing trends for the shelter-in-place cases are similar to those seen for the no-weather cases, except that infiltration causes contaminant to enter the building for the cases where the shelter strategy is implemented before the contaminant release starts. Therefore, the exposure reduction for the $30 \mathrm{~s}$ prior case is no longer $100 \%$, except for the outdoor air intake and return vent sources. In the latter case, the contaminant released into the vent does not migrate to the rest of the building before the purge is implemented. Adding a recirculating air cleaner to the shelter again reduces exposure 
significantly in all cases, with later initiation of sheltering resulting in greater exposure, but still with reductions over $80 \%$ relative to the baseline case.

\begin{tabular}{|c|c|c|c|c|c|}
\hline \multirow[b]{2}{*}{ Retrofit } & \multicolumn{5}{|c|}{ Exposure Relative to Baseline (\%) } \\
\hline & $\begin{array}{c}\text { Outdoor, } \\
\text { General }\end{array}$ & $\begin{array}{c}\text { Outdoor } \\
\text { Air Intake }\end{array}$ & $\begin{array}{c}\text { Indoor, } \\
\text { Lobby }\end{array}$ & $\begin{array}{c}\text { Indoor, } \\
\text { return vent }\end{array}$ & $\begin{array}{c}\text { Loading } \\
\text { Dock }\end{array}$ \\
\hline Outdoor air (OA) filtration & 5.0 & 5.0 & & & \\
\hline Mixed air (MA) filtration & 5.0 & 5.0 & 0.9 & 0.6 & \\
\hline Envelope tightening & 100.2 & 100.2 & 98.7 & 100.2 & \\
\hline Envelope, OA filtration & 5.0 & 5.0 & & & \\
\hline Envelope, OA filter, pressure & 5.7 & 5.7 & 46.1 & 52.5 & \\
\hline Envelope, MA filtration & 0.6 & 0.6 & 0.8 & 0.6 & \\
\hline Envelope, MA filter, pressure & 1.2 & 1.2 & 0.7 & 0.6 & \\
\hline $100 \%$ recirculation & 79.0 & & 145.4 & 139.8 & \\
\hline $5 \% \mathrm{OA}$ intake & 93.6 & 61.7 & 115.9 & 113.8 & \\
\hline $5 \%$ Undersupply & 113.1 & 58.7 & 54.2 & 50.6 & $5.8^{*}$ \\
\hline \multicolumn{6}{|l|}{$10 \%$ baseline filter bypass } \\
\hline $10 \%$ MA filter bypass & 1.8 & 1.8 & 2.1 & 1.8 & \\
\hline 6 s Shutdown & 13.9 & 13.9 & 0.3 & 13.4 & \\
\hline 30 s Shutdown & 67.9 & 67.9 & 0.5 & 67.5 & \\
\hline 1 min Shutdown & 132.8 & 132.8 & 1.2 & 132.4 & \\
\hline 5 min Shutdown & 106.4 & 106.4 & 20.6 & 106.4 & \\
\hline Purge -30 s prior & 115.1 & 115.1 & 0.3 & 0.0 & \\
\hline Purge $-30 \mathrm{~s}$ after & 64.0 & 64.0 & 0.3 & 5.2 & \\
\hline Purge -1 min after & 10.7 & 10.7 & 0.4 & 10.6 & \\
\hline Purge -5 min after & 12.2 & 12.2 & 2.1 & 12.2 & \\
\hline SIP $-30 \mathrm{~s}$ prior & 0.0 & 0.0 & 0.0 & 0.0 & \\
\hline SIP - $30 \mathrm{~s}$ after & 60.3 & 60.2 & 0.4 & 59.9 & \\
\hline SIP - 1 min after & 118.1 & 118.1 & 1.6 & 117.8 & \\
\hline SIP - 5 min after & 96.9 & 96.9 & 21.5 & 96.9 & \\
\hline SIP AC - 30 s prior & 0.0 & 0.0 & 0.0 & 0.0 & \\
\hline SIPAC - $30 \mathrm{~s}$ after & 5.6 & 5.6 & 0.1 & 5.5 & \\
\hline SIP AC - 1 min after & 11.4 & 11.4 & 0.2 & 11.4 & \\
\hline SIP AC - 5 min after & 13.2 & 13.2 & 2.6 & 13.2 & \\
\hline
\end{tabular}

* Exposure relative to the baseline outdoor air intake case.

Table 10 Two-story retrofit effectiveness values (Contaminant G, no weather)

Tables 10 and 11 present the relative exposures for the no-weather and weather cases for the gaseous contaminant $\mathrm{G}$. These results are very similar to those seen in Tables 8 and 9 for contaminant $\mathrm{P}$, except as impacted by the different gaseous removal efficiencies for the baseline and retrofit efficiencies relative to those for the particle filters. For example, the exposure reductions for the outdoor air and mixed air retrofits are larger for contaminant $\mathrm{G}$ because the gas 
filter has a higher efficiency than the enhanced particle filter and the baseline gaseous removal efficiency is zero. In general, the relative exposures for contaminant $\mathrm{G}$ are lower than for the particulate agent, but there are a few exceptions such as the $100 \%$ recirculation and $5 \%$ outdoor air intake "recommissioning" cases, which accentuate the lack of gaseous air cleaning in the baseline case.

\begin{tabular}{|c|c|c|c|c|c|}
\hline \multirow[b]{2}{*}{ Retrofit } & \multicolumn{5}{|c|}{ Exposure Relative to Baseline (\%) } \\
\hline & $\begin{array}{c}\text { Outdoor, } \\
\text { General }\end{array}$ & $\begin{array}{c}\text { Outdoor } \\
\text { Air Intake }\end{array}$ & $\begin{array}{l}\text { Indoor, } \\
\text { Lobby }\end{array}$ & $\begin{array}{c}\text { Indoor, } \\
\text { return vent }\end{array}$ & $\begin{array}{c}\text { Loading } \\
\text { Dock }\end{array}$ \\
\hline Outdoor air (OA) filtration & 40.0 & 5.0 & & & \\
\hline Mixed air (MA) filtration & 6.3 & 0.8 & 1.2 & 0.8 & 18.3 \\
\hline Envelope tightening & 91.0 & 142.8 & 140.5 & 142.6 & 5.0 \\
\hline Envelope, OA filtration & 5.6 & 7.1 & & & \\
\hline Envelope, OA filter, pressure & 5.1 & 8.2 & 66.5 & 75.2 & 0.0 \\
\hline Envelope, MA filtration & 0.6 & 0.8 & 1.1 & 0.8 & 0.7 \\
\hline Envelope, MA filter, pressure & 1.1 & 1.7 & 1.0 & 0.8 & 0.0 \\
\hline $100 \%$ recirculation & 87.6 & & 159.2 & 152.8 & 235.8 \\
\hline $5 \%$ OA intake & 96.2 & 65.2 & 123.3 & 120.3 & 135.3 \\
\hline $5 \%$ Undersupply & 102.9 & 75.9 & 69.9 & 65.5 & 149.5 \\
\hline \multicolumn{6}{|l|}{$10 \%$ baseline filter bypass } \\
\hline $10 \%$ MA filter bypass & 7.8 & 2.4 & 2.9 & 2.4 & 19.6 \\
\hline 6 s Shutdown & 75.3 & 11.0 & 5.7 & 10.5 & 205.5 \\
\hline $30 \mathrm{~s}$ Shutdown & 90.8 & 53.6 & 6.1 & 53.2 & 183.1 \\
\hline 1 min Shutdown & 108.9 & 105.5 & 7.6 & 105.2 & 148.2 \\
\hline 5 min Shutdown & 94.0 & 90.6 & 26.8 & 89.9 & 119.9 \\
\hline Purge $-30 \mathrm{~s}$ prior & 104.1 & 156.1 & 0.5 & 0.0 & 17.8 \\
\hline Purge $-30 \mathrm{~s}$ after & 60.4 & 86.8 & 0.5 & 7.0 & 17.8 \\
\hline Purge -1 min after & 14.8 & 14.5 & 0.6 & 14.4 & 17.9 \\
\hline Purge -5 min after & 17.4 & 16.7 & 2.9 & 16.7 & 19.9 \\
\hline SIP $-30 \mathrm{~s}$ prior & 7.6 & 0.0 & 10.5 & 0.0 & 22.5 \\
\hline SIP - $30 \mathrm{~s}$ after & 57.5 & 80.6 & 11.6 & 80.1 & 19.0 \\
\hline SIP - 1 min after & 107.5 & 158.5 & 14.6 & 158.0 & 20.2 \\
\hline SIP - 5 min after & 104.8 & 90.6 & 46.6 & 135.0 & 50.8 \\
\hline SIPAC $-30 \mathrm{~s}$ prior & 1.3 & 0.0 & 2.2 & 0.0 & 4.4 \\
\hline SIPAC - $30 \mathrm{~s}$ after & 6.4 & 8.4 & 2.3 & 8.4 & 3.7 \\
\hline SIPAC - 1 min after & 12.5 & 17.3 & 2.7 & 17.2 & 6.8 \\
\hline SIPAC - 5 min after & 17.2 & 20.0 & 6.7 & 20.0 & 6.4 \\
\hline
\end{tabular}

Table 11 Two-story retrofit effectiveness values (Contaminant G, with weather) 


\begin{tabular}{|c|c|c|c|c|c|}
\hline \multirow[b]{2}{*}{ Retrofit } & \multicolumn{5}{|c|}{ Exposure Relative to Baseline (\%) } \\
\hline & $\begin{array}{c}\text { Outdoor, } \\
\text { General }\end{array}$ & $\begin{array}{c}\text { Outdoor } \\
\text { Air Intake }\end{array}$ & $\begin{array}{l}\text { Indoor, } \\
\text { Lobby }\end{array}$ & $\begin{array}{c}\text { Indoor, } \\
\text { return vent }\end{array}$ & $\begin{array}{c}\text { Loading } \\
\text { Dock }\end{array}$ \\
\hline Outdoor air (OA) filtration & 546.5 & 81.8 & & & \\
\hline Mixed air (MA) filtration & 648.9 & 94.2 & 96.0 & 94.1 & \\
\hline Envelope tightening & 101.0 & 99.6 & 99.5 & 99.5 & \\
\hline Envelope, OA filtration & 111.2 & 99.6 & & & \\
\hline Envelope, OA filter, pressure & 100.0 & 100.0 & 100.5 & 100.0 & \\
\hline Envelope, MA filtration & 113.5 & 99.9 & 98.7 & 99.9 & \\
\hline Envelope, MA filter, pressure & 100.0 & 100.0 & 104.7 & 100.0 & \\
\hline $100 \%$ recirculation & 161.0 & $\mathrm{~N} / \mathrm{A}$ & 83.9 & 84.3 & \\
\hline $5 \%$ OA intake & 143.5 & 83.8 & 84.0 & 84.0 & \\
\hline $5 \%$ Undersupply & 109.4 & 91.1 & 90.9 & 91.3 & 147.9 \\
\hline $10 \%$ baseline filter bypass & 136.9 & 80.9 & 80.4 & 81.0 & \\
\hline $10 \%$ MA filter bypass & 388.3 & 93.7 & 94.2 & 93.6 & \\
\hline 6 s Shutdown & 706.7 & 55.2 & 1214.1 & 54.7 & \\
\hline 30 s Shutdown & 166.1 & 55.5 & 915.1 & 55.1 & \\
\hline 1 min Shutdown & 97.5 & 55.9 & 488.2 & 55.4 & \\
\hline 5 min Shutdown & 104.7 & 59.4 & 96.7 & 58.9 & \\
\hline Purge -30 s prior & 101.1 & 94.6 & 106.9 & $*$ & \\
\hline Purge $-30 \mathrm{~s}$ after & 106.3 & 94.7 & 106.7 & 94.5 & \\
\hline Purge -1 min after & 165.3 & 94.7 & 105.7 & 94.7 & \\
\hline Purge -5 min after & 168.8 & 95.1 & 97.8 & 95.1 & \\
\hline SIP $-30 \mathrm{~s}$ prior & 36859.9 & $*$ & $*$ & $*$ & \\
\hline SIP - $30 \mathrm{~s}$ after & 107.6 & 93.3 & 1841.6 & 93.3 & \\
\hline SIP - 1 min after & 101.7 & 93.6 & 632.5 & 93.6 & \\
\hline SIP - 5 min after & 121.6 & 97.2 & 159.7 & 97.2 & \\
\hline SIPAC $-30 \mathrm{~s}$ prior & 39241.1 & $*$ & $*$ & $*$ & \\
\hline SIPAC - $30 \mathrm{~s}$ after & 131.1 & 105.2 & 2349.2 & 105.2 & \\
\hline SIPAC - 1 min after & 124.0 & 105.3 & 805.5 & 105.3 & \\
\hline SIPAC - 5 min after & 151.1 & 105.8 & 187.3 & 105.8 & \\
\hline
\end{tabular}

* The exposure with no weather is zero, and therefore the ratio is infinite.

Table 12 Ratio of exposure with weather to exposure without, contaminant $\mathrm{P}$

The impact of envelope infiltration on contaminant entry and, in some cases, retrofit effectiveness has been mentioned. Table 12 shows the impact of weather-induced infiltration more explicitly by comparing the exposure to contaminant $\mathrm{P}$ with weather to the exposure without weather. The entries in this table do not compare the relative exposure to the baseline for each retrofit, but rather compare the exposures for each case with and without weather. The outdoor general source shows the greatest impact of weather-induced infiltration with only a few exceptions. The two filtration retrofits have more than five times greater exposure due to the unfiltered contaminant entry when infiltration is occurring, while the cases with filter bypass 
have less dramatic increases in exposure with weather impacts included. The two cases with reduced outdoor air entry (100\% recirculation and $5 \%$ outdoor air intake) are also strongly impacted by weather-induced contaminant entry. The two early shutdown cases have increased exposure for the outdoor general source and the lobby source. In the first case, the increased exposure is due to contaminant entry with the infiltration air, even after the shutdown occurs. In the lobby case, the weather induces airflow within the building, which moves the contaminant to the occupied zones more effectively than it does without weather. The $30 \mathrm{~s}$ prior SIP cases show dramatic increases in exposure, due to interzone airflow driven by the weather-induced pressures in the building. Some cases have reduced exposure with weather versus without, but none of the reductions are particularly large.

Figures $6 \mathrm{a}$ through $6 \mathrm{c}$ present the two-story office building particle exposures, relative to the baseline case, for the with-weather condition. Figure 6 a presents these results for the filtration retrofits for all five source locations. Figure $6 \mathrm{~b}$ presents the results for the shutdown and purge retrofits, while Figure 6c presents the SIP results. Examination of these figures leads to some broad categories of exposure reduction. While the divisions are somewhat arbitrary, the following categories of exposure level relative to baseline are helpful in considering the results: $25 \%$ or less, about $50 \%$, about $100 \%$, and more than a $25 \%$ increase in exposure. The only retrofits that consistently fall in the lowest exposure category, roughly $25 \%$ or less of baseline, are envelope tightening with enhanced outdoor air or mixed air filtration, the fastest implementation of sheltering without air cleaning, and the two fastest with air cleaning. The only exception is for the loading dock source, where early sheltering increases contaminant entry into the building. The purging response is fairly consistently in the $25 \%$ or less category for the two later purge times, except in the case of the lobby source where purging is more effective.

Outdoor sources, both general and air intake, are of particular interest in buildings with good perimeter security and those that may not be targets themselves but may be near a target. For the two outdoor sources, retrofits that reduce exposure to roughly $25 \%$ or less of baseline include the following: mixed air filtration alone; envelope tightening combined with outdoor or mixed air filtration; the two later purging cycles; the earliest implementation of SIP without air cleaning; and, all but the very slowest implementations with air cleaning. The intake release, but not the outdoor general release, falls in this lowest relative exposure category for outdoor air filtration alone and for the earliest shutdown. Outdoor air filtration reduces the relative exposure by roughly $50 \%$ for the outdoor general release. Most of the other retrofits result in only small, $20 \%$ or less, reductions in the relative exposure for the outdoor releases, while several cases actually increase exposure, in some cases by a significant amount.

Another distinction worth noting is the consistency in the exposure reductions across sources. For example, mixed filtration has a fairly consistent reduction for all five sources, as does the shelter-in-place with air cleaning. Most of the other retrofits are beneficial for some sources, but not for others. 


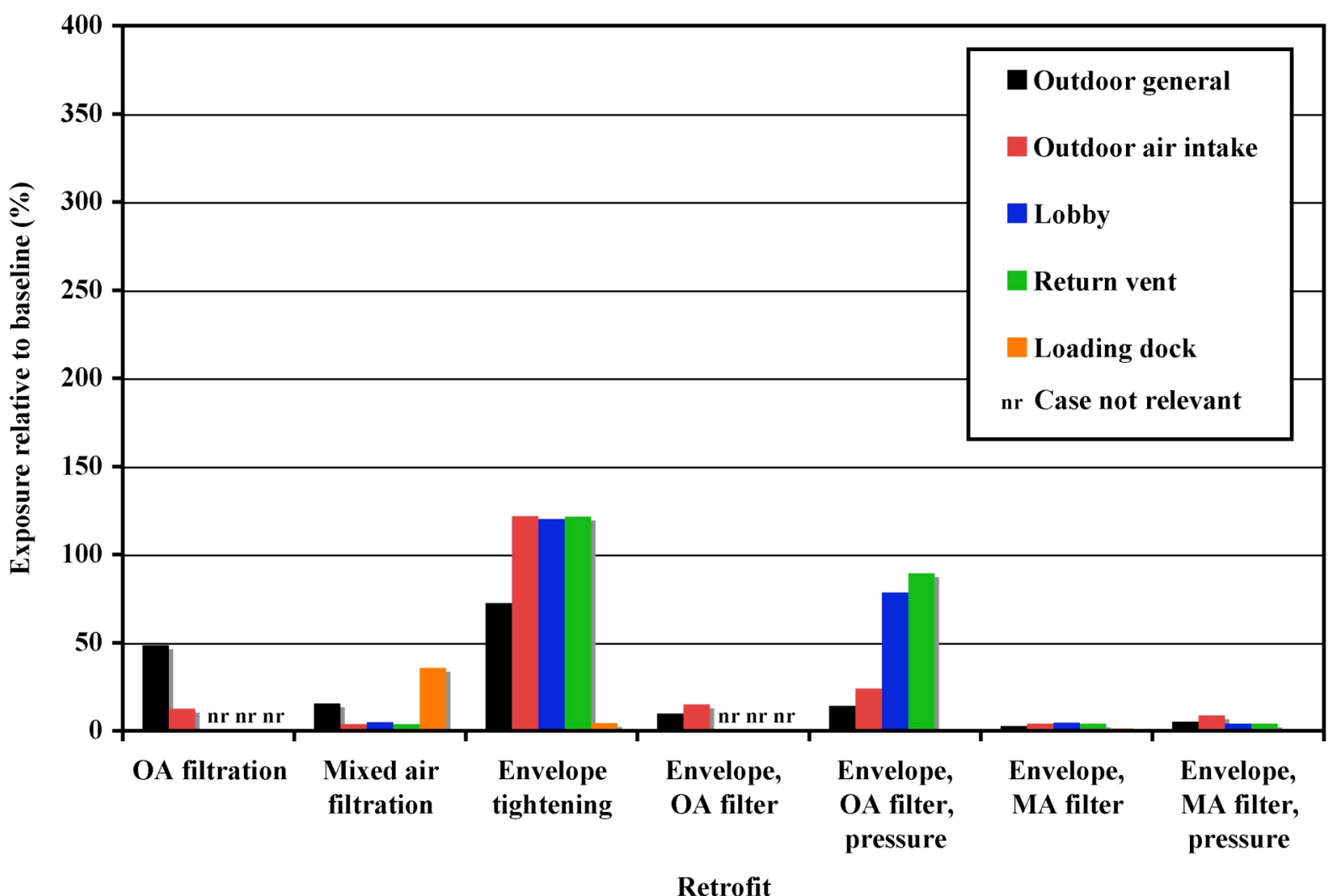

Figure 6a Relative exposure for filtration retrofits with weather, particle releases

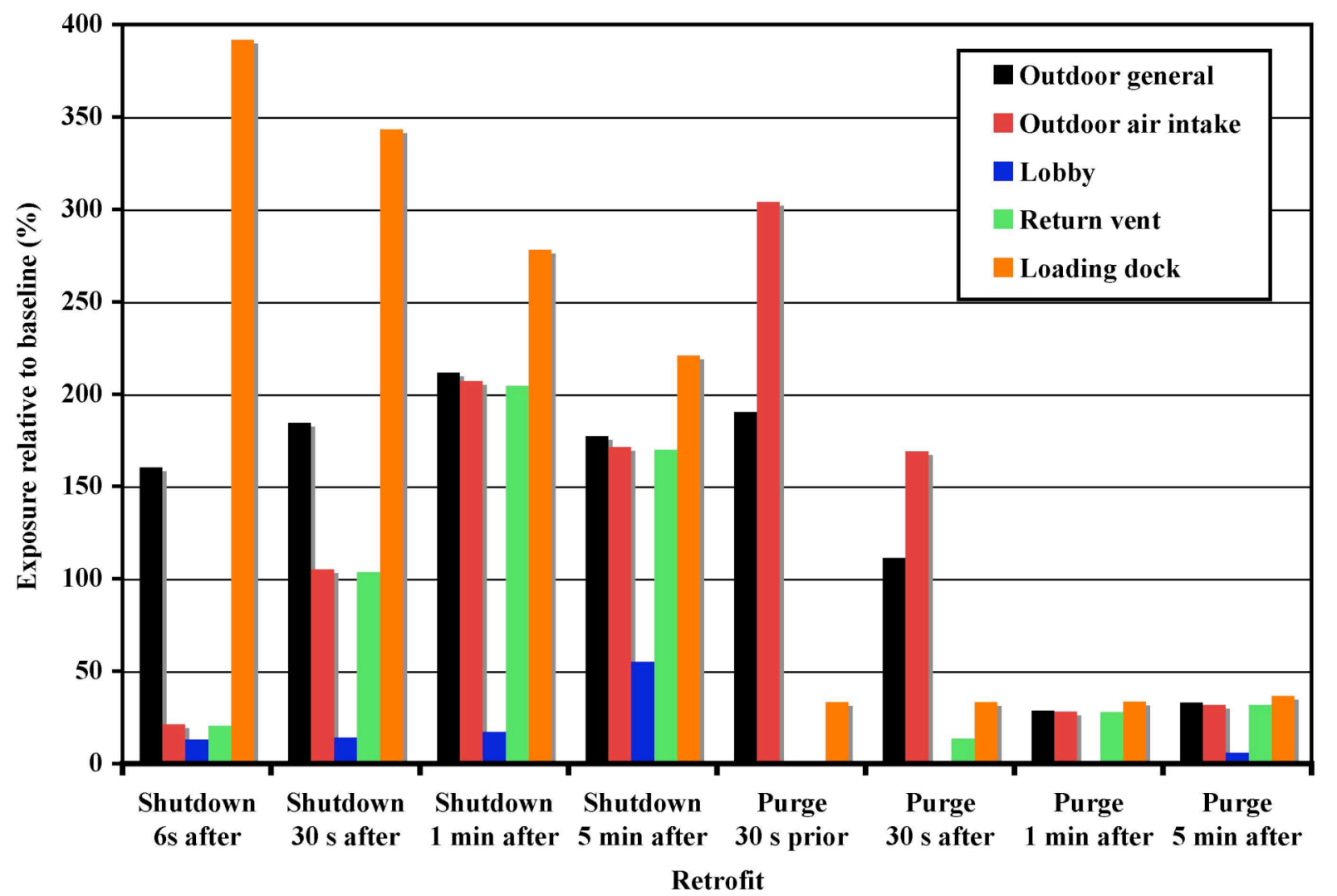

Figure $6 \mathrm{~b}$ Relative exposure for system operation retrofits with weather, particle releases 


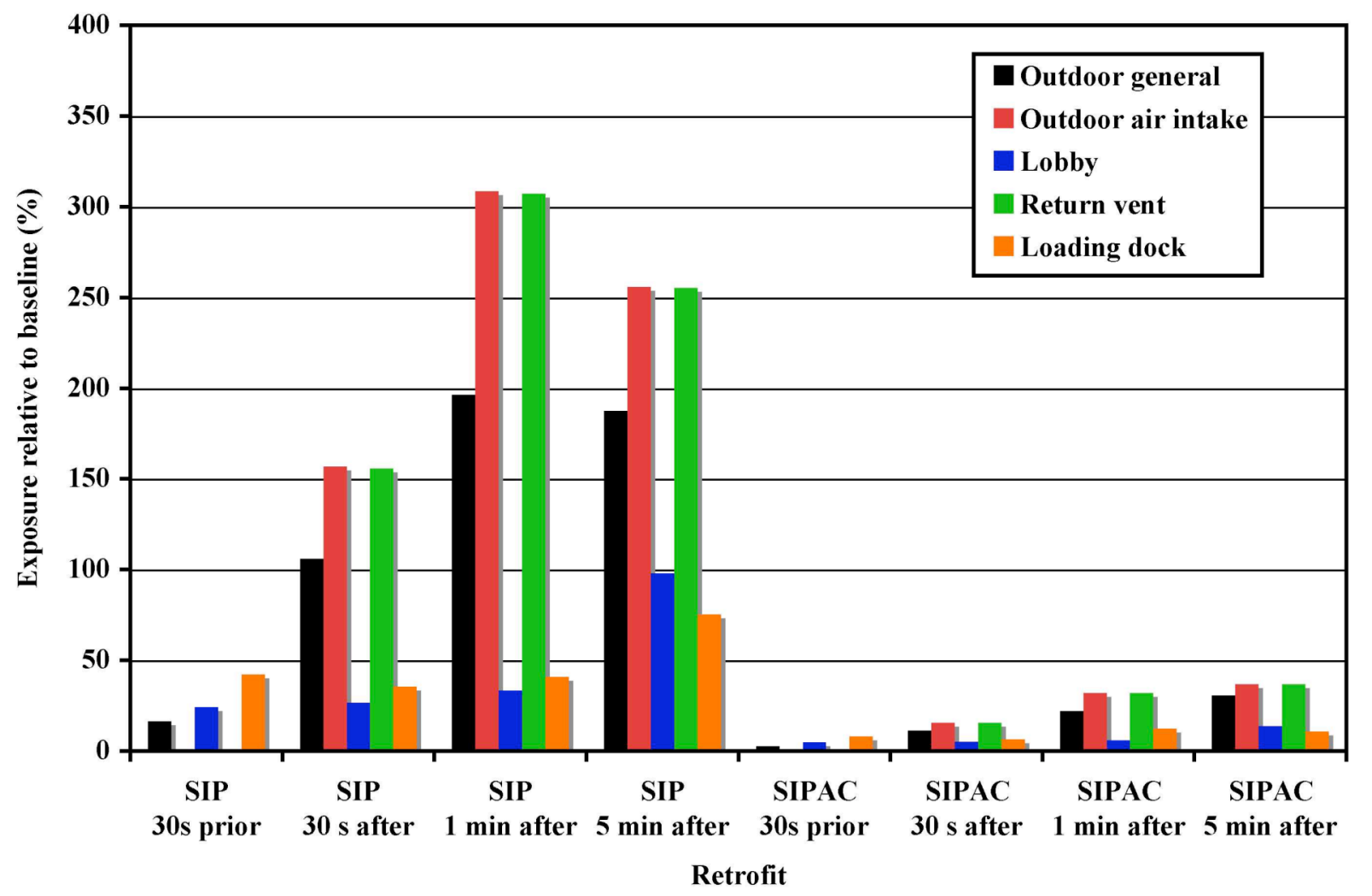

Figure 6c Relative exposure for SIP retrofits with weather, particle releases

The recommissioning cases were run to investigate the importance of system installation, operation and maintenance on exposure. While only a small number were considered, and only for specific values of the relevant parameters, they do provide some useful insight. Figure 7 shows the relative exposure for the five recommissioning cases for the particle releases with weather effects. For $10 \%$ filter bypass around the baseline filter, there is an increase in exposure relative to baseline for all releases, but due to the low baseline filter efficiency the increase is small. However, with the same $10 \%$ bypass around the higher efficiency retrofit filter, the increases are larger, particularly for the intake, lobby and return vent releases. The last three recommissioning cases all relate to system airflow controls. If there is no outdoor air intake (100\% recirculation), the relative exposure increases for the two indoor sources and especially for the loading dock release. The outdoor general source is associated with less exposure because there is no outdoor air intake, which also makes the intake source irrelevant to this case. If the outdoor air intake is reduced by $50 \%$ of its intended value, the exposure to outdoor sources is reduced accordingly while the exposure to indoor sources increases given the lower rate of dilution. Finally, if the building becomes more negative due to an undersupply of $5 \%$ relative to the return flow, there is more contaminant entry for the outdoor general source, but all other exposures are reduced given the higher overall air change rate of the building. The important point of the recommissioning cases is that filter bypass and poor airflow control can increase exposure, presumably by much larger amounts than shown in these cases if the problems are particularly bad. These results demonstrate the importance of operating a system as designed and the value of good system maintenance. 


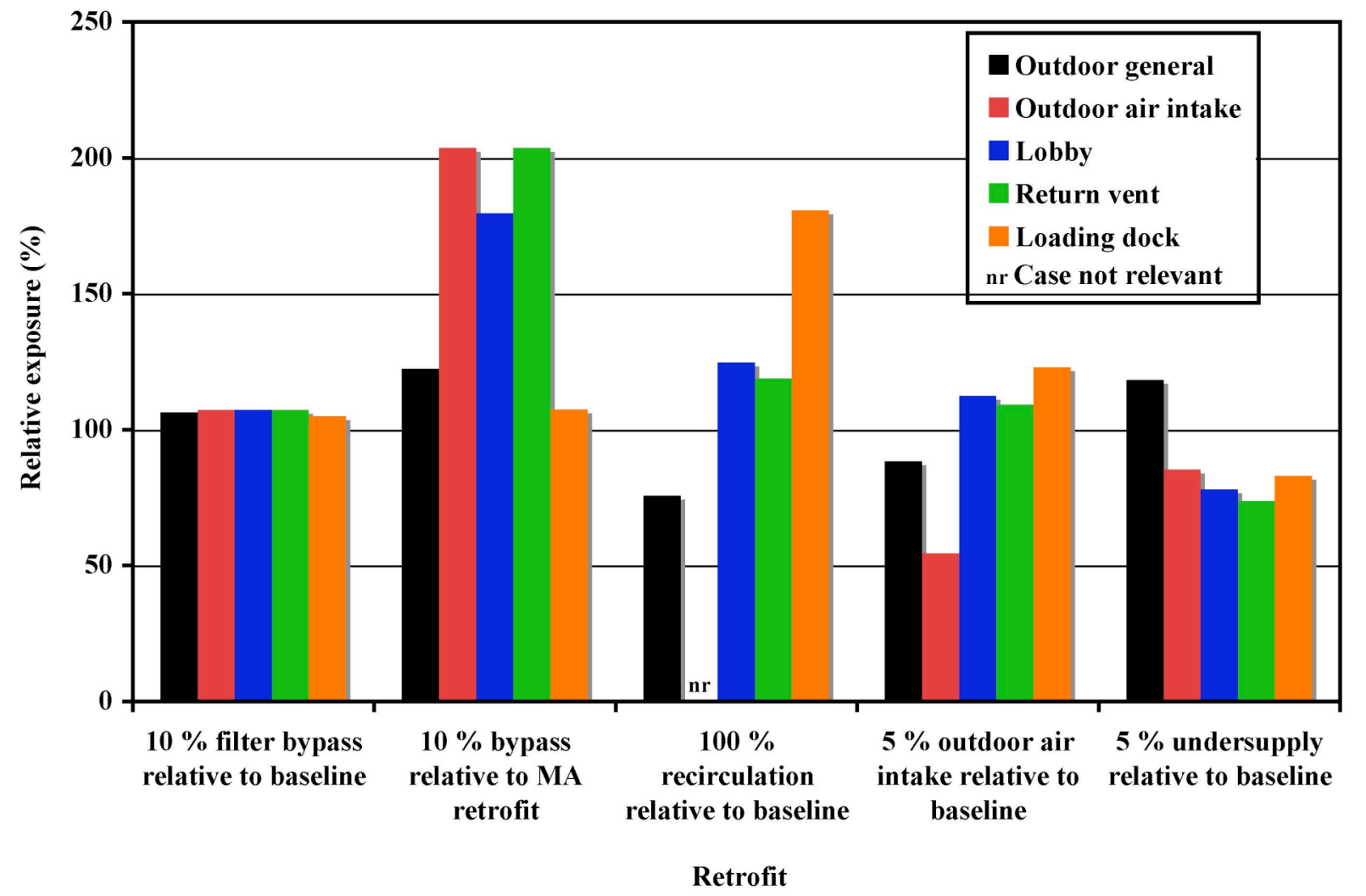

Figure 7 Relative exposure for recommissioning cases with weather, particle releases 


\subsubsection{High-rise office building}

Figure 8 is a plot of the calculated concentrations in the high-rise office building for selected cases subject to an outdoor particle release with no weather-induced infiltration. Note that in the high-rise building, the average exposure includes occupants of the lobby, mail room and other spaces that can have a large impact on the average depending on the source location and contaminant transport dynamics. The baseline results correspond to the solid line that peaks around $3 \times 10^{4}$ particles $/ \mathrm{m}^{3}$ and decays immediately thereafter. The building air change rate for the baseline case with no weather, i.e., driven by mechanical intake alone, is $1.12 \mathrm{~h}^{-1}$. For the noweather conditions, the results for the tight envelope case are identical to those for the baseline case, as indicated in the plot's legend. Tightening the envelope has no effect on the air change rate for the no-weather case because the system flows already pressurize the building. Enhancing the outdoor filtration decreases the concentrations significantly. Those results are also identical to the results for the case that combined envelope tightening and enhanced outdoor air filtration, and are barely distinguishable from the case that combines outdoor filtration, tightening and pressurization with additional outdoor air intake. Increasing the mixed air filtration efficiency decreases the concentration more than the enhanced outdoor air filter. The impact of the shutdown cases is similar to the impact seen in the other buildings, with timing being critical.

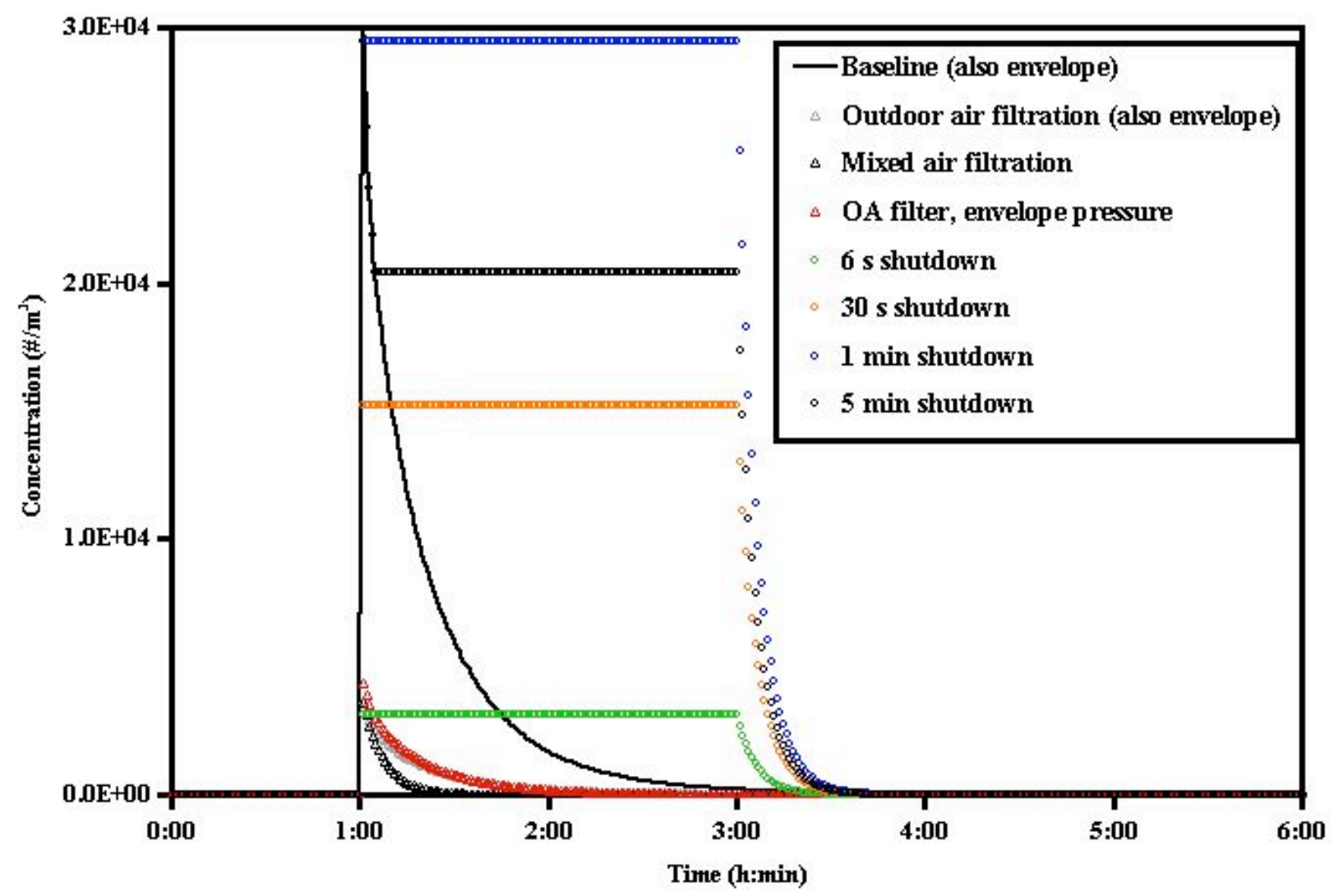

Figure 8 High-rise simulation results for an outdoor particle release (no weather)

Figure 9 shows the same cases as Figure 8, but with weather conditions inducing envelope infiltration. In this case the building air change rate is $1.35 \mathrm{~h}^{-1}$, an increase of $0.23 \mathrm{~h}^{-1}$ relative to the no-weather case. The peak baseline concentration of just over $3 \times 10^{4}$ particles $/ \mathrm{m}^{3}$ is slightly higher than the no-weather case because the non-zero infiltration results in more contaminant entry. The peak concentration for the envelope tightening case is just barely lower than that of 
the baseline case because the decreased contaminant entry tends to balance the decreased dilution rate. The four filtration retrofits all decrease the concentrations significantly, with the mixed air filter resulting in the greatest reduction. The four shutdown cases now show the concentration decaying during the $2 \mathrm{~h}$ shutdown.

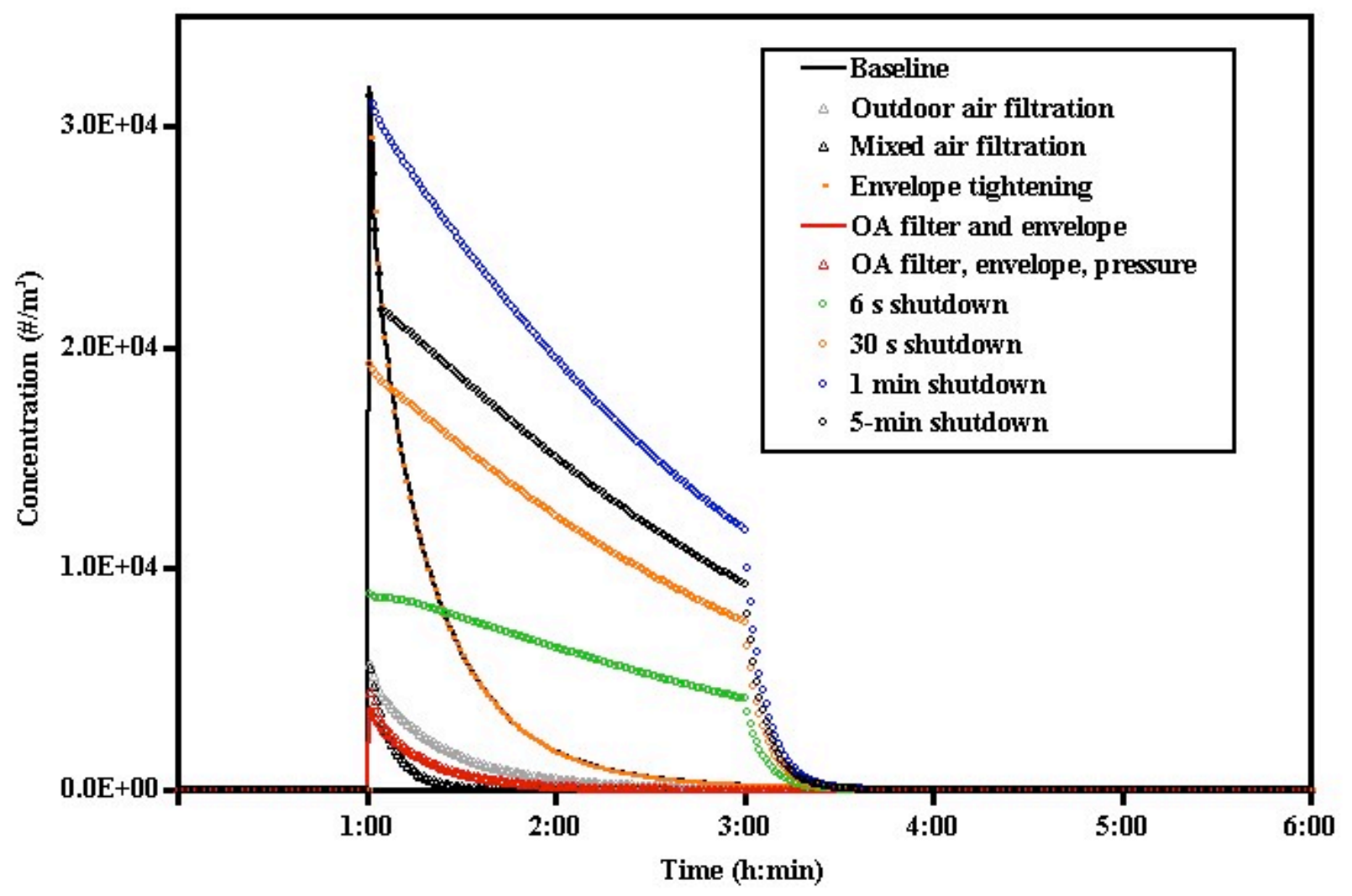

Figure 9 High-rise simulation results for an outdoor particle release (with weather)

The high-rise building is more complex than the other two buildings due to its mix of systems, the non-uniform occupant distribution in the building, and the existence of the lobby and mail room. These features lead to somewhat unique contaminant transport and exposure patterns. For example, Figure 10 shows the concentrations in the Lobby and the $1^{\text {st }}$ and $2^{\text {nd }}$ floors for a lobby release of contaminant $\mathrm{P}$ with no weather. The baseline case has no interior partitions between the lobby and the rest of the $1^{\text {st }}$ floor, and the concentration peaks around $2.5 \times 10^{5}$ particles $/ \mathrm{m}^{3}$ as indicated by the solid black line in the figure. Almost none of the contaminant released in the lobby is transported to the rest of the building, and therefore no line is seen for the $2^{\text {nd }}$ floor baseline concentration. Partitions that separate the lobby from the rest of the $1^{\text {st }}$ floor increase the lobby concentrations (open blue squares) to a peak concentration of almost $2 \times 10^{6}$ particles $/ \mathrm{m}^{3}$, and decrease the concentrations on the rest of the $1^{\text {st }}$ floor (solid blue line) relative to the baseline case. However, after about $15 \mathrm{~min}$, these concentrations are the same as in the baseline case. Again the concentrations on the $2^{\text {nd }}$ floor are so low that no line is seen. Finally, when the lobby is further isolated through the use of a dedicated ventilation system, the lobby concentrations (open red squares) are slightly higher than in the partitioned case. Now the concentrations on the rest of the $1^{\text {st }}$ floor, as well as the $2^{\text {nd }}$ floor, are zero. Therefore, as the cases progress from baseline to partitioned lobby to HVAC isolation of the lobby, the lobby concentrations and the exposure for the small number of lobby occupants increases, but the concentrations and 
exposures in the rest of the building decrease. The difference between average and local exposure are highlighted in Table 13, which shows the average exposure for the occupants of the lobby, the rest of the first floor, the second floor and above, and the entire building for the lobby release and retrofits. In the baseline case, there is only a single zone on the first floor, i.e., the lobby is not a separate zone. There is some exposure throughout the building due to contaminant transport upward from the lobby. Installing partitions increases the exposure of the 3 lobby occupants, but reduces it for the rest of the first floor occupants and those in the higher floors. Finally, isolating the lobby through ventilation reduces the exposure outside the lobby to zero.

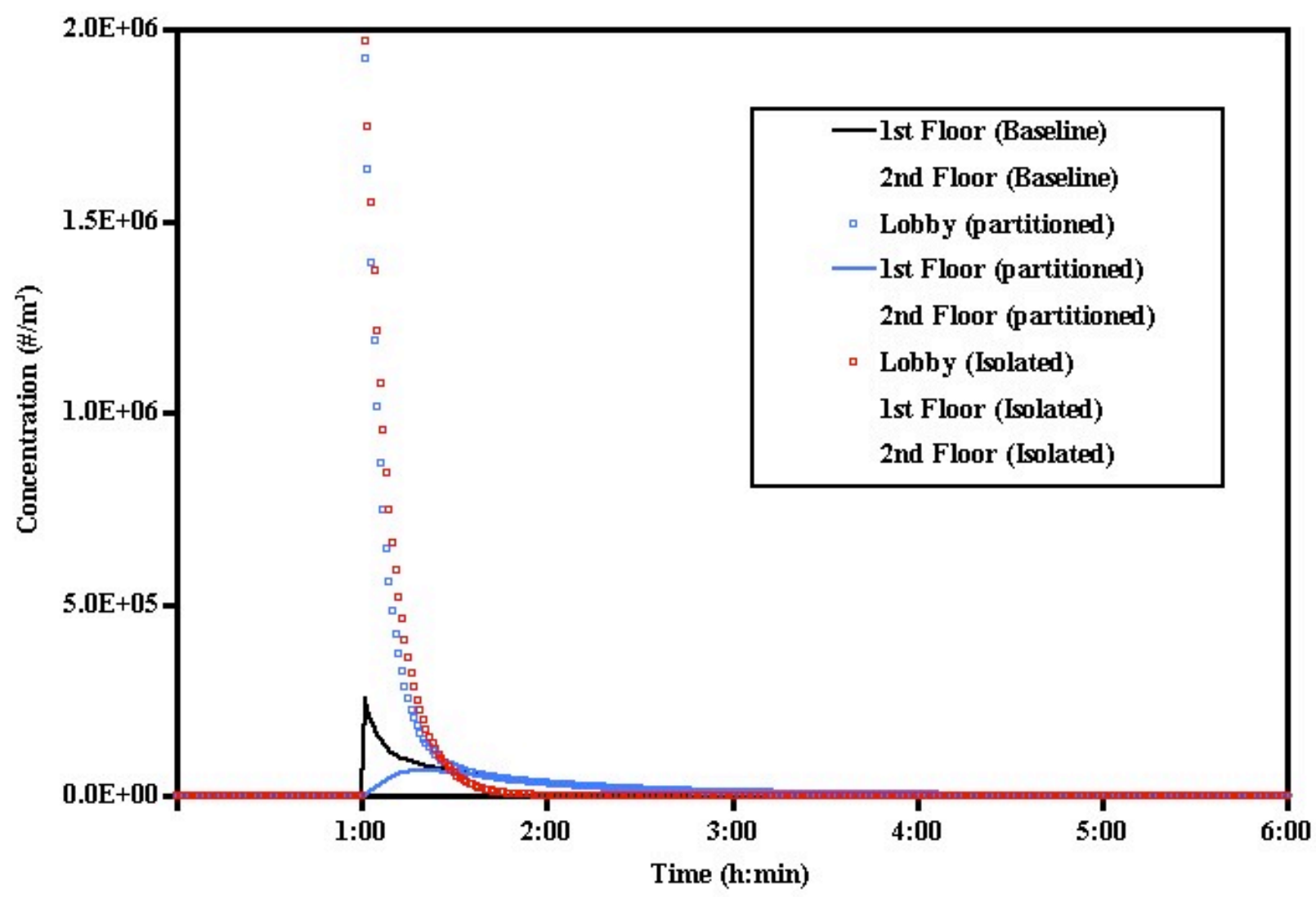

Figure 10 Lower levels of high-rise building for lobby release of contaminant P (no weather)

\begin{tabular}{|l|c|c|c|c|}
\hline \multirow{2}{*}{} & \multicolumn{4}{|c|}{ Average exposure (particle•min/m } \\
\cline { 2 - 5 } & Lobby & $\begin{array}{c}\text { Rest of } \mathbf{1}^{\text {st }} \\
\text { floor }\end{array}$ & $\begin{array}{c}\mathbf{2}^{\text {nd }} \\
\text { floor \& } \\
\text { above }\end{array}$ & $\begin{array}{c}\text { Entire } \\
\text { building }\end{array}$ \\
\hline \multicolumn{1}{|c|}{ Number of occupants } & 3 & 22 & 230 & 285 \\
\hline Baseline & $6.38 \times 10^{6} *$ & $6.38 \times 10^{6}$ & 1105 & $5.60 \times 10^{5}$ \\
\hline Lobby partitions & $1.71 \times 10^{7}$ & $4.52 \times 10^{6}$ & 758 & $5.30 \times 10^{5}$ \\
\hline Lobby partitions \& HVAC isolation & $1.73 \times 10^{7}$ & 0 & 0 & $1.81 \times 10^{5}$ \\
\hline
\end{tabular}

* In the baseline case, the lobby is not a separate zone but is part of the $1^{\text {st }}$ floor zone.

Table 13 High-rise exposures for lobby source and retrofits (Contaminant $\mathrm{P}$, no weather) 
Tables 14 through 17 present the relative exposure for all the retrofit cases for the high-rise office building, with the first two covering P (particle) and the second two covering $\mathrm{G}$ (gas). Each value in the table is the average occupant exposure over $6 \mathrm{~h}$ relative to the baseline case expressed as a percentage. Therefore, a value below $100 \%$ corresponds to a reduction in exposure. Given the varied occupancy and complex zoning of this building, there is a range of exposure values among the various occupant locations that is not revealed by the average exposure as noted in the discussion of Table 13.

Table 14 contains the relative exposure for contaminant $\mathrm{P}$ with no weather-induced infiltration. Enhanced outdoor air filtration decreases exposure to about $12 \%$ of the baseline value, with no difference between the general outdoor and intake releases. A mixed air filter is more effective. This retrofit is not particularly effective for the mail room release because the filters are in the main handlers that don't serve this space and because the mail room exposures are so high. The shutdown cases show the impact of timing discussed previously, but even the fastest shutdown reduces exposure to the outdoor sources by only about $25 \%$. Purging reduces exposure by about $70 \%$, while envelope tightening has little impact on the outdoor sources. Shelter-in-place is fairly effective, with timelier sheltering being more so. Adding filtration to the shelter greatly increases the exposure reduction. The mail room retrofits prevent contaminant from moving to the rest of the building, but the exposure of the mail room occupants is still high, leading to only a $15 \%$ reduction in the average exposure.

\begin{tabular}{|l|c|c|c|c|c|}
\hline & \multicolumn{5}{|c|}{ Exposure Relative to Baseline (\%) } \\
\hline Retrofit & $\begin{array}{c}\text { Outdoor, } \\
\text { General }\end{array}$ & $\begin{array}{c}\text { Outdoor } \\
\text { Air Intakes }\end{array}$ & $\begin{array}{c}\text { Indoor, } \\
\text { Lobby }\end{array}$ & $\begin{array}{c}\text { Indoor, } \\
\text { return vent }\end{array}$ & $\begin{array}{c}\text { Mail } \\
\text { room }\end{array}$ \\
\hline Outdoor air filtration & 12.4 & 12.4 & & & \\
\hline Mixed air filtration & 4.9 & 4.9 & 32.0 & 4.0 & 92.1 \\
\hline 6 s Shutdown & 72.7 & 72.7 & & & \\
\hline 30 s Shutdown & 350.8 & 350.8 & & & \\
\hline 1 min Shutdown & 677.2 & 677.2 & & & \\
\hline 5 min Shutdown & 471.1 & 471.1 & & & \\
\hline 100\% OA purge & 36.9 & & 26.0 & 29.2 & \\
\hline Envelope tightening & 100.2 & 100.2 & 91.1 & 95.5 & \\
\hline Envelope, OA filtration & 12.4 & 12.4 & & & \\
\hline Envelope, OA filter, pressure & 13.5 & & & & \\
\hline SIP - 30 s prior & 5.1 & & & & \\
\hline SIP - 30 s after & 8.6 & & & & \\
\hline SIP - 1 min after & 16.7 & & & & \\
\hline SIP - 5 min after & 41.1 & & & & \\
\hline SIPAC - 30 s prior & 0.4 & & & & \\
\hline SIPAC - 30 s after & 0.1 & & & & \\
\hline SIPAC - 1 min after & 1.7 & & & & \\
\hline SIPAC - 5 min after & 26.1 & & & & \\
\hline Lobby partitions & & & & & \\
\hline Lobby partitions, HVAC isolation & & & & & \\
\hline Depressurize mail room & & & & & \\
\hline Depressurize mail room, filter return & & & & \\
\hline
\end{tabular}

Table 14 High-rise retrofit effectiveness values (Contaminant P, no weather) 
Table 15 contains the exposure reductions for contaminant $\mathrm{P}$ with weather effects, i.e., a nonzero envelope infiltration rate. The exposure reduction associated with enhanced outdoor air filtration in the general case is now lower than for the intake release. Most of the other cases are not impacted very significantly by the inclusion of weather, with some exceptions. The mail room release with the mixed air filter has a more significant reduction in the exposure, though the relative exposure is still fairly high. All of the shutdown cases are impacted by infiltration, with an increase in exposure for the $6 \mathrm{~s}$ shutdown with the general release but a larger decrease for the intake source. All of the other shutdown cases have lower exposures relative to the baseline than the no-weather cases due to the nonzero dilution rates during the shutdown periods. Envelope tightening reduces exposure from the outdoor general release due to less contaminant entry via infiltration, but increases exposure from the other three sources due to the lower outdoor air dilution rate. The shelter-in-place reductions are also lower, particularly without the filtration and air cleaning systems.

\begin{tabular}{|l|c|c|c|c|c|}
\hline & \multicolumn{5}{|c|}{ Exposure Relative to Baseline (\%) } \\
\hline Retrofit & $\begin{array}{c}\text { Outdoor, } \\
\text { General }\end{array}$ & $\begin{array}{c}\text { Outdoor } \\
\text { Air Intakes }\end{array}$ & $\begin{array}{c}\text { Indoor, } \\
\text { Lobby }\end{array}$ & $\begin{array}{c}\text { Indoor, } \\
\text { return vent }\end{array}$ & $\begin{array}{c}\text { Mail } \\
\text { room }\end{array}$ \\
\hline Outdoor air filtration & 24.5 & 12.4 & & & \\
\hline Mixed air filtration & 9.4 & 5.2 & 33.3 & 4.1 & 73.3 \\
\hline 6 s Shutdown & 140.7 & 41.9 & & & \\
\hline 30 s Shutdown & 268.2 & 204.2 & & & \\
\hline 1 min Shutdown & 418.8 & 397.8 & & & \\
\hline 5 min Shutdown & 321.1 & 302.3 & & & \\
\hline 100\% OA purge & 38.3 & & 30.4 & 30.5 & \\
\hline Envelope tightening & 93.8 & 108.9 & 104.3 & 107.8 & \\
\hline Envelope, OA filtration & 11.6 & 13.5 & & & \\
\hline Envelope, OA filter, pressure & 12.6 & & & & \\
\hline SIP - 30 s prior & 34.8 & & & & \\
\hline SIP - 30 s after & 32.0 & & & & \\
\hline SIP - 1 min after & 38.6 & & & & \\
\hline SIP - 5 min after & 63.8 & & & & \\
\hline SIPAC - 30 s prior & 3.2 & & & & \\
\hline SIPAC - 30 s after & 3.1 & & & & \\
\hline SIPAC - 1 min after & 3.9 & & & & \\
\hline SIPAC - 5 min after & 24.4 & & & & \\
\hline Lobby partitions & & & & & \\
\hline Lobby partitions, HVAC isolation & & & & & \\
\hline Depressurize mail room & & & & & \\
\hline Depressurize mail room, filter return & & & & \\
\hline
\end{tabular}

Table 15 High-rise retrofit effectiveness values (Contaminant $\mathrm{P}$, with weather) 
Tables 16 and 17 contain the contaminant G results, without and with weather, for the high-rise building. As was the case in the two-story office building, the results are essentially identical to the results in Tables 14 and 15 for contaminant $\mathrm{P}$, except as impacted by the different removal efficiencies for the gas relative to the particle. For example, the outdoor air and recirculation retrofits have lower relative exposures for contaminant $G$ because the gas filter has a higher efficiency than the enhanced particle filter.

\begin{tabular}{|l|c|c|c|c|c|}
\hline & \multicolumn{5}{|c|}{ Exposure Relative to Baseline (\%) } \\
\hline Retrofit & $\begin{array}{c}\text { Outdoor, } \\
\text { General }\end{array}$ & $\begin{array}{c}\text { Outdoor } \\
\text { Air Intakes }\end{array}$ & $\begin{array}{c}\text { Indoor, } \\
\text { Lobby }\end{array}$ & $\begin{array}{c}\text { Indoor, } \\
\text { return vent }\end{array}$ & $\begin{array}{c}\text { Mail } \\
\text { room }\end{array}$ \\
\hline Outdoor air filtration & 5.0 & 5.0 & & & \\
\hline Mixed air filtration & 1.2 & 1.2 & 16.5 & 0.8 & 85.5 \\
\hline 6 s Shutdown & 47.7 & 47.7 & & & \\
\hline 30 s Shutdown & 230.2 & 230.2 & & & \\
\hline 1 min Shutdown & 445.0 & 445.0 & & & \\
\hline 5 min Shutdown & 324.4 & 324.4 & & & \\
\hline 100 \% OA purge & 24.2 & & 14.1 & 15.9 & \\
\hline Envelope tightening & 100.2 & 100.2 & 88.5 & 92.4 & \\
\hline Envelope, OA filtration & 5.0 & 5.0 & & & \\
\hline Envelope, OA filter, pressure & 5.0 & & & & \\
\hline SIP - 30 s prior & 2.8 & & & & \\
\hline SIP - 30 s after & 5.4 & & & & \\
\hline SIP - 1 min after & 11.0 & & & & \\
\hline SIP - 5 min after & 27.7 & & & & \\
\hline SIPAC - 30 s prior & 0.2 & & & & \\
\hline SIPAC - 30 s after & 0.1 & & & & \\
\hline SIPAC - 1 min after & 1.2 & & & & \\
\hline SIPAC - 5 min after & 14.4 & & & & \\
\hline Lobby partitions & & & & & \\
\hline Lobby partitions, HVAC isolation & & & & & \\
\hline Depressurize mail room & & & & & \\
\hline Depressurize mail room, filter return & & & & \\
\hline
\end{tabular}

Table 16 High-rise retrofit effectiveness values (Contaminant G, no weather) 


\begin{tabular}{|l|c|c|c|c|c|}
\hline & \multicolumn{5}{|c|}{ Exposure Relative to Baseline (\%) } \\
\hline Retrofit & $\begin{array}{c}\text { Outdoor, } \\
\text { General }\end{array}$ & $\begin{array}{c}\text { Outdoor } \\
\text { Air Intakes }\end{array}$ & $\begin{array}{c}\text { Indoor, } \\
\text { Lobby }\end{array}$ & $\begin{array}{c}\text { Indoor, } \\
\text { return vent }\end{array}$ & $\begin{array}{c}\text { Mail } \\
\text { room }\end{array}$ \\
\hline Outdoor air filtration & 17.2 & 5.0 & & & \\
\hline Mixed air filtration & 3.9 & 1.4 & 18.7 & 0.9 & 58.2 \\
\hline 6 s Shutdown & 86.0 & 28.9 & & & \\
\hline 30 s Shutdown & 176.3 & 140.6 & & & \\
\hline 1 min Shutdown & 283.5 & 274.2 & & & \\
\hline 5 min Shutdown & 226.3 & 217.7 & & & \\
\hline 100\% OA purge & 26.2 & & 17.9 & 18.0 & \\
\hline Envelope tightening & 99.7 & 114.3 & 113.5 & 120.1 & \\
\hline Envelope, OA filtration & 5.0 & 5.7 & & & \\
\hline Envelope, OA filter, pressure & 5.0 & & & & \\
\hline SIP - 30 s prior & 20.2 & & & & \\
\hline SIP - 30 s after & 19.4 & & & & \\
\hline SIP - 1 min after & 24.4 & & & & \\
\hline SIP - 5 min after & 42.7 & & & & \\
\hline SIPAC - 30 s prior & 2.0 & & & & \\
\hline SIPAC - 30 s after & 1.9 & & & & \\
\hline SIPAC - 1 min after & 2.6 & & & & \\
\hline SIPAC - 5 min after & 17.0 & & & & \\
\hline Lobby partitions & & & 102.2 & & \\
\hline Lobby partitions, HVAC isolation & & & 34.7 & & \\
\hline Depressurize mail room & & & & & \\
\hline Depressurize mail room, filter return & & & & & \\
\hline
\end{tabular}

Table 17 High-rise retrofit effectiveness values (Contaminant G, with weather) 


\subsection{Summary of Simulation Results}

Multizone airflow and contaminant transport simulations were performed in three buildings to estimate the impacts of selected retrofits on occupant exposure to generic chembio contaminants. The general approach of these simulations is to model a generic contaminant release within or outside a given building and calculate the average occupant exposure to the contaminant, and then to repeat the process for the same building and release scenario with one or more retrofits in place. Therefore, the measure of retrofit performance is based on the change in average occupant exposure relative to the baseline case. As noted earlier, the assumed contaminant release rates and the calculated concentrations have no particular significance in relation to any particular contaminant, and therefore the calculated concentrations cannot be used to estimate any health impacts. Nevertheless they do provide useful insights into the impact of the retrofits considered and the factors (e.g. weather, building features) that determine these impacts.

One key issue to note is that the results presented and the conclusions reached are strongly dependent on the particular building models, sources, systems and other features of the simulations. While a large number of cases were examined, it is always true that each building, system and retrofit application is unique, and the effectiveness in any particular circumstance needs to be determined based on the associated details. Note also that the changes in exposure reported here are based on average exposures, and the effectiveness of a particular retrofit can be locally quite variable in the case of an indoor source. In addition, the modeling approach used in these analyses does not consider within-room concentration gradients.

The results for all three building models showed that the most significant and consistent exposure reductions were associated with enhanced filtration, either of the outdoor airstream alone for exterior releases or the mixed airstream for indoor and outdoor releases. The benefits of filtration were also evident in the shelter-in-place strategies. The size of the reduction depended primarily on the removal efficiencies of the baseline and retrofit filters. Because the amount of contaminant that passes through the filter, and therefore contributes to exposure, depends on one minus the removal efficiency, small changes in efficiency can have relatively large impacts on exposure. For example, a $1 \%$ absolute reduction in the efficiency of a $90 \%$ efficient filter (resulting in $89 \%$ removal) increases the associated exposure by $10 \%$.

While filtration can be quite effective, the impact of filtering the intake air can be degraded by the presence of envelope infiltration in the case of a general outdoor release (not localized to the outdoor air intake). The importance of infiltration has been identified previously as an issue with building protection strategies based on outdoor air filtration (Persily 2004). Due to the strong dependence of infiltration on building envelope airtightness, weather conditions and ventilation system airflow rates, the extent of such degradation cannot be generalized. Strategies based on building pressurization to minimize infiltration will be similarly impacted by envelope leakage. Effective filtration and pressurization strategies require low envelope leakage values. Envelope tightening alone is not a particularly effective retrofit, but achieves its value when combined with effective air filtration.

The impacts of shutdown strategies are highly dependent on their timing relative to the start of a release, with higher effectiveness for earlier implementation. This unsurprising result leads to the question of how a building manager or operator knows when a release is occurring, or has just occurred, and that a system shutdown may be advised. Given the current state of sensing technology and the inherently unpredictable nature of such releases, it is unclear how realistic it is to rely on a shutdown strategy. And as noted in the simulations, a late shutdown retains the contaminant in the building and increases exposure. Therefore, the risk of implementing a system shutdown too late in the event timeline needs to be considered in response planning. 
The use of $100 \%$ outdoor air purging, while potentially effective in removing a contaminant, is also a function of the timing of implementation relative to the release. However, purging was found to be more effective than a system shutdown for most cases simulated. The "ideal" strategy for many cases might be a shutdown before or during a release followed by a purge once the release is over. However, implementing such a two-stage approach would again require knowledge of the timing of the release, which in general is not expected to exist. In contrast, one reason for the effectiveness of the filtration strategies as modeled is that they are 'always on'. In other words, contaminant removal occurs as soon as the source begins, since filtration requires no human or automated intervention. Some have proposed strategies in which the air cleaning capability would be available in an alternate HVAC flow path, which would require, for example, switching the affected airstream from one duct to another. The effectiveness of such a system would therefore again rely on the timing of implementation.

The use of shelter-in-place is generally effective in reducing exposure, but far more so when a recirculating filtration/air cleaning system is employed in the shelter. While early implementation of sheltering is more effective than later sheltering, timing appears to be somewhat less critical than for a shutdown response. Again, these conclusions are true for average exposures, and there can be localized impacts that result in much higher exposures in certain zones of a building. Therefore, quicker sheltering is better, which raises the same notification questions identified in the discussion of system shutdown. Also, while later sheltering still might be effective on average, there can be an issue with exposed occupants bringing contaminant into the shelter on their persons, which is not addressed in this analysis. Additionally, knowledge of when to leave a shelter would be required as eventually occupants in a shelter without air cleaning receive the same exposure as unsheltered occupants. 


\section{CASE STUDY}

A case study was conducted as part of this project to investigate the application of building protection retrofits in two actual buildings. Specifically, the case study involved identifying and designing retrofits to these buildings given their particular floor plans and HVAC system designs. In addition to designing the retrofits, the performance of the retrofits was evaluated using the simulation approach employed in the technical evaluation of the retrofits. The case study also included an economic analysis in which the costs of the retrofit measures were identified and quantified. The cost data were estimated for illustrative purposes as well as to provide sample data for the economic evaluation software developed as part of the project. Two office buildings, with very different floor plans and ventilation system designs, were selected for the case study. One is a high-rise office building with central air-handling systems, in addition to other features of interest including intakes near ground level, a loading dock, a mail room, and a public-access lobby. The other building is a one-story office building with multiple rooftop air handling units and no spaces other than offices.

The retrofit design and cost estimation were performed by an architectural and engineering (A\&E) firm and were based on a list of candidate retrofits identified by NIST. The A\&E firm then proceeded with the design work, producing detailed designs for implementing the retrofits. As part of this effort, the A\&E firm reviewed the existing mechanical and control systems in the two buildings, including all original architectural, structural, mechanical, and electrical plans and any modifications of these plans. The firm also conducted field inspections of the buildings and systems and then performed the design work and prepared detailed descriptions and drawings of the proposed retrofits. They prepared cost estimates for the retrofit work including the following:

Retrofit installation costs (including equipment, materials and parts, required demolition, labor, and performance testing)

Annual filter replacements costs (including material costs and labor, based on an assumed frequency of replacement)

Cost of additional electricity associated with filtration options that significantly increase system pressure drop

These retrofits, and the associated cost estimates, are specific to the buildings examined in terms of the available options and the details of implementation. While the designs and costs are of interest to the general question of building protection, they cannot be applied to other buildings. Determining retrofit options, designs and cost estimates for a specific building always requires consideration of the unique features of that building.

\subsection{Description of Buildings and Retrofits Considered}

High-rise Office Building

The high-rise office building is part of a larger complex of buildings built in the early-1960s. In addition to the office space, the building has an elevator penthouse, basement and sub-basement with a total floor area of about $12,100 \mathrm{~m}^{2}\left(130,500 \mathrm{ft}^{2}\right)$. The east and west facades of the building are faced with grey face brick; insulated porcelain spandrel panels and fixed aluminum frame windows enclose the north and south facades. There are six field assembled air handlers located on the mezzanine level of the building (above the $2^{\text {nd }}$ story). Each unit has a mixing box with outdoor air louvers and dampers (including minimum outdoor air dampers) and a return air duct. These units also have a filter rack, upstream of the coils and accessible from the mixing box, with $10 \mathrm{~cm}$ (4 in) deep pleated filters rated at MERV 6 (ASHRAE 1999). The outside air intake 
louvers for these air handlers are located about $6 \mathrm{~m}(20 \mathrm{ft})$ above ground level. The temperature controls are pneumatic, and each unit is started and stopped manually or by means of time clocks. However, the systems operate $24 \mathrm{~h}$ every day of the year.

The building has a lobby area with a $4.3 \mathrm{~m}(14 \mathrm{ft})$ ceiling and a floor area of about $325 \mathrm{~m}^{2}$ $\left(3500 \mathrm{ft}^{2}\right)$. The lobby has glass curtain walls on two sides and marble-finished walls on the other two and is accessed from a glass-enclosed $14 \mathrm{~m}^{2}\left(150 \mathrm{ft}^{2}\right)$ vestibule with a series of two rows of four balanced glass doors. The lobby is open to the elevator bank serving the building and another wing of the complex. The lobby does not have a dedicated air-conditioning system, but is served by one of the six air handlers located on the mezzanine, which also serves the corridors adjacent to the lobby.

The building has a mail room in the basement, with a floor area of about $334 \mathrm{~m}^{2}\left(3600 \mathrm{ft}^{2}\right)$. The mail room has a suspended acoustical ceiling system and is enclosed by concrete masonry unit (CMU) walls and modular metal partitions. One wall is solid to the ceiling, two walls have doors to interior corridors, and the fourth wall is an exterior wall with a roll-up door to a loading dock area. The mail room does not have a dedicated air handler and is served by a unit in a basement mechanical room that also serves several adjacent spaces. The basement mechanical room contains six other air conditioning units serving other basement and first floor spaces and is fairly crowded with storage tanks, pumps, ductwork and other services. The ceiling plenum above the mail room is also very congested with ductwork, piping and other services.

\section{One-story Office Building}

This building is a contiguous group of large, one-story trailers that have been joined to form a single building of about $1600 \mathrm{~m}^{2}\left(17000 \mathrm{ft}^{2}\right)$. The building is about $4.6 \mathrm{~m}(15 \mathrm{ft})$ tall with six exterior doors, sixty-seven fixed double-glazed windows, and a crawl-space containing electrical and plumbing services. The building is served by twenty-eight rooftop heat pump units that provide heating, cooling and ventilation. Each unit has a $2.5 \mathrm{~cm}$ (1 in) MERV 4 filter and is controlled by a single thermostat in the occupied space.

\section{Candidate Retrofits}

Based on an initial assessment of the buildings, NIST provided the A\&E firm with the following lists of candidate retrofits for consideration in the two buildings.

High-rise building:

Enhanced particle filtration consistent with current air handlers (currently MERV 6)

Enhanced particle filtration with air handler modifications to handle increased pressure drop

Enhanced particle filtration and gaseous air cleaning with air handler modifications

Envelope tightening

Quick shutoff switch

Quick purge switch

Shelter-in-place: tighten shelter spaces, local filtration/air cleaning units Isolate/depressurize lobby: install partitions, dedicated system to depressurize Isolate/depressurize mail room: tighten interior partitions, dedicated system to depressurize Relocate ground level intakes to higher elevation HVAC system testing, adjusting and balancing 
1-story building:

Enhanced particle filtration consistent with current air handlers (currently MERV 4)

Enhanced particle filtration with air handler modifications to handle increased pressure drop

Enhanced particle filtration and gaseous air cleaning with air handler modifications

Envelope tightening

Quick shutoff switch

Quick purge switch

Shelter-in-place: tighten shelter spaces, local filtration/air cleaning units

\subsection{Retrofit Design}

Based on their review of the building design and condition, along with the retrofits identified by NIST, the A\&E firm designed a number of retrofits for the two buildings. As noted earlier, these retrofits and the associated cost estimates are specific to the buildings examined in terms of available options and the details of implementation. Determining options and costs for a specific building always requires consideration of the unique features of that building. Also note that the list of retrofits considered is not comprehensive, and none of these options should be interpreted as either providing the best protection or the most cost-effective option possible.

A number of options were considered for each building as follows. For the high-rise office building, the following retrofits were considered and design work performed:

Filter upgrade \#1: Replace all the MERV 6 particulate filters with MERV 11 filters. MERV 11 is the highest efficiency that can be installed employing existing filter frames and requiring no changes to the existing fans or motors.

Filter upgrade \#2: Replace all the MERV 6 particulate filters with a three-stage filtration system including a $10 \mathrm{~cm}$ (4 in) pre-filter (MERV 8), an $85 \%$ intermediate filter (MERV 13) and a $99.97 \%$ HEPA filter (MERV 17). This option requires the installation of new HEPA filter frames, as well as replacing the fans and motors of the air handlers to handle the increased pressure drop and the main circuit breaker to handle the increased electrical load.

Filter upgrade \#3: Replace all the MERV 6 particulate filters with a multi-stage filtration system including a $10 \mathrm{~cm}$ (4 in) pre-filter (MERV 8), an $85 \%$ intermediate filter (MERV 13), a $99.97 \%$ HEPA filter (MERV 17), an AZDM-TEDA grade carbon gas phase filter, and a $5 \mathrm{~cm}$ ( 2 in) final filter (MERV 11). This option requires the installation of new HEPA filter frames, as well as replacing the fans and motors of the air handlers to handle the increased pressure drop and the main circuit breaker to handle the increased electrical load.

Tighten the exterior envelope of the building: Seal around interior and exterior of windows, doors and penetrations of the building envelope. (Note that it is not possible to know the actual before and after airtightness of the building without conducting fan pressurization tests of building airtightness. There are often significant leaks in commercial building envelopes at wall-floor and wall-roof interfaces that might not necessarily be addressed by these retrofits.)

Shut-off and purge switches: Install quick shut-off and purge switches in a central location of the building, i.e., a guard office that is staffed $24 \mathrm{~h} / \mathrm{d}$.

Elevate outdoor air intakes: Extend the outdoor air intakes from the mezzanine level to the roof. (Note that this option would block more than 100 exterior windows of the building because there is no available internal space through which to run the new ductwork.)

Lobby retrofit with exhaust filtered to level \#2: Isolate the lobby from the rest of the building (other wings and corridors) by providing tempered glass partitions with self-closing glass doors. Also install a new air handling unit in the basement mechanical room to serve the lobby 
only, with level \#2 filtration as described above. The design also includes a new exhaust fan, drawing from the lobby, and filtration level \#2 installed in the outgoing airstream to clean the air before it is exhausted to the outdoors. This exhaust fan is sized to maintain $10 \%$ more exhaust air from the lobby than supply air under normal operating conditions. This retrofit requires a number of electrical modifications to accommodate the new fans and motors.

Lobby retrofit with exhaust filtered to level \#3: Same as above, except the exhaust air from the lobby is filtered to level \#3.

Mailroom retrofit with exhaust filtered to level \#2: Air seal the partitions between the mail room and all adjacent zones. Upgrade the filtration in the air handler serving the mail room to filtration level \#2, which requires the installation of HEPA filter frames. Add the same level of filtration to the exhaust airflow out of the mail room to prevent any agent released in the mail room from impacting the rest of the building. The filtration upgrade requires higher horsepower motors and electrical modifications for both the supply and exhaust fans. The system is to be operated with $10 \%$ more exhaust air from the mail room than supply air.

Mailroom retrofit with exhaust filtered to level \#3: Same as above, except the exhaust air from the mail room is filtered to level \#3.

Shelter-in-place: Designate a number of shelter-in-place spaces in the building, with air sealing of the walls of these spaces. plus a stand-alone, recirculating filtration and air cleaning unit in each such space.

TAB: Test, adjust and balance (TAB) the existing air handling systems to ensure that they are being operated at the design airflow rates. This retrofit, while not necessarily resulting in a direct reduction of occupant exposure to agents, allows the system to be relied on for other protection strategies with a greater degree of confidence. The retrofit may also reduce energy consumption and improve indoor air quality. However, the impacts of such a TAB effort will depend on the as-is condition of the system, specifically the magnitude of the differences between system design and performance.

For the 1-story office building, the following retrofits were considered and design work performed:

Filter upgrade \#1: Replace all the existing MERV 4 particulate filters with MERV 11 filters, employing existing filter frames and requiring no changes to fans or motors.

Filter upgrade \#2: Given the power and space limitations of the rooftop units, it is not possible to upgrade the filtration beyond MERV 11. Therefore, to provide a higher level of filtration, the designer proposed installing two dedicated outdoor air fans on steel platforms on the roof, which would provide filtered outdoor air to the rooftop units. These outdoor air units have filtration consistent with option \#2 for the high-rise office building, specifically, a three-stage system including a $10 \mathrm{~cm}$ (4 in) pre-filter (MERV 8), an $85 \%$ intermediate filter (MERV 13) and a $99.97 \%$ HEPA filter (MERV 17). In addition to the platform, fans, and filters, this option requires electrical system upgrades.

Filter upgrade \#3: Same as above, but with filter option \#3 in the two outdoor air fans. Specifically, this option includes the new support platform, new fans, a multi-stage filtration system including a $10 \mathrm{~cm}$ (4 in) pre-filter, an $85 \%$ intermediate filter (MERV 13), a $99.97 \%$ HEPA filter (MERV 17), an AZDM-TEDA grade carbon gas phase filter, a $5 \mathrm{~cm}$ (2 in) final filter (MERV 11), and electrical system upgrades.

Tighten the exterior envelope of the building: Patch roof leaks, seal around windows, provide doors with gasket hardware, replace door thresholds, and seal around pipe and conduit floor 
penetrations within the building's crawlspace. (Note that it is not possible to know the actual airtightness level without a fan pressurization test. As noted for the high-rise building, there are often other significant leaks in commercial building envelopes that might not be addressed by these sealing efforts.)

Shut-off switches: Install quick shut-off switches in the reception area of the building. (The systems cannot be operated in a purge mode. Therefore, no purge switch option is considered.)

More detailed descriptions of the buildings and retrofit designs are excerpted from the A\&E report and presented in Appendix B. 


\subsection{Economic Evaluation}

The cost data provided by the contractor for each of the retrofits consists of first costs (equipment and installation), annual costs for maintaining the retrofit, and annual costs of additional electrical power required for operation. These costs are summarized in Table 18. The annual maintenance costs consist of the materials and labor associated with filter replacement. Table 19 expands on the maintenance cost entries in Table 18 by providing cost per change (e.g., labor and materials costs) and the assumed number of changes per year for each filter option. The values in Table 19 are given for each air handling unit, so the total maintenance costs are those values multiplied by six. In actual application, the filter-changing schedule is a complex function of the outdoor and indoor conditions, and may be different from these assumed frequencies in a specific building. The annual operating costs are the increase above the base case electrical consumption.

\begin{tabular}{|c|c|c|c|}
\hline \multirow[b]{2}{*}{ Retrofit } & \multicolumn{3}{|c|}{ Costs (thousands of \$) } \\
\hline & $\begin{array}{c}\text { Initial } \\
\text { cost }\end{array}$ & $\begin{array}{c}\text { Annual } \\
\text { maintenance } \\
\text { cost }\end{array}$ & $\begin{array}{c}\text { Annual } \\
\text { operating cost } \\
\text { increase }\end{array}$ \\
\hline \multicolumn{4}{|l|}{ High-rise building } \\
\hline Base case & 0.0 & 2.9 & 0.0 \\
\hline Filtration upgrade \#1 & 71.4 & 1.2 & 0.0 \\
\hline Filtration upgrade \#2 & 291.8 & 21.1 & 39.0 \\
\hline Filtration upgrade \#3 & 1111.3 & 153.0 & 71.3 \\
\hline Envelope tightening & 625.3 & 0.0 & $0.0^{*}$ \\
\hline Shut-off/purge switches & 20.9 & 0.0 & 0.0 \\
\hline Extend intakes to roof & 225.1 & 0.0 & 0.0 \\
\hline Lobby partitions & 64.1 & 0.0 & 0.0 \\
\hline Lobby partitions \& dedicated HVAC system & 198.9 & 1.0 & 1.5 \\
\hline Lobby retrofits, with filtration level \#2 & 215.6 & 5.5 & 8.1 \\
\hline Lobby retrofits, with filtration level \#3 & 273.1 & 5.8 & 10.5 \\
\hline Mailroom air sealing & 29.1 & 0.5 & 0.0 \\
\hline Mailroom air sealing, with filtration level \#2 & 101.3 & 5.2 & 18.5 \\
\hline Mailroom air sealing, with filtration level \#3 & 194.1 & 26.4 & 35.6 \\
\hline Shelter-in-place spaces & 75.8 & 0.0 & 0.0 \\
\hline System testing, adjusting \& balancing & 75.0 & 0.0 & $0.0^{*}$ \\
\hline \multicolumn{4}{|l|}{ 1-story building } \\
\hline Base case & 0.0 & 3.6 & 0.0 \\
\hline Filtration upgrade \#1 & 2.1 & 6.3 & 0.0 \\
\hline Filtration upgrade \#2 & 251.3 & 5.6 & 20.8 \\
\hline Filtration upgrade \#3 & 368.6 & 22.6 & 28.9 \\
\hline Envelope tightening & 32.4 & 0.0 & $0.0^{*}$ \\
\hline Shut-off switch & 11.8 & 0.0 & 0.0 \\
\hline
\end{tabular}

* May reduce building energy consumption and associated operating costs.

Table 18 Summary of Retrofit Cost Estimates 


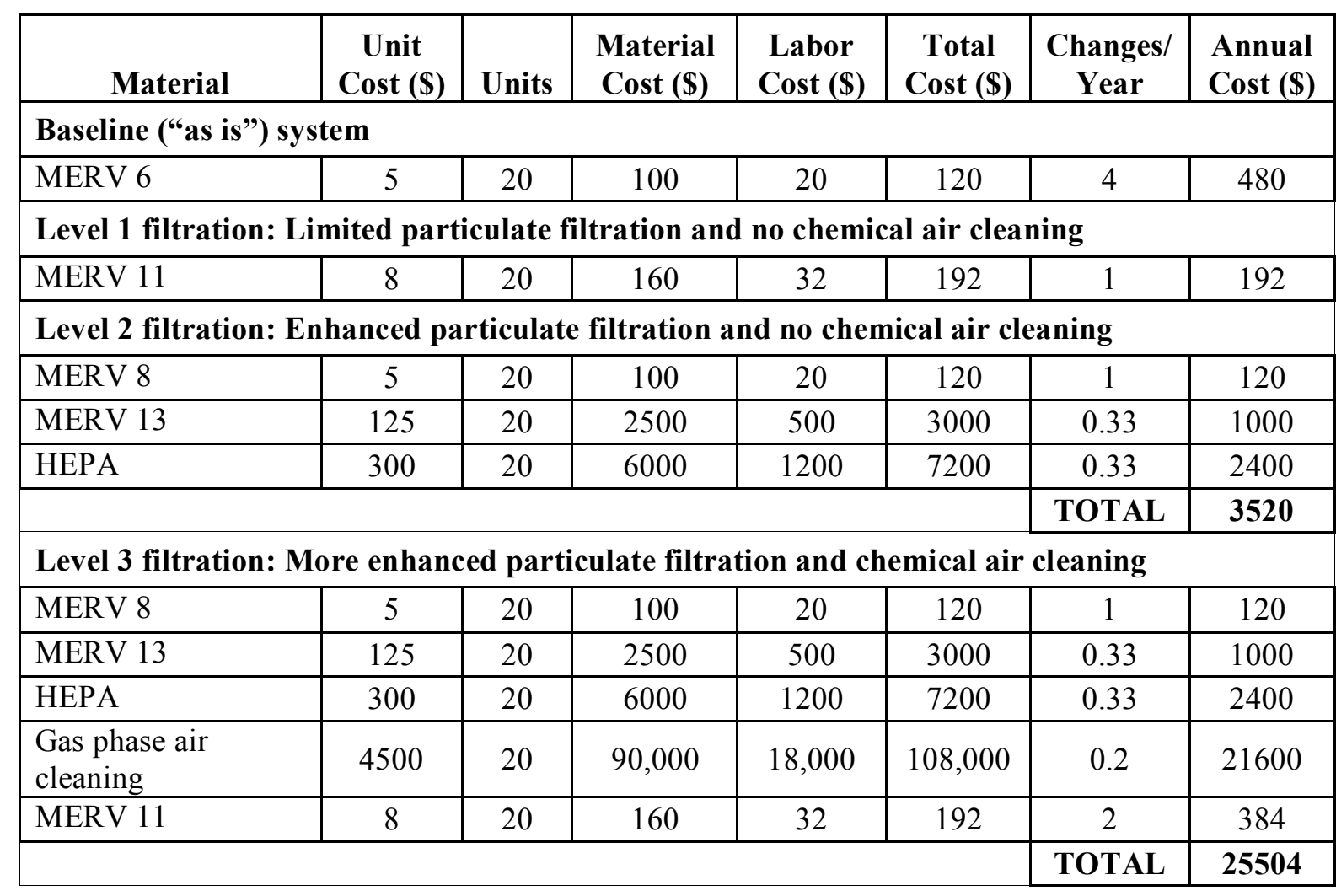

Table 19 Maintenance Costs of Filtration for High-Rise Building

More detailed breakdowns of the initial costs for the retrofits are presented in Appendix C. In addition, life-cycle costs for each retrofit option are included in the presentation of the technical evaluation of the retrofits in the following section.

\subsection{Technical Evaluation}

The degree of protection against generic chembio releases provided by the case study retrofits was investigated through multizone airflow and contaminant transport simulations using the CONTAM program (Walton and Dols 2005). As in the retrofit evaluations presented in Section 2, CONTAM was used to estimate occupant exposure for generic indoor and outdoor releases of both a gaseous and particulate agent, referred to as $\mathrm{G}$ and $\mathrm{P}$ respectively. The exposure was estimated for the baseline (as is) building and then for the building with the selected retrofits installed. For the purposes of these estimates, the exposure was calculated for the occupants over $6 \mathrm{~h}$, with the release of both agents occurring at the beginning of the second hour. Note that potential particle removal processes such as deposition and filtration of infiltrating air by the building walls were not included in the analysis. While these processes might be expected to impact the estimated exposures, they will have a less significant impact on relative exposures between cases than on the absolute exposure for a single case. The results of these simulations are presented in Tables 20a through 20c for the high-rise office building in terms of the ratio of the exposure with the retrofit to the baseline exposure without. Therefore, the values in the table are dimensionless and the lower the value the greater the reduction in exposure. The exposure ratios reported are based on calculated average exposures of all occupants in the building. Table 21 presents the average exposure ratios for the one-story office building. 
Life-cycle costs of the various retrofits are also reported in Tables 20a, 20b, and 20c for the highrise office building and in Table 21 for the one-story office building. Cost data from Tables 18 and 19 are used to calculate life-cycle costs. The life-cycle cost figures in Tables 20 and 21 are based on a 20 -year study period and a $7 \%$ real discount rate. The discount rate is used to adjust future costs for filter replacements (i.e., annual maintenance costs) and additional electricity (i.e., annual operating cost increases) to a present value amount. All life-cycle cost figures are expressed in thousands of dollars. It is important to note that the life-cycle cost figures do not include any potential cost savings, such as reduced energy consumption due to envelope tightening or increased worker productivity due to improved indoor air quality associated with enhanced filtration.

\begin{tabular}{|c|c|c|c|}
\hline & \multicolumn{2}{|c|}{$\begin{array}{c}\text { Exposure Relative to } \\
\text { Baseline (\%) }\end{array}$} & \\
\hline Retrofit & $\begin{array}{c}\text { Agent G } \\
\text { (gas) }\end{array}$ & $\begin{array}{c}\text { Agent P } \\
\text { (particle) }\end{array}$ & $\begin{array}{c}\text { Life-cycle cost } \\
\text { (thousands of dollars) }\end{array}$ \\
\hline Filtration option \#1 & 100 & 64 & 122 \\
\hline Filtration option \#2 & 100 & 15 & 899 \\
\hline Filtration option \#3 & 13 & 15 & 6283 \\
\hline Envelope sealing & 100 & 97 & 625 \\
\hline Filtration \#1 with envelope sealing & 100 & 56 & 748 \\
\hline Filtration \#2 with envelope sealing & 100 & 0 & 1524 \\
\hline Filtration \#3 with envelope sealing & 0 & 0 & 6908 \\
\hline
\end{tabular}

Table 20a Relative Exposure and Life-Cycle Cost for Selected Retrofits in High-Rise Building (outdoor release with weather-induced infiltration)

Table 20a presents relative occupant exposures for a generic outdoor release for the high-rise office building. This outdoor release was modeled as a step change elevation in outdoor concentrations of both gaseous agent $\mathrm{G}\left(1.0 \mathrm{mg} / \mathrm{m}^{3}\right)$ and particulate agent $\mathrm{P}\left(1.0 \times 10^{6}\right.$ particles $/ \mathrm{m}^{3}$ ) lasting for $1 \mathrm{~min}$. The selected retrofits studied for this release included filtration option \#1 (upgrade of existing system filters from MERV6 to MERV11), filtration option \#2 (three-stage filtration system including $10 \mathrm{~cm}$ (4 in) pre-filter (MERV 8), an $85 \%$ intermediate filter (MERV 13) and a 99.97 \% HEPA filter (MERV 17)), filtration option \#3 (multi-stage filtration system including a $10 \mathrm{~cm}$ (4 in) pre-filter (MERV 8), an $85 \%$ intermediate filter (MERV 13), a 99.97 \% HEPA filter (MERV 17), an AZDM-TEDA grade carbon gas phase filter, and a $5 \mathrm{~cm}$ ( 2 in) final filter (MERV 11)), sealing the building envelope, and then each filtration upgrade option in combination with envelope sealing. The weather conditions during the simulation period were an outdoor air temperature of $0{ }^{\circ} \mathrm{C}$ and a wind speed of $5 \mathrm{~m} / \mathrm{s}$ in order to induce a reasonable level of envelope infiltration. The building envelope effective leakage area (at a reference pressure of $4 \mathrm{~Pa}$ ) was $5 \mathrm{~cm}^{2} / \mathrm{m}^{2}$ before $\left(0.07 \mathrm{in}^{2} / \mathrm{ft}^{2}\right.$ ) and $0.7 \mathrm{~cm}^{2} / \mathrm{m}^{2}$ $\left(0.01 \mathrm{in}^{2} / \mathrm{ft}^{2}\right)$ after sealing the envelope. The baseline whole building air change rates were $0.23 \mathrm{~h}^{-1}$ due to infiltration and $1.12 \mathrm{~h}^{-1}$ due to outdoor air intake, for a total of $1.35 \mathrm{~h}^{-1}$. The envelope sealing completely eliminated infiltration under the conditions modeled, leading to a whole building air change rate of $1.12 \mathrm{~h}^{-1}$.

As seen in Table 20a, the predicted exposure reductions for an outdoor contaminant release vary widely from no impact at all (100\% relative exposure) to very nearly a total elimination of 
exposure ( $0 \%$ relative exposure). For the gas agent, the retrofit with the largest reduction is filtration option \#3, which includes a gaseous air cleaner in the outdoor air intakes, combined with envelope sealing for a predicted reduction in exposure of essentially $100 \%$. Without sealing the envelope, filtration option \#3 is predicted to have a smaller impact, with an exposure reduction of $87 \%$. The lower reduction without tightening occurs because of outdoor air entry via infiltration that is not impacted by the air cleaning system. Envelope sealing alone has no impact on exposure to agent $\mathrm{G}$. The other filtration options do not impact agent $\mathrm{G}$ because they include only particle filtration.

For Agent $\mathrm{P}$, filtration option \#2 (and \#3 since it provides equivalent particle filtration) combined with envelope sealing is predicted to reduce exposure by essentially $100 \%$. As with Agent G, the impact of these levels of filtration is lessened if the envelope is not sealed with a predicted exposure reduction of $85 \%$. The lower filtration upgrade (option \#1) has predicted exposure reductions of $36 \%$ and $44 \%$ with and without envelope sealing, respectively. Unlike Agent G, envelope sealing alone is predicted to have a small impact ( $3 \%$ reduction) on exposure because the baseline building includes a particle filter.

\begin{tabular}{|c|c|c|c|}
\hline & \multicolumn{2}{|c|}{$\begin{array}{c}\text { Exposure Relative to } \\
\text { Baseline (\%) }\end{array}$} & \\
\hline Retrofit & $\begin{array}{c}\text { Agent G } \\
\text { (gas) }\end{array}$ & $\begin{array}{c}\text { Agent P } \\
\text { (particle) }\end{array}$ & $\begin{array}{c}\text { Life-cycle cost } \\
\text { (thousands of dollars) }\end{array}$ \\
\hline Lobby Partitions & 101 & 101 & 64 \\
\hline Lobby Partitions \& Isolated HVAC & 34 & 22 & 225 \\
\hline $\begin{array}{c}\text { Lobby Partitions \& Isolated HVAC } \\
\text { \& Return Filtration Option \#2 }\end{array}$ & 34 & 8 & 367 \\
\hline $\begin{array}{c}\text { Lobby Partitions \& Isolated HVAC } \\
\text { \& Return Filtration Option \#3 }\end{array}$ & 8 & 8 & 455 \\
\hline
\end{tabular}

Table 20b Relative Exposure and Life-Cycle Cost for Selected Retrofits in High-Rise Building (lobby release with weather-induced infiltration)

Table $20 \mathrm{~b}$ presents the relative exposure for a source in the lobby of the high-rise office building. The contaminant source was modeled as a 1 min contaminant release of $1 \mathrm{~kg}$ of gaseous agent $\mathrm{G}$ and $1.0 \times 10^{9}$ particles of agent $P$. The selected retrofits studied for this release include the following

- Install partitions to separate the lobby from the remainder of the first floor (modeled leakage of $1 \mathrm{~cm}^{2} / \mathrm{m}^{2}\left(0.01 \mathrm{in}^{2} / \mathrm{ft}^{2}\right)$ at $4 \mathrm{~Pa}$ for lobby walls and $150 \mathrm{~cm}^{2}\left(23.2 \mathrm{in}^{2}\right)$ for each of 2 doors),

- Install the internal partitions and a separate HVAC system with $10 \%$ undersupply to depressurize the lobby relative to the rest of the building,

- Install partitions and a separate HVAC system with $10 \%$ undersupply, plus filter the lobby return air with filtration option \#2 (addition of new outdoor air fans with a threestage particulate filtration system),

- Install partitions and a separate HVAC system with $10 \%$ undersupply, plus filter the lobby return air with filtration option \#3 (addition of new outdoor air fans with a fourstage filtration system including a carbon gas phase filter). 
As seen in Table 20b, the predicted reductions in the average $6 \mathrm{~h}$ exposure to a contaminant release in the lobby vary from a $1 \%$ increase to a $92 \%$ reduction. For Agent G, the retrofit with the largest reduction is filtration option \#3, which includes a gaseous air cleaner in the lobby return, combined with the lobby partitions and isolated HVAC. As stated earlier, the calculated exposure ratios are based on the average exposure of all occupants in the building. Adding lobby partitions alone results in an increase in average exposure to both agents because it increases exposure to occupants in the lobby while only reducing exposure in the remainder of the building by $10 \%$ or less. Using isolated HVAC in combination with the lobby partitions results in an average exposure reduction of $66 \%$ for Agent $\mathrm{G}$ with respect to the baseline case. Adding filtration option \#2 does not impact agent $\mathrm{G}$ because it includes only particle filtration. HVAC isolation combined with the lobby partitions results in a $78 \%$ reduction in average exposure to Agent P. Adding the HEPA filtration (i.e., return filtration options \#2 and \#3) to the other lobby modifications further improves the effectiveness for an exposure reduction of $92 \%$.

Table 20c presents relative occupant exposures for a source in the mail room of the high-rise office building. The contaminant source was modeled as a 1 min contaminant release of $1 \mathrm{~kg}$ of gaseous agent $\mathrm{G}$ and $1.0 \times 10^{9}$ particles of agent $\mathrm{P}$. The selected retrofits studied for this release included the following:

- Seal the mail room (reduce wall, interior doors, exterior doors and ceiling leakage to $1 \mathrm{~cm}^{2} / \mathrm{m}^{2}\left(0.01 \mathrm{in}^{2} / \mathrm{ft}^{2}\right)$ at $4 \mathrm{~Pa}, 10 \mathrm{~cm}^{2}\left(1.6 \mathrm{in}^{2}\right)$ each, $5 \mathrm{~cm}^{2}\left(0.8 \mathrm{in}^{2}\right)$ each and $2.5 \mathrm{~cm}^{2} / \mathrm{m}^{2}$ $\left(0.04 \mathrm{in}^{2} / \mathrm{ft}^{2}\right)$ respectively) and modify the HVAC system to depressurize the mail room with $10 \%$ undersupply,

- Seal the mail room as above, modify the HVAC system with $10 \%$ undersupply, and filter the basement recirculation air with filtration option \#2 (addition of new outdoor air fans with a three-stage particulate filtration system),

- Seal the mail room, modify the HVAC system, and filter the basement recirculation air with filtration option \#3 (addition of new outdoor air fans with a four-stage filtration system including a grade carbon gas phase filter).

\begin{tabular}{|c|c|c|c|}
\hline & \multicolumn{2}{|c|}{$\begin{array}{c}\text { Exposure Relative to } \\
\text { Baseline (\%) }\end{array}$} & \\
\hline Retrofit & $\begin{array}{c}\text { Agent G } \\
\text { (gas) }\end{array}$ & $\begin{array}{c}\text { Agent P } \\
\text { (particle) }\end{array}$ & $\begin{array}{c}\text { Life-cycle cost } \\
\text { (thousands of dollars) }\end{array}$ \\
\hline $\begin{array}{c}\text { Seal Mail Room \& HVAC } \\
\text { undersupply }\end{array}$ & 78 & 78 & 34 \\
\hline $\begin{array}{c}\text { Seal Mail Room \& HVAC } \\
\text { undersupply \& filtration option \#2 in } \\
\text { basement recirculation }\end{array}$ & 78 & 78 & 362 \\
\hline $\begin{array}{c}\text { Seal Mail Room \& HVAC } \\
\text { undersupply \& filtration option \#3 in } \\
\text { basement recirculation }\end{array}$ & 78 & 78 & 895 \\
\hline
\end{tabular}

Table 20c Relative Exposure and Life-Cycle Cost for Selected Retrofits in High-Rise Building (mail room release with weather-induced infiltration)

As seen in Table 20c, the predicted exposure reductions for the mail room contaminant release are $22 \%$ for both agents and all retrofits. However, as with the lobby case, the exposure is the average for the mail room occupants and the occupants of the rest of the building. The retrofits 
increase exposure of the mail room occupants but reduce the exposure of the occupants in the remainder of the building by $100 \%$. As in the case of the lobby retrofits, sealing the mail room and reducing the supply airflow tends to keep the agent from migrating to the rest of the building, thereby increasing the exposure to the mail room occupants. The filtration upgrades do not provide additional protection to the building occupants because they are located in the system exhaust stream and serve only to prevent discharge of contaminants to ambient.

For the one-story building, CONTAM was again used to estimate occupant exposure for a generic outdoor release for the baseline building and then for the building with selected retrofits. This outdoor release was modeled as a step change elevation in the outdoor concentrations of both gaseous agent $\mathrm{G}$ (to $1.0 \mathrm{mg} / \mathrm{m}^{3}$ ) and particulate agent $\mathrm{P}$ (to $1.0 \times 10^{9}$ particles $/ \mathrm{m}^{3}$ ) that lasted for $1 \mathrm{~min}$. The retrofits studied for this building include filtration option \#1 (upgrade of existing system filters from MERV4 to MERV11), filtration option \#2 (addition of dedicated outdoor air fans with a three-stage particulate filtration system), filtration option \#3 (addition of dedicated outdoor air fans with a multi-stage filtration system including a carbon gas phase filter), sealing the building envelope, and each filtration upgrade option in combination with envelope sealing. The weather conditions during the simulation period were an outdoor air temperature of $0{ }^{\circ} \mathrm{C}$ and a wind speed of $5 \mathrm{~m} / \mathrm{s}$ in order to induce a reasonable level of envelope infiltration. The building envelope effective leakage area (at a reference pressure of $4 \mathrm{~Pa}$ ) is $5 \mathrm{~cm}^{2} / \mathrm{m}^{2}\left(0.07 \mathrm{in}^{2} / \mathrm{ft}^{2}\right)$ before and $0.7 \mathrm{~cm}^{2} / \mathrm{m}^{2}\left(0.01 \mathrm{in}^{2} / \mathrm{ft}^{2}\right)$ after sealing the envelope. The baseline whole building air change rates are $0.28 \mathrm{~h}^{-1}$ due to infiltration and $0.89 \mathrm{~h}^{-1}$ due to outdoor air intake, for a total of $1.17 \mathrm{~h}^{-1}$. The envelope sealing completely eliminates infiltration in this building under the conditions modeled, leading to a whole building air change rate of $0.89 \mathrm{~h}^{-1}$. The filtration removal efficiencies used in the simulations are $0 \%$ for agent $\mathrm{G}$ and $5 \%$ for agent $\mathrm{P}$ for the baseline case, $0 \%$ for agent $\mathrm{G}$ and $51.4 \%$ for agent $\mathrm{P}$ for option \#1, $0 \%$ for agent $\mathrm{G}$ and $99.97 \%$ for agent $\mathrm{P}$ for option $\# 2$, and $99.5 \%$ for agent $\mathrm{G}$ and $99.97 \%$ for agent $\mathrm{P}$ for option \#3.

As seen in Table 21, the predicted reductions in the relative exposure to an outdoor contaminant release vary widely from no impact at all up to a greater than $99 \%$ reduction. For the gas agent, the retrofit with the largest reduction is filtration option \#3, which includes a $99.5 \%$ gas air cleaner in the outdoor air intakes, combined with envelope sealing for a predicted reduction in exposure of over $99 \%$. Without envelope sealing, filtration option \#3 is predicted to have a somewhat smaller impact, with an exposure reduction of about $84 \%$. Envelope sealing alone has almost no impact on exposure to agent $\mathrm{G}$. The other filtration options do not impact agent $\mathrm{G}$ because they include only particle filtration.

For Agent P, filtration option \#2 (and \#3 since they provide equivalent particle filtration) combined with envelope sealing is predicted to reduce exposure by over $99 \%$. As with Agent G, the impact of the improved filtration is lessened if the envelope is not sealed, with a predicted exposure reduction of about $82 \%$. The lower filtration upgrade option \#1 has predicted exposure reductions of about $40 \%$ and $54 \%$ with and without envelope sealing, respectively. Unlike Agent $\mathrm{G}$, envelope sealing alone is predicted to have some impact (a $9 \%$ reduction) on exposure because the baseline building includes a particle filter. 


\begin{tabular}{|c|c|c|c|}
\hline & \multicolumn{2}{|c|}{$\begin{array}{c}\text { Exposure Relative to } \\
\text { Baseline (\%) }\end{array}$} & \\
\hline Retrofit & $\begin{array}{c}\text { Agent G } \\
\text { (gas) }\end{array}$ & $\begin{array}{c}\text { Agent P } \\
\text { (particle) }\end{array}$ & $\begin{array}{c}\text { Life-cycle cost } \\
\text { (thousands of dollars) }\end{array}$ \\
\hline Filtration option \#1 & 100 & 60 & 72 \\
\hline Filtration option \#2 & 100 & 18 & 538 \\
\hline Filtration option \#3 & 16 & 18 & 926 \\
\hline Envelope sealing & 100 & 91 & 32 \\
\hline Filtration \#1 with envelope sealing & 100 & 46 & 104 \\
\hline Filtration \#2 with envelope sealing & 100 & 0 & 570 \\
\hline Filtration \#3 with envelope sealing & 0 & 0 & 958 \\
\hline
\end{tabular}

Table 21 Relative Exposure and Life-Cycle Cost for Selected Retrofits in 1-Story Office Building (outdoor release)

\subsection{Discussion of Case Study}

The primary goal of the case study was to apply simulation and economic analysis to two real buildings, both to demonstrate the analysis methodologies and to gain further insights into the retrofits investigated. The case study has provided useful information on the design, implementation and performance of selected chembio retrofits in two very different buildings - a high-rise office building with central air-handling systems and a one-story office building with multiple rooftop units. The technical and economic analysis in the case study highlights the building-specific nature of the design and analysis of the retrofit options, such as multiple levels of filtration, and their associated costs and other economic impacts. Additionally, the case study analysis shows the possibility of completely eliminating exposure to a threat such as the outdoor release by applying a combination of improved filtration and envelope sealing. However, the economic analysis indicates the relatively high cost of accomplishing this level of protection. Information on potential performance and costs such as those presented here are both critical to decision-makers.

In some cases, examination of the results beyond average exposures yields additional insight into the potential retrofit effectiveness. For example, the lobby retrofits result in reductions in average exposure of up to $92 \%$, but the average exposure after retrofit is distorted by differences between occupant exposure in the lobby zone and occupant exposure in the remainder of the building. The reduction in exposure to occupants of non-lobby zones ranges from $97 \%$ to more than $99 \%$ for the cases that include filtration option \#3. Thus, this modification achieves nearly complete isolation of the lobby, which is its intent. However, the retrofit could not protect the lobby occupants from a release in that zone.

The results also show the importance of considering effectiveness and costs of potential combinations of retrofits. For example, sealing the envelope of the one-story office building has a minimal impact on occupant exposure to an outdoor release of Agent $\mathrm{P}$ and no impact on occupant exposure to Agent G. However, when combined with filtration, envelope sealing substantially improves the effectiveness of the filtration retrofits on both agents while increasing first costs by less than $10 \%$ and potentially decreasing operating costs by reducing building heating and cooling loads. 


\section{GUIDANCE}

This section presents guidance on the application of retrofits to better protect buildings from chembio releases. The purpose of this guidance is to present available options for retrofitting existing buildings for improved chembio protection and to discuss where these options are most applicable, the potential benefits and associated costs, and the extent of our current understanding regarding their application and performance. The information in this section is based on information in the literature, other guidance documents and the results of the technical evaluations conducted in this study.

When considering the retrofit of a specific building, it is critical to note that the unique features of the building and its systems must be considered when implementing the retrofit and in forming expectations as to the level of protection that will be realized. Also, while it is more straightforward to define and design protection systems for a particular release (primarily its location and timing), it is rare that such advance knowledge can be expected to exist. The undefined nature of the threats that need to be considered make retrofit selection and design far more challenging and limit the ability to quantify or "guarantee" any particular degree of protection. Nevertheless, this guidance is based on the philosophy that increased protection is a goal worth pursuing, even if the degree of improvement cannot be quantified in advance.

In addition to achieving the improved understanding of retrofit options that will result from the information presented below, there is another key step in the decision-making process regarding a specific building. Before one decides which retrofit options to implement, it is critical to assess the risks to which the building may be exposed. Risk assessment is a well-established process and needs to be carried out to determine the potential likelihood of an event and the associated costs and other impacts if an event does occur. While risk assessment methods and the linkage between the outcome and the resulting actions are beyond the scope of this report, there is some useful discussion in ASHRAE (2003) and FEMA (2005).

This section is organized into three parts, beginning with actions that generally make sense under any circumstance. Most of these actions are consistent with good building and system operation and maintenance, and therefore may be considered part of good practice. The next two groups are organized into retrofit technologies and retrofit approaches. As discussed in Section 1 of this report, the former category refers to specific off-the-shelf technologies, such as filtration and air cleaning devices, while the latter refers to more generic approaches to increasing building protection such as building pressurization and isolation of spaces of potential concern (e.g., mail rooms).

\subsection{General Guidance}

There are a number of actions that can be beneficial under almost any circumstance. In many cases they are associated with only modest costs and sometimes yield additional benefits in terms of reduced energy consumption and improved indoor air quality. Many of these actions have been advocated in prior publications on building protection (ASHRAE 2003a, NIOSH 2002, Price et al., 2003). They tend to focus less on specific threats than on sound building operation and maintenance practices that can support the successful implementation of specific chembio protection strategies and greatly increase the likelihood that any particular response strategy will perform as intended. 


\subsubsection{Understand the Building}

Regardless of the degree of risk to which a particular building may be subject, it is always a good idea to understand the building. In this case, the term "understand" refers to several issues including the layout of the building, the activities within, and what is going on outside the building. As every building is unique to some degree, it is hard to develop a general list of parameters to assess but the following list provides some sense of the type of information that is relevant. The EPA Building Air Quality manual also provides useful guidance for characterizing a building (EPA 1991).

\section{Building layout}

Entrances: where do people enter the building, including "nonstandard" entrances such as loading docks, side entrances and parking garages.

Ground level airflow paths: accessible locations where air can enter a building, including but not limited to outdoor air intakes. Also consider entrances, loading docks, and emergency doors where a negative pressure will pull air into a building.

Space types and occupancy levels: determine what different types of spaces exist in a building (offices, classrooms, meeting rooms, etc.) and where the occupants are generally located.

\section{Building activities}

Occupancy patterns: where and when people arrive and leave the building; is there a predictable schedule; make sure to consider evenings and weekends.

Occupant activities: what people are doing in the building; activities likely to generate contaminants that might be harmful or perceived as harmful to occupants; when these activities take place?

Outside the building

Pedestrian and motor vehicle traffic: is the building located in an area of high pedestrian or motor vehicle activity?

Nearby sources: is the building close to other high-profile buildings, or industrial facilities, transportation stations, roadways or train tracks where an intentional or unintentional release could occur?

In terms of building protection in particular, methods are being developed to assess vulnerability that will address some of the security-specific issues (LBNL 2004).

\subsubsection{Understand the System}

Whether or not one anticipates using the building ventilation system as part of a protective strategy, it is important to understand the system as it is designed to operate and as it is actually operating. Again, every building and its ventilation systems are unique to some degree, but there is some basic information that needs to be assembled and understood. The EPA Building Air Quality manual again provides some useful guidance on ventilation system characterization (EPA 1991). In some cases, these actions may require assistance from individuals that are not part of the building operating staff, such as TAB contractors or engineering consultants.

\section{System design}

Documentation: assemble mechanical drawings and fan specifications; these may not be onsite and are often out of date; if so, current drawings and system specifications are important 
resources that should be developed as soon as resources can be acquired for such an effort, which can be quite involved in many buildings; assemble any existing TAB reports.

Air handler design information: design supply, return and outdoor air intake airflow rates; areas served by each air handler; specified level of filtration.

Exhaust systems: design airflow rates; areas served; operating schedule; location of on/off controls.

Sequence of operations: how systems are intended to operate per time of day, outdoor temperature and humidity, season of the year, including modulation of outdoor air intake and supply airflow rates. This effort also includes understanding fire alarm systems, smoke control modes and any available purge cycles.

\section{System operation}

Airflow rates: supply, outdoor and exhaust airflow rates relative to design values; modulation of same based on time of day and outdoor conditions, again relative to design sequence of operations.

Building pressures: indoor-outdoor pressure differences at entrances and ground level airflow paths under different conditions of weather and ventilation system operation, at a minimum assess at least the direction of the pressure difference; pressure differences between key spaces (e.g., lobbies, mail rooms, parking garages and loading docks) and the surrounding spaces of the building to determine if air will flow from these spaces into the rest of the building, which must include consideration of different weather conditions.

\subsubsection{Inspect the System}

Achieving good system operation requires that the system components be in good working condition. Again, the Building Air Quality guidance document (EPA 2001) contains sound recommendations on the aspects of such an inspection. A more detailed inspection protocol was developed for the EPA Building Assessment, Survey and Evaluation (BASE) Study (EPA 2003, Persily 1993). The components that should be considered in such an inspection include the following:

Outdoor air intakes: cleanliness, open per the operating schedule

Intake dampers and damper linkages: functioning as designed, able to open and close Fans: general condition

Cooling coils: general condition, including cleanliness

Drain pans: cleanliness, rust, existence of standing water and/or microbial growth

Air filters: general condition, condition of seals and existence of bypass

Temperature, humidity and pressure sensors used by building control systems: general condition

\subsubsection{System tune-up}

Based on the information gathered through these efforts to understand the building and its systems, the next step is to make the adjustments necessary to bring the system operation in line with the original design intent and current needs. Such "recommissioning" is like to improve energy efficiency and indoor air quality and is discussed as a retrofit option in Section 4.3. 


\subsection{Retrofit Technologies}

This section presents guidance on several specific retrofit technologies. The guidance includes a brief description of the technology including how it functions and how it's applied, a discussion of existing performance data, the protective impact that can be expected from its application, the associated costs, and finally information gaps regarding the technology. The information presented here reflects the current state of knowledge, but much research and other activity is currently occurring in the area of building protection. It is expected that more information on these technologies will be produced in the future and new technologies will become available. Therefore, it is important that building designers, owners, operators and others responsible for building protection stay abreast of current developments in this rapidly changing area.

\subsubsection{Enhanced Particle Filtration}

\section{Objective}

To increase the removal of particulate contaminants from HVAC system airstreams through the use of higher efficiency particle filters than those currently in place.

\section{Description}

Assuming that an air handler has at least some minimal level of particle filtration (generally used to keep cooling coils and other system components clean), this retrofit involves replacing the existing filters with higher efficiency particle filters. There are two distinct situations in which this retrofit can be implemented. In the first case the new filters are installed in the existing filter racks (perhaps with some slight modifications), such that the pressure drop associated with the higher efficiency filters is compatible with the existing fans and motors. In other cases, the pressure drop associated with the new filters is too high for the existing system and the fans, motors and/or electrical systems need to be modified.

A great deal of information is available on particle filtration, including general discussions of the technology and its application (ASHRAE 2000, NAFA 2001), as well as guidance specific to chembio protection of buildings (NIOSH 2003). As noted in these references, there are three primary types of particulate air filters: mechanical, eletrostatically-charged and electronic. Mechanical filters, which are sometime referred to as media filters and include familiar panel, bag and pleated filters, capture particles via three predominant mechanisms. The first mechanism is impaction, where particles collide with the filter media instead of flowing around the filter fibers and then become attached to the media. Interception is similar to impaction, but rather than colliding directly with the filter fiber, the particle comes in close contact with the fiber as it moves along with the airstream and the forces of attraction result in the particle sticking to the fiber instead of continuing to move with the airstream. Smaller particles can also be captured by diffusion, where random movement of the particles relative to the airstream causes them to come in contact with the filter media and become attached. Figure 11 shows a generic curve of particle removal efficiency as a function of particle size or diameter. (An efficiency of 1.0 means that the filter removes all of the particulate matter that flows into the filter, while a lower efficiency removes the corresponding fraction of the incoming particulate matter.) In general, diffusion is most effective with smaller particles, while impaction and interception are most effective at larger diameters. This difference results in a dip in removal efficiency in the range of $0.2 \mu \mathrm{m}$, which is a particle size that tends to penetrate fairly deeply in the human respiratory system. 


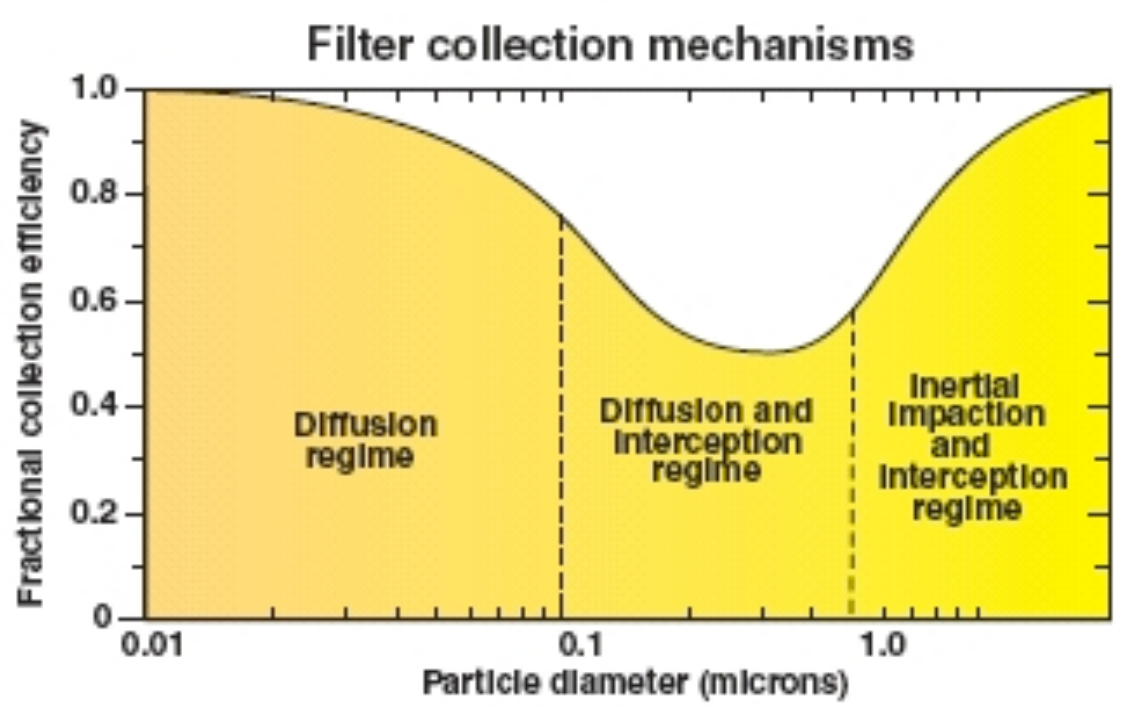

Figure 11 Representation of filter efficiency dependence on particle size (NIOSH 2003)

The use of eletrostatically-charged media can potentially increase particle removal through the interaction of charged media and naturally charged particles. There are multiple approaches to charging the media, and in all cases the performance can be impacted by humidity, time of service, exposure to various airborne contaminants, and dust buildup (or loading) on the filter. Electronic air cleaners employ electrostatic precipitation in which an electric charge is imparted to particles as they pass through an ionizing section of the device. The particles are then collected onto alternately charged plates downstream of the ionizing section. The removal efficiency of these devices is impacted by particle size, air speed, ionizing and collector plate voltages, spacing of the ionizers and collector plates, and coating of the ionizing wires with silicon dioxide over time. Another important consideration with these devices is their potential to emit ozone, particularly if the ionizing wires are damaged.

The particles that are relevant to building security cover a potentially wide range, but the focus is primarily on biological agents including microbes such as bacteria and fungi as well as toxins. A great deal of information is available on the range of bio-agents and their unique characteristics in terms of size, infectiousness, and lethality (Kowalski 2003, Kowalski and Bahnfleth 1999). The predominant size range of interest for these agents is on the order of $1 \mu \mathrm{m}$, but the particle size ranges from as small as a few tenths of a micrometer to several micrometers. The size range is important in relation to the dependence of filter efficiency on particle size depicted in Figure 11. Most mechanical filters have higher removal efficiencies in the size range of interest, i.e., $1 \mu \mathrm{m}$ or greater, but the existence of smaller particles can still be an issue for some agents. 
Available Performance Information

Particle removal efficiencies are fairly well established based on the use of ASHRAE Standard 52.2 (ASHRAE 1999), which provides a rating method referred to as Minimum Efficiency Reporting Value (MERV). The MERV ratings are based on particle size specific removal rates and include the effects of filter loading over time, thereby providing more information than contained in the dust spot efficiency and arrestance values from ASHRAE Standard 52.1 (ASHRAE 1992). MERV values range from 1 to 20, with higher values having higher removal rates. For reference, a $30 \%$ dust spot filter corresponds roughly to a MERV 8 and a HEPA filter corresponds to values of MERV 17 or higher. Figure 12 shows some sample plots of removal efficiency as a function of particle size for a range of MERV values. Note that ASHRAE Standard 62.1-2004 requires the use of at least a MERV 6 filter upstream of all cooling coils or any other wetted surface. Historically, particulate filters have been installed in commercial buildings to keep system components clean, which improves the performance of heat transfer surfaces and reduces the likelihood of microbial growth in ventilation systems, but more recently concerns about indoor air quality and now building security have renewed the consideration of higher levels of filter efficiency (Burroughs 2005a).

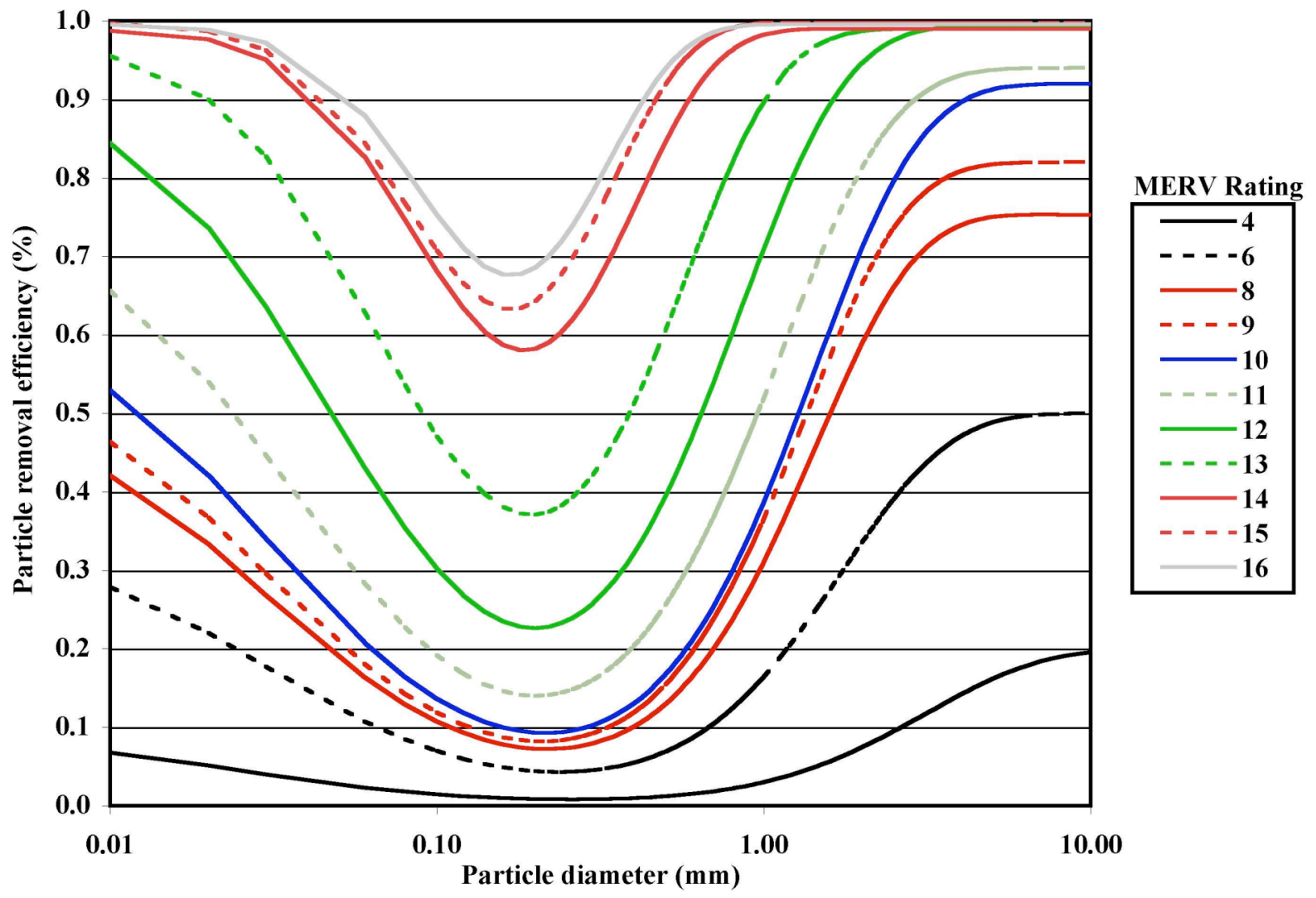

Figure 12 Representative curves of particle removal efficiency for various MERV Levels (Kowalski and Bahnfleth 2002)

While the MERV rating system has been available since 1999, many users and vendors still speak in terms of dust spot efficiency and arrestance, the performance parameters determined with the earlier ASHRAE test method 52.1 (ASHRAE 1992). Table 22 compares the values of the three parameters, along with some information on the types of filters that provide the various efficiency values. 


\begin{tabular}{|c|c|c|c|}
\hline \multirow[b]{2}{*}{$\begin{array}{l}\text { MERV value per } \\
\text { ASHRAE 52.2 }\end{array}$} & \multicolumn{2}{|c|}{$\begin{array}{c}\text { Approximate values from } \\
\text { ASHRAE 52.1 }\end{array}$} & \multirow[b]{2}{*}{ Filter type } \\
\hline & $\begin{array}{l}\text { Dust spot } \\
\text { efficiency }\end{array}$ & Arrestance & \\
\hline 1 & $<20 \%$ & $<65 \%$ & \multirow{4}{*}{$\begin{array}{l}\text { Throwaway media filters; } \\
\text { washable panel filters; } \\
\text { electrostatic panel filters }\end{array}$} \\
\hline 2 & $<20 \%$ & $60 \%-70 \%$ & \\
\hline 3 & $<20 \%$ & $70 \%-75 \%$ & \\
\hline 4 & $<20 \%$ & $75 \%-80 \%$ & \\
\hline 5 & $<20 \%$ & $80 \%-85 \%$ & \multirow{4}{*}{$\begin{array}{l}\text { Pleated filters ( } 25 \mathrm{~mm} \text { to } \\
125 \mathrm{~mm} \text { thick); cartridge } \\
\text { filters; throwaway media filters }\end{array}$} \\
\hline 6 & $<20 \%$ & $85 \%-90 \%$ & \\
\hline 7 & $25 \%$ to $30 \%$ & $>90 \%$ & \\
\hline 8 & $30 \%$ to $35 \%$ & $>90 \%$ & \\
\hline 9 & $40 \%$ to $45 \%$ & $>90 \%$ & \multirow{8}{*}{ Bag and box filters } \\
\hline 10 & $50 \%$ to $55 \%$ & $>95 \%$ & \\
\hline 11 & $60 \%$ to $65 \%$ & $>95 \%$ & \\
\hline 12 & $70 \%$ to $75 \%$ & $>95 \%$ & \\
\hline 13 & $80 \%$ to $90 \%$ & $>98 \%$ & \\
\hline 14 & $90 \%$ to $95 \%$ & $>98 \%$ & \\
\hline 15 & $>95 \%$ & $\mathrm{n} / \mathrm{a}$ & \\
\hline 16 & $\mathrm{n} / \mathrm{a}$ & $\mathrm{n} / \mathrm{a}$ & \\
\hline 17 & $\mathrm{n} / \mathrm{a}$ & $\mathrm{n} / \mathrm{a}$ & \multirow{4}{*}{ HEPA/ULPA filters } \\
\hline 18 & $\mathrm{n} / \mathrm{a}$ & $\mathrm{n} / \mathrm{a}$ & \\
\hline 19 & $\mathrm{n} / \mathrm{a}$ & $\mathrm{n} / \mathrm{a}$ & \\
\hline 20 & $\mathrm{n} / \mathrm{a}$ & $\mathrm{n} / \mathrm{a}$ & \\
\hline
\end{tabular}

Table 22 Comparison of generic particulate filter efficiency values (ASHRAE 1999)

There have been relatively few measurements of installed filter removal efficiencies. A recent field study by Burroughs (2005b) included measurements in several office buildings over 1 year using particle counts up and downstream of filters of different MERV levels. The results did verify that the MERV ratings translated to installed performance, but also found significant leakage at the filter seals. More such measurements are needed to better understand the factors that determine installed performance in order to support improved installation, operation and maintenance practices as needed.

\section{Protective Impacts}

Enhanced particulate filtration can reduce the exposure to bioagents, but the impact depends on the particle diameter of the agent, the filter efficiency at that diameter, the airflow rate through the filter, the quality of filter maintenance and the filter location relative to the contaminant source and the occupants. Given the lack of prior knowledge of the particle size to which one might be subjected and the prevalence of bioagents in the $1 \mu \mathrm{m}$ range, one should expect to realize significant protection from upgrading filtration. And since larger particles (greater than $1 \mu \mathrm{m}$ in diameter) are more readily removed by filtration than smaller ones, high efficiency filters (i.e., HEPA) are not necessarily required to remove close to $99 \%$ of $1 \mu \mathrm{m}$ particles. 
Whether this level of removal provides an adequate level of protection is a separate, but important, issue. At the same time, filtration systems must be properly installed and maintained, just like any other building equipment, to perform as expected over time.

Given the removal efficiency of an upgraded filter relative to the pre-retrofit filter, it is relatively straightforward to determine the potential protective impact. However, since a filter will only remove contaminants that flow through it, the filter location relative to the contaminant source is critical to the exposure reduction that will be realized. The three generic source locations of interest are outdoors, at the air intake, and indoors. An outdoor release that increases the ambient concentration surrounding a building for some period of time will result in contaminant entering the building through the intake (filtered) and through envelope leakage (unfiltered). (Intake air that bypasses the filter due to poor filter sealing is discussed below.) The amount of contaminant that enters the building with the intake air will be reduced by an amount determined by the filter removal efficiency relative to the pre-retrofit value, but the actual exposure reduction will be impacted by the amount of envelope leakage or infiltration relative to the amount of air intake. Assuming that no agent is removed by the building envelope (a conservative assumption because some agents will be "filtered" by the envelope), and ignoring filter bypass as well as particle loss due to deposition onto building surfaces, the impact on the exposure reduction depends primarily on the ratio of the envelope infiltration airflow to the outdoor air intake airflow.

One can express the "effective" filter efficiency as a function of the rated or nominal efficiency $\varepsilon$ of the filter and the ratio of the airflow entering the building via infiltration $Q_{\text {INF }}$ to the airflow entering via the system intake $\mathrm{Q}_{\mathrm{INT}}$ as follows:

$$
\text { Effective filter efficiency }=\frac{\varepsilon}{\left(\frac{Q_{I N F}}{Q_{I N T}}+1\right)}
$$

The rated efficiency $\varepsilon$ is the removal efficiency of the device itself (based on a test performed in accordance with ASHRAE 52.2), again without any filter bypass, while the effective efficiency is the removal efficiency on a whole building scale adjusted for the entry of unfiltered infiltration air. In other words, the effective efficiency is the removal efficiency based on the total amount of air entering the building, not just the intake airflow through the filter.

Figure 13 depicts the dependence of the effective filter efficiency on the rated or nominal efficiency for different values of the ratio of infiltration to intake airflow for an outdoor release. Therefore, if there is no infiltration $\left(\mathrm{Q}_{\mathrm{INF}} / \mathrm{Q}_{\mathrm{INT}}=0\right)$, then the effective efficiency is the same as the rated efficiency. As the infiltration rate increases relative to the intake rate, the effective efficiency decreases relate to the rated efficiency. For example, if infiltration and intake are equal, which is a reasonable first order assumption for a typically leaky commercial building, the effective efficiency will be one-half of the rated efficiency. Envelope infiltration can be thought of as a form of filter bypass, i.e., air that flows around a filter instead of through it and thereby is not exposed to the particle removal processes of the filter. When a contaminant is released directly at or into an air intake, entry via infiltration no longer plays a role and the impact of the filter is determined directly by the rated efficiency of the filter.

Depending on the quality of the filter installation and maintenance over time, airflow bypass around the filter can often be significant (Burroughs 2005a). As in the case of infiltration, airflow that bypasses the filter will not have any contaminant removed, again degrading the effective efficiency of the filtration system. Figure 14 is similar to Figure 13, but includes the impacts of bypass fractions of $5 \%$ and $10 \%$ to show the impacts on effective efficiency. A bypass fraction 
of $5 \%$ means that $5 \%$ of the airstream intended to go through the filter actually flows around it. The figure shows that bypass has slightly more significant impact when the infiltration-to-intake ratio is low, but clearly shows the degradation performance due to filter bypass.

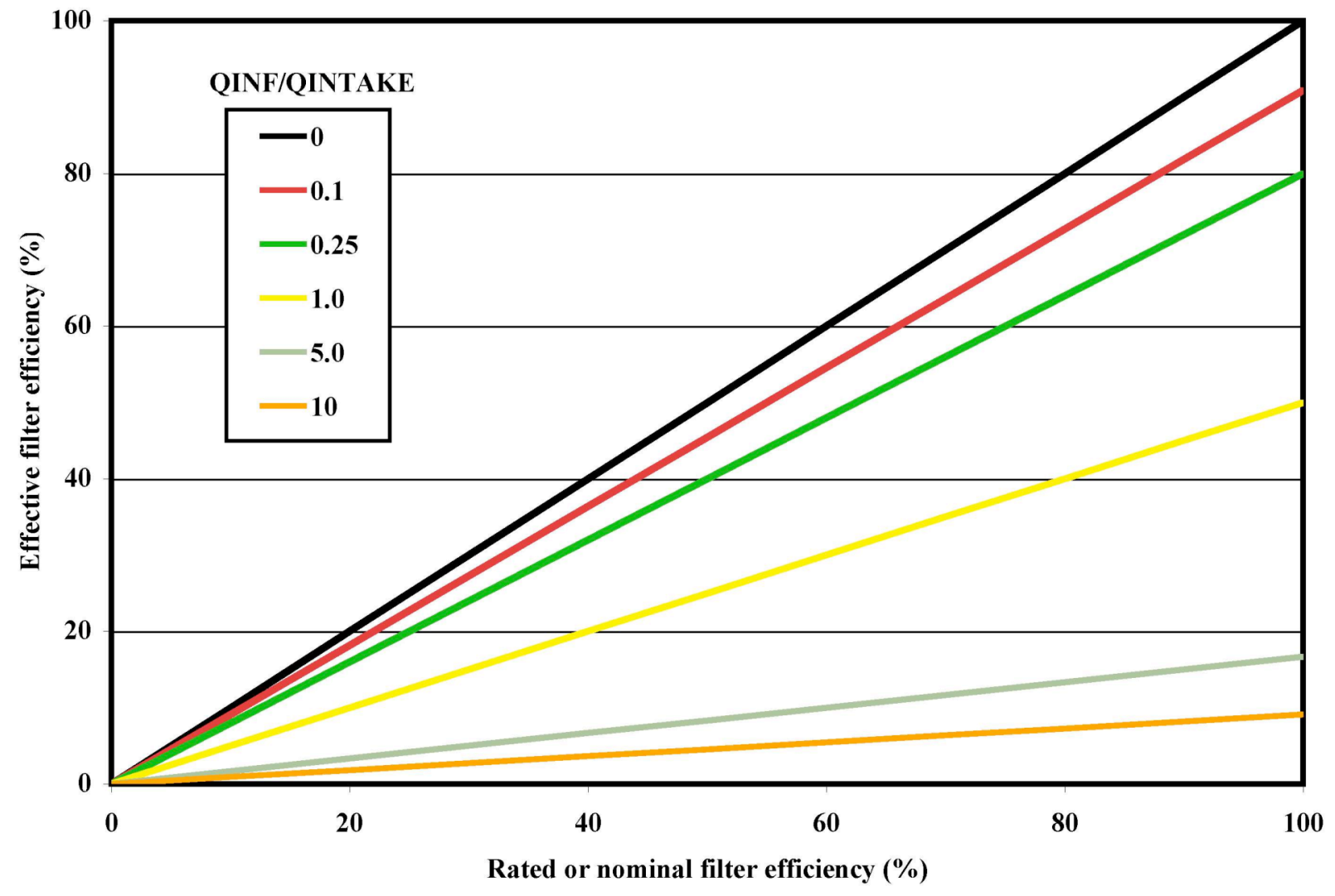

Figure 13 Impact of infiltration on effective filter efficiency

By considering a building airflow system as a single zone, the relative exposure to an outdoor release given an upgrade in filtration from an efficiency $\varepsilon_{1}$ to a higher efficiency $\varepsilon_{2}$ can be expressed as follows:

$$
\text { Relative exposure }=\frac{1-\varepsilon_{2}+\frac{Q_{I N F}}{Q_{I N T}}}{1-\varepsilon_{1}+\frac{Q_{I N F}}{Q_{I N T}}}
$$

Therefore, if there is no infiltration, the relative exposure is the ratio of one minus the "new" efficiency divided by one minus the "old" efficiency. For example, in the simulations of the twostory office building presented in Section 4 with no weather ( $\left.\mathrm{Q}_{\mathrm{INF}}=0\right), \varepsilon_{1}=16.4 \%$ and $\varepsilon_{2}=$ $89.6 \%$. Equation 1 therefore yields a relative exposure for the higher efficiency relative to the lower efficiency of $12.4 \%$, which is the same value as in Table 8 . For nonzero values of QINF, the relative exposure increases, reflecting the degradation in performance for the higher efficiency filtration. In that same example, with weather included, the infiltration rate is $0.22 \mathrm{~h}^{-1}$, and the ratio of $\mathrm{Q}_{\mathrm{INF}}$ to $\mathrm{Q}_{\mathrm{INT}}$ is 0.58 . Equation 2 now yields a relative exposure of $48 \%$, which is very close to the value in Table 9.

Table 23 shows the relative exposure as defined by Equation (2), with lower values corresponding to less exposure with the "new" filter relative to the "old" filter. The first column 
shows the before and after MERV levels, while the second shows the relative exposure assuming no infiltration. The beneficial impacts are seen clearly, with the most significant reductions seen for MERV values of 13 and higher. The third column shows the relative exposure assuming an infiltration rate equal to the intake rate for a general outdoor release, which shows that without addressing infiltration, even the highest filter efficiency retrofits are of limited effectiveness.

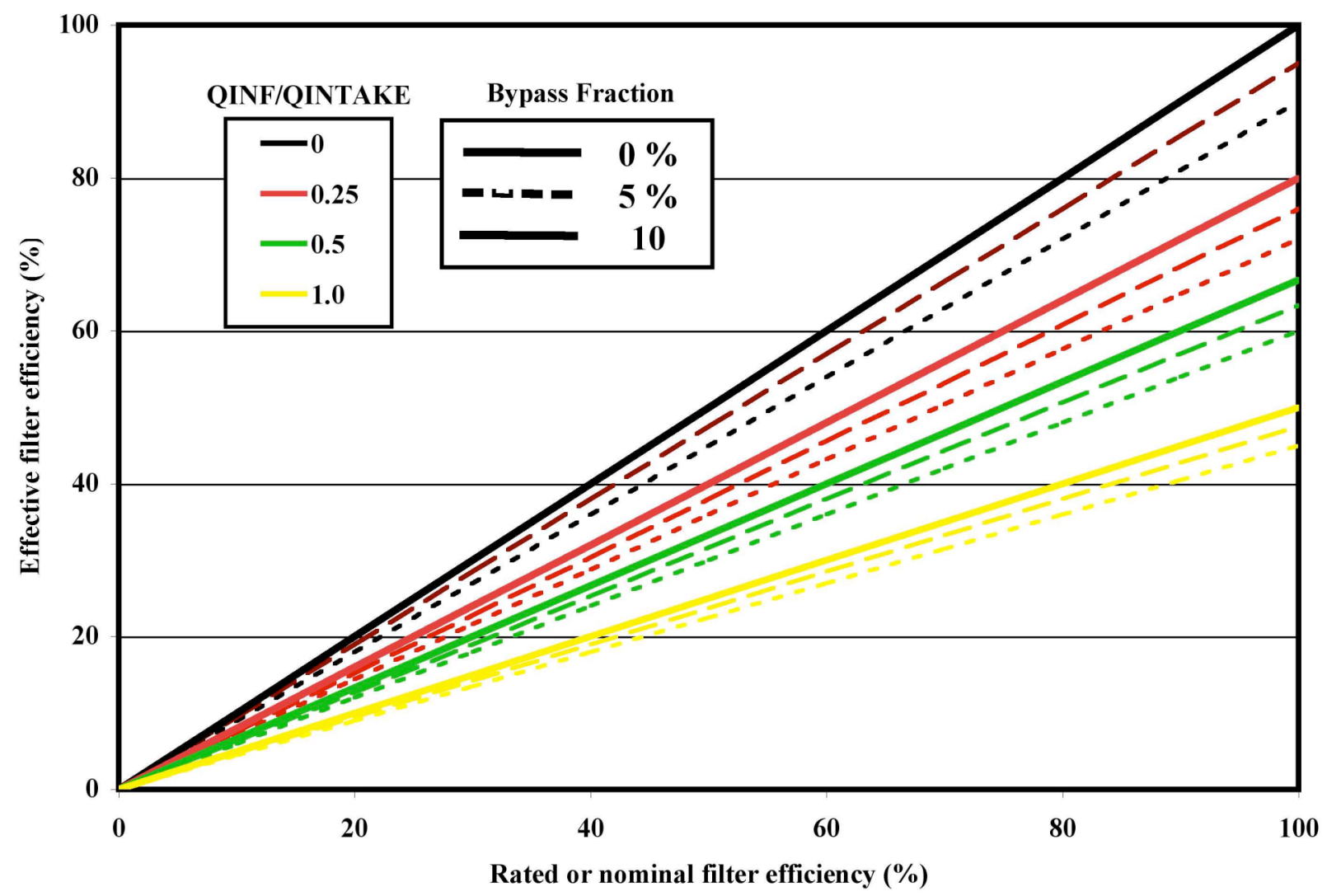

Figure 14 Impact of bypass on effective filter efficiency

\begin{tabular}{|c|c|c|}
\hline \multirow{2}{*}{ Filter upgrade } & \multicolumn{2}{|c|}{ Relative exposure (\%) } \\
\cline { 2 - 3 } & No infiltration & Infiltration = Intake \\
\hline MERV 6 to 8 & 71.8 & 87.1 \\
\hline MERV 6 to 11 & 53.2 & 78.7 \\
\hline MERV 6 to 13 & 12.4 & 60.1 \\
\hline MERV 6 to 16 & 0.6 & 54.7 \\
\hline MERV 8 to 13 & 17.3 & 69.0 \\
\hline MERV 8 to 16 & 0.8 & 62.8 \\
\hline
\end{tabular}

Relative exposure based on removal efficiency at roughly $1 \mu \mathrm{m}$ as follows: MERV $6=16.4 \%$, MERV $8=40 \%$, MERV $11=55.5 \%$, MERV $13=89.6 \%$ and MERV $16=99.5 \%$.

Table 23 Impact of enhanced filtration on exposure to outdoor release

The impacts of filtration in the mixed airstream, a common location of particle filters in most air handling systems, can also be quite significant. Generally, the airflow rate that passes through a mixed air filter is roughly five times higher than the outdoor air intake that passes through an 
outdoor air filter (except under $100 \%$ outdoor air operation). Therefore, mixed air filtration can remove more contaminant from the building for a given level of filtration once the contaminant has entered the building from an outdoor or indoor release. As seen in the simulations, retrofit effectiveness values (i.e., exposure with retrofit relative to exposure without) on the order of $10 \%$ or even less can be realized by filtration of the mixed airstream. But the actual reduction is ultimately a function of the pre and post retrofit filtration efficiency, the airflow through the system, and of course the quality of the installation and maintenance.

When a contaminant is released within the building, the location of that release relative to the occupants and the filter location becomes critical. If the occupants are very close to the release, filtration of the recirculation air may have little or no impact on their exposure. If the release is located such that the contaminant is drawn back via the return system to the filter before being distributed to the rest of the building, then recirculation filtration will be more effective overall. However, occupants in the immediate vicinity of the release may still be significantly exposed to the contaminant.

In addition to the rated efficiency of a filter, the air seal of filter installations is critical to their installed performance and must be addressed regardless of the current or retrofit level of filtration (Burroughs 2005b). In fact, improving the seal of existing filters may have a more significant benefit than replacing the filters with higher efficiency filters without addressing bypass. Filter seal is generally addressed in the installation of higher efficiency, e.g. HEPA, filters, but maintenance of the seal over time is always an issue and routine inspection of the filter seal should be part of normal maintenance practice.

\section{$\underline{\text { Costs }}$}

Like most building retrofits, the cost of enhanced filtration is a combination of first costs and operating costs. Specific examples of both are highlighted in the case study as described in Section 3 and Appendix C, and the software tool developed as part of this project provides the means for properly accounting for all these costs in determining the life-cycle costs of enhance filtration and other retrofits. These costs, specifically the interactions between first costs and operating costs, are discussed in NIOSH (2003) and Arnold et al. (2005).

First costs include the following:

Filters

Design work (in cases where system modifications are required)

Reconfiguration of filter racks (where required)

Modifications of air handling system fans, motors, electrical (where required)

Operating costs include the following:

Filter replacement and maintenance (incremental above replacement costs of existing filters) Increased electrical consumption (when new filters increase pressure drop and require more powerful fans)

Enhanced particle filtration has the potential for improving indoor air quality, which has been associated with increased occupant productivity (Fisk and Rosenfeld, 1997). While difficult to quantify, increased productivity would correspond to an economic benefit associated with better filtration. Better filtration can also reduce dirt build up on heat transfer surfaces and result in better system efficiencies over time. These benefits are also difficult to quantify but nonetheless can be quite real. In addition, better filtration can improve overall building cleanliness, potentially reducing housekeeping costs. In the event that a release occurs, filtration can also reduce the extent and cost of the followup decontamination effort. 
Knowledge gaps

There are several areas where additional information would increase our understanding of the impacts of enhanced particulate filtration. One is measurement of installed performance as a function of system type and configuration, filter type and length of time since installation. As noted earlier, there is very little field performance information, and such measurements provide the only means of verifying the actual impact of filtration in real buildings. In addition, field measurements of filter bypass would also be useful, and could be related to different approaches to filter installation and sealing. Better understanding of the IAQ benefits of improved filtration could also lead to better cost-benefit decisions.

\section{SUMMARY}

The addition or enhancement of particle filtration can significantly reduce exposure to outdoor and indoor releases. As revealed by the simulations discussed in Section 2 of this report and in Table 23, upgrading from typically minimal filtration levels of MERV 6 or 8 to MERV 13 or higher can reduce the exposure to about $10 \%$ of the pre-retrofit case based on consideration of contaminant entry through the intake alone. These simulations also show the advantages of mixed air filtration over outdoor air filtration alone, with the latter not having any impact on indoor releases. Contaminant infiltration via envelope leakage can drastically decrease the effectiveness of improved filtration, though the reduction is difficult to predict without reliable estimates of infiltration rates. The same degradation in the impacts of improved filtration can also occur when filters are poorly sealed in their frames, either initially or over time as seals deteriorate. It is generally more important to first deal with the integrity of these seals before upgrading the filters, and the same may hold true for envelope airtightness as well.

The levels to which filtration can be enhanced are dependent on the air handling system. Fan coil units, small rooftop units and other unitary systems often have limited space for deeper filters and limited fan power to overcome the increases in airflow resistance associated with better filters. This situation was seen in the case study of the one-story office building with rooftop units. When increased protection is needed under such circumstances, it can be a challenge to achieve it through filtration. Larger systems are generally more adaptable to higher levels of filtration, though system modifications to the filter racks and air handler housing, as well as new fans and motors, may be required.

An advantage of enhanced filtration relative to some other retrofits is that it is always working, as opposed to strategies that rely on operator-based response such as system shutdown. The sensitivity of shutdown and other strategies to timing was seen in the retrofit analysis, but no such timing issues exist for filtration. Also, filtration is relatively simple, in that there are no moving parts and as long as air is brought to the filter, it will remove contaminant. In addition, particle filtration is part of current practice and the technology is widely available. Therefore, there are no dramatically new skills required of designers, installers and operators as there would be for some other retrofits. The same applies to maintenance, as filter replacement is also part of current practice. Finally, unlike some retrofit strategies such as system shutdown in the event of an interior release, enhanced filtration shouldn't increase exposure under any scenario. 


\subsubsection{Sorption-based Gaseous Air Cleaning}

\section{Objective}

To remove gaseous contaminants from ventilation airstreams through the use of adsorptive media that captures these contaminants physically or chemically.

\section{Description}

Sorption based gaseous air cleaning is currently employed in a number of applications to control odorous, corrosive or otherwise undesirable gases generated within or outside of buildings. A variety of sorbents are employed including activated carbon, alumina and sorbents impregnated with compounds to remove specific contaminants. The effectiveness of these sorbents depends on the particular sorbent-contaminant combination and the design of the system that brings the air into contact with them. Gaseous air cleaning devices are not typically employed in commercial and institutional buildings, but they are seeing increasing use in a number of applications such as some manufacturing facilities and museums and are receiving increased attention based on concerns about building security. A significant amount of information is available on gaseous air cleaning, including general discussions of the technology and its application (ASHRAE 2003, NAFA 2001), as well as its use in chembio building protection (Kowalski 2002, NIOSH 2003).

Gas phase air cleaning systems remove contaminants through either physical adsorption or chemisorption. Physical adsorption is based on the attractive van der Waals forces between the gas molecules and the sorbent surface, with the removal capacity dependent on the surface area of the sorbent. That dependency is the reason that porous materials with high surface to volume ratios, such as activated carbon, are so effective. Physical adsorption is a reversible process, and therefore temperature has a strong effect on sorption rates resulting in lower removal efficiencies at higher temperatures. In addition, other gas molecules will compete for the available sorption sites. Water vapor acts as one such competitor, and therefore elevated humidity has a significant effect on the rate of adsorption, particularly for activated carbon. Chemisorption involves chemical reactions between the adsorbent surface and the gas molecule, resulting in better retention of the contaminant than physical adsorption alone. To induce chemisorption, adsorbents are impregnated with various chemicals that target certain chemical classes such as acid gases or specific chemicals such as chlorine.

The gaseous contaminants that are relevant to building security cover a wide range, including nerve agents and toxic industrial chemicals. No single sorbent or chemical impregnant is able to remove all contaminants effectively, and therefore a combination of sorbents is needed to fully protect a building and its occupants. Some common adsorbent materials include activated carbon, silica gel, alumna and zeolites, while chemical impregnants include potassium permanganate, phosphoric acid, copper and silver salts, and zinc oxide.

In addition to the specific adsorbent material and contaminant of concern, the removal efficiency of a gas phase air cleaning system depends on surface area of the sorbent particles, the residence time in the adsorbent bed, and the presence of other airborne compounds that compete for adsorption sites. The residence time depends on the media bed depth and the airflow rate through the bed. A deeper bed, while increasing residence time, also increases the pressure drop through the system. The adsorptive capacity of a system, which translates to service life, depends on the mass of adsorbent employed and the contaminant concentrations, including humidity, to which the adsorbent is exposed. These contaminants include both the contaminants the system is intended to remove and others that compete for adsorption sites. 
Available Performance Information

There are currently no standard test methods for determining the contaminant removal efficiency of gaseous air cleaning equipment for use in specifying and sizing these systems. Manufacturers have performance data and experience in a variety of forms that can be useful, but there is not yet the equivalent of a MERV rating for gaseous air cleaning. ASHRAE committee 145P is working on a method of test for gas-phase air cleaning media, which will hopefully be available soon for establishing the performance of different media using a consistent methodology. That committee is also working on a method of testing full-scale air cleaning media beds, which will also be very helpful in the application and specification of such systems.

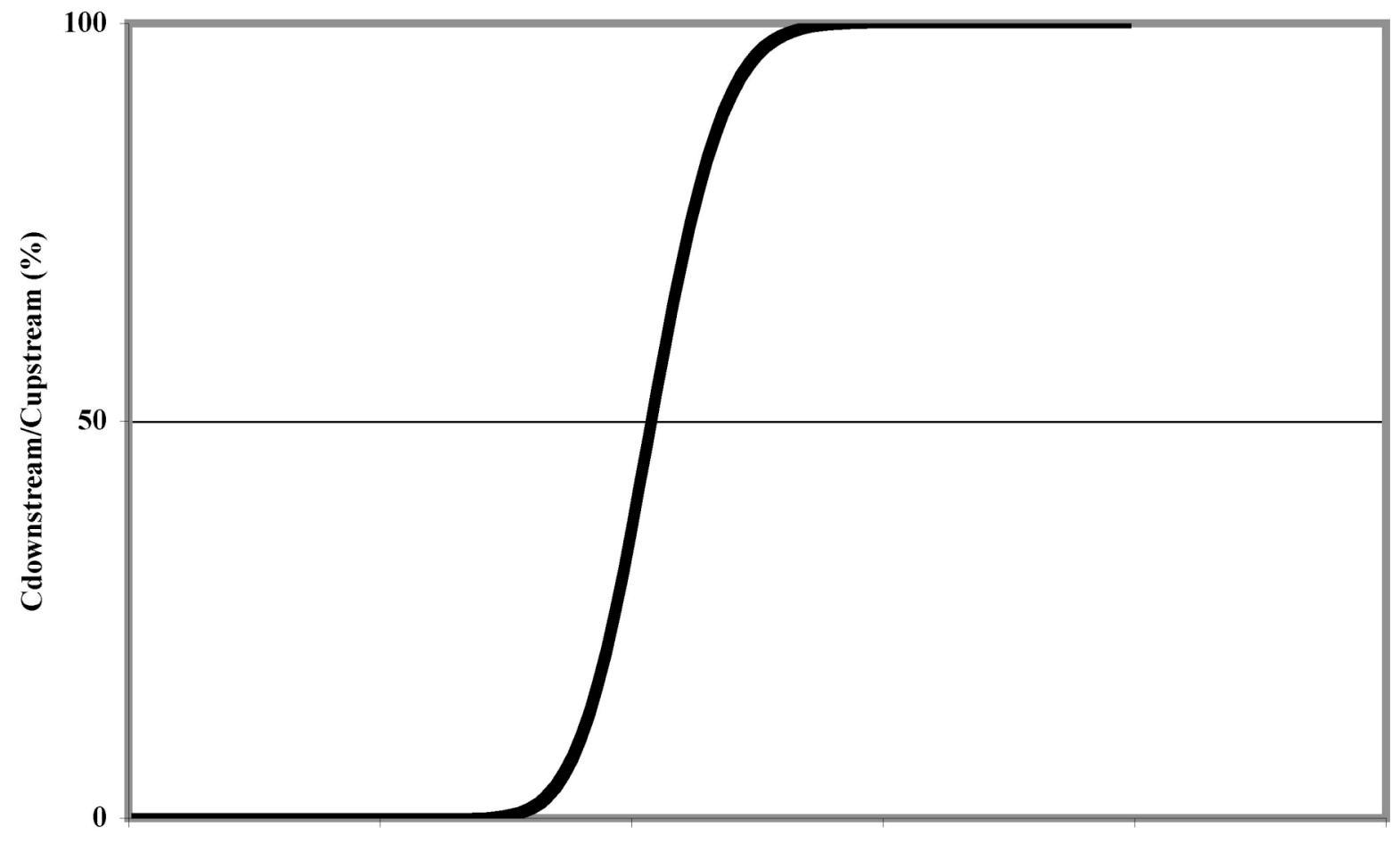

Time

Figure 15 Representative breakthrough curve

The performance of gas phase air cleaning is often described in terms of breakthrough curves. These curves are determined for an adsorbent/contaminant combination using a test apparatus in which an airstream containing a known concentration of the contaminant flows through the adsorbent bed. Breakthrough is generally defined as the condition where the contaminant concentration downstream of the air cleaning device reaches some specific fraction of the upstream or challenge concentration, presumably because the air cleaner sorptive capacity has been exceeded. The breakthrough time is then the time between the initial contact of the contaminant with the adsorbent and the time when breakthrough has occurred at some fraction of the challenge concentration, for example $50 \%$. Figure 15 is a representative breakthrough curve, which plots the ratio of the downstream concentration to the upstream or challenge concentration as a function of time. Initially, very little contaminant gets past the air cleaner, but after sufficient time, the media capacity is exhausted and the contaminant "breaks through" to the downstream side of the system. Breakthrough curves are often determined at relatively high challenge 
concentrations in order to complete the tests in a manageable amount of time. Such breakthrough test results need to be related to the performance at lower and perhaps more realistic concentrations. Nevertheless, breakthrough curves can be generated as a function of chemical properties, bed depth and other system design parameters.

Another key performance parameter is the service life of the filter media, which depends on the mass of adsorbent in the system, the exposure of the media over time to temperature and humidity swings, and the exposure over time to contaminants such as those normally found in air. Service life can be determined analytically for a single contaminant (NAFA 2001), but the influence of other airborne contaminants makes the determination more complicated in practice. Media manufacturers therefore use other approaches such as analyzing a media sample from an installation to assess its remaining capacity, in-place gas monitoring or simply experience from other installations to estimate service life.

\section{Protective Impacts}

Gas phase air cleaning can reduce the exposure to chemical contaminants, with the impact dependent on the removal efficiency and the relative locations of the source, air cleaning system and occupants as discussed for particle filtration. Also as in the case of particle filtration, gas phase air cleaning systems must be properly installed and maintained to achieve the intended performance.

The discussion of potential protective impacts in the previous section on particle filtration is also relevant here. The major difference is that the pre-retrofit removal efficiency is generally zero for gaseous contaminants and the post-retrofit efficiency is a function of the system employed (specifically the sorbent media and its mass) and the specific contaminant being considered. Depending on the media, contaminant, system design, and time and conditions since installation, the removal efficiency can vary from $0 \%$ to $100 \%$. The issues of filter bypass and building envelope infiltration are the same for gaseous air cleaning as they are for particulate filtration. Equation 1 describes the relative exposure for an upgrade in particle filtration, given an outdoor release, as a function of pre and post-retrofit removal efficiency and the infiltration-to-intake ratio. That expression still applies here, with $\varepsilon_{1}=0 \%$ and $\varepsilon_{2}$ set equal to the gaseous removal efficiency $\varepsilon$, as follows:

$$
\text { Relative exposure }=\frac{1-\varepsilon+\frac{Q_{I N F}}{Q_{I N T}}}{1+\frac{Q_{I N F}}{Q_{I N T}}}
$$

Table 24 shows the relative exposure for $100 \%$ and $95 \%$ efficient gaseous air cleaning. Again, envelope infiltration significantly degrades the impact of air cleaning.

\begin{tabular}{|c|c|c|}
\hline \multirow{2}{*}{ Removal efficiency } & \multicolumn{2}{|c|}{ Relative exposure (\%) } \\
\cline { 2 - 3 } & No infiltration & Infiltration = Intake \\
\hline $\mathbf{1 0 0} \%$ & 0.0 & 50.0 \\
\hline $\mathbf{9 5} \%$ & 5.0 & 52.5 \\
\hline
\end{tabular}

Table 24 Impact of gaseous air cleaning on exposure to outdoor release

When the contaminant is released within the building, the location of that release relative to the occupants and the air cleaner becomes critical. If the occupants are very close to the release, air 
cleaning of the recirculation air may have little or no impact on exposure. If the release is located such that the contaminant is drawn back via the return system to the air cleaning system before being distributed to the rest of the building, then air cleaning will be more effective. However, occupants in the immediate vicinity of the release may still be seriously exposed to the release.

\section{$\underline{\text { Costs }}$}

The cost of gas phase air cleaning includes the first and operating costs listed below. Specific examples of both are highlighted in the case study as described in Section 3 and Appendix C.

First costs include the following:

Air cleaning system

Additional space for system (in some buildings, there may be costs associated with floor space based on the loss of rentable space)

Design work (system modifications are generally required for gas phase air cleaning)

Modifications of air handling system fans, motors, electrical

Operating costs include the following:

Media replacement

Increased electrical consumption (associated with increased pressure drop)

In general, gaseous air cleaning systems are associated with a more significant pressure drop than particle filtration devices. These larger pressure drops may in turn may require significant system modifications, including replacement of fans and motors as well as associated electrical upgrades. As was the case for enhanced particle filtration, gas phase air cleaning also has the potential for improving indoor air quality, which may increase occupant productivity.

\section{Knowledge gaps}

Test standards and associated rating systems are the primary need in the application of gas phase air cleaning. As noted above, an ASHRAE committee is working on a method of test for media, to be followed by a full-scale test method. Additional information is also need to better predict and determine media replacement schedules as a function of system design parameters and exposure history of the media.

\section{SUMMARY}

Gas phase air cleaning in outdoor air intakes can reduce exposure to outdoor releases of gaseous contaminants based on the removal efficiency for the particular agent of concern. As seen in the simulations (Section 2) and Table 24, air cleaning can reduce exposure on the order of one minus the filter efficiency given contaminant entry through the intake alone. Envelope infiltration can significantly decrease the effectiveness, with the degradation dependent on the ratio of the infiltration rate to the intake.

Due to the pressure drop and filter depth associated with current gas phase technology, fan coil units, small rooftop units and other unitary systems are generally not compatible with this retrofit technology. Larger systems are generally more easily adaptable to gaseous air cleaning, but modifications may still be required. When designing a gas phase air cleaning installation, it is important to consider the interactions with other system components. For example, locating particle filters upstream of the air cleaning system will protect gas phase sorbent media from being "fouled" by particulate matter. In addition, many adsorption systems are negatively impacted by humidity; therefore it is often preferable that cooling coils be located downstream from the air cleaning system. 
As was mentioned for particle filtration, gas phase air cleaning has the advantage that it is always working, as opposed to strategies that rely on operator-based response such as system shutdown. However, it is important to remember that a gas phase air cleaning system will generally achieve different levels of effectiveness for different contaminants.

\subsubsection{Ultraviolet Germicidal Irradiation (UVGI)}

$\underline{\text { Objective }}$

To kill or otherwise deactivate biological agents through the use of ultraviolet irradiation of the airstream passing through the device.

\section{$\underline{\text { Description }}$}

UVGI systems have been used for many years to kill airborne infectious agents (viruses, bacteria, and bacterial and fungal spores) in healthcare facilities and other venues, with many applications focused on controlling the transmission of tuberculosis. These devices use ultraviolet irradiation in the $250 \mathrm{~nm}$ to $260 \mathrm{~nm}$ wavelength range (the so-called " $\mathrm{C}$ " band of the UV spectrum, sometimes referred to as UVC) and are either installed in the upper portions of a room with shielding to protect the occupants or in ductwork. The use of these devices in healthcare facilities has been described previously and application guidelines have been published by the Centers for Disease Control and Prevention (CDC 1994, 1999a and 1999b) More recently UVGI has been advocated for more general application as an indoor air quality control measure to keep ventilation system components, particularly cooling coils, clean by reducing microbial growth in air handling units (Dillard 2004). UVGI is also being proposed for protecting buildings against bioagents in the event of an intentional release (Kowalski and Bahnfleth 2003).

Available Performance Information

The effectiveness of these devices is typically expressed in terms of deactivation rate, which is primarily a function of device geometry, intensity of the light source, microbial resistance of the bioagent of interest, and residence time of the agent in the field of irradiation. Inactivation or "kill" rates can be predicted with a fair level of reliability based on these parameters (VanOsdell and Foarde 2002). However, there is no standard test method for determining the effectiveness of these devices and they are not generally supplied with the performance data to determine kill rates. Kowalski (2003) has proposed a UVGI Rating Value (URV) from 8-15 that corresponds to an average light intensity expressed in units of $\mathrm{mW} / \mathrm{cm}^{2}$. Based on the exposure time and the susceptibility of a particular organism, the URV value can then be converted to a kill rate for that organism. However, the URV concept has not yet been promulgated in an industry standard, nor has any other rating system of effectiveness. At this point, UVGI systems are described primarily in terms of the lamp specifications including the light intensity expressed in $\mu \mathrm{W} / \mathrm{m}^{2}$. Efforts are currently underway by the International Ultraviolet Association (www.iuva.org) to develop standards to assess the effectiveness of UVGI devices and systems, as well as installation guidelines. In addition, ASHRAE Task Group TG2.UVAS Ultraviolet Air and Surface Disinfection is another source of information including a future ASHRAE Handbook chapter, potential standards and several planned research projects. Also, a number of devices have been tested as part of the U.S. EPA Technology Testing and Evaluation Program, and reports of this testing are available at http://www.epa.gov/nhsrc/. 


\section{Protective Impacts}

The protection provided by UVGI against bioagents is analogous to that provided by any other filtration system, i.e., dependent on the deactivation efficiency for the agent or agents of concern. However, as noted above, efficiency rating systems have not yet been developed. Until they are, it is difficult to assess the degree of protection offered. Kowalski (2003) discusses kill rates as a function of exposure time and light intensity for a number of bioagents and has proposed the URV referred to above. If this concept becomes accepted by the industry and is used to rate devices and installations, it will provide a needed means of comparing products and systems.

Even without a rating system, the impact depends on the airflow through the device, the quality of maintenance, and the device location relative to the source and the building occupants. Lamp output can also degrade over time and is dependent on lamp temperature, therefore both effects need to be considered in designing systems and planning maintenance. Kowalski (2003) and others suggest combining UVGI with particle filtration, since the latter is effective at removing larger microbes such as spores that tend to be more resistant to UVGI.

\section{$\underline{\text { Costs }}$}

These devices consume electrical energy and require maintenance to keep them operating effectively. They are associated with a fairly low pressure drop, which reduces the impacts on fan power and the need to reconfigure ventilation systems. Like most building retrofits, their cost is a combination of first and operating costs.

First costs include the following:

UV lamps, fixtures and associated electrical components

Design work (in cases where system modifications are required)

Reconfiguration of ductwork (where required)

Operating costs include the following:

Electrical energy consumed by lamps

Lamp replacement

As noted for enhanced particle filtration, UVGI has the potential for improving indoor air quality, which has been associated with increased occupant productivity (Fisk and Rosenfeld, 1997). In particular, UVGI can help control bioaerosols in buildings, which can also decrease infectious disease transmission, healthcare costs and sick leave. The use of UVGI in the vicinity of cooling coils has the potential additional benefit of improving heat transfer and more efficient equipment operation. All of these potential benefits can be difficult to quantify, but nevertheless they could be quite important.

\section{$\underline{\text { Knowledge gaps }}$}

The most important needs in the area of UVGI are industry standards to rate devices and installations, as well as guidance for installation and maintenance. As noted above, efforts are underway to meet these needs. Field evaluation of installed systems would also be helpful to better understand maintenance requirements, energy consumption and other parameters.

\section{SUMMARY}

The use of UVGI in ventilation systems can likely reduce exposure to bioagents, but until a rating system is developed and employed by the industry, it will be challenging to design and specify these systems. In the interim, there is experience with UVGI application in healthcare facilities and elsewhere that should be useful in other applications. 


\subsubsection{Photocatalytic Oxidation Air Cleaning (PCO)}

\section{Objective}

To remove organic chemicals, including bioaerosols, from airstreams by flowing the air past a photocatalyst irradiated by UV light.

Description

PCO is an air cleaning approach in which titanium dioxide $\left(\mathrm{TiO}_{2}\right)$ acts as a photocatalyst when irradiated by UV light, removing organic chemicals including both chemical and biological agents. If the photocatalytic reaction is $100 \%$ complete, the byproducts include only water and carbon dioxide, but complete conversion is difficult to achieve in practice. While PCO is not widely used for air cleaning in buildings and there are only a small number of products on the market, it is viewed as a potentially promising technology. PCO devices are commercially available, primarily in stand-alone recirculating units. PCO devices consist of a UV light source configured such that the airflow passing through the device is exposed to both the light and surfaces coated with the catalyst. The photocatalytic reaction oxidizes organic compounds in chemical agents, and presumably in biological agents as well. The effectiveness of cleaners based on UV-PCO technology depends on the photoactivity of the catalyst, the UV light intensity on the catalyst surface, contact time between the contaminated airstream and catalyst surface, the properties of organic chemicals and biological agents, and environmental conditions such as relative humidity and temperature. There are concerns that potentially harmful chemical byproducts may form during operation due to incomplete reaction of the contaminants and that the catalyst can become "poisoned" by exposure to various airborne substances and thereby rendered ineffective. Nevertheless, PCO air cleaners may be expected to have low maintenance requirements and long service life due to the continuous regeneration of the catalyst during operation.

\section{Available Performance Information}

While PCO devices are commercially available, there are no test methods or rating systems for gas or biological removal and the performance data that are available are limited primarily to the results of laboratory research studies (Blake 1994 and 1997, Jacoby et al. 1996, Tompkins and Anderson 2003). However, given a removal efficiency for a particular contaminant, the exposure reductions for a PCO device are analogous to those for other filtration or air cleaning systems.

Specifications for stand-alone devices vary typically include the rated airflow capacity, UV wavelength of the light source, expected life of the light source, efficiency of any particle filtration included in the device, and power consumption. However, this information cannot be used to predict contaminant removal efficiency.

\section{Protective Impacts}

The protection provided by PCO is analogous to that provided by other filtration systems, but without removal efficiencies for particular contaminants, the exposure reduction offered by PCO systems cannot be determined.

\section{$\underline{\text { Costs }}$}

PCO devices consume electrical energy and require maintenance to keep them operating effectively. These devices generally have low pressure drops compared to particle filters and sorption based gaseous air cleaning, which would reduce their impact on fan power when 
installed in a duct system. However, questions exist as to the useful life of the catalysts in practice and the production of undesirable byproducts associated with incomplete photochemical reactions.

Similar to UVGI, the cost of PCO is a combination of first costs and operating costs.

First costs include the following:

PCO components (light sources, catalyst, associated housings, fans for stand-alone units)

Design work (in cases where system modifications are required)

Reconfiguration of ductwork (where required)

Operating costs include the following:

Electrical energy consumed by lamps

Lamp and catalyst replacement

As discussed for the other filtration and air cleaning retrofits, PCO has the potential for improving indoor air quality, which has the potential for increased occupant productivity and reduced healthcare costs. However, PCO technology and application is not yet sufficiently developed and demonstrated to evaluate the magnitude of such benefits.

Knowledge gaps

Similar to UVGI, standards are needed to rate PCO systems, as well as guidance for installation and maintenance. However, unlike UVGI, the technology is still under development and no standardization efforts are yet underway to meet these needs.

\section{SUMMARY}

Photocatalytic oxidation appears to have the potential to reduce exposure to chemical and biological contaminants, but until rating standards are developed, it will be challenging to design and specify these systems. In addition, more experience with the application of PCO in buildings will be needed to understand the factors impacting installed performance.

\section{$\underline{\text { 4.2.5 Work-area Treatment }}$}

\section{Objective}

To capture contaminants at susceptible work areas, e.g. in mail rooms, before they have an opportunity to spread to the rest of the building.

\section{Description}

A variety of devices are available for capturing and removing particulates from work areas, e.g., mail opening stations, which are generally considered relative to the removal of bioaerosols.

These devices are essentially air capture hoods combined with high-efficiency particle filtration systems. Some of these devices also incorporate anti-microbial elements, gaseous air cleaning components and UVGI. Some exhaust to the outdoors while others recirculate the filtered air back into the occupied space. These devices are similar in many ways to biosafety cabinets that have long been employed in research and medical laboratories to contain potentially hazardous substances, and which have well-established application and rating protocols. Biosafety cabinets could conceivably be used for mail opening, but it may be hard to justify the first cost and the training required in all but the highest risk situations. In such cases, a separate mail opening facility is often used instead. 
Available Performance Information

The performance of these devices can be expressed in terms of the airflow rate and contaminant removal efficiency, which for particle filters is fairly straightforward as noted earlier. Gaseous air cleaning or UVGI capabilities cannot be similarity rated due to the lack of standard test methods, though can be tested to meet the needs of a particular application. Another important parameter is the contaminant capture effectiveness, but this parameter is not generally covered in product specifications. Test methods for the capture efficiency of laboratory fume hoods exist (ASHRAE 1995) and could be applied to these devices as well, but the product literature does not make reference to capture efficiency or fume hood testing.

\section{Protective Impacts}

The protection provided by a work area treatment device will depend on the capture efficiency and the filtration/air cleaning removal efficiency for the agent of concern. With good capture and filtration, such a device should be able to capture essentially all of the contaminant. The exposure from any contaminant that is not captured will impact the personnel in the work area based on the airflow patterns in the room, and then the rest of the building occupants based on the quantity that isn't captured and the interzone airflows within the building. It is good practice to maintain mail rooms and other such spaces at a lower pressure than the rest of the building, which should minimize transport to the rest of the building and exposure of other building occupants. Note that typical locations of mail rooms on the lower levels of buildings make them particularly susceptible to stack-driven airflows upward within the building.

\section{$\underline{\text { Costs }}$}

The costs of these work area treatment devices include the first cost of the device, the electrical energy consumed by the fans and the replacement costs of the filter elements. In the event of a contaminated piece of mail entering a building, these devices can prevent contamination of the building, and thereby save a great deal of money associated with building decontamination.

\section{Knowledge gaps}

It would be helpful if these devices were rated for capture efficiency of gases and particles, so that devices could be compared. Also, while particulate removal efficiency can be described, the performance of gaseous air cleaning and UVGI cannot be quantified for these devices.

\section{$\underline{\text { SUMMARY }}$}

Work area treatment devices offer the possibility of capturing contaminants released by a piece of mail or other package entering a building. If effective, they can essentially eliminate occupant exposure. Even if not $100 \%$ effective at capturing the contaminant release, in combination with depressurization of the impacted space, they can limit exposure of other building occupants. 


\subsection{Retrofit Approaches}

This section covers retrofit approaches to increase building protection against airborne chembio releases. As described earlier, these approaches do not consist of a single technology but rather involve a change to a building or its systems or an operational strategy intended to reduce exposure. As in the previous section, the guidance includes a brief description of the approach, a discussion of relevant performance data and the protective impact that can be expected from its application, the associated costs, and current information gaps. As in the case of the retrofit technologies, it is expected that more information on these approaches will be produced in the future and that new ones may become available. Therefore, it is important that building designers, owners, operators and others responsible for building protection stay abreast of current developments.

\subsubsection{System Recommissioning}

\section{Objective}

To improve building and system performance by evaluating existing systems relative to their design and current building conditions, and then making modifications to equipment and maintenance procedures deemed necessary by the evaluation.

\section{Description}

Relying on a building ventilation system to increase building protection from a chembio release requires that the system design be understood and that the system be operated and maintained as intended. Ventilation system recommissioning is a process by which a system's operation is evaluated and then brought into line with its design. If the building use has changed and the design needs updating, then recommissioning would also involve design and system modifications to meet the current building conditions. Depending on the system, recommissioning can involve a number of items including the following: airflow testing and balancing; calibration of temperature, humidity and other sensors used to control system operation; checking dampers for proper operation; reviewing system operating schedules; and confirming system capacity relative to current loads. There are a number of state utility programs and private firms that offer recommissioning services, and the role of commissioning is identified in the EPA Energy Star program (EPA 2004). ASHRAE (1996 and 2005) also has two guidelines that address building and system commissioning.

\section{Available Performance Information}

While there have been a number of case studies in which building ventilation systems were recommissioned, each situation is unique in terms of the system, the degree to which the system deviates from design, and the magnitude and nature of the resulting modifications. Note that most of these efforts have been motivated by energy efficiency goals rather than building security, but the process is not very different. While each situation is different, some of the key performance parameters are listed below:

System outdoor air intake rate

Modulation of outdoor air as a function of outdoor weather (including economizer operation)

System supply airflow rate relative to return airflow rate (relates to building pressurization)

Indoor-outdoor pressure differences across building envelope (not always part of design specification, but important in chembio applications) 
Airflow rates of exhaust fans (e.g. toilet, kitchen)

System operation schedule

Interzone pressures between selected spaces and occupied portions of building (e.g. lobby, loading dock, mail room, underground garage, bathrooms)

There is no comprehensive database of measured versus design values of the above parameters based on recommissioning or other field evaluation efforts. The EPA BASE study did include supply airflow and outdoor air intake measurements, which were compared to design values when design documentation existed (Persily and Gorfain 2004). These comparisons did show significant deviations from design values in many cases, which presumably would have been eliminated through recommissioning efforts.

Envelope tightness measurements, following by sealing retrofits, can also be considered as part of recommissioning, but these are covered separately in the following section.

\section{Protective Impacts}

The benefits of recommissioning in terms of building protection depend on the extent of the deviation of performance relative to design. The simulations presented in Section 2 included several relevant cases, including no outdoor air intake and an intake rate about half of design. In these cases, the exposures to an indoor release were significantly higher than the baseline condition of design outdoor air intake. Other deviations from design that could increase exposure are airflow imbalances that depressurize the building, thereby increasing rate of entry of an outdoor contaminant via infiltration.

\section{$\underline{\text { Costs }}$}

The costs of recommissioning depend on the size and complexity of the building and its ventilation systems. No rules of thumb exist that allow an estimate based on floor area. Similarly the beneficial impacts of recommissioning in terms of energy efficiency and improved indoor air quality are also building and system specific, but nevertheless can be significant. A recent report evaluated a number of commissioning case studies in terms of costs, savings and payback times in new and existing buildings (Mills et al. 2004). While the studies in the report cover all aspects of commissioning, the medians results were as follows: cost of $\$ 2.91 / \mathrm{m}^{2}\left(\$ 0.27 / \mathrm{ft}^{2}\right)$, whole building energy savings of $15 \%$ and payback time of 0.7 years.

\section{Knowledge gaps}

While there is general acknowledgement that recommissioning is a valuable and effective retrofit, there is not much documentation of its effectiveness in terms of system performance or economics. Case studies of recommissioning \would be valuable in providing quantitative evidence of its value. In terms of building protection, it would be very helpful if these studies considered inside-outside and interzone pressure differences as well as building infiltration rates in the pre and post evaluations.

\section{SUMMARY}

Given the significant deviations between ventilation system design and performance that have been shown to exist, recommissioning is likely to have value in many buildings. The specific problems that will be resolved and the extent of the improvements will always depend on the building in question. Most importantly, if the ventilation system is going to be relied on for building protection, a recommissioning effort is essentially required for the system to provide the intended protection. 


\subsubsection{Envelope Tightening}

Objective

To increase building envelope airtightness, thereby reducing the rate of outdoor contaminant entry associated with air infiltration.

\section{Description}

Contaminants that are released outside a building enter the interior through a combination of intentional outdoor air intake through the ventilation system and unintentional air infiltration through openings in the building envelope. The latter mechanism is often more significant than generally assumed given typical levels of building leakage, potentially resulting in significant contaminant quantities entering buildings via envelope infiltration. The infiltration rate of a building is determined by the airtightness of the exterior envelope and the pressure differences acting across the envelope. These pressure differences are determined by the wind speed and direction in combination with the exposure of the building to the wind environment, the indooroutdoor air temperature difference, and imbalances between the ventilation systems airflows into and out of a building or space. The dynamics of envelope leakage and infiltration are described in ASHRAE (2005). This retrofit approach involves increasing the level of building envelope airtightness by sealing leaks in the envelope, thereby reducing air infiltration and contaminant entry given the pressure differences imposed on the envelope.

\section{Available Performance Information}

The impact of this retrofit on exposure will be a function of the pre- and post-retrofit airtightness levels, the corresponding infiltration rates, and the relative fractions of outdoor air entry via intentional intake (generally with some particle filtration) and infiltration (unfiltered). The connection between envelope airtightness and exposure can be complex and is always situation specific. Whole building envelope airtightness is measured through fan pressurization testing in which a fan is used to induce a specific indoor-outdoor pressure difference across the building envelope and the airflow rate required to maintain that pressure difference is measured.

Generally, a series of pressure differences in the range of $10 \mathrm{~Pa}$ to $75 \mathrm{~Pa}$ is induced in such a test, and the corresponding airflow rates are measured. The test procedure has been standardized for many years, and employs either a fan brought to the building for the test or uses the building air handling systems to induce the test pressures (ASTM 2003, CGSB 1996). The results are reported as the airflow rate required to induce a certain reference pressure (e.g., $50 \mathrm{~Pa}$ or $75 \mathrm{~Pa}$ ), typically normalized by building volume, floor area or envelope surface area. These airflow rates are often converted to an "effective leakage area," which is the area of an orifice that would result in the same airflow as that measured through the building envelope at a reference pressure. 
Envelope airtightness has been measured in a relatively small number of commercial buildings. Figure 16 is plot of commercial building airtightness data as a function of year of construction, where airtightness is expressed as the effective leakage area (ELA) in $\mathrm{cm}^{2}$ at a reference pressure of $4 \mathrm{~Pa}$ divided by the above-grade envelope surface area in $\mathrm{m}^{2}$ (Emmerich and Persily 2005). The mean air leakage value for the roughly 150 buildings in the figure is $4.3 \mathrm{~cm}^{2} / \mathrm{m}^{2}$ $\left(0.06 \mathrm{in}^{2} / \mathrm{ft}^{2}\right)$. For reference, a typical U.S. home has a leakage value on the order of about $3 \mathrm{~cm}^{2} / \mathrm{m}^{2}\left(0.04 \mathrm{in}^{2} / \mathrm{ft}^{2}\right)$, while tight U.S. and tight Swedish homes correspond to roughly $1 \mathrm{~cm}^{2} / \mathrm{m}^{2}\left(0.01 \mathrm{in}^{2} / \mathrm{ft}^{2}\right)$ and $0.3 \mathrm{~cm}^{2} / \mathrm{m}^{2}\left(0.004 \mathrm{in}^{2} / \mathrm{ft}^{2}\right)$ respectively. The available data reveal that commercial buildings are not particularly tight relative to homes on a surface area basis, and reveal no relationship between year of construction and air leakage, dispelling the myth that new buildings are "airtight."

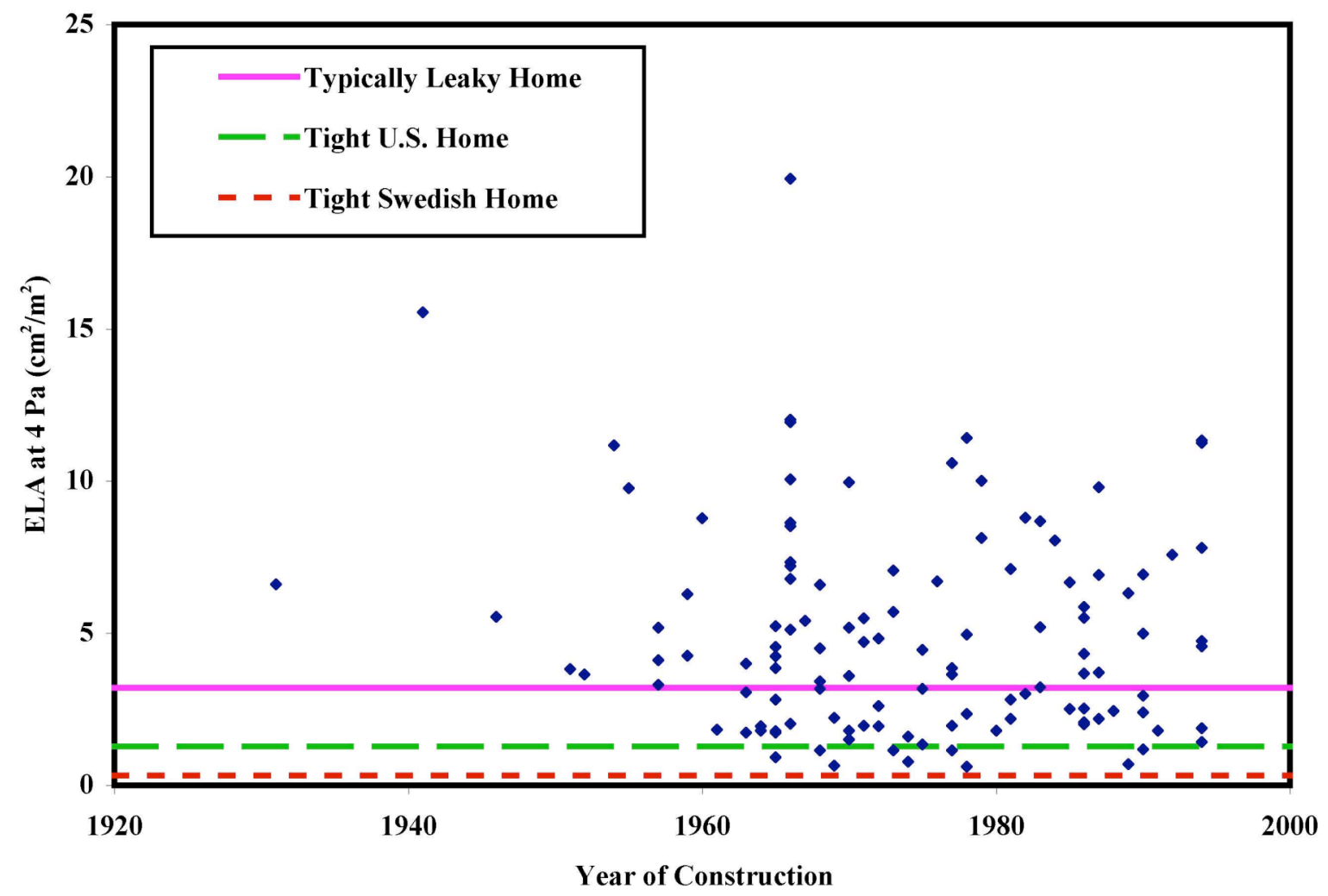

Figure 16 U.S. commercial building airtightness data

The determination of envelope infiltration rates from envelope airtightness values requires consideration of weather-induced pressure differences and the impacts of ventilation system airflows, and is best done using multizone airflow analysis methods such as those embodied in the CONTAM program (Walton and Dols 2005). While simpler relationships between envelope airtightness and infiltration have been developed for low-rise residential buildings (ASHRAE 2005), they are not generally applicable to commercial buildings of any complexity.

Nevertheless, all else being equal, a tighter building will have a lower infiltration rate, and a lower infiltration rate will result in less contaminant entry of an outdoor source.

The impacts of an envelope tightening retrofit are characterized by the change in envelope airtightness. There have only been limited studies reporting before and after envelope airtightness data (Shaw and Reardon 1995, Zhang et al. 1995). While limited, these studies and 
other experience show that reductions in whole building air leakage as large as $50 \%$ can be achieved, not all sealing approaches will necessarily be this effective. Commercial building leakage measurements have shown that windows and doors generally account for a small fraction of the total, in the range of $10 \%$ to $20 \%$ (Persily and Grot 1986). More often, it appears that the dominant leakage sites are at interfaces between different wall sections, wall-floor connections, corners and the interface between the roof and walls. Depending on the wall construction, it can sometimes be quite difficult to access some of these leakage sites for repair and additional experience and guidance is needed to guide retrofit efforts.

\section{Protective Impacts}

Envelope tightening can reduce the exposure to outdoor contaminant releases, with the amount of reduction depending on the change in airtightness, the relative magnitudes of the infiltration and intake rates, and the level of filtration of the intake air. As noted above, a tighter building has a lower infiltration rate and therefore less outdoor contaminant entering a building. At the same time, the lower building air change rate will cause the contaminant that does enter the building to remain there longer, which will increase exposure. Ignoring any impact of filtration, these two effects balance each other out and the exposure over an extended period of time is independent of air change rate. This effect is depicted in figure 17, which shows the indoor concentration at three air change rates corresponding to a short-term increase in the outdoor concentration. While it may not be obvious from this graph, the areas of the indoor concentration curves, i.e., the integrated exposure over time, are identical. Of course, if the occupants leave the building soon after the release or the building is flushed with higher levels of outdoor air intake, then the lower rates will indeed result in less occupant exposure.

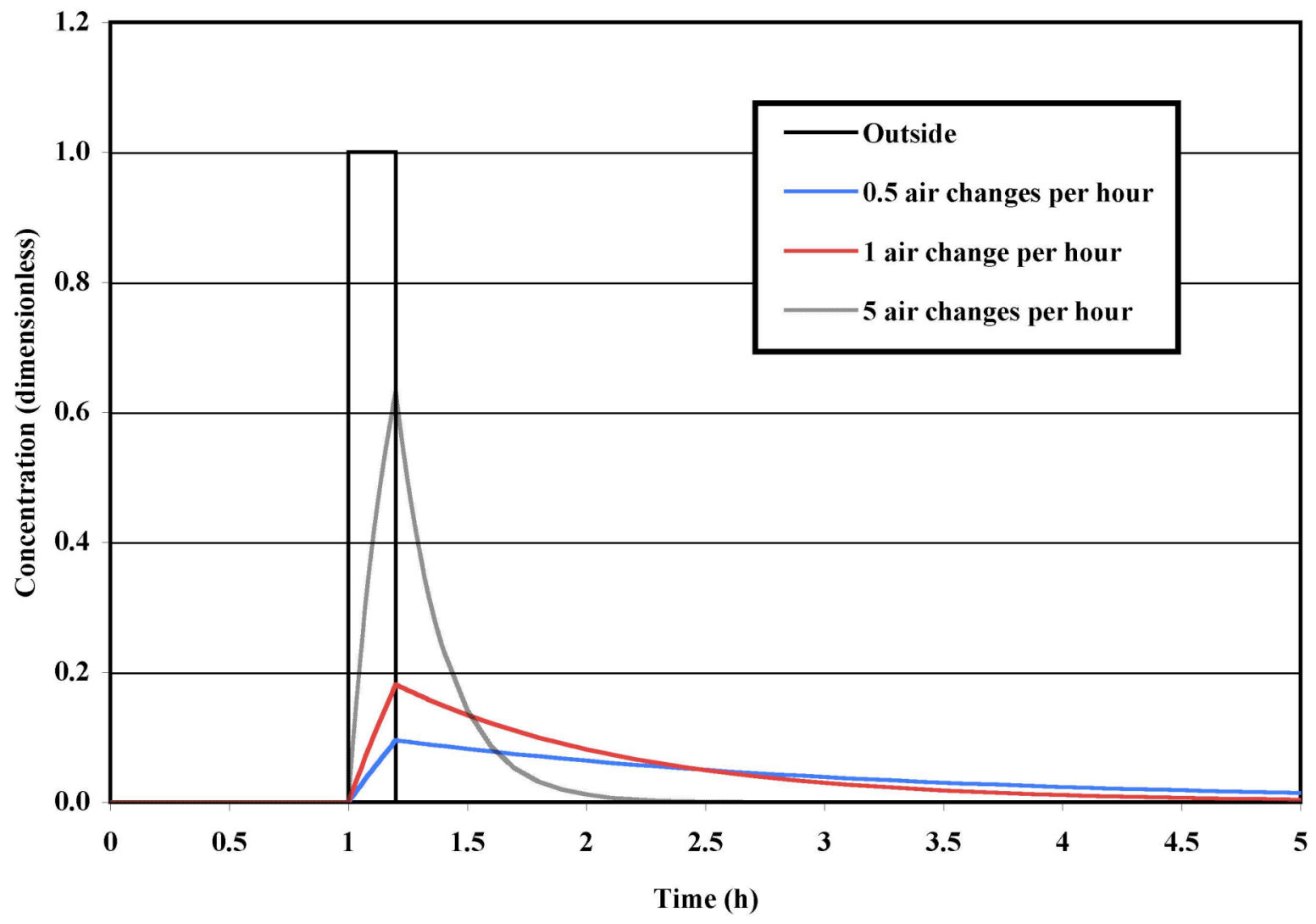

Figure 17 Indoor concentration for different air change rates 
Therefore, tightening alone will not reduce long-term exposure to an outdoor contaminant unless some action is taken to evacuate the occupants or flush the building after the contaminant episode has passed. However, if the outdoor air intake is filtered, then reducing infiltration will reduce exposure. The effects of filtration are generally most relevant to particulate contaminants, since gaseous air cleaning is less common, but the dependency is the same. Equation 4 compares the exposure for two different levels of filtration for a given ratio of infiltration to intake, and can be applied to this retrofit by considering the same level of filtration and two different values of the infiltration to intake ratio.

$$
\text { Relative exposure }=\frac{\left(1-\varepsilon+\frac{Q_{I N F-\text { post }}}{Q_{I N T}}\right) / Q_{T O T A L-p o s t}}{\left(1-\varepsilon+\frac{Q_{I N F-p r e}}{Q_{I N T}}\right) / Q_{T O T A L-p r e}}
$$

where $\varepsilon$ is the filter efficiency of the outdoor air intake, $\mathrm{Q}_{\text {INF-post }}$ is the envelope infiltration rate after tightening, $\mathrm{Q}_{\text {INF-pre }}$ is the infiltration rate before tightening, $\mathrm{Q}_{\text {TOTAL-post }}$ is the total air change rate (intake plus infiltration) after tightening, and $\mathrm{Q}_{\text {TOTAL-pre }}$ is the total air change rate before. Based on this expression, one can calculate the relative exposure after tightening as a function of filter efficiency, as is done in Table 25 assuming an outdoor air intake rate of $1 \mathrm{~h}^{-1}$ and a preretrofit infiltration rate of $1 \mathrm{~h}^{-1}$. The change in exposure is calculated for a $50 \%$ reduction in infiltration and for a more dramatic $90 \%$ reduction, corresponding to post-retrofit infiltration rates of $0.5 \mathrm{~h}^{-1}$ and $0.1 \mathrm{~h}^{-1}$, respectively. The table shows that as the filter efficiency increases, the exposure decreases proportionally as more of the air entering the building passes through the filter. However, the reduction is much smaller for the $50 \%$ infiltration reduction than for the 90 $\%$ reduction, showing that an envelope tightening retrofit must be significant to impact exposure. The extreme case of no filtration at all results in no exposure reduction as expected based on the preceding discussion. These estimates assume no other action such as shelter-in-place, evacuation or outdoor air purging.

\begin{tabular}{|c|c|c|}
\hline \multirow{2}{*}{ MERV level } & \multicolumn{2}{|c|}{ Relative exposure (\%) } \\
\cline { 2 - 3 } & $50 \%$ infiltration reduction & $90 \%$ infiltration reduction \\
\hline $\mathbf{6}$ & 97 & 93 \\
\hline $\mathbf{8}$ & 92 & 80 \\
\hline $\mathbf{1 1}$ & 87 & 69 \\
\hline $\mathbf{1 3}$ & 73 & 34 \\
\hline $\mathbf{1 6}$ & 67 & 19 \\
\hline No filter & 100 & 100 \\
\hline
\end{tabular}

Relative exposure based on removal efficiency at roughly $1 \mu \mathrm{m}$ as follows: MERV $6=16.4 \%$, MERV $8=40 \%$, MERV $11=55.5 \%$, MERV $13=89.6 \%$ and MERV $16=99.5 \%$.

Table 25 Impact of reduced infiltration on exposure to outdoor release 


\section{$\underline{\text { Costs }}$}

The costs of envelope tightening as a retrofit have not been well-established. The case study described in this report includes some estimates, which tend to focus on window and door sealing, but an effective envelope tightening retrofit is likely to involve the sealing of more leakage sites.

First costs will include the following:

Pre-sealing inspection and testing to determine leakage locations

Sealing materials

Labor associated with the sealing efforts

Construction staging such as scaffolding to access exterior leakage sites

Envelope tightening is not associated with any operating costs, but it will result in lower heating and cooling costs. The magnitude of this reduction is in general a function of climate, pre and post retrofit tightness, equipment type and system operating schedule. A study of the energy impacts of infiltration in U.S. office buildings showed that infiltration accounted for about onethird of space heating loads on average, while the fraction of cooling loads was about one-tenth of that (Emmerich et al. 2005). The reduction in these loads due to tightening was estimated to be about $25 \%$ for heating and $15 \%$ for cooling (Emmerich and Persily 1998), but again the reduction achieved will depend on the individual building. However, the potential for energy reduction and, therefore, cost savings by envelope tightening is very real.

In addition, envelope tightening should also improve indoor air quality by decreasing contaminant entry via unfiltered infiltration, which has the potential for productivity increases as noted earlier for improved filtration. Increases in productivity are of course difficult to quantify, but are a potentially significant issue in areas with poor outdoor air quality. Envelope tightening can also improve moisture control in buildings, decreasing the likelihood of condensation within exterior walls and other surfaces and subsequent microbial growth.

\section{Knowledge gaps}

There is a need for more studies of the increases in airtightness achievable through envelope sealing as a function of sealing method and building construction, as well as the costs associated with these efforts. Presumably more envelope tightening efforts will occur in order to improve energy efficiency of existing building, and it is important to collect these data in conjunction with such efforts. Additional information on the energy impacts of tightening would also be useful to better assess and predict the cost effectiveness of these sealing efforts.

\section{SUMMARY}

Enveloping tightening can reduce the entry of outdoor contaminants. However, exposure reduction requires that the intake air be filtered or that the building be evacuated or purged with outdoor air after the outdoor contaminant episode has ended. In general, the exposure reduction will be larger for more effective tightening and better filtration of the outdoor air intake. However, tightening alone is not likely to reduce exposure by more than $50 \%$ unless the intake air filtration is on the order of $90 \%$ or better and the post-tightening infiltration rate is reduced by at least one-half. 


\subsubsection{Building Pressurization}

\section{Objective}

To eliminate or significantly reduce envelope infiltration and the associated contaminant entry by bringing in sufficient amounts of filtered, outdoor air to maintain the building at a higher pressure than outdoors. In this discussion, the pressurization is intended to occur whenever the system is operating rather than in response to an event.

\section{Description}

Building pressurization involves protecting a building against outdoor contaminant releases through the overpressurization of the building interior relative to outdoors and the removal of the outdoor agent from the intake air via filtration and/or air cleaning. To be effective, the amount of air intake must be sufficient to overcome negative pressures that are induced by weather and the operation of other systems, and the level of filtration must be sufficient to remove significant quantities of contaminant. As noted earlier, contaminants that are released outside a building enter the interior through a combination of intentional outdoor air intake through the ventilation system and unintentional air infiltration through openings in the building envelope. The latter mechanism is often more significant than generally assumed given typical levels of building leakage. Building pressurization is therefore intended to counter the latter mechanism by eliminating, or at least reducing, the inward pressure differences that drive infiltration.

Commercial buildings are generally designed with more outdoor air intake than exhaust in order to control infiltration. However, in reality, whether this design goal is achieved or not depends on many factors including the amount of outdoor air intake, its distribution, the magnitude of the pressures that induce infiltration, and the tightness of the building envelope. Very few buildings have actually been evaluated in terms of indoor-outdoor pressure differences, but given the magnitude of weather-driven pressures and the levels of building leakage, it is unlikely that this design goal is being realized in very many circumstances. Cummings et al. (1996a and 1996b) measured building pressures in a number of small commercial buildings in Florida and found many buildings under significant negative pressures relative to outdoors, due to combinations of duct leakage and poor control of system airflows.

\section{Available Performance Information}

The parameters relevant to building pressurization include the excess outdoor air intake (intake minus exhaust), building envelope leakage, building surface-to-volume ratio, and removal efficiency of the filtration and air cleaning systems for the relevant contaminants. Excess outdoor air intake is a ventilation system design parameter, but the values during operation are the relevant parameter. Typical design values for outdoor air intake as a fraction of supply airflow are on the order of $10 \%$ to $20 \%$ in office buildings (Persily and Gorfain 2004). This percentage is reduced somewhat when toilet and other exhaust flows are included. Given that commercial building supply airflow rates are on the order of $5 \mathrm{~L} / \mathrm{s}$ per $\mathrm{m}^{2}\left(1 \mathrm{cfm} / \mathrm{ft}^{2}\right)$ of floor area, typical excess outdoor air rates are roughly $0.5 \mathrm{~L} / \mathrm{s} \bullet \mathrm{m}^{2}\left(0.1 \mathrm{cfm} / \mathrm{ft}^{2}\right)$. Building envelope leakage values, discussed in the previous section, range from as low as $0.5 \mathrm{~cm}^{2}$ of leakage area per $\mathrm{m}^{2}$ of envelope area $\left(0.01 \mathrm{in}^{2} / \mathrm{ft}^{2}\right)$ to as high as $10 \mathrm{~cm}^{2} / \mathrm{m}^{2}\left(0.14 \mathrm{in}^{2} / \mathrm{ft}^{2}\right)$ and greater. Surface-to-volume ratios depend on building size and floor plan. It is more straightforward to instead consider the ratio of envelope surface area to floor area. For a collection of 25 representative U.S. office buildings (Emmerich and Persily 1998), the surface to floor area ratio ranged from 0.03 to 1.50 , with a mean of 0.44 . 
Based on surface to floor area ratio and building leakage, one can calculate the amount of outdoor air required to pressurize a building. Figure 18 presents the results of such a calculation assuming that there are no weather-driven pressures and no internal resistance to airflow within the building. The values in the figure are the airflow rates required to achieve a $5 \mathrm{~Pa}$ indooroutdoor pressure difference, and the lines correspond to different values for the area ratio. There is nothing significant about this particular pressure difference; it is simply used for illustrative purposes. These results indicate that in leaky buildings, especially those with higher area ratios (smaller buildings), relatively large quantities of outdoor air are required to achieve $5 \mathrm{~Pa}$ of pressurization. In the leakiest and smallest buildings, the quantities required are on the order of total design supply air capacities. Performing these calculations with weather-driven pressures would make the required airflows higher, by as much as an order of magnitude under windy and cold conditions. Therefore, it is unlikely that a leaky building can be pressurized at design minimum outdoor air intake airflows. More importantly, the amount of airflow required to pressurize a building needs to be based on its geometry, the weather conditions to which it is likely to be exposed, ventilation system design airflow rates, and building envelope airtightness. If the latter value has not been measured, than a high value should be used to determine a conservative estimate. In an existing building, these indoor-outdoor pressures can be measured under specific conditions of weather and outdoor air intake to determine whether the building is being pressurized. When making such measurements, it is important to measure at multiple points on the building façade, including different sides of the building and multiple elevations.

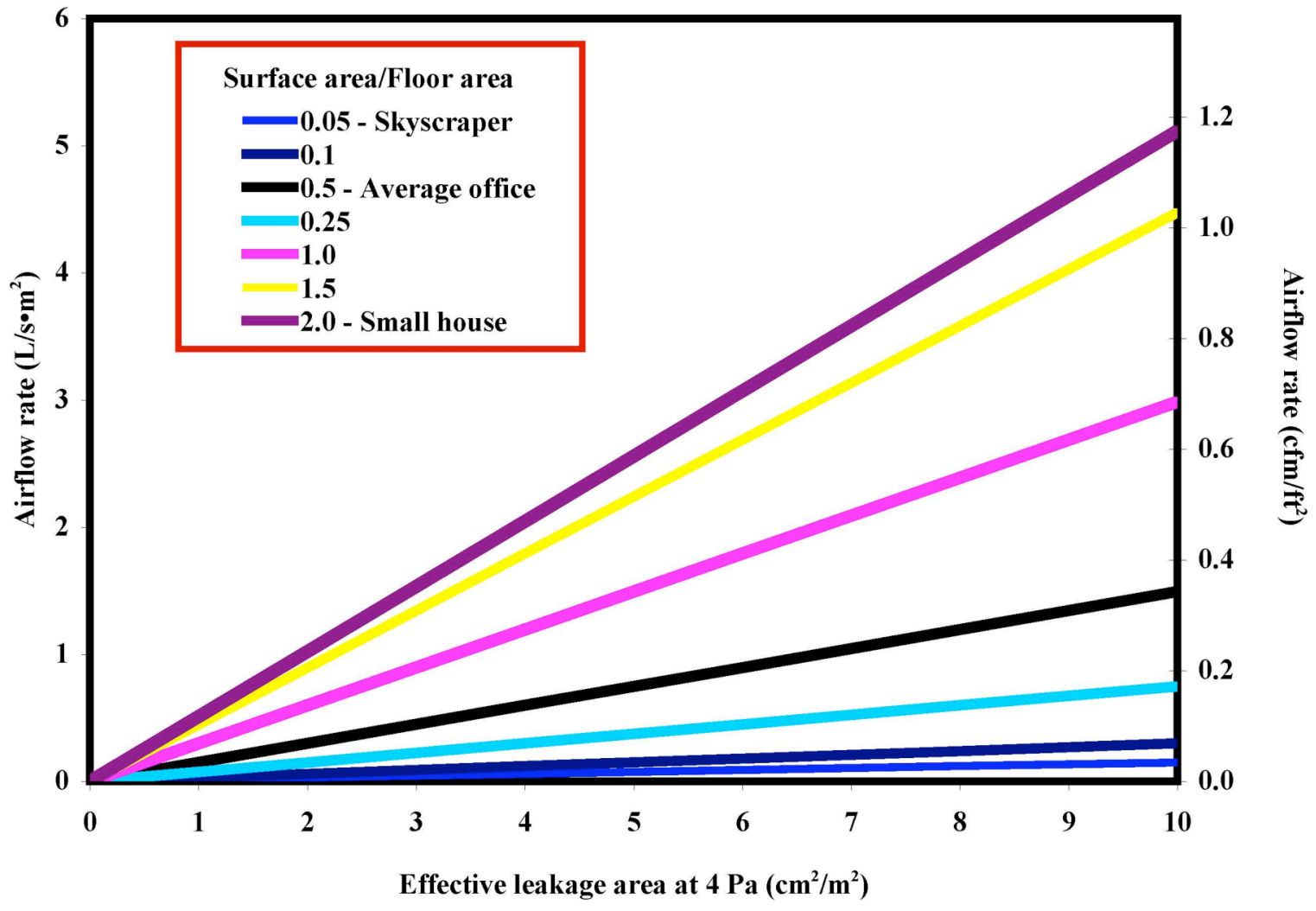

Figure 18 Airflow required for building pressurization to $5 \mathrm{~Pa}$ 
It should be noted that in some buildings, the ventilation system and controls might need to be modified to achieve the desired levels of pressurization

Protective Impacts

Building pressurization, when combined with high efficiency filtration and air cleaning, can be effective in protecting against outdoor contaminant releases. The analysis discussed in the previous section on envelope tightening can again be used to estimate the change in exposure. However, the post-retrofit intake rate $\mathrm{Q}_{\text {INT-post }}$ is higher than the pre-retrofit value $\mathrm{Q}_{\text {INT-post, }}$ and the relevant expression now becomes

$$
\text { Relative exposure }=\frac{\left(Q_{I N T-\text { post }}(1-\varepsilon)+Q_{I N F-\text { post }}\right) / Q_{\text {TOTAL-post }}}{\left(Q_{I N T-\text { pre }}(1-\varepsilon)+Q_{I N F-\text { pre }}\right) / Q_{\text {TOTAL-pre }}}
$$

The reduction is now a function of the new infiltration rate and the amount of intake air required to reduce it, as well as the filter efficiency $\varepsilon$. This equation is used to calculate the exposure reductions shown in Table 26 for three retrofit cases. In the first case, the outdoor air intake is increased by $50 \%$ and the infiltration rate is reduced by $90 \%$. In the second, the intake is increased by $75 \%$ and infiltration reduced by $95 \%$. And in the final case, intake is double and infiltration is eliminated. These particular values do not reflect any particular expectations of the infiltration reduction due to these increases in air intake but are simply employed to demonstrate the impacts of pressurization. The relative exposure is presented for several filter efficiencies, as well as for no filter at all. The latter case shows that pressurization has no impact if there is no filter, as expected. The other cases show the degree of protection from reducing infiltration, with greater reductions for lower infiltration rates and higher filter efficiencies. However, for the two lowest filter efficiencies, pressurization has a limited impact on exposure.

\begin{tabular}{|c|c|c|c|}
\hline \multirow{2}{*}{$\begin{array}{c}\text { Filtration } \\
\text { efficiency }\end{array}$} & \multicolumn{3}{|c|}{ Relative exposure (\%) } \\
\cline { 2 - 4 } & $\begin{array}{c}\text { 50\% intake increase; } \\
\text { infiltration 90 \% lower }\end{array}$ & $\begin{array}{c}75 \% \text { intake increase; } \\
\text { infiltration 95\% lower }\end{array}$ & $\begin{array}{c}100 \% \text { intake increase; } \\
\text { no infiltration }\end{array}$ \\
\hline $\mathbf{2 5 \%}$ & 87.5 & 86.5 & 85.7 \\
\hline $\mathbf{5 0} \%$ & 70.8 & 68.5 & 66.7 \\
\hline $\mathbf{9 5} \%$ & 20.8 & 14.6 & 9.5 \\
\hline $\mathbf{9 9 \%}$ & 14.2 & 7.4 & 2.0 \\
\hline $\mathbf{9 9 . 9} \%$ & 12.7 & 5.7 & 0.2 \\
\hline $\mathbf{1 0 0} \%$ & 12.5 & 5.6 & 0.0 \\
\hline No filter & 100.0 & 100.0 & 100.0 \\
\hline
\end{tabular}

Table 26 Example impacts of building pressurization on exposure to outdoor release

Before increasing outdoor air intake in an attempt to pressurize the building, it is critical to assess the current situation regarding building pressure relative to outdoors. If the building is already under positive pressure, i.e., the infiltration rate is already zero, then bringing in more outdoor air increases space conditioning loads and makes the filter "work harder" without any additional protective benefit. If the filtration is less then $100 \%$ efficient, then the extra outdoor air will actually result in more contaminant entering the building and an increase in exposure. 


\section{$\underline{\text { Costs }}$}

The costs of building pressurization arise primarily from the increased energy consumption associated with heating and cooling the additional outdoor air required to pressurize the building, which are a function of climate and outdoor air quantities. Since it takes less outdoor air to pressurize a building, these costs should serve as a motivation for envelope tightening.

There may also be some first costs associated with modifying the ventilation system and controls to bring in the extra amounts of outdoor air. In some cases, the system may require extra heating and cooling capacity, which would also add to the first costs. Finally, the cost and maintenance issues associated with filtration also apply to building pressurization.

Building pressurization has the potential for positive economic impacts due to indoor air quality and envelope durability improvements associated with reductions in moist outdoor air entering the building envelope.

\section{Knowledge gaps}

While building pressurization is a fairly straightforward concept, the key parameters are the air leakage value for the building in question and the weather conditions for the site. More measured airtightness data would make the design of building pressurization strategies and controls more reliable, but when considering a specific building it is preferable to measure the envelope airtightness of that building.

\section{SUMMARY}

Building pressurization combined with effective filtration can reduce exposure to outdoor releases. The reductions will be higher for higher efficiency filtration and air cleaning. Therefore, good filtration installation and maintenance are critical to the success of this approach. The infiltration rate reduction with pressurization in place needs to be based on weather conditions and building airtightness, such that an appropriate amount of outdoor air is brought into the building. Simply increasing outdoor air intake with the goal of building pressurization may not be effective and could make things worse in some situations. 


\subsubsection{Relocation of Outdoor Air Intakes}

Objective

To move outdoor air intakes, usually to higher elevations, such that they are less accessible to public right-of-ways, therefore making it less likely that an individual can release a contaminant into the intake.

\section{Description}

Outdoor air intakes are sometimes located where they are easily accessed by pedestrians and are therefore vulnerable to someone releasing a contaminant that will be pulled into the building and distributed by the ventilation system. The vulnerabilities created by accessible intake locations have been identified as an issue of concern and recommendations have been made to move such intakes to higher elevations (ASHRAE 2002, NIOSH 2002). The NIOSH document notes that a

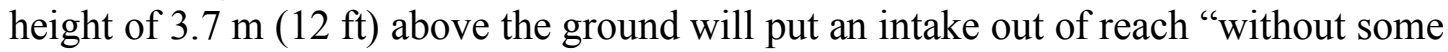
assistance." NIOSH also recommends a sloped and screened covering to the intake, so that an item thrown on the intake will roll off. Figure 19 is a schematic diagram of three potential intake locations, ranging from "vulnerable" to "best." The second schematic clearly shows a sloped intake, while the "best" option stresses elevation instead of slope. Other recommendations noted in these documents include providing distance from building elements that could be used to access intakes, such as loading dock or entryway roofs, and minimizing obstructions near intakes that could make it difficult to observe someone in their vicinity. In some buildings, it may be possible to run the intake ductwork through the building interior to the roof, but that approach consumes valuable interior space that may not make it a realistic option.

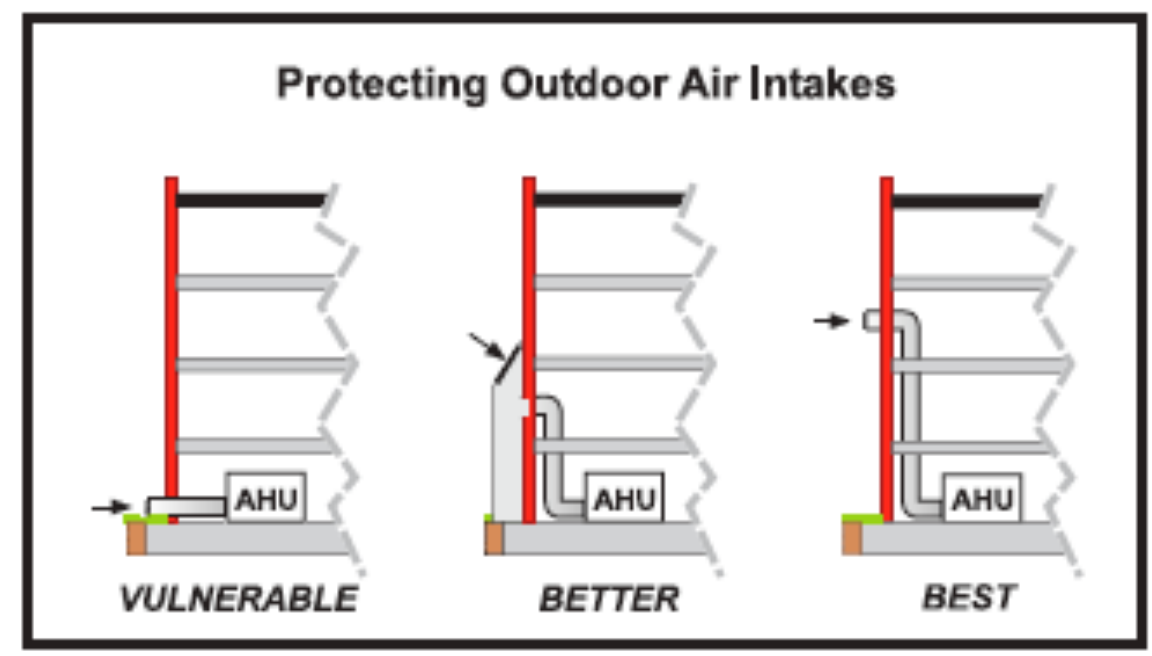

Figure 19 Schematic of intake location options (NIOSH 2002)

\section{Available Performance Information}

There is no quantity that characterizes the degree of accessibility of an air intake, but presumably a higher intake is less likely to be subject to a release. The amount of contaminant that will be drawn into a ventilation system from a release near an intake is a complex function of the airflow patterns around a building. Even without employing complex analysis of airflow patterns and quantitative determinations of accessibility, it is probably reasonable to assume that a release at the intake will be unlikely to occur if it is relocated sufficiently distant from publicly accessible locations. 
The EPA BASE study of 100 randomly selected U.S. office buildings included the characterization of 141 ventilation systems serving the 97 mechanically ventilated buildings in the study (Persily and Gorfain 2004). Among many other parameters, that study included the elevation of the air intakes relative to ground level. The mean value of the intake elevation for these systems is $5.4 \mathrm{~m}(18 \mathrm{ft})$, which may be sufficient in many cases. However, the median

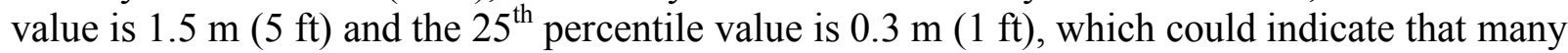
intakes are lower than perhaps they should be. Of course, in addition to elevation, vulnerability of an intake depends on the public access of the intake and physical security around a building.

\section{Protective Impacts}

It seems reasonable to assume that all of a contaminant released directly into an intake will be brought into a building and that moving the intake to an inaccessible location will eliminate any such contaminant entry. However, as noted above, the amount of contaminant that enters from a release near an intake is more complex and its determination requires complex analysis approaches. In cases where an existing intake is in an accessible location, the goal should be to move it as far from such a location as practical. However, as noted in the discussion of costs, in some cases it can be very expensive to move intakes in some buildings and the degree of risk to that building may not justify the cost. As an alternative to moving intakes, closed-circuit television cameras, security lighting, fences and other means of improving physical security have been suggested as reasonable alternatives (NIOSH 2002).

\section{Costs}

There is clearly a cost associated with relocating air intakes, which in some cases can be quite significant. In addition, the relocation may modify the airflow resistance associated with the intake, thereby requiring additional modifications to the air handling system. These costs will be building and system specific, and therefore cannot be generalized. The case study described in this report includes an estimate for a high-rise office building of roughly $\$ 250000$, but that is only one estimate. Costs may be higher or lower in another circumstance. Note, however, that in the case study building, relocating the intakes would have blocked more than 100 windows and compromised the aesthetics of the building, issues that are difficult if not impossible to translate into a dollar value.

There can also be potential indoor air quality improvements from raising outdoor air intakes when there is heavy motor vehicle traffic and other ground level contaminant sources.

\section{$\underline{\text { Knowledge gaps }}$}

Given that this is a relatively effective retrofit, there is little need for detailed analysis of its effectiveness. However, additional case studies of the associated cost for given building and system configurations would be useful to assist building owners in the early stages of retrofit consideration.

\section{$\underline{\text { SUMMARY }}$}

Relocating accessible outdoor air intakes can dramatically improve the level of building protection by essentially removing that vulnerability. However, the practicality and cost of this retrofit can vary among buildings, as well as its importance based on the risks to which that particular building is exposed. In cases where it is determined that relocating the intakes is not an option or won't be pursued, improving the physical security of the intakes and monitoring activities in their vicinity will reduce the vulnerability. 


\subsubsection{Shelter-in-place}

\section{Objective}

To reduce occupant exposure to an outdoor release by moving building occupants to a designated space within a building. This space, which may be equipped with supplemental filtration and air cleaning, will experience lower concentrations due to the outdoor release and thereby provide protection to the building occupants who have moved to this space.

\section{Description}

In the event of an exterior contaminant release, and in some cases an interior release, building occupants can move to a designated space that is relatively isolated from the rest of the building and offers protection from the airborne agent. During such sheltering, the building HVAC and exhaust systems are all deactivated to eliminate intentional outdoor air intake into the building, leaving only unintentional air infiltration. The degree of protection will increase if the space is well isolated in terms of airflow by having tight boundaries and even more so if the space is equipped with a filtration and air cleaning system to remove contaminants that do enter the space. This approach is also sometimes referred to as "collective protection."

Shelter-in-place is a well-established concept and has been implemented in a variety of settings and planning efforts. For example, FEMA's Chemical Stockpile Emergency Preparedness Program (CSEPP) has generated much information, guidance and training material for planning in the event of a chemical release at a chemical storage site or industrial facility (Blewett et al. 1996). As noted in this and other publications, there are four basic approaches to shelter-in-place:

Normal: closing all windows and doors, and turning off all mechanical equipment, such as HVAC systems

Expedient: applying temporary air sealing measures to a shelter space, such as taping over vents or placing plastic sheeting over windows

Enhanced: applying permanent air sealing measures to a shelter space

Pressurized: providing filtered/cleaned air to the shelter to achieve an elevated air pressure relative to outside the shelter, thereby greatly limiting air and contaminant entry

Much of the guidance that has been issued in the selection and preparation of shelter-in-place spaces in buildings focuses on size, location and accessibility (NICS 1999 and 2001, Price et al. 2003). In many cases, sheltering is envisioned as lasting for hours, until the outdoor contaminant has cleared and it is safe to leave the building. In situations where sheltering is expected to last longer, requirements for food, water and other basic needs become important. In fact, as was discussed for envelope tightening, unless the shelter is provided with filtration and air cleaning, the exposure in the shelter will eventually approach that experienced outdoors. Therefore, leaving the shelter and the building when it is safe outdoors is an important aspect of this strategy. In addition, carbon dioxide will build up in the shelter over time, which is another reason for short term use of this strategy unless ventilation and air cleaning are employed.

A key aspect of shelter-in-place, as noted in the referenced guidance material, is the training of the building occupants to move quickly to the shelter when directed. Training drills are noted as useful exercises, similar to evacuation training drills.

\section{Available Performance Information}

Key variables related to this approach include the airtightness of interior partitions of the shelter and the airtightness of the exterior envelope of the building itself. Existing building airtightness 
data were discussed under the Envelope Airtightening approach. Even less information is available on shelter airtightness, but studies are in progress that include such measurements. If filtration or air cleaning is employed, the airflow rate through that system and the filter/air cleaner removal efficiencies for the contaminant of concern are relevant. Airflow rates are generally specified for commercial units or can otherwise be determined for systems designed for specific installation. As discussed earlier, particulate removal efficiencies are expressed in terms of MERV levels but gaseous air cleaning efficiencies are more difficult to determine.

\section{Protective Impacts}

Shelter-in-place can provide significant protection against outdoor contaminant releases, as seen in the simulation results in Section 2. Timing of occupant movement into the shelter is critical, however, as is the timing of their leaving the shelter after the outdoor contaminant has cleared. The simulations discussed in Section 2 showed exposure reductions on the order of $90 \%$ or more if the occupants moved into the shelter before the release for a two-hour sheltering period. Filtration and air cleaning reduce exposure even more. But moving into the shelter after the release had begun greatly reduces the effectiveness of the sheltering.

The parameters that will determine the effectiveness of shelter-in-place are the exterior envelope and shelter airtightness values, the outdoor weather driving infiltration and contaminant into the building, interior zoning and temperatures as they affect internal airflow patterns, the relative timing and duration of the release and the sheltering, and the existence and effectiveness of any filtration and air cleaning employed.

A significant amount of research has also been done on shelter-in-place, but most of it focuses on the building itself as the shelter as opposed to a designated space within the building (Blewett and Arca 1999, Fradella and Siegel 2005, Sohn et al. 2005). Jetter and Whitfield (2005) examined the protection provided by an interior bathroom of a residence, in which tracer gas tests were used to estimate airflow rates between the shelter, the rest of the house and the outdoors. A later experimental study by Jetter and Proffitt (2006) considered the protection offered by shelters in commercial buildings. Swansiger et al. (2005) looked at the use of interior stairwells, pressurized with filtered outdoor air as an SIP option.

\section{Costs}

There is some cost involved in setting up a shelter-in-place, particularly airtightening of the interior partitioning and equipment costs for a filtration and air cleaning system if employed. In general, these systems are only employed if needed, and therefore they are not associated with any significant operating costs. There are some maintenance costs to ensure that the system will function properly in the event it is needed.

\section{$\underline{\text { Knowledge gaps }}$}

While shelter-in-place is fairly straightforward, the biggest question regarding its implementation is knowing that a release has taken place, or is about to take place, and that sheltering is the appropriate action. A warning system based on contaminant monitoring could answer these questions, but this type of warning system is not typically available. Therefore, better information is needed on how to determine that sheltering is called for, and when the occupants should subsequently leave the shelter and go outdoors. There is also a need for better information on shelter airtightness values and how these values relate to the degree of protection offered. 


\section{SUMMARY}

Shelter-in-place, especially when implemented in a timely fashion, can reduce exposure to outdoor releases. The reductions will be higher if filtration and air cleaning are employed in the shelter. Effective sheltering depends on proper selection of shelter spaces in a building, airtightening of the partitions to adjacent spaces, and training of the occupants to move quickly to the shelters when directed to do so.

\subsubsection{Isolation of Special-use Spaces}

\section{$\underline{\text { Objective }}$}

To limit contaminant releases in vulnerable spaces from impacting the rest of the building, thereby reducing exposure to the bulk of the building occupants.

\section{Description}

Some building spaces are more vulnerable to interior releases due to public access (e.g., lobbies and parking garages) or mail and delivery activities (e.g., mail rooms and loading docks). Due to the increased vulnerability of such spaces, keeping them at a lower pressure than adjacent portions of the building can provide some protection in the event of an incident. Such isolation can be achieved through ventilation airflow control, i.e., exhausting more air than is being supplied, and will generally be easier to achieve and control if these spaces are served by a dedicated system. This approach is more likely to be successful if attention is paid to the airtightness of the boundaries between the space and the rest of the building.

\section{Available Performance Information}

The effectiveness of this approach is determined by the magnitude of the negative pressure achieved in the space relative to adjoining spaces, which is a function of the system airflows to and from the space and adjoining spaces as well as the airtightness of the space boundaries. Other important variables include weather conditions as they impact building pressures and the operation of other ventilation systems in the building. The supply and exhaust airflow differential and the airtightness of the space boundaries required for effective isolation need to be considered on a case-by-case basis as impacted by system airflow rates, weather conditions, and location of the space in the building. For example, lower level spaces, which include lobbies, loading docks and many mail rooms, are more subject to stack-driven flows upward within a building. Multizone airflow modeling is useful in assessing these situations and defining system airflows and levels of partition airtightness required for effective isolation.

\section{Protective Impacts}

If effectively implemented, space isolation will limit contaminant migration to other spaces within a building. The occupants of the space where the release occurs will be exposed, however, perhaps to significant quantities of contaminant, and this approach will not protect them.

Examples of this approach were discussed in the case study of the high-rise office building, where isolating the mail room and the lobby was considered.

\section{$\underline{\text { Costs }}$}

There may be some initial costs associated with airtightening or modifications of system airflow rates to achieve the desired pressure relationships. The latter will require some maintenance in terms of periodically checking system balancing to determine that these pressure relationships still exist. In some cases a new air handling system may be required, which will also involve 
some operating costs. There may also be some first and maintenance costs associated with controls to modulate the system airflows in response to real-time pressure monitoring between the space and an adjacent space. The costs of isolating the mail room and the lobby of the highrise case study building are discussed in Section 3.

Knowledge gaps

Additional information on interior partition airtightness, as typically constructed and after airtightening, would be helpful in the design of isolation strategies. These data would also allow more specific guidance on the differential airflow quantities required for effective isolation as a function of building climate as well as floor plan and elevation.

\section{SUMMARY}

Isolation of special-use spaces can contain indoor contaminant releases, thereby protecting the rest of the building from significant exposure. This approach requires consideration of the pressures that need to be counteracted and will be more effective if the partitions to adjacent spaces are air sealed.

\subsubsection{System Shutdown and Purging}

\section{Objective}

To effectively implement a quick shutdown of all ventilation systems or to induce a $100 \%$ outdoor air purge when such actions will reduce occupant exposure to a contaminant release.

\section{$\underline{\text { Description }}$}

In some circumstances, shutting down a building ventilation system or operating it with $100 \%$ outdoor air intake may help protect building occupants from a chembio release. Shutdown involves turning off all ventilation equipment, including makeup air and exhaust fans. It is important to include all equipment, since leaving on a toilet exhaust system will contribute to building depressurization and actually increase contaminant entry for an outdoor release. Implementing a $100 \%$ purge can be effective in removing an agent that has already been distributed within a building. Ventilation systems equipped with economizer cycles are already equipped with the necessary controls to implement such an action. However, for both shutdown and purging, the circumstances under which such an action will be beneficial are very dependent on the release location and timing, the amount of time that has passed since the release occurred, and how much contaminant if any has been distributed within the building and where.

Timing is critical to the effectiveness of a shutdown response, and a single-switch or "panic button" that implements shutdown all at once instead of having to individually deactivate each piece of equipment will support more timely implementation. Such single-switch control is generally much easier to set up in digital control systems than in pneumatic systems, though the latter can result in faster transmission of the action to the equipment. The location of the switch and the protocols for who operates and under what circumstances are critical issues that need to be considered in advance of any incident, and training exercises are useful to increase the likelihood that such a response will be implemented as intended.

Even with good controls and a single switch, it takes time for a typical ventilation system to shut down due to delays associated with fan spin-down and damper closing. These delays can be countered by installing braking systems on fans and quick closing, tight dampers, but these items are not standard in commercial building systems and will increase costs. 
Available Performance Information

Since both shutdown and purging are building-specific in their implementation and impact, there are no generic performance data describing these approaches. In a given building, key performance parameters include the building air change rate, i.e., infiltration under shutdown and the intake airflow under purging, and the time it takes to implement the response.

In the case of shutdown, the system-off infiltration rate of a building is a strong function of weather conditions. This rate can be measured with tracer gas techniques or predicted with multizone airflow modeling, but these approaches require a certain level of sophistication. Perhaps more important is to assess and understand the airflow patterns into and within a building with the system off. These patterns can be assessed through the use of smoke pencils and the measurement of pressure differences at key locations in the building, including entrances (including secondary entrances such as loading docks), elevator and stairway doors at multiple building levels, windows at multiple elevations, and roof access doors. Such an effort can help to understand where air enters and leaves the building with the system off and thereby result in a better sense of where contaminants may enter the building and how they might move through it. It is important to conduct such an airflow assessment under different weather conditions (wind and outdoor temperature), as the airflow patterns will be impacted by weather.

Purging airflows are less likely to be impacted by weather, but it is still important to verify that the implementation of a purge cycle operates as intended. Verification can involve measuring system airflows, in particular the outdoor air intake rate. A less involved assessment includes inspecting the intake, recirculation and exhaust dampers and the fan speeds to make sure the system is in fact operating in a manner that will bring in the maximum amount of outdoor air.

\section{Protective Impacts}

The degree of exposure reduction from either a shutdown or purge is dependent on the timing of the response relative to the release, the location of the release relative to the occupants, and the building layout and system design. This variability was seen in the simulation results presented in Section 2, where timing was seen to be critical and the exposure impacts were quite variable based on the details of the release.

Shutdown is likely to be most effective if an outdoor release has occurred and there is sufficient warning to initiate the shutdown before the contaminant is brought into the building by the ventilation system. In some circumstances, a shutdown may also be effective if an agent has entered a building or has been released indoors and shutting down the system prevents the contaminant from being distributed within the building. However, realizing the benefits of a shutdown in such a situation requires a level of understanding of the release timing and location and the building airflow patterns that is not necessarily realistic. Also, system shutdown will lose the ability to pressurize the building with the system, which will increase contaminant entry if an outdoor release is still in progress.

A purge cycle makes sense if a contaminant has already been distributed within a building and the best course of action is to remove it as quickly as possible. Such situations include a release into a system return, or even an intake, or a localized release that has mixed within the building. However, realizing the benefits of a purge cycle requires knowledge that such an event has occurred and the contaminant has migrated within the building to a degree that purging makes sense. There is the associated issue of occupant awareness during such an event. If there is sufficient awareness of the circumstances of an event that purging is an appropriate response, then it is likely that evacuation of the occupants is also a reasonable response as well. One exception might be if evacuation is not an option due to conditions outside the building. 


\section{$\underline{\text { Costs }}$}

There are costs associated with the controls to quickly convert system operation into a shutdown or purge mode, as well as the periodic maintenance to confirm that the controls are operational. The costs will depend on the system type and complexity, and the controls that already exist in the building. A detailed design review will be required to determine what work is needed to implement these controls and the costs involved, as was done in the two case study buildings. If fan braking systems and quick acting dampers are required, they will increase costs accordingly. There are no economic benefits associated with shutdown and purge capabilities, but having them in place does provide a response that might be appropriate under other circumstances such as less extreme indoor air quality incidents.

\section{Knowledge gaps}

As noted above, the most important information gaps are how shutdown and purging will impact airflow patterns and contaminant movement in a specific building under a specific release scenario. More studies of their implementation in individual buildings should improve our general understanding of the impacts, as well as how and when to implement these responses.

\section{SUMMARY}

As noted above, the degree of exposure reduction from either a shutdown or purge response depends on the timing of the response, the nature of the release, and the building layout and system design. It is unlikely to be entirely clear when either response is advised, but having the capability is worth considering in the event that it is needed. Even if the controls and equipment are not modified to speed the implementation of shutdown or purging, it makes sense to know how to shut down all systems quickly, how to implement a purge cycle using existing controls, and how either action will impact air movement patterns in a building. Note that in the absence of reliable information regarding a chembio release, implementing a shutdown or purge cycle can actually increase rather exposure in some circumstances.

\section{$\underline{\text { 4.3.8 Automated HVAC Response }}$}

\section{Objective}

To modify the operation of a building's ventilation system in response to a contaminant sensor in a manner that reduces occupant exposure.

\section{Description}

Given a timely and reliable signal from a contaminant sensor, a building's automated control systems could modify ventilation system operation to contain the contaminant in the zone of an indoor release, or in the case of an outdoor release to prevent it from entering a building and to maintain the rest of the building and egress paths at low and presumably safe concentrations. These modifications could include stopping and starting fans, repositioning dampers, or securely closing doorways. These concepts have been used for many years in smoke control systems to contain smoke in the fire zone and provide a safe evacuation route for the building occupants (Klote and Milke 2002). The manner in which a system's configuration and operation would be modified depends on the building and system design, and the nature of the contaminant release.

Available Performance Information

The speed, reliability, and ultimately cost contaminant sensors are key to the application of automated HVAC response and can be considered the weak link. Given the speed at which air 
moves within buildings, a very fast sensor is required to initiate a change in system operation before the contaminant has spread within the building and defeated the goals of the approach. Also, the sensor must be reliable to avoid both false negatives and positives. Sensors also need to have a range of detection capabilities to cover the various chemical and biological agents of interest. In addition to fast sensors, the system changes also need to be implemented more quickly than most ventilation systems can change operating modes. This requirement means that fast acting and tight dampers will need to be installed in place of typical dampers. Fan braking systems are also needed to stop the airflows more quickly than is generally possible in typical ventilation systems.

\section{$\underline{\text { Protective Impacts }}$}

In theory, if the sensors and system capabilities are available, and the building and system airflow dynamics are well understood, this approach would be able to provide a high level of protection. However, sensors that are fast and inexpensive enough are not currently available for any applications other than very high security buildings where the costs are justified. Until sensor cost and reliability improves, this approach is not a practical option in other buildings.

\section{Costs}

The cost of this approach includes the contaminant sensors, which are very expensive at this time and include both the first and maintenance costs. In addition, the tight dampers and fan braking systems noted above also involve first costs. Finally, such a system will involve design costs related to the system and control modifications.

Knowledge gaps

As noted, the biggest need to make this option more realistic is the development of fast, reliable and affordable sensors covering a range of chembio agents. Much work is in progress in sensor development, but it will still be some time before the sensors are available to support application of this approach at a reasonable cost.

\section{$\underline{\text { SUMMARY }}$}

While automated HVAC operational changes can in theory reduce occupant exposures, the technology to implement this approach does not currently exist. It is not clear when the situation will change, but it is likely some years before this option will be widely available. 


\subsection{Guidance Summary}

This section has reviewed a number of retrofit technologies and options for controlling exposure to chemical and biological contaminant releases. The guidance provided is summarized in Tables 27 and 28. Note the separate entry in the fifth row Table 27 for filtration and gaseous air cleaning that points out the key advantage that these technologies are always in effect, assuming the systems are properly installed and maintained, and therefore there is no need for proper timing or implementation decisions. Also, filtration and air cleaning will not increase exposure if implemented at the "wrong" time, unlike some other responses. The biggest problem with gaseous air cleaning in particular is the lack of standards for testing and rating these systems, but efforts are underway that should remedy this situation.

\begin{tabular}{|c|c|c|c|}
\hline Retrofit & Advantages & Disadvantages & Comments \\
\hline $\begin{array}{l}\text { Enhanced } \\
\text { Particle } \\
\text { Filtration }\end{array}$ & $\begin{array}{l}\text { Protection against bioagents. } \\
\text { Standard for removal } \\
\text { efficiency, MERV values. } \\
\text { Part of current practice. } \\
\text { General IAQ improvements. }\end{array}$ & $\begin{array}{l}\text { Pressure drop associated } \\
\text { with high efficiency } \\
\text { filters. }\end{array}$ & $\begin{array}{l}\text { Must control filter } \\
\text { bypass before } \\
\text { upgrade. } \\
\text { Combination with } \\
\text { envelope tightening } \\
\text { provides maximum } \\
\text { protection against } \\
\text { outdoor releases. } \\
\end{array}$ \\
\hline $\begin{array}{l}\text { Gaseous Air } \\
\text { Cleaning }\end{array}$ & $\begin{array}{l}\text { Protection against gaseous } \\
\text { agents. } \\
\text { General IAQ improvements. }\end{array}$ & $\begin{array}{l}\text { No standard test method. } \\
\text { Pressure drop associated } \\
\text { with high efficiency } \\
\text { filters. } \\
\text { More design guidance } \\
\text { needed. }\end{array}$ & $\begin{array}{l}\text { Challenge of protecting } \\
\text { against range of } \\
\text { gaseous contaminants. }\end{array}$ \\
\hline $\begin{array}{l}\text { UV } \\
\text { Germicidal } \\
\text { Irradiation }\end{array}$ & $\begin{array}{l}\text { Protection against bioagents. } \\
\text { Low pressure drop. } \\
\text { General IAQ improvements. }\end{array}$ & $\begin{array}{l}\text { No standard test method. } \\
\text { Design guidance needed. }\end{array}$ & $\begin{array}{l}\text { Challenge of protecting } \\
\text { against range of } \\
\text { biological } \\
\text { contaminants. }\end{array}$ \\
\hline $\begin{array}{l}\text { Photocatalytic } \\
\text { Oxidation }\end{array}$ & $\begin{array}{l}\text { Protection against bioagents } \\
\text { and gases. } \\
\text { Low pressure drop. }\end{array}$ & $\begin{array}{l}\text { No standard test method. } \\
\text { No standard method to } \\
\text { determine if catalyst has } \\
\text { become poisoned. } \\
\text { Design guidance needed. }\end{array}$ & $\begin{array}{l}\text { Challenge of protecting } \\
\text { against range of } \\
\text { biological and } \\
\text { gaseous contaminants. }\end{array}$ \\
\hline $\begin{array}{l}\text { All filtration } \\
\text { and air } \\
\text { cleaning } \\
\text { technologies }\end{array}$ & $\begin{array}{l}\text { Always operating; no timing } \\
\text { issues. } \\
\text { Doesn't increase exposure } \\
\text { for any release scenarios. }\end{array}$ & $\begin{array}{l}\text { Lack of test methods for } \\
\text { gaseous air cleaning, } \\
\text { UVGI and PCO. }\end{array}$ & $\begin{array}{l}\text { Must address envelope } \\
\text { air leakage to realize } \\
\text { effectiveness. } \\
\text { Bypass will decrease } \\
\text { effectiveness. } \\
\text { Combination of } \\
\text { methods needed to } \\
\text { protect against range } \\
\text { of chembio agents. }\end{array}$ \\
\hline $\begin{array}{l}\text { Work-area } \\
\text { Treatment }\end{array}$ & $\begin{array}{l}\text { Capture of contaminant } \\
\text { releases associated with } \\
\text { localized activities. }\end{array}$ & $\begin{array}{l}\text { Current equipment not } \\
\text { rated for capture } \\
\text { efficiency. } \\
\text { Lack of test methods for } \\
\text { gaseous removal. }\end{array}$ & \\
\hline
\end{tabular}

Table 27 Summary of Retrofit Guidance for Retrofit Technologies 


\begin{tabular}{|c|c|c|c|}
\hline Retrofit & Advantages & Disadvantages & Comments \\
\hline $\begin{array}{l}\text { System } \\
\text { Recommissioning }\end{array}$ & $\begin{array}{l}\text { Improves reliability of } \\
\text { HVAC systems for other } \\
\text { protective responses. } \\
\text { IAQ and energy efficiency } \\
\text { improvements. }\end{array}$ & $\begin{array}{l}\text { Provides no additional } \\
\text { protection beyond that } \\
\text { inherent in the design. }\end{array}$ & $\begin{array}{l}\text { Benefits depend on } \\
\text { difference between } \\
\text { design intent and } \\
\text { existing } \\
\text { performance. }\end{array}$ \\
\hline $\begin{array}{l}\text { Envelope } \\
\text { Tightening }\end{array}$ & $\begin{array}{l}\text { Protects against outdoor } \\
\text { releases if effective } \\
\text { filtration in place. } \\
\text { IAQ and energy efficiency } \\
\text { improvements. }\end{array}$ & $\begin{array}{l}\text { Effective filtration } \\
\text { required to realize } \\
\text { benefits. }\end{array}$ & $\begin{array}{l}\text { More data needed on } \\
\text { cost and } \\
\text { effectiveness of } \\
\text { sealing retrofits. }\end{array}$ \\
\hline $\begin{array}{l}\text { Building } \\
\text { Pressurization }\end{array}$ & $\begin{array}{l}\text { Protects against outdoor } \\
\text { releases if effective } \\
\text { filtration in place. }\end{array}$ & $\begin{array}{l}\text { Challenging to implement } \\
\text { and maintain under all } \\
\text { conditions in some } \\
\text { buildings. }\end{array}$ & $\begin{array}{l}\text { Amount of extra } \\
\text { outdoor air based } \\
\text { on climate and } \\
\text { airtightness. } \\
\text { Pressurization can } \\
\text { lead to envelope } \\
\text { moisture problems } \\
\text { in cold climates. }\end{array}$ \\
\hline $\begin{array}{l}\text { Relocation of Air } \\
\text { Intakes }\end{array}$ & $\begin{array}{l}\text { Protects against tampering } \\
\text { with accessible intakes. } \\
\text { Potential IAQ benefits by } \\
\text { avoiding ground level } \\
\text { contaminant sources. }\end{array}$ & $\begin{array}{l}\text { Can be costly and } \\
\text { impractical in some } \\
\text { circumstances. }\end{array}$ & \\
\hline Shelter-in-place & $\begin{array}{l}\text { Protects occupants against } \\
\text { outdoor, and some } \\
\text { indoor, releases. }\end{array}$ & $\begin{array}{l}\text { Timing of occupant } \\
\text { movement critical to } \\
\text { effectiveness. } \\
\text { Need to know that an } \\
\text { incident has taken place } \\
\text { that merits sheltering. }\end{array}$ & $\begin{array}{l}\text { Occupant training } \\
\text { and } \\
\text { communication } \\
\text { important. }\end{array}$ \\
\hline $\begin{array}{l}\text { Isolation of } \\
\text { Special Spaces }\end{array}$ & $\begin{array}{l}\text { Protects bulk of building } \\
\text { from releases in more } \\
\text { vulnerable spaces. }\end{array}$ & $\begin{array}{l}\text { Does not protect those in } \\
\text { space of release. }\end{array}$ & $\begin{array}{l}\text { Requires design } \\
\text { based on driving } \\
\text { pressures and } \\
\text { airtightness. } \\
\text { Lack of clear } \\
\text { guidance on design } \\
\text { pressure difference. }\end{array}$ \\
\hline $\begin{array}{l}\text { Shutdown and } \\
\text { Purging }\end{array}$ & $\begin{array}{l}\text { Can protect against } \\
\text { outdoor or indoor } \\
\text { releases under some } \\
\text { circumstances. }\end{array}$ & $\begin{array}{l}\text { Poor timing can increase } \\
\text { exposure. } \\
\text { Requires knowledge that } \\
\text { an incident has taken } \\
\text { place that merits action. }\end{array}$ & $\begin{array}{l}\text { Even if proper action } \\
\text { not always } \\
\text { obvious, capability } \\
\text { has value. }\end{array}$ \\
\hline $\begin{array}{l}\text { Automated } \\
\text { HVAC Response }\end{array}$ & $\begin{array}{l}\text { Can contain release and } \\
\text { provide occupants with } \\
\text { low contaminant zones. }\end{array}$ & $\begin{array}{l}\text { Requires sensing beyond } \\
\text { current technology. } \\
\text { Proper response depends } \\
\text { on details of system and } \\
\text { release; not always clear. } \\
\text { Wrong timing or action } \\
\text { can increase exposure. }\end{array}$ & \\
\hline
\end{tabular}

Table 28 Summary of Retrofit Guidance for Retrofit Approaches 
Given the wide range of potential retrofit options, decisions on which options to implement can be confusing. While the appropriate actions in a given building are inherently specific to that building, Table 29 presents a very simplified framework for considering the various retrofit options discussed in this report. The table contains four categories, with the first being those retrofits that may reasonably be implemented in any building. These include recommissioning and enhanced particle filtration based on the energy and IAQ benefits. Shelter-in-place is also included in this category because it is good to have such a contingency plan in response to a wide range of events. Shelter-in-place may range from simply designating such spaces in a building, and perhaps some minimal air sealing, to a more comprehensive effort to prepare a space that might include high levels of air sealing, provisions for food and water, and filtration and air cleaning capabilities. The second category includes options that should be considered independent of the threats to a given building. The first two are included based in part on their energy and potential IAQ benefits, but since they can be quite complex and costly in some facilities, they may not be appropriate in all circumstances. Shutdown and purging are also included in the category because they are good options to have available, but may not be readily implemented in some systems without costly modifications.

\begin{tabular}{|l|l|}
\hline \multicolumn{1}{|c|}{ RETROFITS } & \multicolumn{1}{c|}{ COMMENTS } \\
\hline Implement in any building & Based on energy and IAQ benefits. \\
\hline System Recommissioning & $\begin{array}{l}\text { Range of options depending on threats and } \\
\text { building. }\end{array}$ \\
\hline Enhanced Particle Filtration & \\
\hline Shelter-in-place & Based on energy and potential IAQ benefits. \\
\hline Consider independent of threats & $\begin{array}{l}\text { As long as not cost-prohibitive for existing } \\
\text { HVAC system and controls. }\end{array}$ \\
\hline Building Pressurization & \\
\hline Shutdown and Purging & \\
\hline $\begin{array}{l}\text { Consider if threats indicate and costs } \\
\text { commensurate }\end{array}$ & \\
\hline Isolation of Special Spaces & \\
\hline Relocation of Air Intakes & $\begin{array}{l}\text { More likely to be appropriate in healthcare } \\
\text { facilities. }\end{array}$ \\
\hline Work-area Treatment & \\
\hline Gaseous Air Cleaning & \\
\hline $\begin{array}{l}\text { More performance data or technology } \\
\text { development needed for general application }\end{array}$ & \\
\hline UV Germicidal Irradiation & \\
\hline Photocatalytic Oxidation & \\
\hline Automated HVAC Response & \\
\hline
\end{tabular}

Table 29 Framework of Retrofit Options

The third category includes several retrofits whose implementation must be carefully considered based on the threats and costs. This category is probably one of the more challenging situations, where one must balance the risk of the threats with potentially significant costs. The fourth category includes two air purification technologies that while commercially available are not 
associated with a lot of performance data and design guidance. They may be appropriate in some situations, but it can be difficult to determine at the present time. Automated HVAC response is also listed in the final category due primarily to the limits of current sensor technology.

Nevertheless, there are some situations where the risks may be so significant that this approach needs to be employed despite it cost and challenges. 


\section{CONCLUSIONS}

This report has presented and discussed a number of retrofit options for improving the protection of buildings against chembio releases, including information as to their potential impact on occupant exposure and their cost. This information is intended to help building owners and others faced with decisions of how best to protect their buildings from such releases. In order to make these decisions for a particular building, the responsible parties must begin with an assessment of the risk of the building and its vulnerabilities, and as a result determine the level of protection and the associated expenditures that are appropriate. These decisions are difficult, though some guidance has been developed to assist in making them. But given that a decision has been made to increase the protection of a building through the application of such retrofits, the information in this report should be useful in determining which retrofits make sense for a given building and system and how they should be implemented.

The retrofit options considered in this report focus on commercially available options for engineering and building system retrofits, as opposed to physical security and other building management approaches. The options include filtration and air cleaning technologies, changes in ventilation system operation, attempts to reduce the entry of outdoor releases via envelope infiltration, and shelter-in-place. However, before pursuing any of these retrofit options in a particular building, it is essential to assess the current condition of the building's HVAC systems and to bring their operation in line with the design intent through a so-called recommissioning effort. Such an effort should address system airflow rates, control systems and the associated sensors, filter fit and air seal, and other aspects of system operation and maintenance. Without a properly operating ventilation system and a maintenance program to keep it that way, no retrofit should be expected to provide the level of protection of which it may be capable.

In terms of the retrofits themselves, filtration and air cleaning have the advantage of not relying on any advance warning of a release and a human or automated response. Particle filtration benefits from an established method of test that allows one to select filters based on MERV ratings, while gaseous air cleaning and other air cleaning options do not yet have such a method of test. This lack of standards makes it much more difficult to specify such systems and to determine the anticipated benefits. For a filtration or air cleaning system to be effective, it must be properly installed and maintained over time with a focus on controlling bypass around the filters. When considering outdoor contaminant sources, reducing envelope leakage is critical to achieving the potential benefits of filtration. If the building has typical levels of envelope airtightness, the resulting infiltration can defeat the high levels of protection that are possible with good filtration and air cleaning. Similarly, while reducing infiltration through airtightening and system airflow control can provide protection against such outdoor releases, these approaches are much more effective if there is good filtration of the intake air.

Many of the other retrofit options require sound operational decisions during a chembio release in order to provide effective protection. Such decisions include whether and when to shut down a system or use it to purge the building, and whether and when to send occupants to a shelter-inplace zone. Making and implementing these decisions depends on knowledge about the event, training in advance of the event, and communications both before and during the event.

While this effort has provided useful insight and tools for considering chembio retrofits, additional work would be valuable in increasing the understanding of retrofit impacts for more building and system types, release scenarios and retrofit approaches. In particular, there are specific building types that are fairly unique and merit more individual attention such as educational, healthcare and retail facilities. In addition, unitary systems and fan coil units are limited in the filtration options that they can accommodate and need to be examined more 
closely. Finally, there are an infinite number of release and building occupancy scenarios that may be considered. Further examination beyond the generic cases studied here are likely to provide additional insights into building protection. Other ideas for followup work include field testing to 'validate' the simulation results, tools to help with the design and implementation of the retrofit options, and research to document the indoor air quality and energy efficiency benefits of some of the retrofits. 


\section{ACKNOWLEDGEMENTS}

This effort was supported by the U.S. Environmental Protection Agency under Interagency Agreement No. DW-13-93010301-0, but was not subjected to EPA peer review. The conclusions in this paper are therefore those of the authors and are not necessarily those of the U.S. EPA. The authors express their appreciation to John Chang and Jacky Rosati at EPA, as well as Harold Marshall, Julie Wean, Doug Thomas, and Jatin Patel at NIST. The assistance of Jose Reig and Guillermo Ramsey of ESE Architects and Engineers are also acknowledged. The following reviewers made many helpful suggestions that are greatly appreciated by the authors: William Bahnfleth, Barney Burroughs, Joan Bursey, Michael Gressel, Patrick Spahn and Steve Treado. 


\section{REFERENCES}

AMCA. 1998. AMCA Standard 500-D-98, Laboratory Methods of Testing Dampers for Rating. Air Movement and Control Association International.

Arnold, D.B., Matela, D.M., Veeck, A.C. 2005. Life-Cycle Costing of Air Filtration. ASHRAE Journal. 47 (11): 30-32.

ASHRAE. 2005. HVAC Fundamentals Handbook, Chapter 27, Ventilation and Infiltration. American Society of Heating, Refrigerating and Air-Conditioning, Engineers.

ASHRAE. 2005. ASHRAE Guideline 0-2005, The Commissioning Process. American Society of Heating, Refrigerating and Air-Conditioning, Engineers.

ASHRAE. 2004. ANSI/ASHRAE Standard 62.1-2004, Ventilation for Acceptable Indoor Air Quality. American Society of Heating, Refrigerating and Air-Conditioning, Engineers.

ASHRAE. 2003a. Report of Presidential Ad Hoc Committee for Building Health and Safety under Extraordinary Incidents on Risk Management Guidance for Health, Safety and Environmental Security under Extraordinary Incidents. American Society of Heating, Refrigerating and Air-Conditioning Engineers.

ASHRAE. 2003b. HVAC Applications Handbook, Chapter 45, Control of Gaseous Indoor Air Contaminants. American Society of Heating, Refrigerating and Air-Conditioning, Engineers.

ASHRAE. 2000. HVAC Systems and Equipment Handbook, Chapter 24 Air Cleaners for Particulate Contaminants. American Society of Heating, Refrigerating and Air-Conditioning, Engineers.

ASHRAE. 1999. ANSI/ASHRAE Standard 52.2-1999 Method of Testing General Ventilation Air-Cleaning Devices for Removal Efficiency by Particle Size. American Society of Heating, Refrigerating and Air-Conditioning, Engineers.

ASHRAE. 1996. ASHRAE Guideline 1-1996, The HVAC Commissioning Process. American Society of Heating, Refrigerating and Air-Conditioning, Engineers.

ASHRAE. 1995. ANSI/ASHRAE Standard 110-1995, Method of Testing Performance of Laboratory Fume Hoods. American Society of Heating, Refrigerating and Air-Conditioning, Engineers.

ASHRAE. 1992. ANSI/ASHRAE Standard 52.1-1992, Method of Testing General Ventilation Air-Cleaning Devices for Removal Efficiency by Particle Size. American Society of Heating, Refrigerating and Air-Conditioning, Engineers.

ASTM. 2003. E779-03, Standard Test Method for Determining Air Leakage Rate by Fan Pressurization. American Society for Testing and Materials.

Blake, D.M. 1994 Bibliography of Work on the Photocatalytic Removal of Hazardous Compounds from Water and Air, NREL/TP-430-6084. National Renewable Energy Laboratory.

Blake, D.M. 1997. Bibliography of Work on the Heterogeneous Photocatalytic Removal of Hazardous Compounds from Water and Air Update Number 2 To October 1996, NREL/TP-43022197. National Renewable Energy Laboratory.

Blewett, W.K., Reeves, D.W., Arca, V.J., Fatkin, D.P., Cannon, B.D. 1996. Expedient Sheltering in Place: An Evaluation for the Chemical Stockpile Emergency Preparedness Program. ERDECTR-336. Chemical Research, Development \& Engineering Center.

Blewett, W.K., Arca, V.J. 1999. Experiments in Sheltering in Place: How Filtering Affects Protection Against Sarin and Mustard Vapor. ECBC-TR-034. U.S. Army Edgewood Chemical Biological Center.

Burroughs, H.E.B. 2005a. Filtration and Building Security. ASHRAE Journal. 47 (4): 24-29. Burroughs, H.E.B. 2005b. Improving Filtration Effectiveness. HPAC Engineering. December. 
CGSB. 1996. CAN/CGSB-149.15-96, Determination of the Overall Envelope Airtightness of Buildings by the Fan Pressurization Method Using the Building's Air Handling Systems. Canadian General Standards Board.

CDC. 1994. Guidelines for Preventing the Transmission of Mycobacterium Tuberculosis in Health-Care Facilities. Centers for Disease Control and Prevention, Atlanta, GA.

CDC. 1999a. Guidelines for the Application of Upper-Room Ultraviolet Germicidal Irradiation for Preventing Transmission of Airborne Contagion-Part I: Basic Principles. Centers for Disease Control and Prevention.

CDC. 1999b. Guidelines for the Application of Upper-Room Ultraviolet Germicidal Irradiation for Preventing Transmission of Airborne Contagion-Part II: Design. Centers for Disease Control and Prevention.

Chapman, R.E. 2003. Applications of Life-Cycle Cost Analysis to Homeland Security Issues in Constructed Facilities: A Case Study, NISTIR 7025, National Institute of Standards and Technology.

Chapman, R.E., Leng, C.J. 2004. Cost-Effective Responses to Terrorist Risks in Constructed Facilities, NISTIR 7073, National Institute of Standards and Technology.

Cummings, J.B., Withers, C.R., Moyer, N., Fairey, P., McKendry, B. 1996a. Uncontrolled Air Flow in Non-Residential Buildings, FSEC-CR-878-96. Florida Solar Energy Center.

Cummings, J.B., Withers, C.R., Moyer, N.A, Fairey, P.W., McKendry, B.B. 1996b. Field Measurement of Uncontrolled Airflow and Depressurization in Restaurants." ASHRAE Transactions, 102 (1).

Dillard, W.M. 2004. Should Germicidal Ultraviolet Become Standard Practice? ASHRAE IAQ Applications. 5(2): 57-62.

Emmerich, S., Persily, A. 2005. Airtightness of Commercial Buildings in the U.S. Proceedings of the 26th Air Infiltration and Ventilation Centre Conference, Brussels.

Emmerich, S.J, McDowell, T.P., Anis, W. 2005a. Investigation of the Impact of Commercial Building Envelope Airtightness on HVAC Energy Use, NISTIR 7238. National Institute of Standards and Technology.

Emmerich, S.J, Persily, A.K., McDowell, T.P. 2005b. Impact of Infiltration on Heating and Cooling Loads in U.S. Office Buildings. Proceedings of the 26th Air Infiltration and Ventilation Centre Conference, Brussels.

Emmerich, S., Persily, A. 1998. Energy Impacts of Infiltration and Ventilation in U.S. Office Buildings Using Multizone Airflow simulation. Proceedings of IAQ and Energy '98. American Society of Heating, Refrigerating and Air-Conditioning Engineers, Inc.

EPA. 2004. Energy Star Building Upgrade Manual. U.S. Environmental Protection Agency. EPA. 2003. A Standardized EPA Protocol for Characterizing Indoor Air Quality in Large Office Buildings. U.S. Environmental Protection Agency.

EPA. 1991. Building Air Quality. A Guide for Building Owners and Facility Managers, 400/191/003. U.S. Environmental Protection Agency.

FEMA. 2005. Risk Assessment: A How-To Guide to Mitigate Potential Terrorist Attacks Against Buildings, FEMA 452. Federal Emergency Management Agency.

Fisk, W.J., Rosenfeld, A.H. 1997. Estimates of Improved Productivity and Health from Better Indoor Environments. Indoor Air. 7 (3): 158-172.

Fradella, J., Siegel, J.A. 2005. An Evaluation of Shelter-in-Place Strategies in Four Industrial Buildings. Proceedings of 10th International Conference on Indoor Air Quality and Climate, Beijing. Tshinghua University Press. 3360-3364. 
Jacoby, W.A., Blake, D.M., Fennell, J.A., Boulter, J.E., LeAnn M. Vargo, George, M.C., Dolberg, S.K. 1996. Heterogeneous Photocatalysis for Control of Volatile Organic Compounds in Indoor Air. Journal of the Air \& Waste Management Association, 46: 891 - 898.

Jetter, J.J., Whitfield, C. 2005. Effectiveness of Expedient Sheltering in Place in a Residence. Journal of Hazardous Materials, A119: 31-40.

Jetter, J.J., Proffitt, D. 2006. Effectiveness of Expedient Sheltering in Place in Commercial Buildings. Journal of Homeland Security and Emergency Management, 3 (2): Article 4.

Klote, J.H., Milke, J.A. 2002. Principles of Smoke Management Systems. Atlanta, GA, American Society of Heating, Refrigerating and Air-Conditioning Engineers, Inc.

Kowalski, W.J. 2003. Immune Building Systems Technology. Mc-Graw-Hill.

Kowalski, W.J., Bahnfleth, W.P. 2003. Immune-Building Technology and Bioterrorism Defense. HPAC Engineering. January, 57-62.

Kowalski, W.J., Bahnfleth, W.P. 2002. MERV Filter Models for Aerobiological Applications. Air Media. Summer: 13-17.

Kowalski, W.J., Bahnfleth, W.P., Whittam, T.S. 1999. Filtration of Airborne Microorganisms: Modeling and Prediction. ASHRAE Transactions. 105 (2): 4-17.

LBNL. 2004. Building Vulnerability Assessment \& Mitigation Program (BVAMP). Lawrence Berkeley National Laboratory, http://SecureBuildings.lbl.gov.

Mills, E., Friedman, G., Powell, T., Bourassa, N., Claridge, D., Haasel, T., Piette, M.A. 2004.

The Cost-Effectiveness of Commercial-Buildings Commissioning. LBNL 56637. Lawrence Berkeley National Laboratory.

NAFA. 2001. NAFA Guide to Air Filtration, 3rd Edition. National Air Filtration Association. NICS. 1999. Shelter in Place at Your Office. Charleston, West Virginia: National institute for Chemical Studies.

NICS. 2001. Sheltering in Place as a Public Protective Action. Charleston, West Virginia: National institute for Chemical Studies.

NIOSH. 2003. Guidance for Filtration and Air-Cleaning Systems to Protect Building Environments from Airborne Chemical, Biological, or Radiological Attacks. National Institute for Occupational Safety and Health, DHHS (NIOSH) Publication No. 2003-136.

NIOSH. 2002. Guidance for Protecting Building Environments from Airborne Chemical, Biological, or Radiological Attacks. National Institute for Occupational Safety and Health, DHHS (NIOSH) Publication No. 2002-139.

Persily, A. 2004. Building Ventilation and Pressurization as a Security Tool. ASHRAE Journal, Vol. 46 (9): 18-21.

Persily, A., Gorfain, J. 2004. Analysis of Ventilation Data from the U.S. Environmental Protection Agency Building Assessment Survey and Evaluation (BASE) Study. NISTIR 7145. National Institute of Standards and Technology.

Persily, A.K., Ivy, E.M. 2001. Input Data for Multizone Airflow and IAQ Analysis, NISTIR 6585. National Institute of Standards and Technology.

Persily, A. 1999. Myths About Building Envelopes, ASHRAE Journal, 41(3): 39-47.

Persily, A.K. 1993. Building and HVAC Characterization for Commercial Building Indoor Air Quality Investigations, NISTIR 4979. National Institute of Standards and Technology.

Persily, A. K., Grot, R.A. 1986. Pressurization Testing of Federal Buildings. ASTM STP 904, Measured Air Leakage of Buildings, 184-200. American Society for Testing and Materials.

Price, P.N., Sohn, M.D., Gadgil, A.J., Delp, W.W., Lorenzetti, D.M., Finlayson, E.U., Thatcher, T.L., Sextro, R.G., Derby, E.A., Jarvis, S.A. 2003. Protecting Buildings From a Biological or 
Chemical Attack: actions to take before or during a release. LBNL-51959. Lawrence Berkeley National Laboratory.

Shaw, C. Y., Reardon, J.T. 1995. Changes in Airtightness Levels in Six Office Buildings. ASTM STP 1255, Airflow Performance of Building Envelopes, Components, and Systems. 47-57. American Society for Testing and Materials.

Sohn, M.D., Sextro, R.G., Lorenzetti, D.M. 2005. Assessing Sheltering-in-Place Responses to Outdoor Toxic Releases. Proceedings of 10th International Conference on Indoor Air Quality and Climate, Beijing. Tshinghua University Press. 1792-1796.

Swansiger, W.A., Barrows, A.P., Blewett, W.K., Rossman, R., Brockmann, J.E., Homicz, G.F., Sparks, M.H., Stern, S.M., Pegram, D. 2005. Performance Testing of a Prototypical Stairwell Safe Haven. SAND2005-0509. Albuquerque, New Mexico: Sandia National Laboratories.

Tompkins, D.R., Anderson, M.A. 2001. Evaluation of Photocatalytic Air Cleaning Capability. Final report RP-1134. American Society of Heating, Refrigerating and Air-Conditioning Engineers.

VanOsdell, D., Foarde, K.2002. Defining the Effectiveness of UV Lamps Installed in Circulating Air Ductwork. Research Triangle Institute, Report No. ARTI-21CR/610-40030-01.

Walton, G.N., Dols, W.S. 2005. CONTAMW 2.4 User Guide and Program Documentation, NISTIR 7251. National Institute of Standards and Technology.

Zhang, J.S., Shaw, C.Y., Magee, R.J., Cheung, M.S.. 1995. Evaluation of Retrofit Measures for Improving Air-Tightness of Exterior Wall Components in a High-Rise Office Building.

Proceedings of Indoor Air Quality, Ventilation and Energy Conservation in Buildings, Montreal. Vol. 1, 315-322. 


\section{Appendix A: Life-Cycle Cost Analysis Tool for Chem/Bio Protection of Buildings: Software Primer (software available for download at http://www2.bfrl.nist.gov/software/LCCchembio/index.htm)}

\section{Background}

The National Institute of Standards and Technology (NIST) is a non-regulatory federal agency within the U.S. Commerce Department's Technology Administration. NIST develops and promotes measurement, standards, and technology to enhance productivity, facilitate trade, and improve quality of life. In the aftermath of the attacks of September 11, 2001, NIST has taken a key role in enhancing the nation's homeland security.

NIST's Building and Fire Research Laboratory (BFRL) has as its mission to meet the measurement and standards needs of the building and fire safety communities. A key element of that mission is BFRL's commitment to homeland security. Specifically, the goal of BFRL's homeland security effort is to develop and implement the standards, technology, and practices needed for cost-effective improvements to the safety and security of buildings and building occupants, including evacuation, emergency response procedures, and threat mitigation.

Due to concerns about potential airborne chemical and biological releases in or near buildings, building owners and managers and other decision makers are considering retrofitting their buildings to provide better protection against such events. A wide range of technologies and approaches are being proposed with varying levels of efficacy and cost, as well as with varying degrees of applicability to any particular building or ventilation system.

Through support from the EPA Safe Buildings Program, BFRL's Indoor Air Quality and Ventilation Group and the Office of Applied Economics (OAE) are developing guidance on building retrofit technologies and approaches to promote increased building protection from chemical and biological attack. This guidance will provide building owners, managers, engineers, and other decision makers with information about various retrofit strategies to improve the safety of their buildings against airborne hazards and with economic tools for use in selecting cost-effective approaches to mitigating those hazards.

The Life-Cycle Cost Analysis Tool (LCAT) for Chem/Bio protection of buildings incorporates and integrates research being conducted by OAE under the EPA Safe Buildings Program and under BFRL's homeland security effort. OAE's research focuses on developing economic tools to aid facility owners and managers in the selection of cost-effective strategies that respond to natural and man-made hazards. Economic tools include evaluation methods, standards that support and guide the application of those methods, and software for implementing the evaluation methods. OAE's research has produced a three-step protocol for developing a risk mitigation plan for cost-effective protection of constructed facilities. This protocol has three essential components: risk assessment, identification of potential mitigation strategies, and economic evaluation. LCAT is designed to help implement the third step in the protocol, economic evaluation.

A brief synopsis of the three-step protocol is provided here. Users interested in an in-depth description of the three-step protocol are referred to NISTIR 7073. Risk assessment is used to identify the risks confronting a facility and includes development of possible damage scenarios, probability assessments for these scenarios, and identification of the facility's vulnerabilities and critical areas. Identification of mitigation strategies provides performance and cost data for the possible combinations of risk mitigation strategies. Combinations of risk mitigation strategies are 
used to create a candidate set of alternatives for in-depth economic evaluation. The third component, economic evaluation, enables building owners and managers to evaluate each alternative combination of risk mitigation strategies and the sequence of cash flows associated with their implementation. The alternative combination that results in the lowest life-cycle cost is designated the cost-effective risk mitigation plan.

\section{Economic Evaluation Methods}

Several methods of economic evaluation are available to measure the economic performance of a new technology, a building system, or like investment, over a specified time period. Two of these methods - life-cycle cost and present value of net savings - are especially well suited to the economic evaluation of $\mathrm{Chem} / \mathrm{Bio}$ hazard mitigation retrofit strategies. OAE has extensive experience with both methods. OAE's research on life-cycle cost analysis spans more than 30 years. Early work by OAE economists led to the development of an industry consensus standard, ASTM E 917, for the life-cycle cost method. OAE's life-cycle cost research was extended to the economics of protection against natural disasters shortly thereafter. More recent work has focused on specifying cost-effective responses to terrorist risks. OAE's research on present value of net savings paralleled its research on the life-cycle cost method and led to the development of an industry consensus standard, ASTM E 1074. OAE's ongoing research links the standardized economic evaluation methods with a well-defined cost-accounting framework and software to make implementation straightforward. The algorithms "sit" behind the LCAT graphical user interface. OAE believes most users prefer it that way, so they can focus on only those data elements required to perform the life-cycle cost calculations. Users interested in mastering the calculation procedures/algorithms employed in LCAT are referred to NISTIR 7073.

\section{Life-Cycle Cost Method}

The life-cycle cost (LCC) method measures, in present-value or annual-value terms, the sum of all relevant costs associated with owning and operating a building over a specified period of time. The basic premise of the LCC method is that, to an investor or decision maker, all costs arising from that investment decision over time are potentially important to that decision. Applied to Chem/Bio hazard mitigation, the LCC method encompasses all relevant costs over a designated study period, including the costs of designing, retrofitting, constructing/installing, operating, maintaining, repairing, replacing, and disposing of a particular design or system. Pure benefits that result (e.g., increased rental income due to improvements) are also included in the calculation of LCC.

The LCC method is particularly suitable for determining whether the higher initial cost of a building or system specification is economically justified by lower future costs when compared to an alternative with a lower initial cost but higher future costs. If a design or system specification has both a lower initial cost and lower future costs relative to an alternative, an LCC analysis is not needed to show that the former is economically preferable.

The alternative with the lowest initial investment cost (i.e., first cost) is typically referred to as the base case. The LCC method compares alternative, mutually exclusive, Chem/Bio retrofit strategies that satisfy a minimum level of functionality to determine which is the least-cost means (i.e., minimizes life-cycle cost) of satisfying that level over a specified study period. 


\section{Present Value of Net Savings Method}

Information used to compute $\mathrm{LCC}$ can also be used to calculate the present value of net savings (PVNS). PVNS measures the net savings from investing in a given alternative instead of investing in the foregone opportunity (e.g., the base case). PVNS equals the difference between the LCC of the base case and the LCC of the mutually exclusive alternative under consideration. Any pure benefits that result (e.g., increased rental income due to improvements) are included in the calculation of PVNS, since they are included in the LCC calculation. With respect to the base case, if PVNS is positive, the alternative is economic; if it is zero, the alternative is as good as the base case; if it is negative, the alternative is uneconomical.

\section{Getting Started}

The software includes four case study applications. The four case study applications are: (1) a high-rise office building; (2) an office building lobby; (3) an office building mail room; and (4) a single-story office building. Associated with each case study application are two case study files. One file is a high-level summary of the proposed retrofit alternatives. The second file contains a detailed listing of cost items associated with each of the proposed retrofit alternatives. The case study files provide a convenient frame of reference through which you can learn about the capabilities of the software and experiment with the various means for editing, creating, and deleting data elements. The case study files are designed to illustrate a wide variety of software features through a set of simplified, yet fairly realistic building-related examples.

\section{Tips on Analysis Strategy}

Developing a cost-effective risk mitigation plan is a complicated process, entailing two distinct levels of analysis. This "analysis strategy" systematically adds increased detail to the decision problem. The first level is referred to as the baseline analysis. Here we are working with our best "guess" estimates. The baseline analysis provides a frame of reference for the sensitivity analysis, which systematically varies, selected sets of data elements to measure their economic impacts on project outcomes, such as the life-cycle costs of competing alternatives.

The starting point for conducting an economic evaluation is to do a baseline analysis. In the baseline analysis, all data elements entering into the calculations are fixed. For some data, the input values are considered to be known with certainty. Other data are considered uncertain and their values are based on some measure of central tendency, such as the mean or the median, or input from subject matter experts. Baseline data represent a fixed state of analysis. For this reason, the analysis results are referred to as the baseline analysis. The term baseline analysis is used to denote a complete analysis in all respects but one; it does not address the effects of uncertainty. When you open any of the case study files, the data elements displayed on the various software screens are the baseline values.

Sensitivity analysis measures the impact on project outcomes of changing the values of one or more key data elements about which there is uncertainty. Sensitivity analysis can be performed for any measure of economic performance (e.g., life-cycle cost or present value of net savings). Therefore, a sensitivity analysis complements the baseline analysis by evaluating the changes in output measures when selected data inputs are allowed to vary about their baseline values. 


\section{Overview of the Case Study Applications}

The case study applications describe a variety of Chem/Bio retrofit strategies for four prototypical building renovation projects. Note that the cost estimates are for purposes of illustration only - actual renovations of different building types will face different costs and different risk profiles. The cost data associated with the four prototypical building renovation projects are presented in Appendix $\mathrm{C}$ of this report, where they are presented at two levels of detail. A "summary" format highlights the key cost items. The summary listing records the type of cost information that would be suitable for presentation to senior management or other decision makers. The summary formats provide the basis for the four sets of Summary case study files - one for each prototypical building renovation project. A "detailed" format covers the type of cost information that would be provided as part of a building condition assessment. The detailed listing of cost items "rolls up" into the cost items listed in the summary format. The detailed formats provide the basis for the four sets of Detailed case study files.

\section{Assumptions and Cost Data}

Each of the four case study applications covers a 20 year period beginning in 2005. Life-cycle costs are calculated using a $7 \%$ real discount rate for the baseline analysis. Information on cost items is needed in order to calculate life-cycle costs. Cost items are classified under two broad headings: (1) protection costs and (2) event-related losses.

Protection costs represent all costs tied to the building or facility under analysis that are not associated with an event. Protection costs include the initial capital investment outlays for facilities and site work, future costs for filter replacements and electricity for fan motors, future costs for space heating and cooling, future renovations, and any salvage value for plant and equipment remaining at the end of the study period. Protection costs are classified as either investment costs or non-investment costs.

Event-related losses are based on annual outcomes, each of which has a specified probability of occurrence. Each outcome has a non-negative number of cost items associated with it (i.e., an outcome may have no cost items associated with it if it results in zero losses). Note that although logic is included within the software tool to handle event-related losses, no estimates of these losses are included in the case study applications. 


\section{High-Rise Office Building}

The objective is to protect an 11 story high-rise office building from external discharge of contaminants from a single source near the outside air intakes and from a larger cloud approaching the building. The floor area of the 11 story high-rise office building is $11148 \mathrm{~m}^{2}$ $\left(120000 \mathrm{ft}^{2}\right)$. The building was erected in the mid-1960s and has a rectangular configuration. The building has been well maintained and does not show significant signs of aging. The outside air intake louvers are approximately $6.1 \mathrm{~m}(20 \mathrm{ft})$ above the ground. A variety of materials compose the exterior envelope, including granite, marble, face brick, glass, and extruded aluminum. The facades on the short axis of the building are faced with grey face brick. The facades on the long axis of the building are insulated porcelain spandrel panels and fixed aluminum frame windows.

The high-rise office building includes a lobby and a mail room. Retrofit strategies to protect the lobby from a discharge of contaminants carried by an individual and to protect the mail room from introduction of contaminants in mail packages are handled in separate analyses.

To protect the building from an external release of contaminants, it is desirable to seal the building envelope and retrofit filters in the air-handling units. The proposed improvements are presented as three options. Each option has a different filtration level.

\section{Retrofit Alternatives for Protecting the High-Rise Office Building}

Option 1 (Filtration Level 1) provides a low level of particle filtration capability and no gaseous capability. Option 1 involves the following set of improvements. Sealing the exterior windows to make the building more airtight. Relocating the outside air intake to the roof. Replacing existing Minimum Efficiency Reporting Value (MERV) 6 filters with MERV 11 high capacity filters. Modifying the electrical feeders to accommodate higher motor horsepower. Providing an electrical quick shut off mechanism to stop the air handlers and return exhaust fans as needed during an emergency. Sealing and isolating six conference rooms to serve as shelters-in-place during an emergency.

Option 2 (Filtration Level 2) provides a high level of protection against particles but no gaseous protection. Option 2 involves the following set of improvements. Sealing the exterior windows to make the building more airtight. Relocating the outside air intake to the roof. Replacing existing MERV 6 filters with a three-stage filter consisting of: MERV 8 pre-filter, $85 \%$ efficient MERV 13 intermediate filter, and a 99.97 \% High Efficiency Particulate Air (HEPA) filter. Modifying the electrical feeders to accommodate higher motor horsepower. Providing an electrical quick shut off mechanism to stop the air handlers and return exhaust fans as needed during an emergency. Sealing and isolating six conference rooms to serve as shelters-in-place during an emergency.

Option 3 (Filtration Level 3) provides a high level of protection against particle and gaseous agents. Option 3 involves the following set of improvements. Sealing the exterior windows to make the building more airtight. Relocating the outside air intake to the roof. Replacing existing MERV 6 filters with a five-stage filter consisting of: MERV 8 pre-filter, $85 \%$ efficient MERV 13 intermediate filter, $99.97 \%$ HEPA filter, 99.9\% gas phase filter, and MERV 11 post filter. Modifying the electrical feeders to accommodate higher motor horsepower. Providing an electrical quick shut off mechanism to stop the air handlers and return exhaust fans as needed during an emergency. Sealing and isolating six conference rooms to serve as shelters-in-place during an emergency. 


\section{Office Building Main Lobby}

The objective is to protect the main lobby from a discharge of contaminants carried by an individual. The main lobby is a $4.3 \mathrm{~m}(14 \mathrm{ft})$ high space that is approximately $325 \mathrm{~m}^{2}\left(3500 \mathrm{ft}^{2}\right)$ in size. The lobby is defined by exterior glass curtain walls on two sides and marble finished walls on the other two sides. It is accessed from the exterior through a $14 \mathrm{~m}^{2}\left(150 \mathrm{ft}^{2}\right)$ glass enclosed vestibule with a series of two rows of four balanced glass doors. The lobby is open to an elevator bank.

To protect the main lobby from a discharge of contaminants carried by an individual, it is desirable to isolate the lobby with airtight walls and doors and to provide an air conditioning system dedicated to the lobby capable of maintaining the entire lobby under negative pressure. The system must also be capable of purging the lobby — one hundred percent outside air and exhaust - and filtering the supply and exhaust air. The proposed improvements are presented as two options. Each option has a different filtration level. The two options link to Filtration Levels 2 and 3 for the high-rise office building. Filtration Level 1 was not considered because it would not provide the level of protection desired for the main lobby.

\section{Retrofit Alternatives for Protecting the Main Lobby}

Option 1 (Filtration Level 2) provides a high level of protection against particles but no gaseous protection. Option 1 involves the following set of improvements. Isolate the open side of the lobby from the rest of the building by installing tempered glass partitions with self-closing doors that allow building occupants continued access to the lobby. Install a new air handling unit to serve the main lobby only. Relocate the outside air intake to the roof. Equip the air handling unit with a three-stage filter consisting of: MERV 8 pre-filter, $85 \%$ efficient MERV 13 intermediate filter, and a $99.97 \%$ HEPA filter. Modify electrical feeders to accommodate higher motor horsepower. Remove the existing exhaust fan and install two new exhaust fans: one to serve as return/exhaust fan to the existing air handling unit the second to return/exhaust the air to the new air handling unit and run an exhaust duct from the return duct to an existing louver near the fan and install filters at the discharge side of the new exhaust fan. Install a quick shut off mechanism to stop the fans. Maintain the main lobby under negative pressure with respect to the surrounding areas and the outdoors during normal operations and during an emergency.

Option 2 (Filtration Level 3) provides a high level of protection against particle and gaseous agents. Option 2 involves the following set of improvements. Isolate the open side of the lobby from the rest of the building by installing tempered glass partitions with self-closing doors that allow building occupants continued access to the lobby. Install a new air handling unit to serve the main lobby only. Relocating the outside air intake to the roof. Equip the air handling unit with a five-stage filter consisting of: MERV 8 pre-filter, $85 \%$ efficient MERV 13 intermediate filter, $99.97 \%$ HEPA filter, $99.9 \%$ gas phase filter, and MERV 11 post filter. Modify electrical feeders to accommodate higher motor horsepower. Remove the existing exhaust fan and install two new exhaust fans: one to serve as return/exhaust fan to the existing air handling unit the second to return/exhaust the air to the new air handling unit and run an exhaust duct from the return duct to an existing louver near the fan and install filters at the discharge side of the new exhaust fan. Install a quick shut off mechanism to stop the fans. Maintain the main lobby under negative pressure with respect to the surrounding areas and the outdoors during normal operations and during an emergency. 


\section{Office Building Mail Room}

The objective is to protect the mail room from contaminants coming in via mailed packages. The mail room is approximately $334 \mathrm{~m}^{2}\left(3600 \mathrm{ft}^{2}\right)$ in size. It has a $2.3 \mathrm{~m}$ (7 ft 8 in) high suspended acoustical ceiling and is enclosed with CMU walls and modular steel partitions. The mail room has three interior walls and one exterior wall. One wall and all interior partitions extend to the height of the ceiling. On two walls, a total of three single and double doors lead directly into interior corridors. There is a roll-up door on the exterior wall, which serves as a receiving area for the mail room.

To protect the mail room from contaminants coming in via mailed packages, it is desirable to isolate the mail room with airtight walls and doors and to provide a separate dedicated air conditioning system capable of maintaining the mail room under negative pressure. The system must also be capable of purging the mail room - one hundred percent outside air and exhaustand filtering the supply and exhaust air. The proposed improvements are presented as two options. Each option has a different filtration level. The two options link to Filtration Levels 2 and 3 for the high-rise office building. Filtration Level 1 was not considered because it would not provide the level of protection desired for the mail room.

\section{Retrofit Alternatives for Protecting the Mail Room}

Option 1 (Filtration Level 2) provides a high level of protection against particles but no gaseous protection. Option 1 involves the following set of improvements. Seal mail room envelope; walls, ceiling, doors, and slabs. Provide upgraded filtration to the existing air conditioning system and provide a new dedicated return/exhaust fan. Equip the existing air handling unit with a three-stage filter consisting of: MERV 8 pre-filter, $85 \%$ efficient MERV 13 intermediate filter, and a $99.97 \%$ HEPA filter. Modify electrical feeders to accommodate higher motor horsepower. Equip the existing exhaust fan with a MERV 8 pre-filter, an $85 \%$ efficient MERV 13 intermediate filter, and a $99.97 \%$ HEPA filter. Install a quick shut off mechanism to stop the fans. Maintain the mail room negative with respect to the surrounding areas and the outdoors during normal operations and during an emergency.

Option 2 (Filtration Level 3) provides a high level of protection against particle and gaseous agents. Option 2 involves the following set of improvements. Seal mail room envelope; walls, ceiling, doors, and slabs. Provide upgraded filtration to the existing air conditioning system and provide a new dedicated return/exhaust fan. Equip the existing air handling unit with a five-stage filter consisting of: MERV 8 pre-filter, $85 \%$ efficient MERV 13 intermediate filter, $99.97 \%$ HEPA filter, $99.9 \%$ gas phase filter, and MERV 11 post filter. Modify electrical feeders to accommodate higher motor horsepower. Equip the existing exhaust fan with a MERV 8 prefilter, an $85 \%$ efficient MERV 13 intermediate filter, a $99.97 \%$ HEPA filter, a $99.9 \%$ gas phase filter, and a MERV 11 post filter. Install a quick shut-off mechanism to stop the fans. Maintain the mail room negative with respect to the surrounding areas and the outdoors during normal operations and during an emergency. 


\section{Single-Story Office Building}

The objective is to protect a single-story office building from external discharge of contaminants from a single source near the outside air intakes and from a larger cloud approaching the building. The gross floor area of the office building is $1612 \mathrm{~m}^{2}\left(17350 \mathrm{ft}^{2}\right)$. The air conditioning system consists of 28 rooftop heat pumps. Each heat pump controls its own outdoor intake making it necessary to protect 28 air intake locations. The system does not have exhaust fans. The excess air is relieved through barometric dampers. Therefore, controlled purging is not possible. In addition, the rooftop units cannot be retrofitted with the necessary filters due to the low static pressure of the fans and lack of space to install the filters.

The physical arrangement of this building makes it difficult to retrofit the filters. The proposed improvements are presented as three options. Each option has a different filtration level. The three options link to Filtration Levels 1, 2, and 3 for the high-rise office building.

\section{Retrofit Alternatives for Protecting the Single-Story Office Building}

Option 1 (Filtration Level 1) provides a low level of particle filtration capability and no gaseous capability. Option 1 involves the following set of improvements. Seal the exterior envelope to make the building more airtight. Replace existing MERV 4 filters with MERV 11 filters. Install quick shut-off mechanism to stop the rooftop heat pumps.

Option 2 (Filtration Level 2) provides a high level of protection against particles but no gaseous protection. Option 2 involves the following set of improvements. Seal the exterior envelope to make the building more airtight. Provide an outside fan with a three-stage filter consisting of: MERV 8 pre-filter, $85 \%$ efficient MERV 13 intermediate filter, and a $99.97 \%$ HEPA filter. Duct the filtered air to the intake of each rooftop unit. Install the fan and filter on a new platform at roof level with the ductwork on the roof. Install quick shut-off mechanism to stop the rooftop heat pumps and outdoor air fans.

Option 3 (Filtration Level 3) provides a high level of protection against particle and gaseous agents. Option 3 involves the following set of improvements. Seal the exterior envelope to make the building more airtight. Provide an outside fan with a five-stage filter consisting of: MERV 8 pre-filter, $85 \%$ efficient MERV 13 intermediate filter, $99.97 \%$ HEPA filter, $99.9 \%$ gas phase filter, and MERV 11 post filter. Duct the filtered air to the intake of each rooftop unit. Install the fan and filter on a new platform at roof level with the ductwork on the roof. Install quick shut-off mechanism to stop the rooftop heat pumps and outdoor air fans.

\section{The Cost-Accounting Framework}

The flexibility of the life-cycle cost method enables us to classify and analyze costs in a variety of ways. The result is a more focused representation of costs, referred to as the cost-accounting framework. The cost-accounting framework provides a convenient means for summarizing all costs entering into the life-cycle cost calculations. The framework is organized around a Budget Category classification. The Budget Category classification uses cost types and cost items. The cost types are used as placeholders for summarizing and reporting aggregated cost information. Each cost type is a collection of cost items. Each cost item has a unique set of identifiers that places it within the cost-accounting framework.

The Budget Category classification has three cost types based on which category of the budget the funds come from. These cost types are: (1) Capital Investment; (2) O\&M (Operations and 
Maintenance); and (3) Other. These cost types correspond to widely used budget categories for private and public sector cost accounting. It is important to note that the dollar amounts accruing to all three cost types are inclusive of any expected event-related losses. In the context of the previous section, Capital Investment costs accrue to the investment cost category and O\&M and Other costs accrue to the non-investment cost category. All acquisition costs, including costs related to planning, design, purchase, and construction, are investment-related costs and fall under the Capital Investment cost type. Residual values (resale, salvage, or disposal costs) and capital replacement costs are also investment-related costs. Capital replacement costs are usually incurred when replacing major systems or components (e.g., replacing an exhaust fan) and are paid from capital funds. Cost items falling under the O\&M cost type include energy and water costs, maintenance and repair costs, and minor replacements (e.g., replacing belts and seals) related to maintenance and repair. O\&M costs are usually paid from an annual operating budget, not from capital funds. Other costs are non-capital costs that cannot be attributed to the O\&M cost type.

\section{Navigating Within the Software}

This section gives you a guided tour of Version 1.0 of the Life-Cycle Cost Analysis Tool (LCAT 1.0). The goal of the guided tour is for you to work systematically through the hierarchy of screens used to input, analyze, and display project-related data.

\section{Opening/Creating a Project File}

Launch the software by clicking on LCAT 1.0 icon found on your desktop or by clicking LCAT 1.0 in the Start menu in Programs/Life-Cycle Cost Analysis Tool. The first screen to appear prompts you to open an existing project file, create a new project file, or open an example project. Figure A1 is a reproduction of the Prompt window. Recall that the software comes with a set of case study files. Thus, even when you launch the software for the first time, there are already several example project files, any of which you may choose to open. If you select $O p e n$ an Existing Project or Open an Example Project and click the Start button, then you will be taken to the Open Project window. The Prompt window also includes a View Tips check box. If you select View Tips and click the Start button, you will be taken to the Software Tips window. (Throughout this section, software features (e.g., buttons) are highlighted through the use of italics font.)

Figure A2 displays the Software Tips window. The Software Tips window is designed as a handy reference for first-time users. It highlights material contained in this Primer as well as several basic concepts for navigating within the software and for saving results.

As a first step, open one of the case study files and use the File Save As feature to make additional copies with $l c c$ extensions. Suggested file names are test01.lcc and test02.lcc. Use the test files to gain familiarity with the software. This way, if you inadvertently change or delete a data element, or create a new data element, you can go back to the case study file for the reference solution. When you use the File Save As feature with one of the case study files, the new file (e.g., test01.lcc) will be saved in the "existing projects" directory. If you exit the software and later wish to open a user-created "test" file, you will need to select Open an Existing Project from the Prompt window.

Figure A3 is a sample Open Project window. Figure A3 lists the various case study files provided with the software. The Open Project window shown in Figure A3 was opened by 
selecting the Open an Example Project option in the Prompt window and clicking the Start button. Note that the high-rise office building has two case study files-High-Rise Office (Summary).lcc and High-Rise Office (Detailed).lcc. The "summary" file is an abbreviated version of the high-rise office building case study. It provides a convenient means for highlighting key features of the software. It is used within the Primer to illustrate these software features. The "detailed" file demonstrates how to handle a fairly complicated retrofit project. It focuses on breaking out the various cost items presented in the summary file into their constituent parts.

Highlighting the desired file and clicking the Open button opens that file. Double clicking on the highlighted file opens the file as well. The Open Project window includes a Cancel button. If you click on the Cancel button, you will return to the Prompt window.

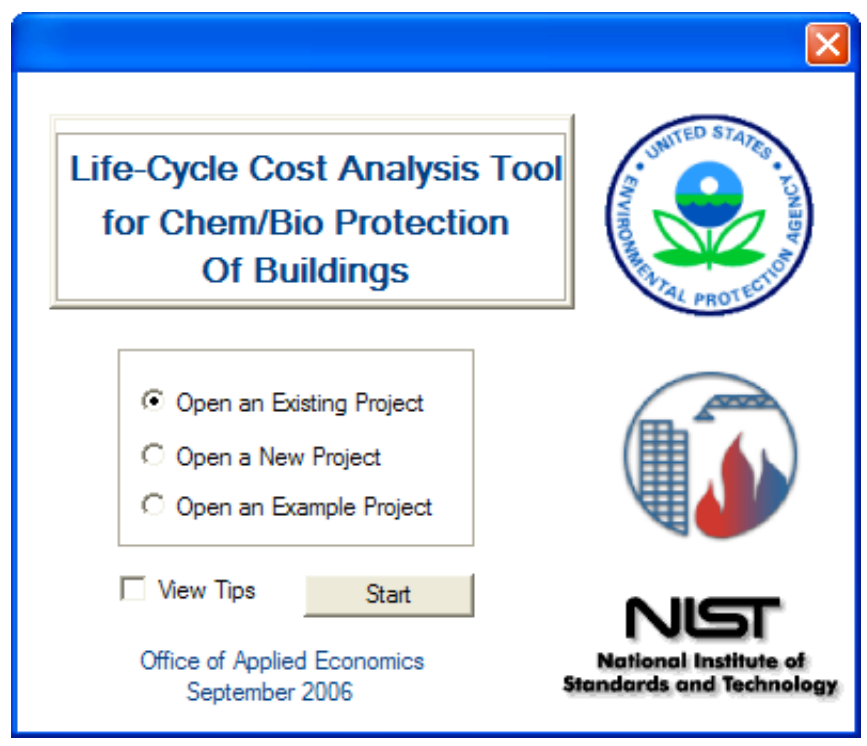

Figure A1 Life-Cycle Cost Analysis Tool Prompt Window 


\section{Welcome!}

This software enables you to define hazard scenarios, identify possible consequences of those scenarios and compare costs associated with different strategies for protecting your facilities from Chem/Bio hazards.

The following are a few tips for using the software.

- View the software primer, case study examples, and a glossary of terms, by clicking on the Help menu.

- Use the $\underline{X}$ in the upper right hand corner to exit a window.

- Save your data while working by clicking Save from the File menu.

- Enter data following the tree hierarchy in the Cost Summary Window starting with the Description section then add data for Alternatives and finally enter the Cost/Loss information.

- Evaluate how changes in a single variable impact the calculated values of life-cycle costs in the Sensitivity Analysis section.

- Use the Data report to verify data inputs. Use the Results report to rewiew the results.

\section{Figure A2 Software Tips Window}

\begin{tabular}{|c|c|c|}
\hline Open Example Project & & $?$ \\
\hline Look in: $\square$ example & \multicolumn{2}{|c|}{ 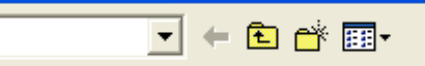 } \\
\hline 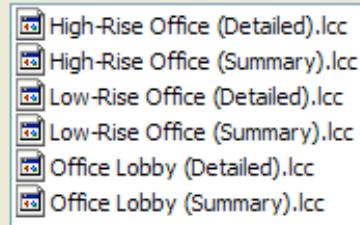 & \multicolumn{2}{|c|}{$\begin{array}{l}\text { 國 Office Mail Room (Detailed).lcc } \\
\text { 國 Office Mail Room (Summary).lcc }\end{array}$} \\
\hline File name: $\quad$ Floc & & Open \\
\hline Files of type: $\quad$.Icc & $\nabla$ & Cancel \\
\hline
\end{tabular}

\section{Figure A3 Open Project Window}

\section{Cost Summary Window and Main Menu}

The Cost Summary window is displayed whenever a new project is started, an existing project file is opened, or a case study file is opened. When a project is created, the Cost Summary window is blank. Figure A4 is an example of the Cost Summary window display when starting a new project. As you enter data into the software, the Cost Summary window displays the current value of life-cycle costs for each cost type and alternative being analyzed. It is recommended that 
you keep the Cost Summary window open while working in the software. If you wish to close the window, it can be reopened at any time by selecting Project from the tool bar and then selecting Cost Summary.

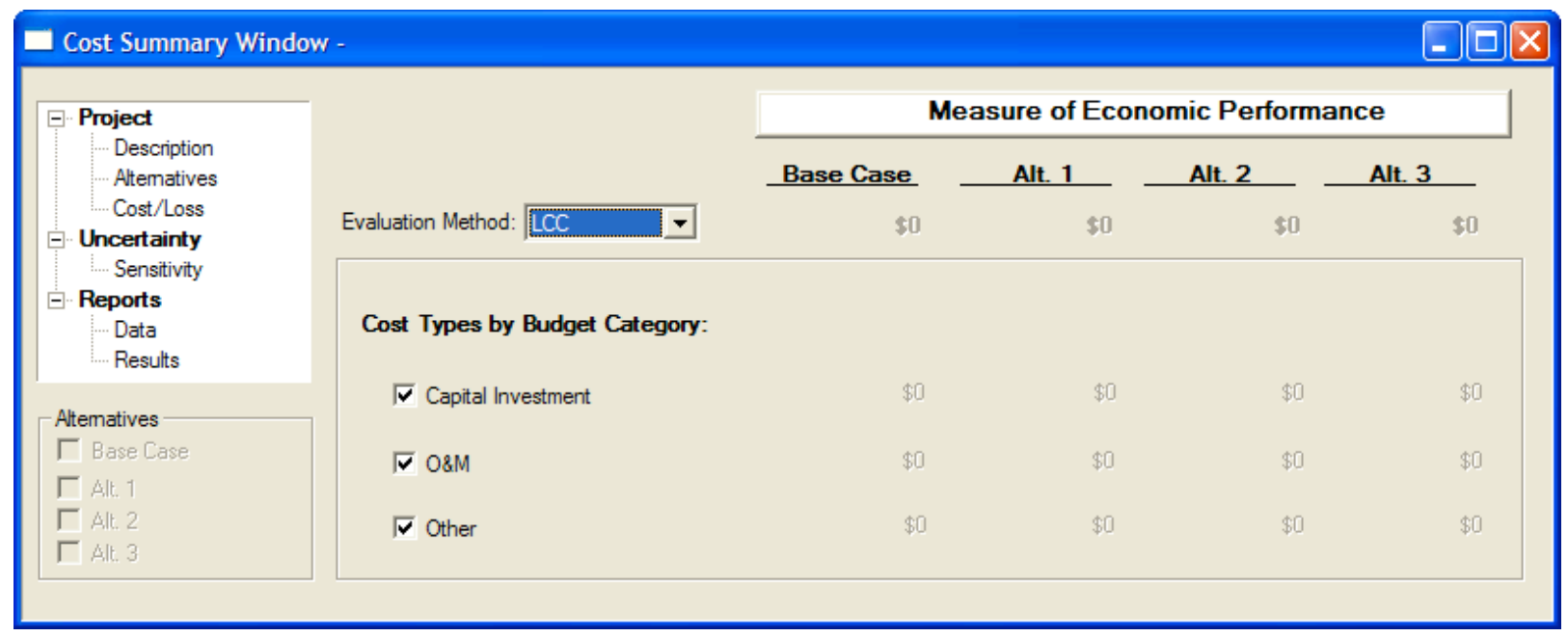

\section{Figure A4 Cost Summary Window When Starting a New Project}

The software is designed to analyze up to four alternatives (see Figure A4). The Cost Summary window allows you to select both the cost types and the alternatives to be included in the economic evaluation. These "choices" are represented in Figure A4 by the "cost type" check boxes and the "alternative" check boxes within the Alternatives group box in the lower left-hand corner.

A tree on the left-hand side of the Cost Summary window serves as the Main Menu to the software. The tree contains three top-level nodes: Project, Uncertainty, and Reports. Recall that software features are highlighted through the use of italics font. The tool bar at the top of the Cost Summary window provides another means for accessing the three top-level nodes. The tool bar also includes File and Help options. File options include Save, Save As, Close Project, and Exit. Help options include Tips, which opens the Software Tips window, and Help, which opens an on-line version of the Primer and a Glossary of Terms. If you wish to print the on-line Primer from the Help menu, click Print the selected topic option from the Print Topics pop-up window and then select which printer from the pop-up Print window.

\section{Project Information}

The options listed under the Project node allow you to enter project information, define alternatives, and manage cost-related information.

Clicking the Description option on the Main Menu opens the Project Description window. Here you can enter project information such as the project's name, a brief description of the project, the base year selected for all present value calculations, the length of the study period, whether a constant dollar or current dollar analysis is to be performed, and the discount rate. Note that when a constant dollar analysis is selected, you must use a real discount rate. When a current dollar analysis is selected, you must use a nominal discount rate. Within LCAT 1.0, the nominal discount rate and the real discount rate are linked via a formula that includes a term for general 
inflation. Figure A5 displays the Project Description window for the high-rise office building case study. The descriptive material is designed to help decision makers differentiate among multiple projects competing for limited investment funds.

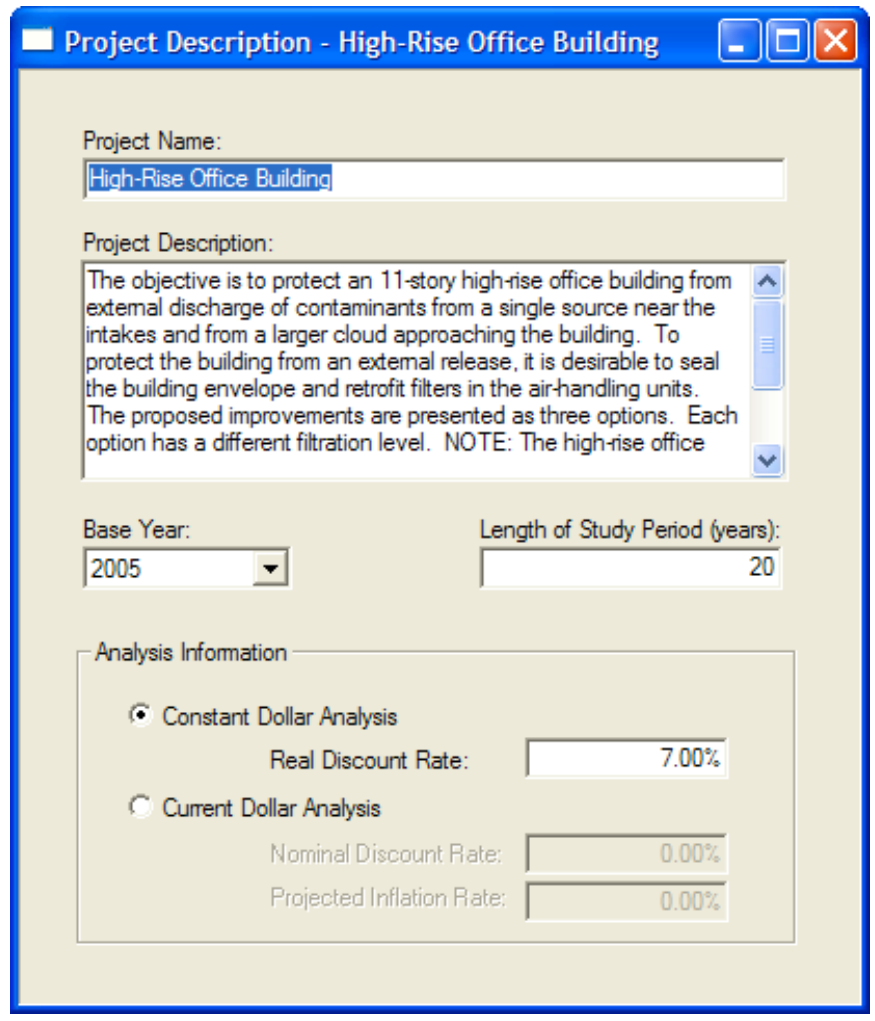

\section{Figure A5 Project Description Window for the High-Rise Office Building Case Study}

Clicking the Alternatives option opens the Project Alternatives window, which allows you to add and delete project alternatives as well as enter information about the alternatives. Figure A6 displays the Project Alternatives window for the high-rise office building case study. The Base Case tab is selected. The window is constructed so you can switch from one alternative to another. The text box in the middle of the window allows you to enter a brief description of the alternative, which serves to differentiate one alternative from another. 


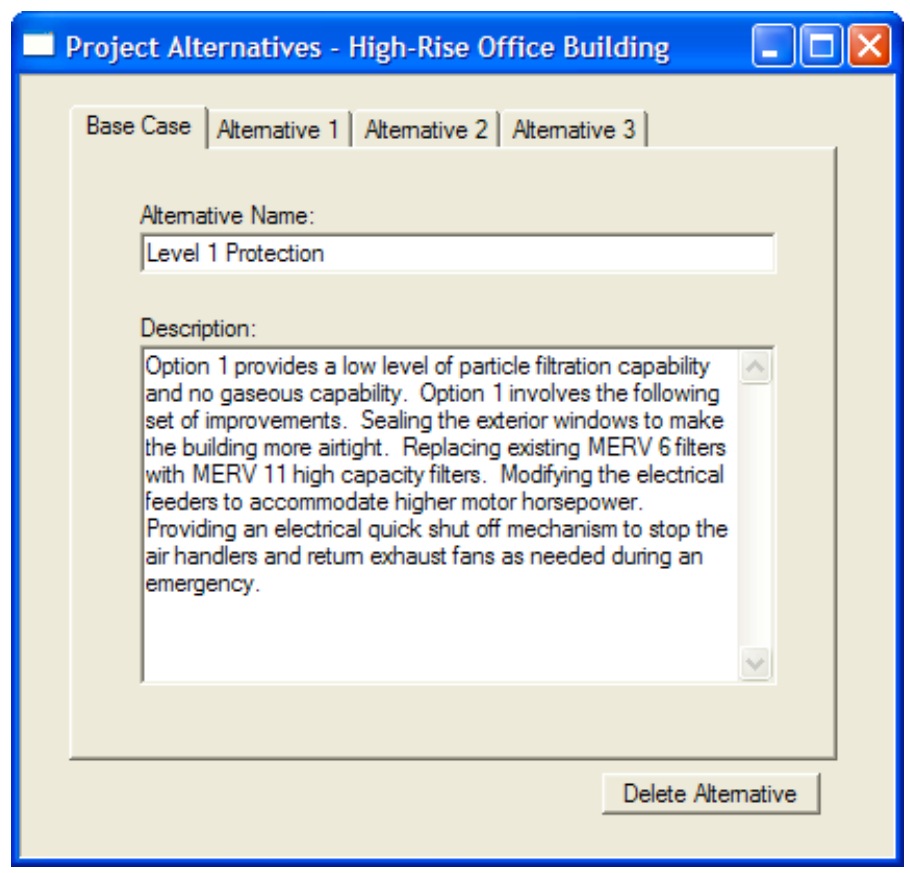

\section{Figure A6 Project Alternatives Window for the High-Rise Office Building Case Study}

Cost-related input screens for the software product are of two basic types: (1) protection costs and (2) event-related losses. You access these screens by selecting the Cost/Loss option on the Main Menu.

\section{Protection Costs}

Clicking the Cost/Loss option opens the Protection Costs/Event-Related Losses window. This screen manages the creation, deletion, and editing of protection costs and event-related losses. Upon entering the Protection Costs/Event-Related Losses window, you must select the alternative for which information is to be reviewed or input. Both the costs and events portions of the window are active for the selected alternative. Since our focus is on protection costs, however, we will address only the cost portion of the window here. The following subsection deals with event-related losses. Once the alternative is selected, the Protection Costs/EventRelated Losses window displays all cost items associated with that alternative. Figure A7 is an example of the Protection Costs/Event-Related Losses window for the Base Case. Notice that the protection costs are listed in alphabetical order according to their Budget Category-Investment, O\&M, and Other. If a large number of cost items have been entered, some costs will be hidden, but can be viewed by scrolling down the list. In this case, no costs are hidden. 


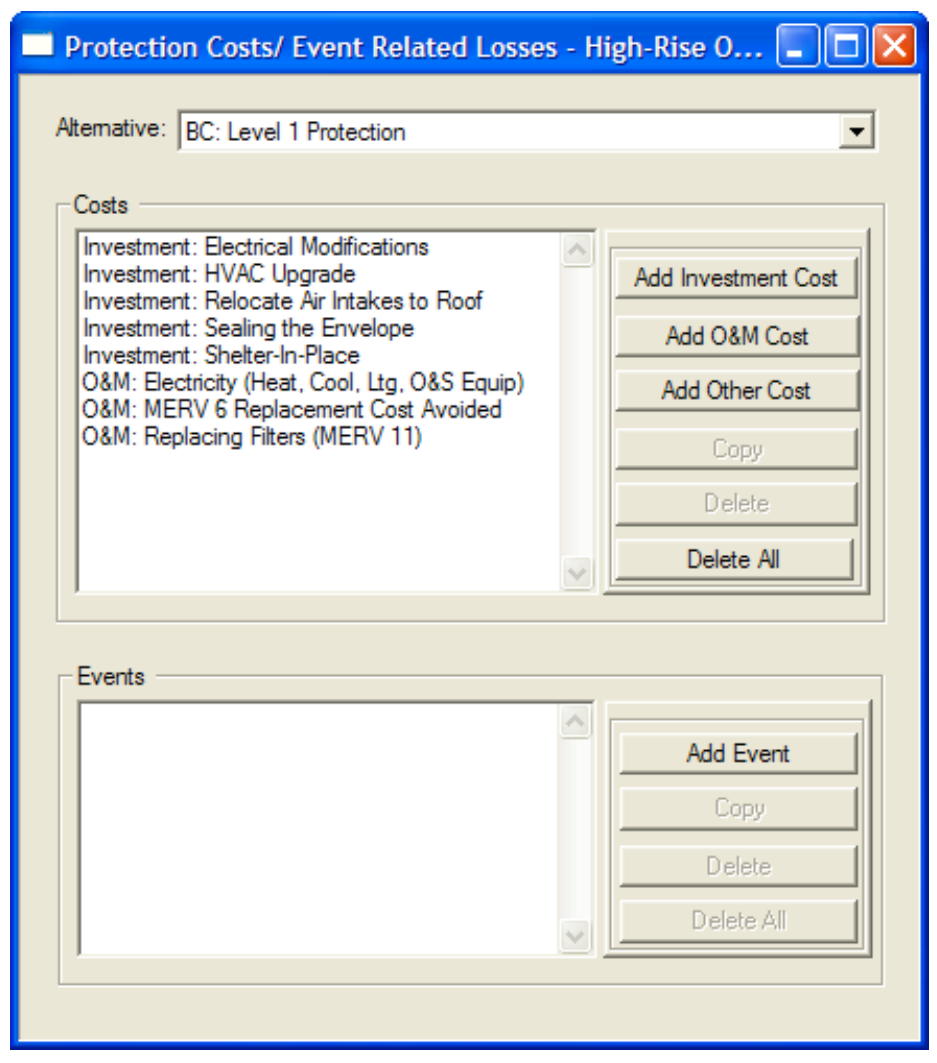

\section{Figure A7 Protection Costs/Event-Related Losses Window for the High-Rise Office Building Case Study: Protection Costs for the Base Case}

Highlighting and clicking the selected cost item opens the appropriate Cost Information window. This "edit" feature allows you to review and, if desired, modify any previously recorded information for the cost item of interest. Figure A8 is an example of the Capital Investment Cost Information window for the high-rise office building case study. Figure A8 displays information on the HVAC Upgrade cost item for Alternative 1 (Option 2, enhanced protection from biological agents). Figure A9 is an example of the O\&M Cost Information window for the Replacing HEPA Filters cost item for Alternative 1. Figure A10 is an example of the Other Cost Information window for the Change in Traffic Pattern cost item for Alternative 2 (Option 3 , enhanced protection from chemical and biological agents).

The Protection Costs/Event-Related Losses window is the means through which new cost items are created. The creation of a new cost item is accomplished by selecting the appropriate Budget Category cost type button-Add Investment Cost, Add O\&M Cost, or Add Other Cost-from the list on the right. The software then opens the Cost Information window associated with the selected cost type. The Cost Information windows allow you to name the cost item, generate a cost estimate via separate entries for quantity and unit cost, and specify the timing of cash flows and any escalation rates that need to be applied (see Figures A8, A9, and A10). 
Cost Item: HVAC Uparade

Quantity:

Unit Cost:

\begin{tabular}{|r|}
$\longdiv { 1 . 0 0 }$ \\
\hline S 209.445 .00
\end{tabular}

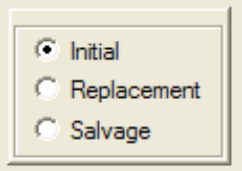

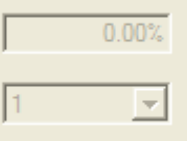

Figure A8 Capital Investment Cost Information Window for the High-Rise Office Building Case Study: HVAC Upgrade for Alternative 1

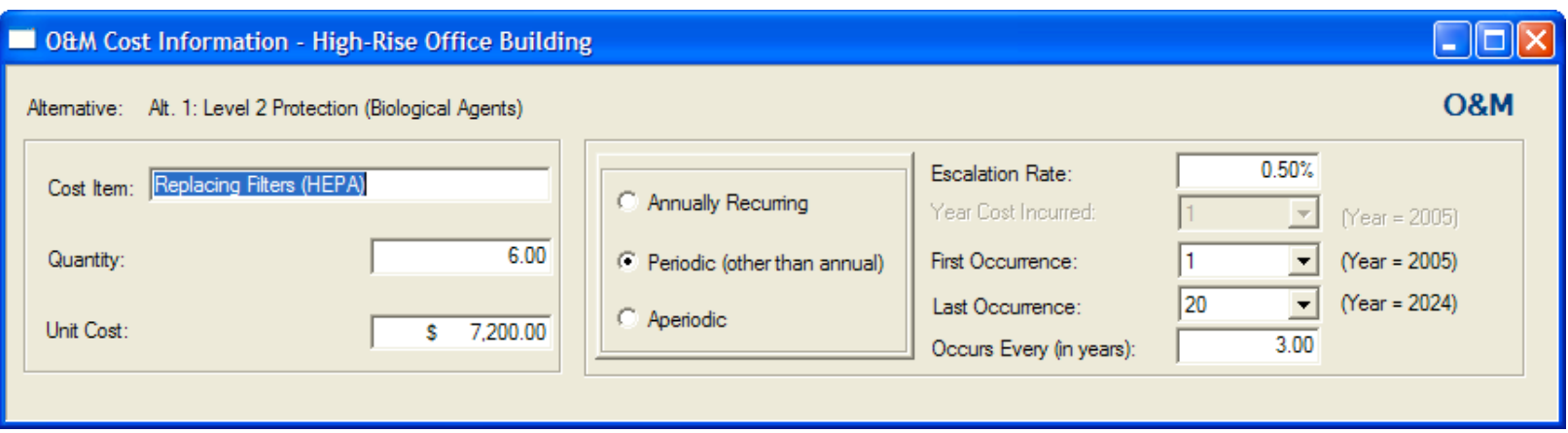

Figure A9 O\&M Cost Information Window for the High-Rise Office Building Case Study: Replacing HEPA Filters for Alternative 1

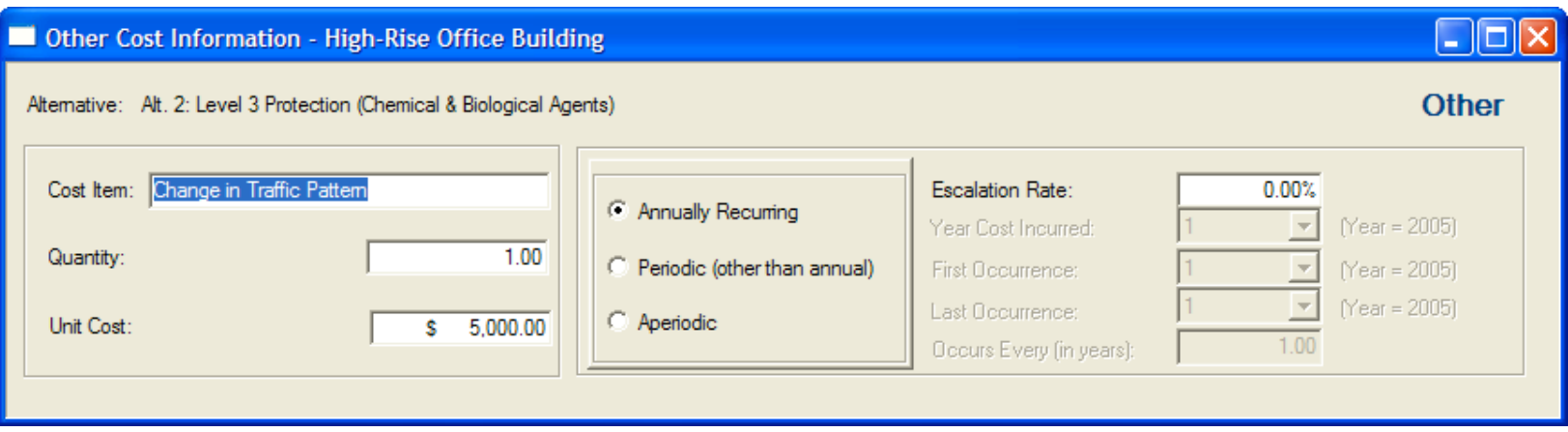

\section{Figure A10 Other Cost Information Window for the High-Rise Office Building Case Study: Change in Traffic Pattern for Alternative 2}

Reference to Figures A8, A9, and A10 record the cost choices that map individual cost items into the cost types reported in the Cost Summary window. The Capital Investment Cost Information window offers three choices for classifying a cost item: (1) Initial; (2) Replacement; and (3) Salvage. An initial investment cost, as its name implies, occurs at the beginning of the Base Year (i.e., Year 1 or, in this case, 2005). A capital replacement cost occurs in some future year. Use the drop down menu to specify the year in which the capital replacement is to take place, recalling that Year 1 is the Base Year. A salvage value is a negative capital cost (i.e., a receipt) occurring at the end of the study period. The salvage value is the value of the asset, assigned for 
tax computation purposes, that is expected to remain at the end of the depreciation period. The choices for classifying a cost item for O\&M and Other costs (see Figures A9 and A10) are the same: (1) Annually Recurring; (2) Periodic (other than annual); and (3) Aperiodic. Periodic costs, such as HEPA filter replacements, occur less frequently than annually - say every three years. Aperiodic costs are one-time costs that occur at some point in the future. If feasible, when preparing estimates for a cost item, include allowances for design/engineering services, taxes, overhead, and other indirects. 


\section{Event-Related Losses}

Treatment of event-related losses is an important part of a "balanced" life-cycle cost analysis whenever chem/bio or other man-made or natural hazards are involved. LCAT 1.0 treats events as a hierarchy. Associated with an event are outcomes and outcome probabilities. Associated with outcomes are outcome costs. The combination of outcome probabilities and outcome costs are the "losses" associated with a given event.

As noted earlier, clicking the Cost/Loss option opens the Protection Costs/Event-Related Losses window. This screen manages the creation, deletion, and editing of protection costs and eventrelated costs. Upon entering the Protection Costs/Event-Related Losses window, you must select the alternative for which information is to be reviewed or input. Both the costs and events portions of the window are active for the selected alternative. However, we will address only the event-related costs portion of the window here. Once the alternative is selected, the screen displays all events associated with that alternative.

Highlighting and clicking the selected event opens the Event Information window. This feature allows you to review and, if desired, modify any previously recorded information for the event of interest. The Protection Costs/Event-Related Losses window is the means through which new events are created. The creation of a new event is accomplished by selecting Add Event from the list on the right. The software then opens the Event Information window. The Event Information window allows you to name the event, provide a brief description of the event, enter the dates of first and last occurrence, and edit event-related outcomes. First occurrence and last occurrence specify the period of time over which a specific set of event-related losses occur. The rationale behind "breaking" events up into segments over the study period is that some mitigation measures may affect outcome probabilities. Such mitigation measures, if implemented in the future, might significantly reduce outcome probabilities and hence event-related losses. Figure A11 is an example of the Event Information window.

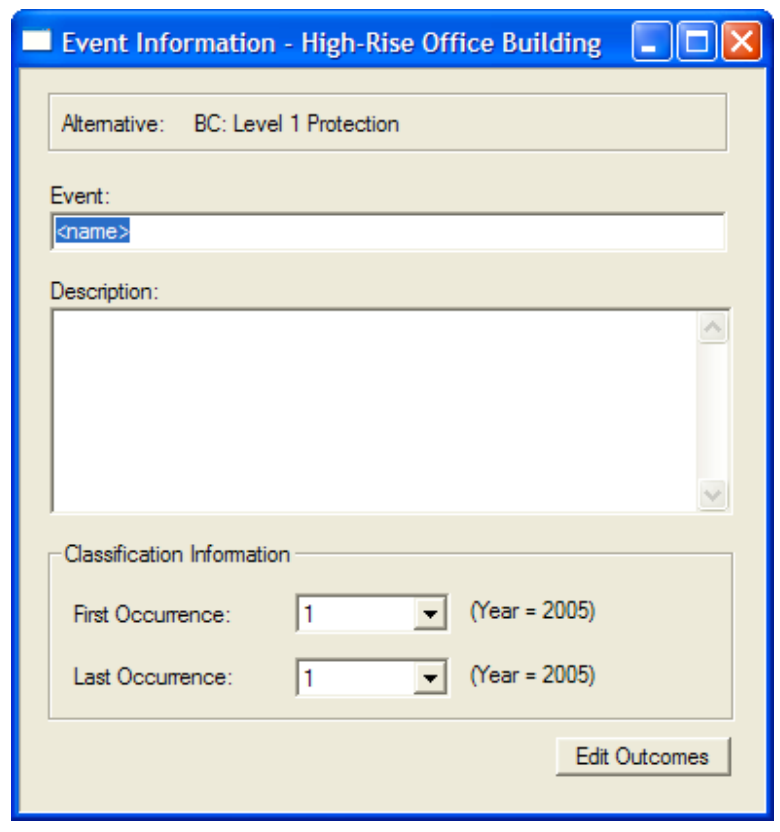

Figure A11 Event Information Window 
Associated with each event is a set of outcomes. Information on event-related outcomes is accessed via the Outcomes/Outcome Costs window. This screen is reached by clicking the Edit Outcomes option in the Event Information window (see Figure A11). Clicking the Edit Outcomes option opens the outcomes portion of the Outcomes/Outcome Costs window. Figure A12 is an example of the Outcomes/Outcome Costs window. This screen manages the creation, deletion, and editing of outcomes. The Outcomes/Outcome Costs window displays all outcomes associated with the event of interest. The event/outcome costs portion of the Outcomes/Outcome Costs window is initially grayed out, indicating that it is inactive. However, once an outcome is selected, the costs associated with that outcome become active.

Highlighting and clicking the selected outcome opens the appropriate Outcome Information window. This feature allows you to review and, if desired, modify any previously recorded information for the outcome of interest. The Outcomes/Outcome Costs window is the means through which new outcomes are created. The creation of a new outcome is accomplished by selecting Add Outcome from the list on the right. The software then opens the Outcome Information window. The Outcome Information window allows you to name the outcome, provide a brief description of the outcome, assign a probability of occurrence for the outcome (outcome probabilities are a byproduct of the risk assessment), update the sum of all outcome probabilities for the event of interest, and edit outcome-related cost items. Figure A13 is an example of the Outcome Information window.

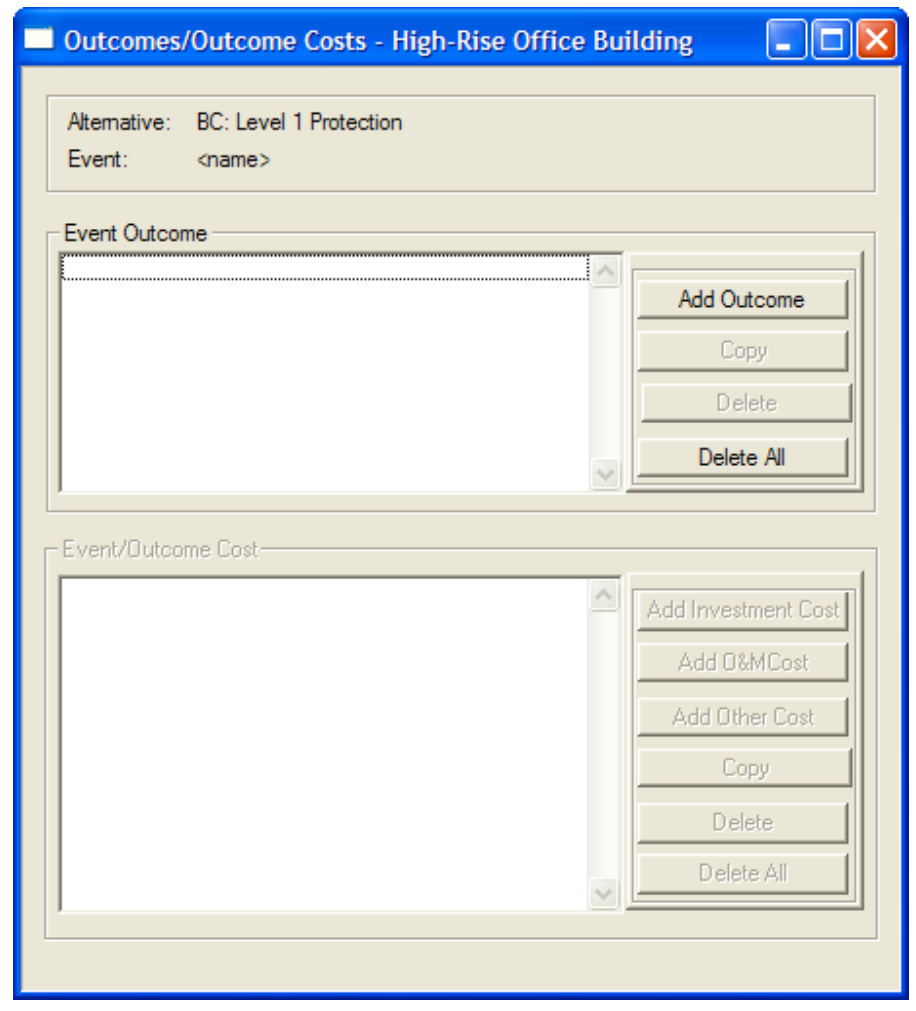

Figure A12 Outcomes/Outcome Costs Window 
Outcomes are characterized by their severity and their occurrence probabilities. An event includes the full range of outcomes from no damage to extreme damage. For a given event, the sum of all outcome probabilities equals 1.0. Thus the no damage outcome would usually have a very high probability, corresponding to maintenance of the status quo, whereas an extreme damage outcome would have a very low probability. Outcome probabilities are the "key" driver of event-related losses, since these losses are "expected" values. Outcome probabilities are expressed as annual values. Thus, the "chance" an event-outcome combination occurs in a given year equals its outcome probability.

Because event-related losses are expected to have a major influence on which alternative is the most cost effective, the sum of all outcome probabilities is required to equal 1.0 in order for either the Data Report or the Results Report to be output. OAE's objective was to avoid situations where losses were either ignored (i.e., a sum less than 1.0) or double counted (i.e., a sum greater than 1.0). Once an event has been created and one or more outcomes assigned to it, it is possible to edit the outcome probabilities. Once the sum of all outcome probabilities equals 1.0 (100\% in the Probability Information group box), it is possible to generate both the Data Report and the Results Report. The Data Report is designed as a check on user-supplied inputs, so it includes the outcome probabilities.

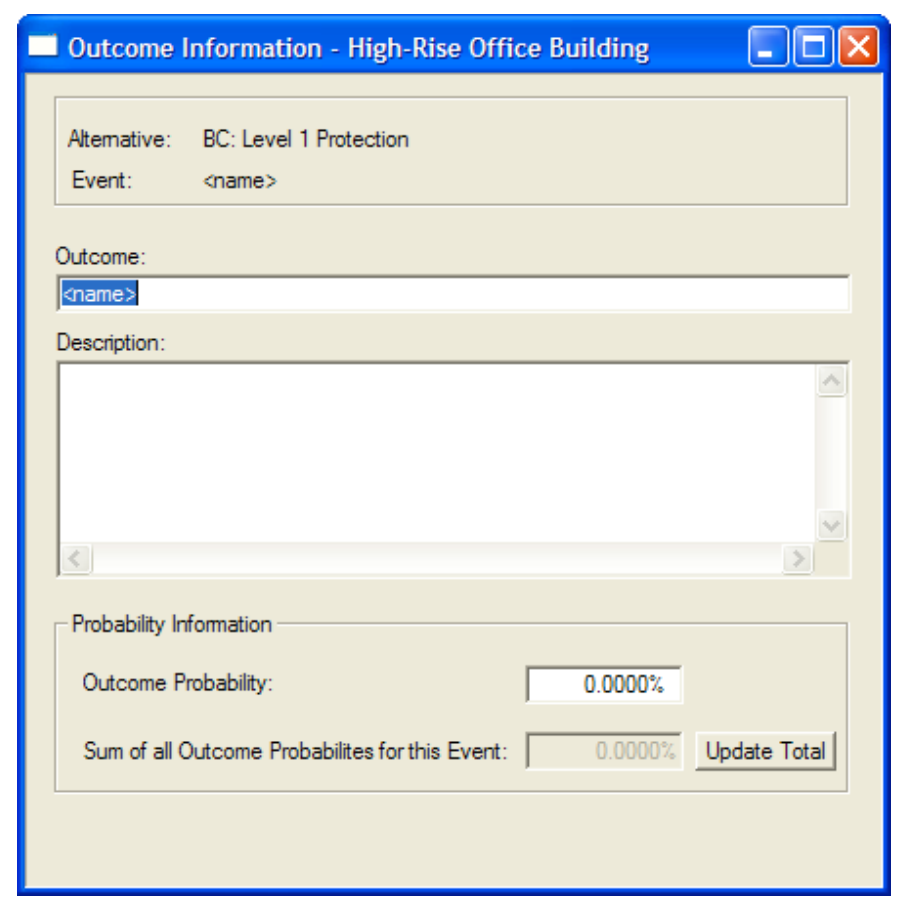

\section{Figure A13 Outcome Information Window}

Associated with each outcome is a set of event-related cost items. Typical event-related cost items are damage to the facility, loss of use of the facility (e.g., function and contents), and medical expenses. For example, if an event-outcome combination produced damage to the facility, equipment replacements might result. Information on event-related cost items is accessed by closing the Outcome Information window (see Figure A13), which reveals the event/outcome cost portion of the Outcomes/Outcome Costs window. This screen manages the 
creation, deletion, and editing of event-related cost items. The Outcomes/Outcome Costs window displays all event-related cost items associated with the outcome of interest.

Highlighting and clicking the selected event-related cost item opens the appropriate

Event/Outcome Cost Information window. This feature allows you to review and, if desired, modify any previously recorded information for the event-related cost item of interest. The Outcomes/Outcome Costs window is the means through which new event-related cost items are created. The creation of a new event-related cost item is accomplished by selecting the appropriate Budget Category cost type button-Add Investment Cost, Add O\&M Cost, or Add Other Cost - from the list on the right. The software then opens the Event/Outcome Cost Information window. The Event/Outcome Cost Information window allows you to name the event-related cost item, generate a cost estimate via separate entries for quantity and unit cost, and specify any escalation rates that need to be applied. Figure A14 is an example of the Event/Outcome Cost Information window.

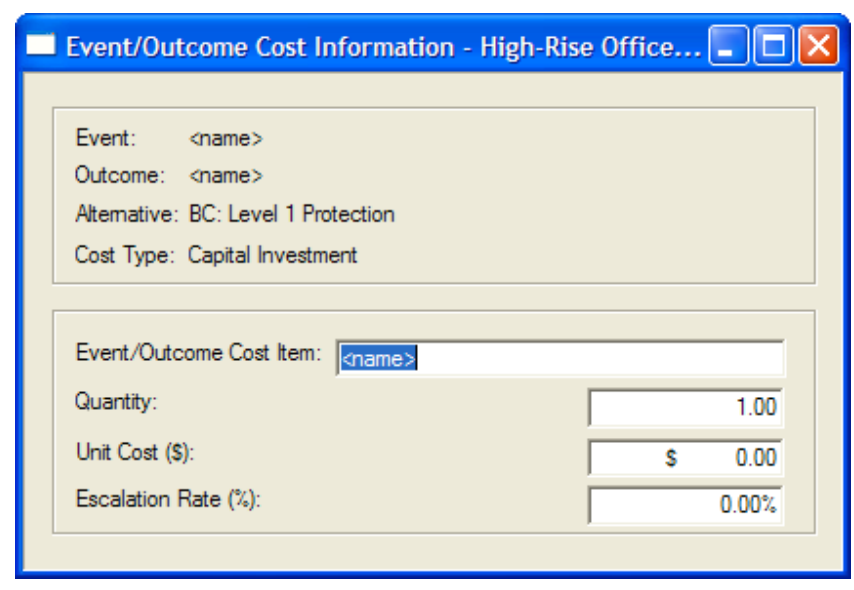

Figure A14 Event/Outcome Cost Information Window

\section{Cost Summary Window}

Once all data have been input, the Cost Summary window displays the life-cycle costs for each alternative. Costs are reported for each cost type and in total. Figure A15 reproduces the Cost Summary window for the completed baseline analysis for the high-rise office building case study. 


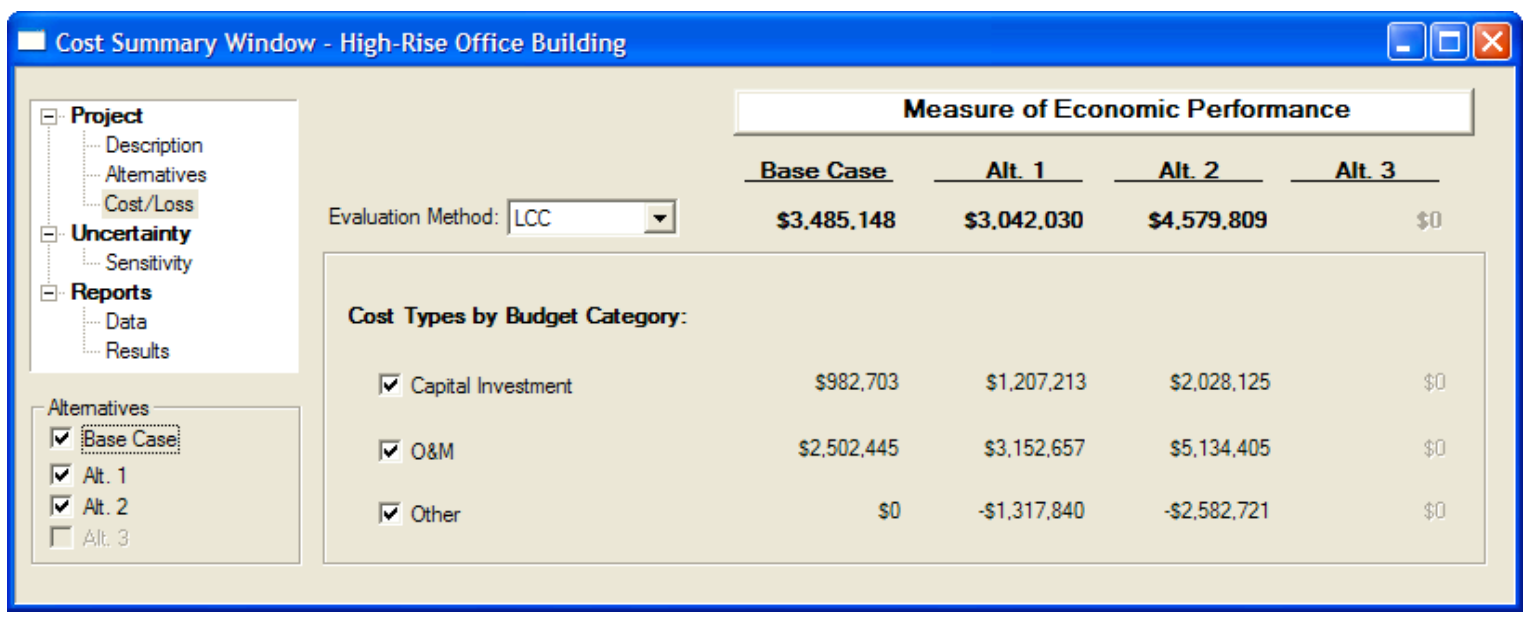

\section{Figure A15 Cost Summary Window for the High-Rise Office Building Case Study: Baseline Analysis}

The Cost Summary window provides the option for you to view calculated values for a measure of economic performance other than life-cycle costs. The drop down menu in the Evaluation Method box lets you select the PVNS (present value net savings) as an alternative measure of economic performance. The PVNS values reported on the Cost Summary window are calculated vis-à-vis the Base Case. PVNS measures net savings of investing in the given alternative instead of investing in the Base Case. Thus when the PVNS method is selected, the only meaningful values are the ones listed under the column headings Alt. 1, Alt. 2, and Alt. 3.

\section{Sensitivity Analysis}

Recall that in the baseline analysis all data elements entering into the calculations are fixed. Thus, the baseline analysis is a complete analysis in all respects but one: it does not address the effects of uncertainty. Note that the baseline analysis for the four case study applications includes only protection costs.

Sensitivity analysis, as implemented in LCAT 1.0, lets you evaluate how changes in a single variable impact the calculated values of life-cycle costs. The sensitivity analysis feature in LCAT 1.0 is based on techniques presented in ASTM Standard Guide E 1369. Depending on the variable selected, it may impact a single alternative or it may impact all alternatives.

The Sensitivity Analysis window is entered by clicking the Sensitivity option under the Uncertainty node. The window, as configured in Version 1.0, has a single tab, Change in a Single Factor.

The left-hand side of the Change in a Single Factor tab lists the hierarchy of factors that can be evaluated. Each factor is associated with a node in the hierarchy. Upon entering the tab, the Project and Alternatives nodes appear at the left. All alternatives evaluated in the baseline analysis are listed immediately below the Alternatives node. The squares immediately to the left of each node in the hierarchy are marked with a + (plus sign) or a - (minus sign). A plus sign means that additional nodes and/or factors reside beneath that node. A minus sign means that a node has been opened. Since each project has alternatives associated with it, upon entering the 
Change in a Single Factor tab, you will note that the Alternatives node has a minus sign in its square on the left.

Nodes can be opened or closed. For example, clicking the square by the Project node opens the node and the single factor Discount Rate (7.00 \%) appears beneath it. Note that there is no square to the left of Discount Rate. This means that Discount Rate is a factor that can be selected for evaluation. Note that the factor line in the hierarchy includes both the factor name (Discount Rate) and its value (7.00\%). Highlighting the factor Discount Rate $(7.00 \%)$ selects that factor. The right-hand side of the screen includes the Results group box, a drop down menu for percent changes about the baseline value of the selected factor, and a Compute button. Clicking on the Compute button causes three sets of values to be computed. Figure A16 shows the results of a $10 \%$ deviation about the baseline value of the discount rate. Note that the name of the factor appears at the upper left-hand corner of the Results group box. Since the Discount Rate is the same for each alternative, results for the Base Case, Alternative 1, and Alternative 2 are reported. Note that the Minimum, Baseline, and Maximum values for the factor, Discount Rate, are displayed. Reference to Figure A16 shows that the discount rate has a fairly strong impact on the computed value of life-cycle costs for the Base Case, Alternative 1, and Alternative 2.

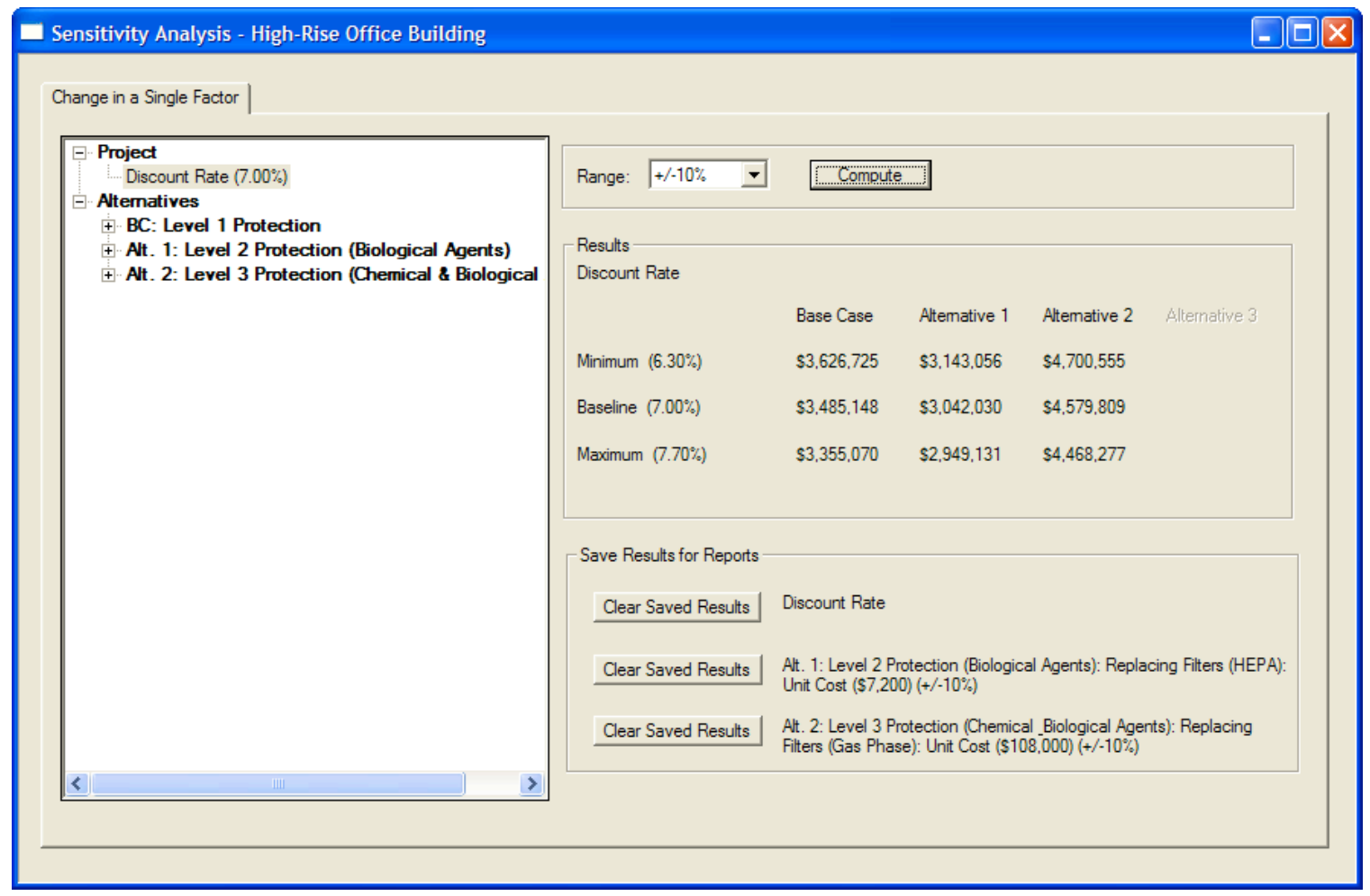

\section{Figure A16 Sensitivity Analysis Window: Using the Change in a Single Factor Tab to Evaluate the Impact of the Discount Rate on Life-Cycle Costs}

Figure A17 uses Alternative 2 to illustrate how to open up the hierarchy within a given alternative. The nodes immediately beneath the Alt. 2: Level 3 Protection (Chemical \& Biological Agents) node are labeled Costs and Events. Additional nodes are listed beneath the Costs node. Opening the Costs node, we see that 11 nodes are listed beneath it. These nodes correspond to the cost items entered via the Capital Investment, O\&M, and Other Cost 
Information windows. Note that each of the 11 nodes indicates the budget category it falls under. One of the 11 nodes has been opened - O\&M: Replacing Gas Phase Filters - to reveal factors. The factor selected for analysis is the Unit Cost of Replacing Gas Phase Filters. Under the Range drop down menu, we have selected a $10 \%$ deviation about the baseline value of the annually recurring Unit Cost of \$108 000 (i.e., \$648 000 for all six units). Clicking the Compute button causes three sets of values to be computed. Because this factor only affects Alternative 2, only values for Alternative 2 are displayed. Reference to the Results group box reveals that this factor has a strong impact on life-cycle costs.

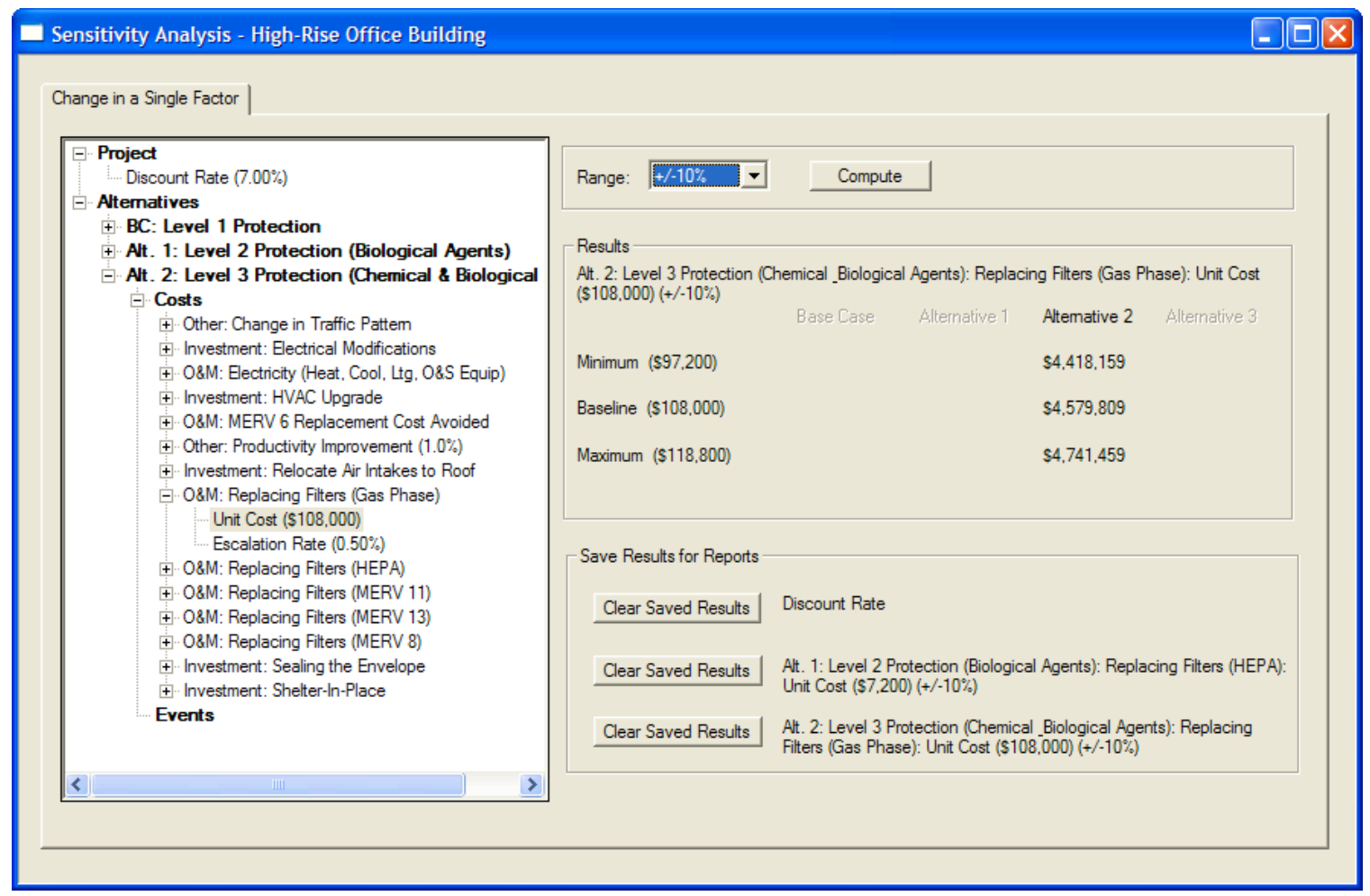

\section{Figure A17 Sensitivity Analysis Window: Using the Change in a Single Factor Tab to Evaluate the Impact of the Unit Cost of Replacing Gas Phase Filters on Life- Cycle Costs for Alternative 2}

Event-related costs are evaluated by opening the Events node for the alternative of interest. If events have been entered, the nodes listed beneath the Events node are the individual events defined by the user. Beneath each individual event node are the outcomes. If an outcome had costs associated with it, then the event/outcome cost items are listed as nodes beneath it. The factors - unit cost and escalation rate - appear beneath each event/outcome cost item.

The bottom right-hand portion of the window contains the Save Results for Reports group box. As its name suggests, the Save Results buttons may be used to save up to three sets of computed results. For example, the discount rate had a strong impact on life-cycle costs for the Base Case, Alternative 1, and Alternative 2. Thus, saving these results might prove useful in supporting a recommendation for one alternative over another. Any results that you choose to save will appear in the Results Report. Note that more than one range can be used and saved for a single factor. 


\section{Reports}

The Life-Cycle Cost Analysis Tool produces two types of reports. Although the reports share a number of similarities in terms of their content, their functions are very different. Each report is accessed via the Reports node on the main menu. Clicking the Data or Results option under the Reports node takes you to the selected report type.

The Data Report is intended as a means for checking the accuracy of the information that you entered into the Life-Cycle Cost Analysis Tool. The Results Report is designed to help you "drill down" on how individual cost items are distributed across Budget Category cost types. This approach gives you a snapshot of all of the costs entering the analysis, expressed in present value terms, which "roll up" into the life-cycle costs recorded in the Cost Summary window. The Results Report also includes any sensitivity analyses you decide to save. The Results Report is intended for submission to senior management as part of the documentation supporting the specific project being considered for funding. The Results Report is sufficiently detailed to provide a concise snapshot of the underlying data, including the candidate set of alternatives evaluated, the types of analyses performed, and the results of those analyses.

Clicking on the Data option under the Reports node opens the Data Report. The Data Report consists of: (1) a Cover Sheet; (2) Background Information on the project (e.g., Project Name, Project Description, Study Period, and Analysis Information); (3) Alternative Information Descriptive Summary (e.g., Alternative Name, Alternative Description, Event Name, Event Description, Outcome Name, Outcome Description, and Key Parameters); (4) Alternative Information - Protection Cost Data Summary (e.g., Cost Item and Dollar Amount); and (5) Alternative Information - Event/Outcome Cost Data Summary (e.g., Event, Outcome, Event/Outcome Cost Item, and Dollar Amount). Figure A18 reproduces the Cover Page of the Data Report for the high-rise office building case study.

Verifying the accuracy of input data is essential to ensure that the results of the economic evaluation are consistent with the underlying data. The Data Report is specifically designed to verify the accuracy of the input data. Figure A19 provides information on the protection costs for Alternative 1. 


\begin{tabular}{|c|}
\hline High-Rise Office Building \\
Data Report \\
$12 / 01 / 2006$ \\
\hline
\end{tabular}

Life-Cycle Cost Analysis Tool for

Chem/Bio Protection of Buildings
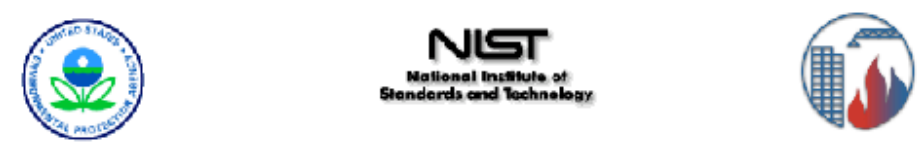

Figure A18 Cover Page of the Data Report for the High-Rise Office Building Case Study 
Alternative Information - Protection Costs Data Summary

Protection Costs Summary: Level 2 Protection (Biological Agents)

Cost Item

Electrical Modifications

Electricity (Heat, Cool, Ltg, O\&S Equip)

HVAC Upgrade

MERV 6 Replacement Cost Avoided

Productivity Improvement $(0.5 \%)$

Relocate Air Intakes to Roof

Replacing Filters (HEPA)

Replacing Filters (MERV 13)

Replacing Filters (MERV 8)

Sealing the Envelope

Sherlter-In-Place

$\begin{array}{lrrl}\begin{array}{c}\text { First } \\ \text { Year }\end{array} & \begin{array}{c}\text { Last } \\ \text { Year }\end{array} & \begin{array}{c}\text { Occurs } \\ \text { Every }\end{array} & \text { Category } \\ 2005 & 2005 & 1.00 & \text { Capital Investment } \\ 2005 & 2024 & 1.00 & \text { O\&M } \\ 2005 & 2005 & 1.00 & \text { Capital Investment } \\ 2005 & 2024 & 1.00 & \text { O\&M } \\ 2005 & 2024 & 1.00 & \text { Other } \\ 2005 & 2005 & 1.00 & \text { Capital Investment } \\ 2005 & 2024 & 3.00 & \text { O\&M } \\ 2005 & 2024 & 3.00 & \text { O\&M } \\ 2005 & 2024 & 1.00 & \text { O\&M } \\ 2005 & 2005 & 1.00 & \text { Capital Investment } \\ 2005 & 2005 & 1.00 & \text { Capital Investment }\end{array}$

$\begin{array}{lr}\begin{array}{cr}\text { Escalation } \\ \text { Rate }\end{array} & \text { Amount (\$) } \\ 0.00 \% & 107,365.00 \\ -0.10 \% & 278,981.00 \\ 0.00 \% & 209,445.00 \\ 0.50 \% & -2,880.00 \\ 0.60 \% & -118,293.00 \\ 0.00 \% & 225,261.00 \\ 0.50 \% & 43,200.00 \\ 0.50 \% & 18,000.00 \\ 0.50 \% & 720.00 \\ 0.00 \% & 625,326.00 \\ 0.00 \% & 39,816.00\end{array}$

\section{Figure A19 Protection Costs Data Summary Page of the Data Report for Alternative 1}

Clicking on the Results option under the Reports node opens the Results Report. The Results Report consists of: (1) a Cover Sheet; (2) Background Information on the project (e.g., Project Name, Project Description, Study Period, and Analysis Information); (3) Alternative Information - Descriptive Summary (e.g., Alternative Name, Alternative Description, Event Name, Event Description, Outcome Name, Outcome Description, and Key Parameters); (4) Summary of LifeCycle Costs; (5) Summary of Costs by Alternative sorted by Budget Category (e.g., Cost Item and Present Value Dollar Amount); (5) Summary of Annual Costs by Alternative and Budget Category (e.g., Present Value Dollar Amounts for each Year for Capital Investment, O\&M, Other, and in Total); (6) Summary of Annual Costs by Alternative (e.g., Present Value Dollar Amounts for each Year for each Alternative); and (6) any saved sensitivity analyses.

Figure A20 reproduces the Summary of Life-Cycle Costs Page of the Results Report for the high-rise office building case study. When you examine Figure A20, you will note that it is a reproduction of the Cost Summary window for the baseline analysis. Figure A20 includes the check boxes to indicate clearly whether any data elements have been excluded from the lifecycle cost totals. Figure A20 is the starting point for the "drill down" analysis of the computed values for life-cycle costs. 


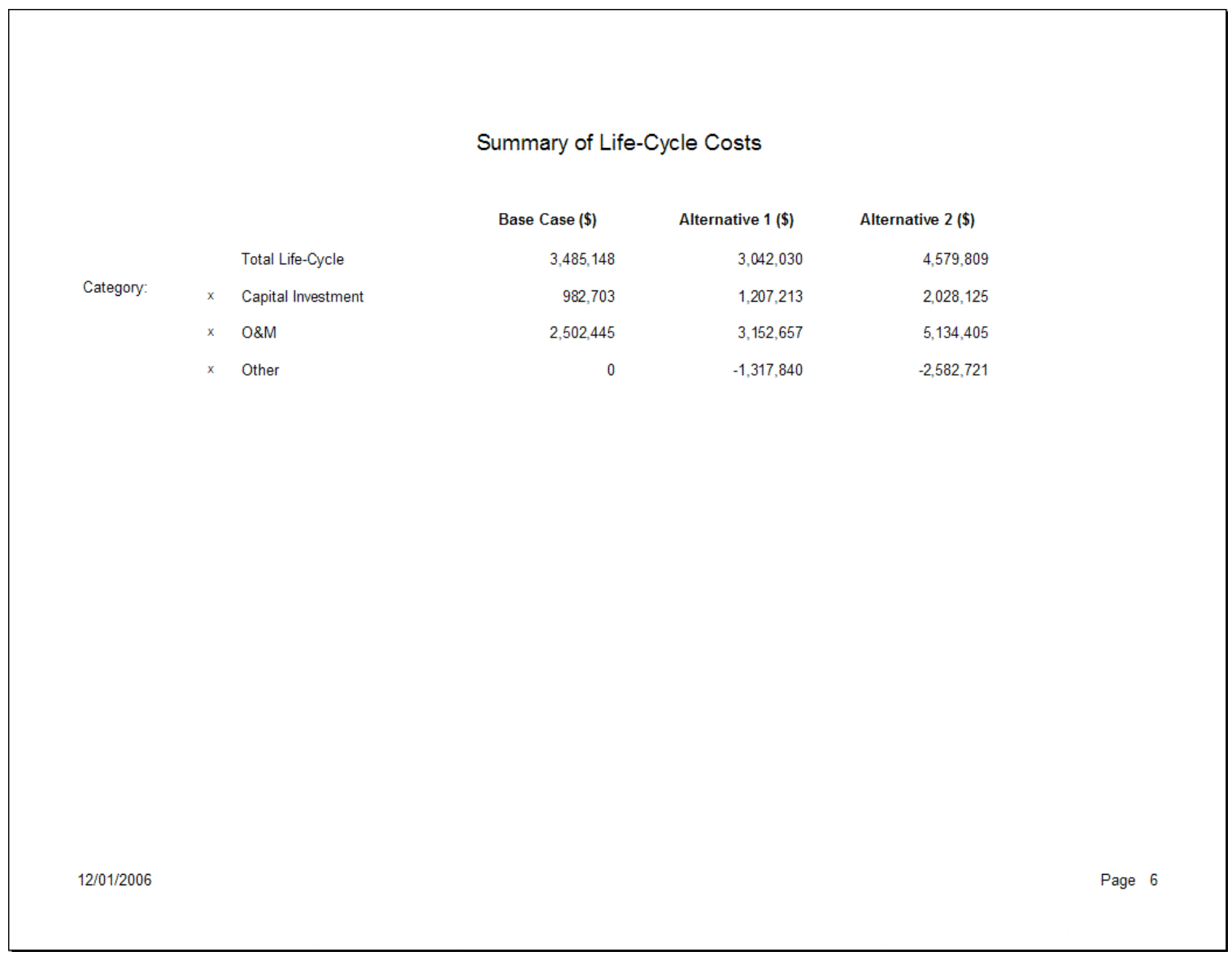
Figure A20 Summary of Life-Cycle Costs Page of the Results Report for the High-Rise
Office Building Case Study

Figure A21 is the second page of the three-page Summary of Costs by Alternative portion of the Results Report. Figure A21 covers Alternative 1. All costs are expressed in present value dollar amounts and include designations for the cost types, which map them into the cost-accounting framework. If you wish to examine how a particular cost item contributes to the amounts shown on the Summary of Life-Cycle Costs page, choose the cost item, see where it fits in the costaccounting framework, and then trace it back to Summary of Life-Cycle Costs page.

Because event-related cost items are very similar across alternatives (e.g., damage to the facility and loss of use of the facility) but differ in their magnitude, it is sometimes desirable to use the Summary of Costs by Alternative to calculate a "loss differential" between the Base Case and one of more of the alternatives. This can be done for either a single event-related cost item, a combination of event-related cost items, or all event-related losses. For example, if damage to the facility were the event-related cost item of interest, subtract its value for the alternative of interest from its value for the Base Case. To do this, you will need to pull values from at least two Summary of Costs by Alternative sections of the Results Report—one for the Base Case and one for each alternative of interest. 


\section{Summary of Costs by Alternative}

$\begin{array}{llr}\text { Alternative 1: } & \text { Level 2 Protection (Biological Agents) } & \\ \text { Budget Category } & \text { Cost Item } & \text { Present Value (\$) } \\ \text { Capital Investment } & & 107,365 \\ & \text { Electrical M odifications } & 209,445 \\ & \text { HV AC Upgrade } & 225,261 \\ & \text { Relocate Air Intakes to Roof } & 625,326 \\ & \text { Sealing the Envelope } & 39,816 \\ & \text { Sherlter-In-Place } & 2,931,084 \\ \text { O\&M } & \text { Electricity (Heat, Cool, Ltg, O\&S Equip) } & -31,815 \\ & \text { MERV 6 Replacement Cost Avoided } & 173,248 \\ & \text { Replacing Filters (HEPA) } & 72,187 \\ & \text { Replacing Filters (MERV 13) } & 7,954 \\ \text { Replacing Filters (MERV 8) } & -1,317,840 \\ \text { Other } & & 3,042,030\end{array}$

\section{Figure A21 Summary of Costs by Alternative Page of the Results Report for Alternative 1}

In developing a cost-effective risk mitigation plan, it is useful to see how costs are distributed over time. The Results Report provides two separate means for examining and assessing annual costs. The Summary of Annual Costs by Alternative and Budget Category provides a detailed disaggregated synopsis of annual costs. Thus, if you want to examine how major equipment 
replacements affect annual costs, examine the entries under the Capital Investment heading and look for years in which significant increases in costs occur. The Summary of Annual Costs by Alternative provides aggregated side-by-side comparisons of the alternatives being evaluated. Figure A22 reproduces the Summary of Annual Costs by Alternative page for the high-rise office building case study. These side-by-side comparisons are useful in determining when a particular alternative has a "bulge" in costs - say at the beginning of the study period or associated with a major replacement - or when one alternative's annual costs begin to escalate at a significantly higher rate. Both pieces of information are useful in understanding the pros and cons of each alternative being evaluated. It is important to recognize that the goal of the analysis is to gain insights into the decision problem. 


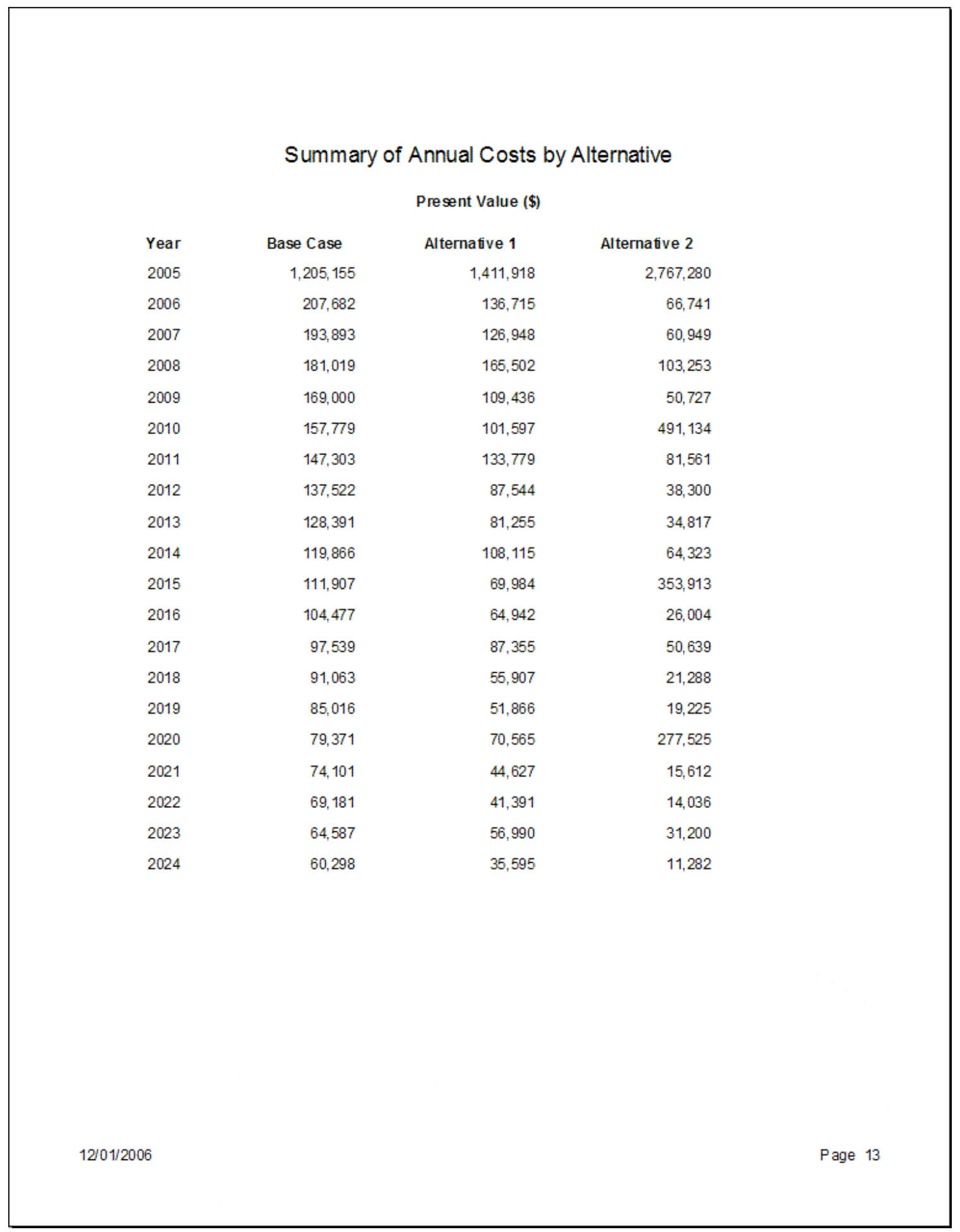

Figure A22 Summary of Annual Costs by Alternative Page of the Results Report for the High-Rise Office Building Case Study 


\section{Next Steps}

Now that you have completed the guided tour, use the test files to gain familiarity with the software. Experiment with the various means for editing, creating, and deleting data elements. Create simple applications using your own data to master the full capabilities of the Life-Cycle Cost Analysis Tool. Build more complex applications and use the sensitivity analysis feature to evaluate how changing the values of key inputs affect economic performance. Use the Results Report to learn how to drill down on key cost drivers and use that information to help guide you in conducting and saving additional sensitivity analyses. Have as a goal to use the software as a decision support tool; it is largely self documenting, it lays out the information going into the analysis, and provides guidance in choosing a cost-effective risk mitigation plan.

Visit the OAE website (http://www.bfrl.nist.gov/oae/oae.html) to learn about future updates and pending software releases.

\section{References}

ASTM. 2002. ASTM Standard E 1369, Standard Guide for Selecting Techniques for Treating Uncertainty and Risk in the Economic Evaluation of Buildings and Building Systems, American Society for Testing and Materials.

ASTM. 2005. ASTM Standard E 917, Standard Practice for Measuring Life-Cycle Costs of Buildings and Building Systems, American Society for Testing and Materials.

ASTM. 2006. ASTM Standard E 1074, Standard Practice for Measuring Net Benefits and Net Savings for Investments in Buildings and Building Systems, American Society for Testing and Materials.

Chapman, R.E., Leng, C.J. 2004. Cost-Effective Responses to Terrorist Risks in Constructed Facilities, NISTIR 7073, National Institute of Standards and Technology. 


\section{Appendix B: Retrofit Design Documentation}

\section{Disclaimer}

The retrofits presented in this appendix are specific to the buildings examined in terms of the available options and the details of implementation, and are based on the efforts of a single A\&E firm and are not necessarily optimal for these or any other buildings. While the recommendations and designs are of interest to the general question of building protection, they cannot necessarily be generalized to other buildings. Determining retrofit options and designs for a specific building always requires consideration of the unique features of that building.

\section{Background}

Section 3 of this report described a case study investigating the application of building protection retrofits in two actual buildings, specifically to identify and design potential retrofits to these buildings given their particular floor plans and HVAC system designs. Two office buildings, with very different floor plans and ventilation system designs, were selected for the case study. One is a high-rise office building with central air-handling systems serving most of the building, in addition to several other features of interest including intakes near ground level, a loading dock, a mail room, and a public-access lobby. The other building is a one-story office building with multiple rooftop air handling units and no spaces other than offices.

The retrofit design and cost estimation was performed by an architectural and engineering (A\&E) firm and was based on a list of candidate retrofits identified by NIST. The A\&E firm then proceeded with the design work, producing detailed designs for implementing the retrofits. As part of this effort, the A\&E firm reviewed the existing mechanical and control systems in the two buildings, including all original architectural, structural, mechanical, and electrical plans and any modifications of these plans. The firm also conducted field inspections of the buildings and systems and then performed the design work and prepared detailed descriptions and drawings and cost estimates of the proposed retrofits.

This appendix contains more detailed descriptions of the buildings and retrofit designs that are excerpted from the A\&E report. 


\section{A \& E Description of Existing Condition}

This case study includes two buildings located in an office/lab complex in a suburban area. The first building is a high-rise office building with an office tower referred to as Wing A. The scope of this study covers the tower served by Mechanical Room \#4 in the Mezzanine level, the Main Lobby of the high-rise office building, and the Mailroom in the basement of Wing B of the highrise office building. Additionally, the scope includes the rooftop heat pumps on the roof of a second building - a one-story office building.

\section{High-rise Office Building Tower}

The high-rise office building, built in the mid 1960s, is an eleven story tower with an elevator penthouse, basement and sub-basement covering an area of $130500 \mathrm{ft}^{2}$. At its base, the structure is flanked by adjoining one and two story wings, which includes Wing B, with a central open courtyard.

A variety of materials compose the exterior walls including granite, marble, face brick, glass and extruded aluminum. The east and west facades of the tower are faced with grey face brick with insulated porcelain spandrel panels and fixed aluminum frame windows enclosing the north and south elevations.

There are six air-conditioning units (ACU-A1, ACU-A2, ACU-A3, ACU-A4, ACU-A5, and ACU-A6) installed in the Mechanical Room \#4 located in the mezzanine floor of Wing A. The units are field assembled panel construction. The units are generally in good condition and some of the coils have been replaced, while others appear to be the original design. Each unit has a mixing box with outside air louvers, outside air dampers, minimum outside air dampers, and return air. Each unit has a filter rack holding 20 in x 20 in x 4 in $30 \%$ pleated filters. There were several manufacturer's filters represented, but it is fair to assume these are nominal ASHRAE $30 \%$ filters (per ASHRAE Standard 52.1) or MERV 6 filters (per ASHRAE Standard 52.2). The filters are upstream accessible through an access door located in the mixing section of each unit. There is also an downstream access door that serves the access section between the filter bank and the heating coil section.

With the exception of air handling units ACU-3 and ACU-4, the supply fans are original installation. All the motors were replaced with high efficiency motors recently.

Exhaust/return fans designated E-A-1, E-A-2, E-A-3, E-A-4, E-A-5 and E-A-6 return the air to their corresponding air handling unit or exhaust the air depending if the units are operating with the minimum outside air or under the economizer cycle.

The air handling units are all fed from the Motor Control Centers MCC-A1 and MCC-A2 located in the same Mechanical Room. Combination starters and disconnect switches for supply and exhaust fans for ACU-A1, ACU-A3, ACU-A4, and ACU-A5, are installed in Motor Control Center MCC-A1 and starter/disconnects for supply and exhaust fans are installed in MCC-A2.

Mechanical Room \#4 is in the mezzanine level and the bottom of the outside air intake louvers are around $20 \mathrm{ft}$ above the ground. The building has a rectangular configuration, with the north and south sides full of windows at the floors above the mezzanine and outside air intake louvers at the Mechanical Room.

The temperature controls are pneumatic and each ACU is started and stopped manually or by means of time clocks installed in each unit's control panel. The ACUs operate $24 \mathrm{~h} / \mathrm{d}$ all year round. 
High-rise Office Building, Main Lobby

The Main Lobby is a $14 \mathrm{ft}$ high space that is approximately 3,500 $\mathrm{ft}^{2}$ in floor area. It is defined by exterior glass curtain walls on the north and east sides and marble finished walls on the south and west sides. It is accessed from the exterior through a $150 \mathrm{ft}^{2}$ glass enclosed airlock with a series of two rows of four balanced glass doors located on the east wall.

On the southern perimeter, the Lobby is open to the elevator bank of Wing A and an exhibition space located in Wing B. The Lobby is also open to Wing E west of Wing A.

The Main Lobby does not have a dedicated air-conditioning unit, but is served by Air Handling Unit ACU-A2 and return/exhaust fan E-A-2. Air Handling Unit ACU-A2 located in the mezzanine mechanical room serves the Main Lobby and the adjacent corridors. Four supply air branches with hot water reheat coils are each connected to the main supply air duct from ACUA2. Two of the ducts run down to the Main Lobby (adjacent to the elevators) and supply air to linear diffuser located at the north and east perimeter walls of the Main Lobby. The other two supply ducts supply air to Corridor \#13, Corridor \#14, and the Exhibit area.

The return/relief exhaust air fan E-A-2 returns the air to ACU-A2 or exhausts it depending on the outdoor conditions. A 50 in $\times 30$ in return duct connected to E-A-2 returns the air from the Main Lobby, the adjacent corridors, and the Exhibit area. The duct is connected to an 84 in $\mathrm{x} 48$ in $\mathrm{x}$ 24 in sheet metal plenum in the Lobby's ceiling plenum. A 48 in x 13 in duct returns the air from the Main Lobby and is connected to the same plenum. 33 in x 20 in, 33 in x 27 in, and 40 in x 7 in ducts return the air from Corridor \#13, Corridor \#14, and the Exhibit area and are connected to the same plenum.

Exhaust fan E-A-2 is located in a space between the two elevator shafts behind exhaust fan E-A8 .

The temperature controls are pneumatic and air handling unit ACU A2 and the exhaust/return fan E-A-2 are started and stopped manually or by means of time clocks installed in the unit's control panel. The ACU and the fan operate $24 \mathrm{~h}$ all year round.

The Main Lobby air handling unit ACU-A2 supply and return/exhaust fans E-A-2 are fed from the Motor Control Center MCC-A2 located in Mechanical Room \#4 on the Mezzanine Floor.

\section{High-rise Office Building, Mail Room}

The Mail Room is approximately $3600 \mathrm{ft}^{2}$ and has a $7 \mathrm{ft} 8$ in high suspended acoustical ceiling system. It is enclosed by CMU walls and modular metal partitions. With the exception of the east, west and south walls, the north wall and all other interior partitions extend to the height of the ceiling. On the east and west walls a total of three single and double doors lead directly into an interior corridor. There is a roll-up door on the exterior south wall in the Receiving Area and the Mail Room.

The Mail Room does not have a dedicated air-conditioning unit. Air handling unit ACU-BI and return fan E-A-2a operate at minimum outside air and have the capability to modulate to $100 \%$ outdoor air (economizer cycle). Air handling unit ACU-BI is located in the mechanical room on the basement of Wing B. ACU-Bl is of field assembled panel construction. The unit is in good condition and serves the Mail Room and other surrounding rooms. The mechanical room is crowded with six ACUs, several exhaust fans, domestic hot water storage tanks, pumps, overhead ductwork, piping, electrical conduits, etc. The ceiling plenum in the Mail Room is also fairly congested with ductwork, piping, electrical conduits, etc. 
The return/relief exhaust air fan E-B-la returns the air from the areas surrounding the Mail Room to ACU-BI or exhausts the air depending on whether the ACU is operating with minimum outside air or under the economizer mode. The exhaust air fan E-B-lb exhausts the air from the Mail Room without returning any air to ACU-BI. Both fans are located in the mechanical equipment room \#2 in the basement of Wing B.

The temperature controls are pneumatic and air handling unit ACU B-I and the return fan E-A-la and exhaust fan E-B-1b are started and stopped manually or by means of time clocks installed in the unit's control panel The ACU and the fan operates $24 \mathrm{~h}$ all year round.

The Mail Room air handling unit supply and return/exhaust fans are fed from the Motor Control Center MCC-B1 located in the Mechanical Room \#2.

One-story office building

The one-story office building is a contiguous group of large one-story trailers that have been joined to form a single building of $17040 \mathrm{ft}^{2}$. The building is approximately $15 \mathrm{ft}$ high with 6 exterior single and double doors and 67 fixed double glazed windows. Additionally, the floor is penetrated by a number of plumbing pipes and electrical conduits coming from the crawl space.

Twenty-seven rooftop heat pump units provide heating, ventilation, and air-conditioning to the one-story office building. Each unit is controlled by a single room thermostat. These units are built to have 1 in thick throw-away air filters.

The Rooftop heat pumps are currently fed from two panels located in the Electrical Equipment Room.

\section{A \& E Findings and Recommendations}

\section{High-rise Office Building Tower}

\section{General Findings}

Without the benefit of a detailed inspection of the exterior glazed areas of the building, it is believed that decades of aging and weathering will necessitate substantial resealing around the glazed surfaces and exterior penetrations.

To extend the six outside air intakes from the mezzanine mechanical room to the roof will require running ductwork up the exterior walls, blocking around 130 windows and compromising the aesthetics of the building. Extending the outside air intakes through the inside the building with ductwork will require valuable space at each floor.

The installed air filters are MERV 6 with an efficiency of $25 \%$ to $30 \%$.

The existing Motor Control Center MCC-A1 and MCC-A2 have adequate capacity and available spare/space modules to accommodate the proposed modifications.

The protection needed against release outdoor or indoor of a biological or chemical attack will require the installation of quick shut-off switch and quick purge switch to be centrally located in the guard control office that is manned $24 \mathrm{~h}$. Currently there are no areas designated as sheltersin-place to protect the occupants of the building. 


\section{Recommended Retrofits}

SEALING BUILDING ENVELOPE

Seal and reseal, as required, around interior and exterior of windows, doors and penetrations at the building envelope.

\section{ELEVATE OUTDOOR AIR INTAKES}

Extend the six outside air intakes, from the Mezzanine mechanical room to the roof by installing ductwork on the exterior.

IMPLEMENT SHELTER-IN-PLACE

To augment the ability of building occupants to shelter-in-place, areas of refuge should be distributed through out the building. These "shelters-in-place" will be sealed rooms in which the building occupants will assemble for a defined period of time.

INSTALL SHUT-OFF AND PURGE SWITCHES

Protection against outdoor or indoor release of a biological or chemical attack requires the installation of quick shut-off switch and quick purge switch to be centrally located in the guard control office that is continuously manned. The electrical system that will provide an immediate shutdown of the AHU's supply fans consists of a shut-off switch to be located in the Guard Control Office in the basement and will control a multipole relay to be installed in an available space bucket in the existing Motor Control Center MCC-A1 in Mechanical Room \#4. Each relay contact is then connected to the corresponding starter of the supply fan in MCC-A1 and MCCA2.

The electrical system that will provide an immediate start-up of the AHU's exhaust fans consists of a purge switch to be located in the Guard Control Office in the basement and will control a multipole relay to be installed in an available spare bucket in the existing Motor Control Center MCC-A1 located in the Mechanical Room \#4. Each relay contact is then connected to the corresponding starter of the exhaust fan in MCC-A1 and MCC-A2.

\section{UPGRADE TO FILTRATION LEVEL I}

Upgrade all filters from the current MERV 6 filters to 4 in MERV11 high capacity filters. This change will result in increased efficiency and longer life relative to the standard capacity filter. Utilize the existing 20 in x 20 in frames, so major changes to the structure will not be required. Changes to the fan and motor are not required.

\section{UPGRADE TO FILTRATION LEVEL 2}

Upgrade each AHU with a three-stage filter system consisting of 4 in pre-filter, $85 \%$ intermediate filter, and $99.97 \%$ HEPA filter. Remove the existing filter bank assembly to achieve this level of filtration. Install a new field fabricated, build-up bank of HEPA rated frames within the existing AHUs with new safing on all four sides. The frames will have HEPA clamping mechanism to achieve $99.97 \%$ seal. Safings will consist of $18 / 20$ gauge galvanized steel. Screw in place and seal with an appropriate sealant the frames and safing. To achieve the maximum amount of filter area the nominal frame size will be 24 in x 24 in and 12 in x 24 in, as required.

Replace the following fans and motors because of the increase in pressure requirements to meet the requirements of additional static pressure drop:

a. ACU-Al: Replace the existing $15 \mathrm{hp}$ fan motor with a new $25 \mathrm{hp}$ motor.

b. ACU-A2: Replace the $15 \mathrm{hp}$ motor with a new $25 \mathrm{hp}$ motor. 
c. ACU-A3: Replace the $30 \mathrm{hp}$ motor with a new $40 \mathrm{hp}$ motor.

d. ACU-A4: Replace the $25 \mathrm{hp}$ motor with a new $40 \mathrm{hp}$ motor.

e. ACU-A5: Replace the $40 \mathrm{hp}$ motor with a $50 \mathrm{hp}$ motor.

f. ACU-A6: Replace the supply fan S-A-6(B) with a new fan and the $20 \mathrm{hp}$ motor with a new $40 \mathrm{hp}$ motor.

The pre-filter should be changed four times per year, one final filter change per year, and one HEPA filter change per year.

Modify the Motor Control Center MCC-A1 and MCC-A2 by removing existing ACU-Al thru ACU-A6 combination starters/disconnect switch and associated feeders. Provide for new motors:

a. ACU-Al: Install in MCC-A1 combination starter size 2 and $60 \mathrm{~A}$ disconnect switch and connect new 25 hp motor with $3 \# 6$ and $1 \# 10$ ground in 1 in conduit.

b. ACU-A2: Install in MCC-A2 combination starter size 2 and 60 A disconnect switch and connect new 25 hp motor with 3 \#6 and 1 \#10 ground in 1 in conduit.

c. ACU-A3: Install in MCC-A1 combination starter size 3 and 100 A disconnect switch and connect new $40 \mathrm{hp}$ motor with $3 \# 3$ and $1 \# 8$ ground in $11 / 4$ in conduit.

d. ACU-A4: Install in MCC-A1 a combination starter size 3 and 100 A disconnect switch and connect new $40 \mathrm{hp}$ motor with $3 \# 3$ and $1 \# 8$ ground in $11 / 4$ in conduit.

e. ACU-A5: Install in MCC-A1 a combination starter size 3 and 125 A disconnect switch and connect new $50 \mathrm{hp}$ motor with $3 \# 2$ and $1 \# 6$ ground in $11 / 4$ in conduit.

f. ACU-A6: Install in MCC-A2 a combination starter size 3 and 100 A disconnect switch and connect new $40 \mathrm{hp}$ motor with $3 \# 3$ and $1 \# 8$ ground in $11 / 4$ in conduit.

The modifications to the Motor Control Center MCC-A1 and MCC-A2 will result in a considerable increase in the load. Replace the existing main circuit breaker in switchboard 101Al with new 3 pole, $600 \mathrm{~A}$ and connect to the MCC-A1 and MCC-A2 with new $600 \mathrm{~A}$ feeder.

UPGRADE TO FILTRATION LEVEL 3

Upgrade each AHU with a five-stage filter system consisting of 4 in pre-filter, $85 \%$ intermediate filter, $99.97 \%$ HEPA filter, $99.99 \%$ gas phase filter, and 2 in post filter. Remove the existing filter bank assembly to accommodate this level of filtration. Include ASZM-TEDA military grade carbon (per US Army standard EA-C-1704) designed for chemical agents as the gas phase filter bank designed to provide approximately $0.10 \mathrm{~s}$ of residence time. Remove the existing filter bank assembly to achieve this level of filtration. Install two new field-fabricated, build up banks of HEPA rated frames within the existing AHUs with new safing on all four sides. The frames will be 14 gauge stainless steel with welded corners and ground filter seal surface. The frames will have HEPA clamping mechanism to achieve $99.97 \%$ seal. Safings will consist of 18/16 gauge stainless steel. Weld in place the frames and safing, mechanically fasten, and seal them to the plenum with appropriate sealant. To achieve the maximum amount of filter area the nominal frame size will be 24 in x 24 in and 12 in x 24 in as required to achieve the maximum of filter area.

Replace the following fans and motors because of the increase in pressure requirements to meet the requirements of additional static pressure drop:

a. ACU-Al: Replace the supply fan S-A-1(C) with a new supply fan and the $15 \mathrm{hp}$ motor with 
a $40 \mathrm{hp} \mathrm{motor.}$

b. ACU-A2: Replace the $15 \mathrm{hp}$ motor with a $30 \mathrm{hp}$ motor.

c. ACU-A3: Replace the $30 \mathrm{hp}$ motor with a new $50 \mathrm{hp}$ motor.

d. ACU-A4: Replace the supply fan S-A-4(B) with a new fan and the 25 hp motor with a new $50 \mathrm{hp}$ motor.

e. ACU-A5: Replace the $40 \mathrm{hp}$ motor with a new $75 \mathrm{hp}$ motor.

f. ACU-A6: Replace the supply fan S-A-6(B) with a new fan and the $20 \mathrm{hp}$ motor with a new $50 \mathrm{hp}$ motor.

Modify the Motor Control Center MCC-A1 and MCC-A2 by removing existing ACU-A1 thru ACU-A6 combination starter/disconnect switches and associated feeders. Provide for new motors:

a. ACU-A1: Install in MCC-A1 combination starter size 3 and 100 A disconnect switch and connect new $40 \mathrm{hp}$ motor with $3 \# 3$ and $1 \# 8$ ground in $11 / 4$ in conduit.

b. ACU-A2: Install in MCC-A2 combination starter size 3 and 70 A disconnect switch and connect new $30 \mathrm{hp}$ motor with 3 \#4 and 1 \#8 ground in 1 in conduit.

c. ACU-A3: Install in MCC-A1 combination starter size 3 and $125 \mathrm{~A}$ disconnect switch and connect new 50 hp motor with 3 \#2 and 1 \#6 ground in 1 1/4 in conduit.

d. ACU-A4: Install in MCC-A1 combination starter size 3 and 125 A disconnect switch and connect new $50 \mathrm{hp}$ motor with $3 \# 2$ and $1 \# 6$ ground in 1 1/4 in conduit.

e. ACU-A5: Install in MCC-A1 combination starter size 4 and 175 A disconnect switch and connect new $75 \mathrm{hp}$ motor with $3 \# 2$ and $1 \# 6$ ground in 2 in conduit.

f. ACU-A6: Install in MCC-A2 combination starter size 3 and 125 A disconnect switch and connect new $50 \mathrm{hp}$ motor with $3 \# 2$ and 1 \#6 ground in 1 1/4 in conduit.

The modification to the Motor Control Center MCC-A1 and MCC-A2 results in a considerable increase in the load. Replace the existing main circuit breaker in switchboard 101-Al with new 3 pole, $600 \mathrm{~A}$ and connect to the MCC-A1 and MCC-A2 with new $600 \mathrm{~A}$ feeder.

\section{High-rise Office Building, Main Lobby}

\section{General Findings}

Given the present configuration, it is not possible to contain a release that occurs within the Lobby. However, it is important to install airtight physical barriers to limit contaminant spread into the rest of the building.

To maintain the air conditioning of the Main Lobby independent from the surrounding areas, a new AHU (ACU-A-2a) and exhaust fan (E-A-2a) will be required. Currently, ACU-A2 supplies air to the Main Lobby, Corridor \#13, Corridor \#14, and the Exhibit area, and return/exhaust fan E-A-2 returns air to the unit or exhausts it during the air economizer cycle from these areas. The amount of air circulated through the Lobby should be removed from ACU-A2 and E-A-2 to maintain the Lobby independent from the other areas.

To isolate the Main Lobby from the surrounding areas, fan E-A-2 should be replaced by two fans: 1) New fan E-A-2 should replace the existing fan and return the air from the non-Lobby spaces to air handling unit ACU-A-2; and, 2) New fan E-A-2a should be dedicated to 
return/exhaust the air from the Lobby to the new ACU 2a. The new air exhaust fan should be fitted with Filtration Level 2 or 3 to prevent spreading hazardous materials from the Main Lobby to the outdoors during an emergency.

There are two options for the new exhaust fan E-A-2a. It should be equipped with Filtration Level 2 or 3. Installation of Filtration Level 1 is not recommended because it will not provide the level of protection required when discharging contaminated air to the outside.

The space available to install new air handling unit, exhaust fan, filters, and ductwork is very tight and will require removal and relocation of existing ductwork, piping, control and electrical panels, and electrical conduits. Some of the headroom could be reduced due to installation of new ductwork under existing ductwork, piping, and electrical conduits. Due to existing conditions, the installation of Filtration Level 3 will be considerably more difficult than Level 2 ,

\section{Recommended Retrofits}

ELEVATE OUTDOOR AIR INTAKES

Relocate the outside air intakes to the roof.

\section{PHYSICAL SEPARATION}

Isolate the east lobby of Wing A from the rest of the building by providing tempered glass partitions with self-closing glass doors that will allow the building occupants continued access to the Lobby and exhibition spaces. The isolating partitions will also include a matching marble finish above the glazed areas.

The building is has a sprinkler system, therefore isolating the Lobby in the manner proposed will not compromise egress requirements, impair visibility or prohibit the transmittance of natural light.

Accessory door hardware will take into account the style and character of the existing building, including its door hardware, and will seal potential points of air infiltration and enable the mechanical system to maintain the designed air pressure differentials between adjacent spaces.

\section{HVAC ISOLATION}

Install a new air handling unit (ACU-A2a) in Mechanical Equipment Room \#4 to serve the Main Lobby only. Provide ACU-A2a with air economizer cycle, air filters, hot water preheat coil, cooling coil, and supply fan. Install the unit in the southeast corner of the room in front of ACUA-2. Connect the supply duct from the unit to the existing supply duct with hot water reheat coils serving the Lobby. Install chilled water branches from the nearby mains to the cooling coil and hot water branches from the nearby hot water mains to the heating coil. Bring outside air to the unit from an existing louver installed in the northeast corner of the room.

Remove the existing exhaust fan E-A-2 and instead install two new exhaust fans. One fan (E-A2) to serve as return/exhaust fan to the existing ACU-A2 from the areas surrounding the Lobby. Also, install a second fan (E-A-2a) to return/exhaust the air to the new ACU-A2a and run an exhaust duct from the return duct to an existing louver near the fan. Install filters at the discharge side of the new exhaust fan E-A-2a.

Select and balance ACU-A2a and E-A-2a to maintain the Main Lobby approximately 10\% negative with respect to the surrounding areas and the outdoors during normal operation and during emergency.

UPGRADE TO FILTRATION LEVEL 2

Equip the AHU with a Level 2 filter system consisting of 4 in pre-filter, $85 \%$ intermediate filter, 
and $99.97 \%$ HEPA filter in a filter section and a $7.5 \mathrm{hp}$ motor.

Install in Motor Control Center MCC-A2 a combination starter size 1 and 20 A disconnect switch and connect new 7.5 hp motor with $3 \# 12$ and $1 \# 12$ ground in 3/4 in conduit.

Provide fan E-A-2a with Filtration Level 2 system.

Equip the fan with a $5 \mathrm{hp}$ motor to meet the additional requirements of the filters static pressure drop. Remove in MCC-A2 combination starter/disconnect switch for fan E-A2 and associated feeder. Install in place combination starter size 0 and $15 \mathrm{~A}$ disconnect switch and connect new $5 \mathrm{hp}$ motor with $3 \# 12$ and $1 \# 12$ ground in 3/4 in conduit. Install in MCC-A2 combination starter size 1 and $20 \mathrm{~A}$ disconnect switch and connect new 7.5 hp motor with $3 \# 12$ and $1 \# 12$ ground in $3 / 4$ in conduit.

\section{UPGRADE TO FILTRATION LEVEL 3}

Equip the AHU with Filtration Level 3 consisting of 4 in pre-filter, $85 \%$ intermediate filter, $99.97 \%$ HEPA filter, $99.99 \%$ gas phase filter, and 2 in post filter in a filter section, and a $7.5 \mathrm{hp}$ motor.

Install in Motor Control Center MCC-A2 a combination starter size 1 and 20A disconnect switch and connect new $7.5 \mathrm{hp}$ motor with $3 \# 12$ and $1 \# 12$ ground in 3/4 in conduit.

Provide fan E-A-2a with a Level 3 filter system consisting of 4 in pre-filter, $85 \%$ intermediate filter, $99.97 \%$ HEPA filter, $99.99 \%$ gas phase filter, and 2 in post filter in a filter section.

Equip fan E-A-2a with a $7.5 \mathrm{hp}$ motor to meet the additional requirements of the filter's static pressure drop. Remove in MCC-A2 combination starter/disconnect switch for fan E-A2 and associated feeder. Install in place combination starter size 0 and $15 \mathrm{~A}$ disconnect switch and connect new 7.5 hp motor with $3 \# 12$ and $1 \# 12$ ground in 3/4 in conduit. Install in MCC-A2 combination starter size 1 and 20 A disconnect switch and connect new E-A-2 7.5 hp motor with $3 \# 12$ and $1 \# 12$ ground in 3/4 in conduit.

High-rise Office Building, Mail Room

\section{General Findings}

The walls, ceilings and doors are not airtight and cannot contain a release within the room.

It will not be possible to install a dedicated new air handling unit in Mechanical Room \#2 due to congestion in the Mechanical Room and ceiling space above the Mail Room. In addition, a new outside air duct would need to be installed from the present unit's outside air intake to the top of the existing architectural louver located above a Wing D entrance door. This duct modification will raise the outside air intake to around $30 \mathrm{ft}$ (roof level) from the ground. Therefore, since a new dedicated unit cannot be installed, the fallback position is to upgrade the filtering system of the existing AHU.

The existing exhaust fan E-B-2b dedicated to the Mail Room will need to be fitted with a new filter bank with one of the two filter options ( 2 or 3 ) to prevent spreading hazardous materials from the Mail Room to the outdoors during an emergency.

Installation of Filtration Level I filters, as described above, is not recommended because it will not provide the quality of protection required for the Mail Room.

During a previous expansion and renovation of the Mail Room, a corridor between the room and the loading dock became part of the Mail Room, the air registers connected to the exhaust duct from the exhaust fan E-13-1A were removed, and the duct was abandoned in place. Presently, 
the air supplied to the Mail Room is exfiltrated through two transfer grilles to the adjacent corridors at the east and west side of the room.

\section{Recommended Retrofits}

PHYSICAL SEPARATION

Seal room envelope; walls, ceilings, doors and slabs.

HVAC ISOLATION

Maintain the Mail Room at negative pressure all the time during normal and emergency operation by adjusting the supply and return airflows.

UPGRADE TO FILTRATION LEVEL 2

Upgrade ACU-B1 with Filtration Level 2 system consisting of 4 in pre-filter, $85 \%$ intermediate filter, and $99.97 \%$ HEPA filter. Remove the existing filter bank assembly to achieve this level of filtration. Install a new field fabricated, build up bank of HEPA-rated frames within the existing AHU with new safing on all four sides. The frames will have HEPA clamping mechanisms to achieve $99.97 \%$ seal. Safings will consist of 18/20 gauge galvanized steel. Screw in place and seal with an appropriate sealant the frame and safing. To achieve the maximum amount of filter area the nominal frame size will be 24 in x 24 in and 12 in $x 24$ in as required.

Replace the existing $25 \mathrm{hp}$ fan motor with a new $40 \mathrm{hp}$ motor to overcome the additional static pressure. Remove from MCC-B1 the combination starter/disconnect switch for fan S-B-1 and associated feeder. Install in-place combination starter size 3 and $100 \mathrm{~A}$ disconnect switch and connect new $40 \mathrm{hp}$ motor with 3 \#3 and I \#8 ground in $11 / 4^{\text {in }}$ conduit.

Equip existing exhaust fan E-B-2b with Filtration Level 2 system consisting of 4 in pre-filter, $85 \%$ intermediate filter, and $99.97 \%$ HEPA filter in a filter section.

Remove MCC-B1 combination starter/disconnect switch for fan E-B-1 b and associated feeder. Install in-place combination starter size 0 and 15A disconnect switch and connect new $2 \mathrm{hp}$ motor with 3 \#12 and 1 \# 12 grounds in 3/4 in conduit.

Replace the existing $1 \mathrm{hp}$ fan motor with a $2 \mathrm{hp}$ motor to meet the additional static pressure drop associated with the filter.

The pre-filter should be changed four times per year, one final filter change per year, and one HEPA filter change per year.

\section{UPGRADE TO FILTRATION LEVEL 3}

Upgrade ACU-B1 with Filtration Level 3 system consisting of 4 in pre-filter, $85 \%$ intermediate filter, $99.97 \%$ HEPA filter, $99.99 \%$ gas phase filter, and 2 in post filter. Remove the existing filter bank assembly to achieve this Level of filtration. The filter bank for the gas phase will include ASZM-TEDA military grade carbon designed for chemical agents and be designed to provide approximately $0.10 \mathrm{~s}$ of residence time. Remove the existing filter bank assembly to achieve this level of filtration. Install two new field fabricated, build up banks of HEPA rated frames within the existing AHU with new safing on all four sides. The frames will be 14 gauge stainless steel with welded corners, welded, and ground filter seal surface. The frames will have HEPA clamping mechanisms to achieve $99.97 \%$ seal. Safings will consist of 18/16 gauge stainless steel. Weld in place the frames and safing, mechanically fasten, and seal them to the plenum with appropriate sealant. To achieve the maximum amount of filter area the nominal frame size will be 24 in $\times 24$ in and 12 in $\times 24$ in as required to achieve the maximum of filter area. 
Replace the existing $25 \mathrm{hp}$ fan motor with a new $40 \mathrm{hp}$ motor to overcome the additional static pressure. Remove in MCC-B1 the combination starter/disconnect switch for fan S-B-1 and associated feeder. Install in-place combination starter size 3 and 100A disconnect switch and connect new $40 \mathrm{hp}$ motor with 3 \#3 and 1 \#8 ground 1 1/4 in conduit.

Equip the fan with Filtration Level 3 system consisting of 4 in pre-filter, $85 \%$ intermediate filter, 99.97\% HEPA filter, 99.9 9\% gas phase filter, and 2 in post filter.

Replace the existing fan and the $1 \mathrm{hp}$ motor with a new fan with a $2 \mathrm{hp}$ motor to meet the additional static pressure drop. Remove in MCC-B1 the combination starter/disconnect switch for fan E-B-1b and associated feeder. Install in place combination starter size 0 and $15 \mathrm{~A}$ disconnect switch and connect new 2 hp motor with 3 \#12 and 1 \#12 in 3/4 in conduit.

The pre-filter should be changed four times per year, one final filter change per year, and one HEPA filter change per year for more efficient and energy saving operation.

\section{One-story office building}

\section{General Findings}

The one-story office building is a modular type building composed of 24 trailers attached together. The building is heated, ventilated, and air conditioned by 28 rooftop heat pumps. The space where the supply fan and the motor are located in the heat pumps is tight and will not permit the replacement of the installed fan with a larger supply fan and motor to handle additional static pressure that will be able to support more efficient particle and gaseous removal filters. Neither is there enough space to install additional filters inside the heat pumps. In addition, the units have air economizer systems that supply $100 \%$ outside air while in this mode of operation and will require the selection of the filters to handle the larger airflow.

\section{Recommended Retrofits}

The provision of better outside air filtration to the heat pumps will require the installation of one or two outside air supply fan on the roof with filter banks for each of the three filter options indicated above for the high-rise office building and running a supply duct from the fan to each unit. There are 28 rooftop heat pump units on the roof (approximately one per trailer) supplying $1600 \mathrm{cfm}$ each with approximately $160 \mathrm{cfm}$ minimum outside air each during normal operation and $1600 \mathrm{cfm}$ during air economizer operation. The outside air introduced by each unit, which is not exhausted through toilet exhaust and exfiltration, is exhausted by means of a barometric damper in each unit. During an emergency, each unit's fan should supply $1600 \mathrm{cfm}$ outside air each for a total of $44800 \mathrm{cfm}$. About $35840 \mathrm{cfm}$ should be exhausted and $8900 \mathrm{cfm}$ should remain in the building to maintain around $20 \%$ positive pressure during emergencies. The outside air intake filters will require a casing of $10 \mathrm{ft} \mathrm{H} \mathrm{x} 10 \mathrm{ft} \mathrm{W}$ and 24 in in depth (or similar dimensions) for Option No. 2 and $10 \mathrm{ft} \mathrm{H} \mathrm{x} 10 \mathrm{ft} \mathrm{W}$ and 52 in depth (or similar dimensions) for Option No. 3. To achieve the maximum amount of filter area the nominal frame size will be 24 in $\times 24$ in and 12 in $\times 24$ in as required.

The supply fan alone will weigh approximately $3400 \mathrm{lbs}$ plus the weight of the filter banks and the ductwork. The building's roof will not be able to support all this weight unless additional structural reinforcement is provided. Another option is to install two fans with the filters and ductwork, but still will require additional structural reinforcement.

Instead of installing the fan(s) and filter bank(s) on the roof, they can be installed on an elevated platform at the same height as the roof and adjacent to the east side of the building and from 
there the ductwork run to each heat pump.

Variable frequency drive(s) should be provided to modulate the outside air fan(s) to supply the minimum outside air during normal operation and $100 \%$ air during emergency operation.

The 28 rooftop heat pumps are powered from HVAC panels PA-7 and PA- 8 and both panels are full with each containing circuits for 14 heat pumps. The proposed installation of two outside air fans shall instead be powered each from the main panels PA-1 and PA-2.

Upgraded filtration should be provided as indicated below.

The protection needed against release of biological or chemical attack will require the installation of quick shut-off switch to be located at reception desk.

\section{SEALING BUILDING ENVELOPE}

To enhance the airtightness of the structure, it is recommended to patch roof leaks, seal around exterior windows, provide exterior doors with gasket hardware to close gaps between door leaves, replace exterior door thresholds with others designed to form a seal at the base of doors, and seal around pipe and conduit floor penetrations within the building's crawl space.

\section{INSTALL SHUT-OFF SWITCH}

The protection needed against outdoor releases requires the installation of quick shut-off switches to stop the rooftop heat pumps. This switch is to be located at the reception desk.

\section{UPGRADE TO FILTRATION LEVEL 1}

Installation of Filtration Level 1 filters is not recommended because it will not provide the quality of protection required. However, the existing filtration could be improved by replacing the existing MERV 4 filters with 1 in thick MERV 11 filters. The MERV 11 filters will not affect the system static pressure.

\section{UPGRADE TO FILTRATION LEVEL 2}

Provide two outside air supply fans on two steel platforms, supported by steel legs on footings and with metal grating, adjacent to the east side of the building and at the same height of the roof. Provide with each fan a $7 \mathrm{ft} \mathrm{H} \times 8 \mathrm{ft} \mathrm{W}$ filter bank, with Filtration Level 2 as described for the high-rise office building. Connect the new fans to the filter banks and to their respective heat pump units with ductwork to each unit's air intake. Provide variable frequency drives for each fan to modulate the outside air to each unit during normal operation and during emergency operation. Provide automatic controls with a static pressure sensor in each fan supply duct to control the respective fan. Interlock the exhaust fans controls with the existing heat pumps controls.

Provide a $20 \mathrm{hp}$ motor with each outside air supply fan. Install in main panel PA-1 and PA-2 each a 3 pole, 50 A circuit breaker for each of the proposed supply fans. Install combination variable frequency drive, disconnect switch at each supply fan location, and connect the $20 \mathrm{hp}$ motors with 3 \# 8 and 1 \# 10 ground in 1 in conduit.

\section{UPGRADE TO FILTRATION LEVEL 3}

Provide two outside air supply fans on two platforms adjacent to the east side of the building at roof height. Provide each fan with a $3.5 \mathrm{ft}$ x $4 \mathrm{ft}$ filter bank with Filtration Level 3 as described above. Connect the new fans to the filter banks and to their respective heat pump units with ductwork to each unit's air intake. Provide variable frequency drive for each fan to modulate the outside air to each unit during normal operation and during emergency operation. Provide automatic controls with a static pressure sensor in each fan supply duct to control the respective 
fan. Interlock the exhaust fans controls with the existing heat pumps controls.

Provide a $25 \mathrm{hp}$ motor with each of the two outside air supply fan. Install in main panel PA-I and PA-2 each a 3 pole, 70 A circuit breaker for each of the proposed supply fans. Install combination variable frequency drive, disconnect switch at each supply fan location, and connect the $25 \mathrm{hp}$ motors with 3 \# 6 and I \# 8 ground in 1 1/4 in conduit. 


\section{Appendix C Case Study Retrofit Costs Per Unit of Floor Area}

The cost data presented in this appendix are based on a critical analysis of the contractorprovided estimates for initial capital costs (i.e., first costs) and annual-recurring costs for filter replacement for a variety of chembio retrofit strategies in the two case study buildings. ${ }^{1}$ This appendix presents a fairly detailed classification of cost data, in which major cost items (e.g., HVAC Upgrade) are broken down into their constituent cost items (e.g., Remove Existing Filter Bank).

The cost data are presented as a series of tables. The tables are organized around four retrofit categories in the two case study buildings: (1) High-rise office building; (2) Lobby in the highrise office building; (3) Mail room in the high-rise office building; and (4) Low-rise office building. Within each category, the tables are organized around the three levels of filtration considered as well as the non-filtration retrofits. The three filtration levels are as follows: Level 1, minimal protection from biological agents and no protection from chemical agents; Level 2, enhanced protection from biological agents and no protection from chemical agents; and, Level 3 , enhanced protection from biological agents and enhanced protection from chemical agents. Tables C. 1 through C.3 present initial capital costs in the high-rise office building for Filtration Levels 1 through 3 respectively. Table C. 4 covers annual-recurring costs for the filter replacements for the high-rise office building. Table C.5 covers initial capital costs for the highrise office building for five non-filtration retrofits, i.e., envelope sealing, moving the outdoor air intake, installing quick shut-off/purge switches, shelter-in-place, and system testing and balancing. Tables C.6 and C.7 cover initial capital costs for the Lobby in the high-rise office building for Filtration Levels 2 and 3. Table C.8 covers initial capital costs for the two nonfiltration retrofits of the lobby, i.e., installing interior partitions between the lobby and the rest of the first floor, and raising the outdoor air intake serving the lobby. Tables C.9 and C. 10 cover initial capital costs for Filtration Levels 2 and 3 in the mail room in the high-rise office building. Table C.11 covers initial capital costs for sealing the mail room partitions from the rest of the basement. Tables C.12 through C.14 cover initial capital costs for Filtration Levels 1 through 3 in the low-rise office building. Table C.15 covers initial capital costs for sealing the envelope of the low-rise office building. Note that the sums of the constituent cost items in the tables may not add to the dollar amount for the major cost items due to independent rounding.

With the exception of Table C.4, which deals with annual recurring costs for filter replacement rather than initial capital costs, each table has four columns: (1) Cost Item; (2) Total Cost; (3) Cost per Square Foot $\left(\$ / \mathrm{ft}^{2}\right)$; and (4) Cost per Square Meter $\left(\$ / \mathrm{m}^{2}\right)$. The entries under the Cost Item column record the major cost items in boldface font (e.g., HVAC Upgrade); each constituent cost item is indented and printed in regular font. The values under the Total Cost column record the overall cost for the major cost item in boldface font. The constituent cost items are printed in regular font; their sum is equal to the dollar amount for the major cost item. Columns 3 and 4 are patterned after Column 2. The per unit cost for each major cost item is shown in boldface font and the per unit costs for each constituent cost item are shown in regular font. Note that the sums of per unit costs of the constituent cost items may not add to the dollar amount for the major cost item due to independent rounding.

Table C.4, which covers annual filter replacement costs for the high-rise office building, is broken into two parts. Part A reports annual costs per air-handling unit (AHU). There are six

\footnotetext{
${ }^{1}$ Note that the cost estimates are for purposes of illustration only-actual renovations of different buildings will face different costs and different risk profiles.
} 
AHUs in the high-rise office building. Part B reports annual costs per unit of floor area. Part A of Table C.4 has nine columns. The first two columns designate the system and type of filter. Table C.4 makes reference to four systems: (1) As Is; (2) Filtration Level 1; (3) Filtration Level 2; and (4) Filtration Level 3. Filters are designated by their MERV (Minimum Efficiency Reporting Value) rating, as HEPA (High Efficiency Particulate Air), or as Gas Phase ACS (Air-Cleaning System). Columns 3 through 7 record the information needed to calculate the cost per change per AHU. Column 8 records the number of changes per year for each type of filter. Column 9 records the annual cost per AHU for each system and type of filter. Part B of Table C. 4 has four columns: (1) Cost Item; (2) Total Annual Cost; (3) Cost per Square Foot ( $\left.\$ / \mathrm{ft}^{2}\right)$; and (4) Cost per Square Meter $\left(\$ / \mathrm{m}^{2}\right)$. The entries under the Cost Item column record the system in boldface font; each constituent cost item (i.e., type of filter) is indented and printed in regular font. The values under the Total Annual Cost column record the overall cost for the system in boldface font. The constituent cost items are printed in regular font; their sum is equal to the dollar amount for the system. Columns 3 and 4 are patterned after Column 2. The annual cost per unit for each system is shown in boldface font and the annual cost per unit for each constituent cost item is shown in regular font. Note that the sums of the annual costs per unit of the constituent cost items may not add to the annual cost per unit for the system due to independent rounding. 
Table C.1 Cost for Level 1 Filtration for the High-Rise Office Building

\begin{tabular}{|l|c|c|c|}
\hline \multicolumn{1}{|c|}{ Cost Item } & Total Cost & \multicolumn{2}{c|}{ Cost Per Unit Floor Area } \\
\cline { 3 - 4 } & $\mathbf{( \$ )}$ & $\mathbf{\$} / \mathbf{f t}^{\mathbf{2}}$ & $\mathbf{\$} \mathbf{m}^{\mathbf{2}}$ \\
\hline HVAC Upgrade & $\mathbf{7 1 ~ 3 5 4}$ & $\mathbf{0 . 5 9}$ & $\mathbf{6 . 4 0}$ \\
\hline Remove Existing Filter Bank & 3640 & 0.03 & 0.33 \\
\hline $\begin{array}{l}\text { Upgrade Air Handling Unit w/ One Bank MERV 11 } \\
\text { Frames, Clips and Filters }\end{array}$ & 1843 & 0.02 & 0.17 \\
\hline Safing, Stiffener Bars and Welding & 2070 & 0.02 & 0.19 \\
\hline Electric Motor 25 hp w/ Belts and Pulley & 8467 & 0.07 & 0.76 \\
\hline Electric Motor 40 hp w/ Belts and Pulley & 11773 & 0.10 & 1.06 \\
\hline Electric Motor 50 hp w/ Belts and Pulley & 6643 & 0.06 & 0.60 \\
\hline Centrifugal Fan 40 hp & 21303 & 0.18 & 1.91 \\
\hline Miscellaneous & 8504 & 0.07 & 0.76 \\
\hline Balance Air Handling Unit & 3848 & 0.03 & 0.35 \\
\hline Mobilization and Demobilization & 1600 & 0.01 & 0.14 \\
\hline Clean-Up & 1664 & 0.01 & 0.15 \\
\hline
\end{tabular}


Table C.2 Cost for Level 2 Filtration for the High-Rise Office Building

\begin{tabular}{|l|c|c|c|}
\hline \multicolumn{1}{|c|}{ Cost Item } & Total Cost & Cost Per Unit Floor Area \\
\cline { 3 - 4 } & $\mathbf{( \$ )}$ & $\mathbf{\$} / \mathbf{f t}^{\mathbf{2}}$ & $\mathbf{\$ \mathbf { m } ^ { 2 }}$ \\
\hline HVAC Upgrade & $\mathbf{2 0 9 4 4 5}$ & $\mathbf{1 . 7 5}$ & $\mathbf{1 8 . 7 9}$ \\
\hline Remove Existing Filter Bank & 3640 & 0.03 & 0.33 \\
\hline Remove Electric Motor \& Assembly Wiring & 3952 & 0.03 & 0.35 \\
\hline Remove Centrifugal Fan & 520 & $0.00 *$ & 0.05 \\
\hline Upgrade the Air Handling Unit w/ One Bank of HEPA & 135465 & 1.13 & 12.15 \\
\hline Rated Galvanized Steel, Frames, Clips and Filters & 2070 & 0.02 & 0.19 \\
\hline Safing, Stiffener Bars and Welding & 8467 & 0.07 & 0.76 \\
\hline Electric Motor 25 hp w/ Belts and Pulley & 11773 & 0.10 & 1.06 \\
\hline Electric Motor 40 hp w/ Belts and Pulley & 6643 & 0.06 & 0.60 \\
\hline Electric Motor 50 hp w/ Belts and Pulley & 21303 & 0.18 & 1.91 \\
\hline Centrifugal Fan 40 hp & 8501 & 0.07 & 0.76 \\
\hline Miscellaneous & 3848 & 0.03 & 0.35 \\
\hline Balance Air Handling Unit & 1600 & 0.01 & 0.14 \\
\hline Clean-Up & 1664 & 0.01 & 0.15 \\
\hline Mobilization and Demobilization & $\mathbf{8 6 4 1 5}$ & $\mathbf{0 . 7 2}$ & $\mathbf{7 . 7 5}$ \\
\hline Electrical Modifications & 3921 & 0.03 & 0.35 \\
\hline Remove Miscellaneous (Wire, Conduit and Switches) & 5883 & 0.05 & 0.53 \\
\hline SWBD C/B - 600 A, 3P & 24246 & 0.20 & 2.17 \\
\hline Wire Miscellaneous & 22271 & 0.19 & 2.00 \\
\hline Conduit: 3 in EMT & 6864 & 0.06 & 0.62 \\
\hline Combination Starter Size 2/Switch & 15692 & 0.13 & 1.41 \\
\hline Combination Starter Size 3/Switch & 978 & 0.01 & 0.09 \\
\hline Conduit: 1 in EMT & 2182 & 0.02 & 0.20 \\
\hline Conduit: 1 1/4 in EMT & 1055 & 0.01 & 0.09 \\
\hline Disc. Switch 60 A, 3P & 2217 & 0.02 & 0.20 \\
\hline Disc. Switch 100 A, 3P & 1107 & 0.01 & 0.10 \\
\hline Disc. Switch 200 A, 3P & & & \\
\hline
\end{tabular}

* Entries recorded as 0.00 indicate values less than $\$ 0.01$. 
Table C.3 Cost for Level 3 Filtration for the High-Rise Office Building

\begin{tabular}{|c|c|c|c|}
\hline \multirow{2}{*}{ Cost Item } & \multirow{2}{*}{$\begin{array}{l}\text { Total Cost } \\
\text { (\$) }\end{array}$} & \multicolumn{2}{|c|}{ Cost Per Unit Floor Area } \\
\hline & & $\$ / \mathbf{f t}^{2}$ & $\$ / \mathbf{m}^{2}$ \\
\hline HVAC Upgrade & 1025156 & 8.54 & 91.96 \\
\hline Remove Existing Filter Bank & 3640 & 0.03 & 0.33 \\
\hline Remove Electric Motor \& Assembly Wiring & 3952 & 0.03 & 0.35 \\
\hline Remove Centrifugal Fan & 1560 & 0.01 & 0.14 \\
\hline $\begin{array}{l}\text { Upgrade the Air Handling Unit w/ One Bank of HEPA } \\
\text { Rated Galvanized Steel, Frames, Clips and Filters }\end{array}$ & 843564 & 7.03 & 75.67 \\
\hline Safing, Stiffener Bars and Welding & 6493 & 0.05 & 0.58 \\
\hline Electric Motor $30 \mathrm{hp} \mathrm{w} /$ Belts and Pulley & 6351 & 0.05 & 0.57 \\
\hline Electric Motor $50 \mathrm{hp} \mathrm{w/} \mathrm{Belts} \mathrm{and} \mathrm{Pulley}$ & 8868 & 0.07 & 0.80 \\
\hline Electric Motor $75 \mathrm{hp} \mathrm{w/} \mathrm{Belts} \mathrm{and} \mathrm{Pulley}$ & 13286 & 0.11 & 1.19 \\
\hline Centrifugal Fan $40 \mathrm{hp}$ & 21303 & 0.18 & 1.91 \\
\hline Centrifugal Fan 50 hp & 68933 & 0.57 & 6.18 \\
\hline Miscellaneous & 39215 & 0.33 & 3.52 \\
\hline Balance Air Handling Unit & 3848 & 0.03 & 0.35 \\
\hline Clean-Up & 1600 & 0.01 & 0.14 \\
\hline Mobilization and Demobilization & 2544 & 0.02 & 0.23 \\
\hline Electrical Modifications & 91617 & 0.76 & 8.22 \\
\hline Remove Miscellaneous (Wire, Conduit and Switches) & 3957 & 0.03 & 0.35 \\
\hline SWBD C/B - 600 A, 3P & 5883 & 0.05 & 0.53 \\
\hline Wire Miscellaneous & 24996 & 0.21 & 2.24 \\
\hline Conduit: 3 in EMT & 22271 & 0.19 & 2.00 \\
\hline Combination Starter Size 3/Switch & 19615 & 0.16 & 1.76 \\
\hline Combination Starter Size 4/Switch & 5435 & 0.05 & 0.49 \\
\hline Conduit: 1 in EMT & 414 & $0.00 *$ & 0.04 \\
\hline Conduit: 1 1/4 in EMT & 2327 & 0.02 & 0.21 \\
\hline Conduit: 2 in EMT & 813 & 0.01 & 0.07 \\
\hline Disc. Switch $100 \mathrm{~A}, 3 \mathrm{P}$ & 1478 & 0.01 & 0.13 \\
\hline Disc. Switch $200 \mathrm{~A}, 3 \mathrm{P}$ & 4428 & 0.04 & 0.40 \\
\hline
\end{tabular}

* Entries recorded as 0.00 indicate values less than $\$ 0.01$. 
Table C.4 Summary of Annual Filter Replacement Costs for the High-Rise Office Building

Part A Annual Costs per Air-Handling Unit

\begin{tabular}{|c|c|c|c|c|c|c|c|c|}
\hline \multirow{2}{*}{ System } & \multirow{2}{*}{ Material } & \multicolumn{5}{|c|}{ Cost Per Change Per AHU (costs in \$) } & \multirow{2}{*}{ Changes/Year } & \multirow{2}{*}{$\begin{array}{l}\text { Annual Cost } \\
\text { Per AHU (\$) }\end{array}$} \\
\hline & & Unit Cost & Units & Material Cost & Labor Cost & Total & & \\
\hline As Is & MERV 6 & 5 & 20 & 100 & 20 & 120 & 4 & 480 \\
\hline \multicolumn{9}{|c|}{ TOTAL } \\
\hline Level 1 & MERV 11 & 8 & 20 & 160 & 32 & 192 & 1 & 192 \\
\hline \multicolumn{9}{|c|}{ TOTAL } \\
\hline \multirow{3}{*}{ Level 2} & MERV 8 & 5 & 20 & 100 & 20 & 120 & 1 & 120 \\
\hline & MERV 13 & 125 & 20 & 2500 & 500 & 3000 & 0.33 & 1000 \\
\hline & HEPA & 300 & 20 & 6000 & 1200 & 7200 & 0.33 & 2400 \\
\hline \multicolumn{9}{|c|}{ TOTAL } \\
\hline \multirow{5}{*}{ Level 3} & MERV 8 & 5 & 20 & 100 & 20 & 120 & 1 & 120 \\
\hline & MERV 13 & 125 & 20 & 2500 & 500 & 3000 & 0.33 & 1000 \\
\hline & HEPA & 300 & 20 & 6000 & 1200 & 7200 & 0.33 & 2400 \\
\hline & GPAC & 4,500 & 20 & 90000 & 18000 & 108000 & 0.2 & 21600 \\
\hline & MERV 11 & 8 & 20 & 160 & 32 & 192 & 2 & 384 \\
\hline \multicolumn{9}{|c|}{ TOTAL } \\
\hline
\end{tabular}

NOTE: Costs are per AHU and there are six AHUs in the building. 
Table C.4 Summary of Filter Replacement Costs for High-Rise Office Building (Continued)

Part B Annual Cost Per Unit of Floor Area

\begin{tabular}{|} 
Cost Item & Total Annual Cost & \multicolumn{2}{|c|}{ Cost Per Unit Floor Area } \\
\cline { 3 - 4 } \multicolumn{2}{|c|}{} & $\mathbf{\$})$ & $\mathbf{\$} / \mathbf{f t}^{\mathbf{2}}$ & $\mathbf{\$} / \mathbf{m}^{\mathbf{2}}$ \\
\hline System As Is & $\mathbf{2 8 8 0}$ & $\mathbf{0 . 0 2}$ & $\mathbf{0 . 2 6}$ \\
\hline MERV 6 & 2880 & 0.02 & 0.26 \\
\hline System Level 1 & $\mathbf{1 1 5 2}$ & $\mathbf{0 . 0 1}$ & $\mathbf{0 . 1 0}$ \\
\hline MERV 11 & 1152 & 0.01 & 0.10 \\
\hline System Level 2 & $\mathbf{2 1 ~ 1 2 0}$ & $\mathbf{0 . 1 8}$ & $\mathbf{1 . 8 9}$ \\
\hline MERV 8 & 720 & 0.01 & 0.06 \\
\hline MERV 13 & 6000 & 0.05 & 0.54 \\
\hline HEPA & 14400 & 0.12 & 1.29 \\
\hline System Level 3 & $\mathbf{1 5 3 0 2 4}$ & $\mathbf{1 . 2 8}$ & $\mathbf{1 3 . 1 2}$ \\
\hline MERV 8 & 720 & 0.01 & 0.06 \\
\hline MERV 13 & 6000 & 0.05 & 0.54 \\
\hline HEPA & 14400 & 0.12 & 1.29 \\
\hline GPAC & 129600 & 1.08 & 11.63 \\
\hline MERV 11 & 2304 & 0.02 & 0.21 \\
\hline
\end{tabular}


Table C.5 Cost for Non-filtration Retrofits for the High-Rise Office Building

\begin{tabular}{|c|c|c|c|}
\hline \multirow{2}{*}{ Cost Item } & \multirow{2}{*}{$\begin{array}{l}\text { Total Cost } \\
\text { (\$) }\end{array}$} & \multicolumn{2}{|c|}{ Cost Per Unit Floor Area } \\
\hline & & $\$ / \mathbf{f t}^{2}$ & $\$ / \mathbf{m}^{2}$ \\
\hline Sealing the Envelope & 625326 & 5.21 & 56.09 \\
\hline Seal Exterior Windows and Openings & 352285 & 2.94 & 31.60 \\
\hline Swing Staging Equipment & 214611 & 1.79 & 19.25 \\
\hline Scaffolding & 54858 & 0.46 & 4.92 \\
\hline Seal Doors and Thresholds & 3573 & 0.03 & 0.32 \\
\hline Move Outside Air Intake to Roof & 225261 & 1.88 & 20.21 \\
\hline Swing Staging Equipment & 7495 & 0.06 & 0.67 \\
\hline Scaffolding & 10363 & 0.09 & 0.93 \\
\hline Duct Support & 11899 & 0.10 & 1.07 \\
\hline Painting & 11258 & 0.09 & 1.01 \\
\hline Remove Louver $-8 \mathrm{ft} \times 4 \mathrm{ft}$ & 208 & $0.00 *$ & 0.02 \\
\hline Bird Screen & 2804 & 0.02 & 0.25 \\
\hline Ductwork & 178256 & 1.49 & 15.99 \\
\hline Clamps, Anchors & 2978 & 0.02 & 0.27 \\
\hline Shelter-In-Place (covers six shelters in building) & 93812 & 0.78 & 8.42 \\
\hline Seal Doors and Thresholds & 5359 & 0.04 & 0.48 \\
\hline $\begin{array}{l}\text { Miscellaneous sealing (Registers, Windows, } \\
\text { Fixtures, Plates) }\end{array}$ & 4990 & 0.04 & 0.45 \\
\hline Seal Ceiling Slab Openings & 22318 & 0.19 & 2.00 \\
\hline Supply Damper Incl. Elect. Motor - 10 in Dia & 3706 & 0.03 & 0.33 \\
\hline Return Damper Incl. Elect. Motor - 16 in $x 8$ in & 3438 & 0.03 & 0.31 \\
\hline Stand Alone Filtration/Air Cleaning Units & 54000 & 0.45 & 4.84 \\
\hline Quick Shut-Off and Purge & 20949 & $\mathbf{0 . 1 7}$ & 1.88 \\
\hline System Testing, Adjusting and Balancing & 75000 & 0.63 & 6.73 \\
\hline
\end{tabular}

* Entries recorded as 0.00 indicate values less than $\$ 0.01$. 
Table C.6 Cost for Level 2 Filtration for the Office Building Lobby

\begin{tabular}{|c|c|c|c|}
\hline \multirow{2}{*}{ Cost Item } & \multirow{2}{*}{$\begin{array}{l}\text { Total Cost } \\
\text { (\$) }\end{array}$} & \multicolumn{2}{|c|}{ Cost Per Unit Floor Area } \\
\hline & & $\$ / \mathbf{f t}^{2}$ & $\$ / m^{2}$ \\
\hline HVAC Upgrade & $\$ 14112$ & 40.60 & 437.27 \\
\hline Ductwork & 1407 & 0.40 & 4.33 \\
\hline Caps & 139 & 0.04 & 0.43 \\
\hline Air Handling Unit - ACU-A2 w/ Coils & 8529 & 2.44 & 26.24 \\
\hline Ductwork & 23225 & 6.64 & 71.46 \\
\hline $\begin{array}{l}\text { Duct Insulation - Fiberglass Board Type } 3 \text { Lb Density - } 1 \\
1 / 2 \text { in Thick }\end{array}$ & 15693 & 4.48 & 48.29 \\
\hline Louver 48 in $x 48$ in with Wall Opening & 279 & 0.08 & 0.86 \\
\hline Duct - Flex. Connector & 235 & 0.07 & 0.72 \\
\hline 2 in Dia. Piping - Sch. 40 & 1409 & 0.40 & 4.34 \\
\hline Reducer 6 in $\times 2$ in & 464 & 0.13 & 1.43 \\
\hline 2 in Dia. Piping Hook-up & 5168 & 1.48 & 15.90 \\
\hline 2 in Dia. Elbow & 786 & 0.22 & 2.42 \\
\hline 2 in Dia. Piping Fiberglass Insulation -1 1/2 in Thick & 382 & 0.11 & 1.18 \\
\hline 2 in Dia. Piping - Sch. 40 & 1409 & 0.40 & 4.34 \\
\hline Demobilization & 800 & 0.23 & 2.46 \\
\hline Reducer 3 in $\times 2$ in & 317 & 0.09 & 0.97 \\
\hline 2 in Dia. Piping Hook-up & 5168 & 1.48 & 15.90 \\
\hline 2 in Dia. Elbow & 786 & 0.22 & 2.42 \\
\hline 2 in Dia. Piping Fiberglass Insulation $-11 / 2$ in Thick & 382 & 0.11 & 1.18 \\
\hline Concrete Pad & 394 & 0.11 & 1.21 \\
\hline Louver 0/A Air & 595 & 0.17 & 1.83 \\
\hline Balancing Air Handling Unit & 494 & 0.14 & 1.52 \\
\hline Controls & 16698 & 4.77 & 51.38 \\
\hline Piping & 1409 & 0.40 & 4.34 \\
\hline Valve Tag (Brass - 2 in Dia.) & 464 & 0.13 & 1.43 \\
\hline $\begin{array}{l}\text { Upgrade the Air Handling Unit w/ One (1) Bank of HEPA } \\
\text { Rated Galvanized Steel, Frames, Clips and Filters }\end{array}$ & 13631 & 3.89 & 41.94 \\
\hline Clean-Up & 624 & 0.18 & 1.92 \\
\hline Housing & 1932 & 0.55 & 5.94 \\
\hline Exhaust Fan E-A2 & 5819 & 1.66 & 17.90 \\
\hline Exhaust Fan E-A2B & 4266 & 1.22 & 13.12 \\
\hline HEPA Solution Budget Double Wall Insulated & 2645 & 0.76 & 8.14 \\
\hline $\begin{array}{l}\text { Remove \& Relocate Existing Piping, Ductwork, Electrical } \\
\text { Conduit \& Wire and Additional Material }\end{array}$ & 24998 & 7.14 & 76.92 \\
\hline Mobilization and Demobilization & 1567 & 0.45 & 4.82 \\
\hline Electrical Modifications & 9432 & 2.69 & 29.02 \\
\hline Remove Miscellaneous (Wire, Conduit, Switches) & 254 & 0.07 & 0.78 \\
\hline Combination Starter Size 1/Switch & 5354 & 1.53 & 16.47 \\
\hline Wire: \#12 THHN & 1349 & 0.39 & 4.15 \\
\hline Conduit: $3 / 4$ in EMT & 1050 & 0.30 & 3.23 \\
\hline Disc. Switch, 30 A, 3P & 1425 & 0.41 & 4.38 \\
\hline
\end{tabular}


Table C.7 Cost for Level 3 Filtration for the Office Building Lobby

\begin{tabular}{|c|c|c|c|}
\hline \multirow{2}{*}{ Cost Item } & \multirow{2}{*}{$\begin{array}{l}\text { Total Cost } \\
\quad(\$)\end{array}$} & \multicolumn{2}{|c|}{ Cost Per Unit Floor Area } \\
\hline & & $\$ / \mathbf{f t}^{2}$ & $\$ / \mathbf{m}^{2}$ \\
\hline HVAC Upgrade & 199609 & 57.03 & 614.18 \\
\hline Ductwork & 1407 & 0.40 & 4.33 \\
\hline Caps & 139 & 0.04 & 0.43 \\
\hline Air Handling Unit - ACU-A2 w/ Coils & 8529 & 2.44 & 26.24 \\
\hline Ductwork & 27194 & 7.77 & 83.67 \\
\hline $\begin{array}{l}\text { Duct Insulation - Fiberglass Board Type, } 3 \text { Lb Density - } 1 \\
1 / 2 \text { in Thick }\end{array}$ & 19653 & 5.62 & 60.47 \\
\hline Louver 48 in $x 48$ in with Wall Opening & 279 & 0.08 & 0.86 \\
\hline Duct - Flex. Connector & 235 & 0.07 & 0.72 \\
\hline 2 in Dia. Piping - Sch. 40 & 1409 & 0.40 & 4.34 \\
\hline Reducer 6 in $\times 2$ in & 464 & 0.13 & 1.43 \\
\hline 2 in Dia. Piping Hook-up & 5168 & 1.48 & 15.90 \\
\hline 2 in Dia. Elbow & 786 & 0.22 & 2.42 \\
\hline 2 in Dia. Piping Fiberglass Insulation -1 1/2 in Thick & 382 & 0.11 & 1.18 \\
\hline 2 in Dia. Piping - Sch. 40 & 1409 & 0.40 & 4.34 \\
\hline Reducer 3 in $\times 2$ in & 317 & 0.09 & 0.97 \\
\hline 2 in Dia. Piping Hook-up & 5168 & 1.48 & 15.90 \\
\hline 2 in Dia. Elbow & 786 & 0.22 & 2.42 \\
\hline 2 in Dia. Piping Fiberglass Insulation -1 1/2 in Thick & 382 & 0.11 & 1.18 \\
\hline Concrete Pad & 394 & 0.11 & 1.21 \\
\hline Louver 0/A Air & 595 & 0.17 & 1.83 \\
\hline Balancing Air Handling Unit & 494 & 0.14 & 1.52 \\
\hline Controls & 16698 & 4.77 & 51.38 \\
\hline Piping & 1409 & 0.40 & 4.34 \\
\hline Valve Tag (Brass - 2 in Dia.) & 464 & 0.13 & 1.43 \\
\hline Clean-Up & 624 & 0.18 & 1.92 \\
\hline Housing & 1932 & 0.55 & 5.94 \\
\hline Exhaust Fan E-A2 & 5819 & 1.66 & 17.90 \\
\hline Exhaust Fan E-A2C & 4266 & 1.22 & 13.12 \\
\hline HEPA and Gas Filter Equipment & 65843 & 18.81 & 202.59 \\
\hline $\begin{array}{l}\text { Remove \& Relocate Existing Piping, Ductwork, } \\
\text { Electrical Conduit \& Wire and Additional Material }\end{array}$ & 24998 & 7.14 & 76.92 \\
\hline Mobilization and Demobilization & 2366 & 0.68 & 7.28 \\
\hline Electrical Modifications & 9432 & 2.69 & 29.02 \\
\hline Remove Miscellaneous (Wire, Conduit, Switches) & 254 & 0.07 & 0.78 \\
\hline Combination Starter Size 1/Switch & 5354 & 1.53 & 16.47 \\
\hline Wire: \#12 THHN & 1349 & 0.39 & 4.15 \\
\hline Conduit: $3 / 4$ in EMT & 1050 & 0.30 & 3.23 \\
\hline Disc. Switch, $30 \mathrm{~A}, 3 \mathrm{P}$ & 1425 & 0.41 & 4.38 \\
\hline
\end{tabular}


Table C.8 Cost for Non-filtration Retrofits for the Office Building Lobby

\begin{tabular}{|l|c|c|c|}
\hline \multirow{2}{*}{ Cost Item } & Total Cost & \multicolumn{2}{c|}{ Cost Per Unit Floor Area } \\
\cline { 3 - 4 } & $\mathbf{( \$ )}$ & $\mathbf{\$} / \mathbf{f t}^{\mathbf{2}}$ & $\mathbf{\$} / \mathbf{m}^{\mathbf{2}}$ \\
\hline Isolating the Lobby & $\mathbf{6 4} \mathbf{0 6 7}$ & $\mathbf{1 8 . 3 0}$ & $\mathbf{1 9 7 . 1 3}$ \\
\hline Marble & 23508 & 6.72 & 72.33 \\
\hline Concrete Lintel & 475 & 0.14 & 1.46 \\
\hline 1/2 Tempered Glass & 10473 & 2.99 & 32.22 \\
\hline Metal Doors (Frames) Hdw & 23424 & 6.69 & 72.07 \\
\hline Seal Doors and Thresholds & 3873 & 1.11 & 11.92 \\
\hline CMU & 2314 & 0.66 & 7.12 \\
\hline Extend Outside Air Intake to Roof & $\mathbf{2 3 7 7 3}$ & $\mathbf{6 . 7 9}$ & $\mathbf{7 3 . 1 5}$ \\
\hline Opening Wall & 400 & 0.11 & 1.23 \\
\hline Bird Screen & 140 & 0.04 & 0.43 \\
\hline Ductwork & 11842 & 3.38 & 36.44 \\
\hline Clamps, Anchors & 496 & 0.14 & 1.53 \\
\hline Swing Staging Equipment & 1458 & 0.42 & 4.49 \\
\hline Scaffolding & 5073 & 1.45 & 15.61 \\
\hline Duct Support & 2400 & 0.69 & 7.38 \\
\hline Painting & 1964 & 0.56 & 6.04 \\
\hline
\end{tabular}


Table C.9 Cost for Level 2 Filtration for the Office Building Mail Room

\begin{tabular}{|c|c|c|c|}
\hline \multirow{2}{*}{ Cost Item } & \multirow{2}{*}{$\begin{array}{l}\text { Total Cost } \\
\quad(\$)\end{array}$} & \multicolumn{2}{|c|}{ Cost Per Unit Floor Area } \\
\hline & & $\$ / \mathbf{f t}^{2}$ & $\$ / m^{2}$ \\
\hline HVAC Upgrade & 63350 & 17.60 & 189.67 \\
\hline Remove Existing Filter Bank & 607 & 0.17 & 1.82 \\
\hline Remove Electric Motor \& Assembly Wiring & 693 & 0.19 & 2.08 \\
\hline $\begin{array}{l}\text { Upgrade the Air Handling Unit w/ One (1) Bank of HEPA } \\
\text { Rated Galvanized Steel, Frames, Clips and Filters }\end{array}$ & 16940 & 4.71 & 50.72 \\
\hline Safing, Stiffener Bars and Welding & 345 & 0.10 & 1.03 \\
\hline Housing Filters & 2400 & 0.67 & 7.19 \\
\hline Ductwork & 6773 & 1.88 & 20.28 \\
\hline Duct Insul. - Fiberglass Board Type - Thick $11 / 2$ in & 5818 & 1.62 & 17.42 \\
\hline Electric Motor $2 \mathrm{hp}$ & 688 & 0.19 & 2.06 \\
\hline Electric Motor $40 \mathrm{hp} \mathrm{w/} \mathrm{Belts} \mathrm{and} \mathrm{Pulley}$ & 5887 & 1.64 & 17.62 \\
\hline Exhaust Fan E-A2 & 4267 & 1.19 & 12.78 \\
\hline Exhaust Fan E-A2B & 4267 & 1.19 & 12.78 \\
\hline Exhaust Fan Filters (3 Stage) & 8907 & 2.47 & 26.67 \\
\hline Handling and Shipping $5 \%$ on Material & 1708 & 0.47 & 5.11 \\
\hline Clean-Up & 277 & 0.08 & 0.83 \\
\hline Sealant & 223 & 0.06 & 0.67 \\
\hline Balancing Air Handling Unit & 641 & 0.18 & 1.92 \\
\hline Exhaust Register 24 in $\times 12$ in & 654 & 0.18 & 1.96 \\
\hline Exhaust Registers 24 in $\times 12$ in & 654 & 0.18 & 1.96 \\
\hline Mobilization and Demobilization & 1600 & 0.44 & 4.79 \\
\hline Electrical Modifications & 8897 & 2.47 & 26.64 \\
\hline Remove Miscellaneous (Wire, Conduit, Switches) & 667 & 0.19 & 2.00 \\
\hline Combination Starter Size 3/Switch & 3923 & 1.09 & 11.75 \\
\hline Miscellaneous Wire & 483 & 0.13 & 1.45 \\
\hline Conduit: $11 / 4$ in EMT & 388 & 0.11 & 1.16 \\
\hline Disc. Switch, 100 A, 3P & 739 & 0.21 & 2.21 \\
\hline Combination Starter Size 0/Switch & 1785 & 0.50 & 5.34 \\
\hline Conduit: $3 / 4$ in EMT & 438 & 0.12 & 1.31 \\
\hline Disc. Switch, $30 \mathrm{~A}, 3 \mathrm{P}$ & 475 & 0.13 & 1.42 \\
\hline
\end{tabular}


Table C.10 Cost for Level 3 Filtration for the Office Building Mail Room

\begin{tabular}{|c|c|c|c|}
\hline \multirow{2}{*}{ Cost Item } & \multirow{2}{*}{$\begin{array}{l}\text { Total Cost } \\
\text { (\$) }\end{array}$} & \multicolumn{2}{|c|}{ Cost Per Unit Floor Area } \\
\hline & & $\$ / \mathbf{f t}^{2}$ & $\$ / \mathbf{m}^{2}$ \\
\hline HVAC Upgrade & 156118 & 42.85 & 461.87 \\
\hline Remove Existing Filter Bank & 607 & 0.17 & 1.82 \\
\hline Remove Electric Motor \& Ass. Wiring & 693 & 0.19 & 2.08 \\
\hline Remove Exhaust Fan & 260 & 0.07 & 0.78 \\
\hline $\begin{array}{l}\text { Upgrade the Air Handling Unit w/ One (1) Bank of HEPA } \\
\text { Rated Galvanized Steel, Frames, Clips and Filters }\end{array}$ & 81592 & 22.66 & 244.29 \\
\hline Safing, Stiffener Bars and Welding & 345 & 0.10 & 1.03 \\
\hline Housing Filters & 3310 & 0.92 & 9.91 \\
\hline Ductwork & 6773 & 1.88 & 20.28 \\
\hline Duct Insul. - Fiberglass Board Type - Thick $11 / 2$ in & 5818 & 1.62 & 17.42 \\
\hline Electric Motor $2 \mathrm{hp}$ & 688 & 0.19 & 2.06 \\
\hline Electric Motor $40 \mathrm{hp} \mathrm{w} /$ Belts and Pulley & 5887 & 1.64 & 17.62 \\
\hline Exhaust Fan E-A2 & 4267 & 1.19 & 12.78 \\
\hline Exhaust Fan E-A2C & 4983 & 1.38 & 14.92 \\
\hline Exhaust Fan $2 \mathrm{hp}$ & 1852 & 0.51 & 5.54 \\
\hline Exhaust Fan Filters (5 Stage) & 30389 & 8.44 & 90.98 \\
\hline Handling and Shipping $5 \%$ on Material & 5081 & 1.41 & 15.21 \\
\hline Clean-Up & 424 & 0.12 & 1.27 \\
\hline Sealant & 254 & 0.07 & 0.76 \\
\hline Balancing Air Handling Unit & 641 & 0.18 & 1.92 \\
\hline Exhaust Registers 24 in $\times 12$ in & 654 & 0.18 & 1.96 \\
\hline Mobilization and Demobilization & 1600 & 0.44 & 4.79 \\
\hline Electrical Modifications & 8897 & 2.47 & 26.64 \\
\hline Remove Miscellaneous (Wire, Conduit, Switches) & 667 & 0.19 & 2.00 \\
\hline Combination Starter Size 3/Switch & 3923 & 1.09 & 11.75 \\
\hline Wire Miscellaneous & 483 & 0.13 & 1.45 \\
\hline Conduit: $11 / 4$ in EMT & 388 & 0.11 & 1.16 \\
\hline Disc. Switch, 100 A, 3P & 739 & 0.21 & 2.21 \\
\hline Combination Starter Size 0/Switch & 1785 & 0.50 & 5.34 \\
\hline Conduit: $3 / 4$ in EMT & 438 & 0.12 & 1.31 \\
\hline Disc. Switch, 30 A, 3P & 475 & 0.13 & 1.42 \\
\hline
\end{tabular}


Table C.11 Cost Per Unit of Floor Area for the Air Sealing Retrofit of the Mail Room

\begin{tabular}{|l|c|c|c|}
\hline \multirow{2}{*}{ Cost Item } & Total Cost & \multicolumn{2}{|c|}{ Cost Per Unit Floor Area } \\
\cline { 3 - 4 } & $\mathbf{( \$ )}$ & $\mathbf{\$} / \mathbf{f t}^{\mathbf{2}}$ & $\mathbf{\$} / \mathbf{m}^{\mathbf{2}}$ \\
\hline Sealing the Envelope & $\mathbf{2 9 ~ 0 8 6}$ & $\mathbf{8 . 0 8}$ & $\mathbf{8 7 . 0 8}$ \\
\hline Seal/Patch Corridor Walls & 15798 & 4.39 & 47.30 \\
\hline Replace/Install Thresholds & 952 & 0.26 & 2.85 \\
\hline Seal Doors & 1570 & 0.44 & 4.70 \\
\hline Seal/Patch Ceiling Slab & 10766 & 2.99 & 32.23 \\
\hline
\end{tabular}

Table C.12 Cost for Level 1 Filtration for the Low-Rise Office Building

\begin{tabular}{|l|c|c|c|}
\hline \multicolumn{1}{|c|}{ Cost Item } & Total Cost & \multicolumn{2}{c|}{ Cost Per Unit Floor Area } \\
\cline { 3 - 4 } & $\mathbf{( \$ )}$ & $\mathbf{\$} / \mathbf{f t}^{\mathbf{2}}$ & $\mathbf{\$ \mathbf { m } ^ { 2 }}$ \\
\hline HVAC Upgrade & $\mathbf{2 0 9 9}$ & $\mathbf{0 . 1 2}$ & $\mathbf{1 . 3 0}$ \\
\hline Remove Filters & 170 & 0.01 & 0.11 \\
\hline New Filters & 956 & 0.06 & 0.59 \\
\hline Clean-Up & 173 & 0.01 & 0.11 \\
\hline Mobilization & 800 & 0.05 & 0.50 \\
\hline Electrical Modifications & $\mathbf{1 1 7 9 2}$ & $\mathbf{0 . 6 8}$ & $\mathbf{7 . 3 1}$ \\
\hline Remove Panel CB - 400 A & 213 & 0.01 & 0.13 \\
\hline MCB - 400 A w/ Shunt Trip, 480 V & 9806 & 0.57 & 6.08 \\
\hline Emergency Mushroom Push Button & 223 & 0.01 & 0.14 \\
\hline Wire: \#12 THHN & 346 & 0.02 & 0.21 \\
\hline Conduit: 3/4 in EMT & 1203 & 0.07 & 0.75 \\
\hline
\end{tabular}


Table C.13 Cost for Level 2 Filtration for the Low-Rise Office Building

\begin{tabular}{|l|c|c|c|}
\hline \multicolumn{1}{|c|}{ Cost Item } & Total Cost & \multicolumn{2}{c|}{ Cost Per Unit Floor Area } \\
\cline { 3 - 4 } & $\mathbf{( \$ )}$ & $\mathbf{\$} / \mathbf{f t}^{\mathbf{2}}$ & $\mathbf{\$ / \mathbf { m } ^ { \mathbf { 2 } }}$ \\
\hline HVAC Upgrade & $\mathbf{1 9 3 7 3 4}$ & $\mathbf{1 1 . 1 7}$ & $\mathbf{1 2 0 . 1 8}$ \\
\hline $\begin{array}{l}\text { One (1) Bank of HEPA Rated, Casing and Filters, Clips } \\
\text { and Filters }\end{array}$ & 90031 & 5.19 & 55.85 \\
\hline Steel Platform for Fans \& Filters & 26877 & 1.55 & 16.67 \\
\hline Centrifugal Fan 20 hp & 26235 & 1.51 & 16.28 \\
\hline Ductwork & 42071 & 2.42 & 26.10 \\
\hline Clean-Up & 624 & 0.04 & 0.39 \\
\hline Sealant & 856 & 0.05 & 0.53 \\
\hline Balancing Air Handling Unit & 6239 & 0.36 & 3.87 \\
\hline Mobilization & 800 & 0.05 & 0.50 \\
\hline Electrical Modifications & $\mathbf{6 9 5 5 0}$ & $\mathbf{4 . 0 1}$ & $\mathbf{4 3 . 1 5}$ \\
\hline Panel C/B: 70A - 3P - 480 V W/S Hunt Trip & 1696 & 0.10 & 1.05 \\
\hline VFD/Switch, 25 hp, 4 BOV, NEMA 3R & 46370 & 2.67 & 28.77 \\
\hline Wire: \#6 THHN & 1634 & 0.09 & 1.01 \\
\hline Wire: \#8 THHN & 412 & 0.02 & 0.26 \\
\hline Conduit: 1 1/4 in RGS & 7495 & 0.43 & 4.65 \\
\hline Remove Panel CB - 400 A & 213 & 0.01 & 0.13 \\
\hline MCB - 400 A w/ Shunt Trip, 480 V & 9806 & 0.57 & 6.08 \\
\hline Emergency Mushroom Push Button & 223 & 0.01 & 0.14 \\
\hline Wire: \#12 THHN & 365 & 0.02 & 0.23 \\
\hline Conduit: 3/4 in EMT & 1337 & 0.08 & 0.83 \\
\hline
\end{tabular}


Table C.14 Cost for Level 3 Filtration for the Low-Rise Office Building

\begin{tabular}{|l|c|c|c|}
\hline \multirow{2}{*}{ Cost Item } & Total Cost & \multicolumn{2}{c|}{ Cost Per Unit Floor Area } \\
\cline { 3 - 4 } & $\mathbf{( \$ )}$ & $\mathbf{\$} / \mathbf{f t}^{\mathbf{2}}$ & $\mathbf{\$ \mathbf { m } ^ { 2 }}$ \\
\hline HVAC Upgrade & $\mathbf{2 8 4} \mathbf{1 3 2}$ & $\mathbf{1 6 . 3 8}$ & $\mathbf{1 7 6 . 2 6}$ \\
\hline $\begin{array}{l}\text { One (1) Bank of HEPA Rated, Casing and Filters, Clips } \\
\text { and Filters }\end{array}$ & 172189 & 9.92 & 106.82 \\
\hline Steel Platform for Fans \& Filters & 26877 & 1.55 & 16.67 \\
\hline Ductwork & 42071 & 2.42 & 26.10 \\
\hline Centrifugal Fan & 34475 & 1.99 & 21.39 \\
\hline Clean-Up & 624 & 0.04 & 0.39 \\
\hline Sealant & 856 & 0.05 & 0.53 \\
\hline Balancing Air Handling Unit & 6239 & 0.36 & 3.87 \\
\hline Mobilization & 800 & 0.05 & 0.50 \\
\hline Electrical Modifications & $\mathbf{6 9 5 5 0}$ & $\mathbf{4 . 0 1}$ & $\mathbf{4 3 . 1 5}$ \\
\hline Panel C/B: 70A - 3P - 480 V W/S Hunt Trip & 1696 & 0.10 & 1.05 \\
\hline VFD/Switch, 25 hp, 4 BOV, NEMA 3R & 46370 & 2.67 & 28.77 \\
\hline Wire: \#6 THHN & 1634 & 0.09 & 1.01 \\
\hline Wire: \#8 THHN & 412 & 0.02 & 0.26 \\
\hline Conduit: 1 1/4 in RGS & 7495 & 0.43 & 4.65 \\
\hline Remove Panel CB - 400A & 213 & 0.01 & 0.13 \\
\hline MCB - 400 A w/ Shunt Trip, 480 V & 9806 & 0.57 & 6.08 \\
\hline Emergency Mushroom Push Button & 223 & 0.01 & 0.14 \\
\hline Wire: \#12 THHN & 365 & 0.02 & 0.23 \\
\hline Conduit: 3/4 in EMT & 1337 & 0.08 & 0.83 \\
\hline
\end{tabular}

Table C.15 Cost for Envelope Air Sealing of the Low-Rise Office Building

\begin{tabular}{|l|c|c|c|}
\hline \multicolumn{1}{|c|}{ Cost Item } & Total Cost & \multicolumn{2}{c|}{ Cost Per Unit Floor Area } \\
\cline { 3 - 4 } & $\mathbf{( \$ )}$ & $\mathbf{\$} / \mathbf{f t}^{\mathbf{2}}$ & $\mathbf{\$} / \mathbf{m}^{\mathbf{2}}$ \\
\hline Seal Envelope & $\mathbf{3 2 ~ 3 5 6}$ & $\mathbf{1 . 8 6}$ & $\mathbf{2 0 . 0 7}$ \\
\hline Seal Exterior Windows & 7046 & 0.41 & 4.37 \\
\hline Seal Crawl Space Openings & 17332 & 1.00 & 10.75 \\
\hline Seal Doors and Thresholds & 2680 & 0.15 & 1.66 \\
\hline Sheet Metal & 2866 & 0.17 & 1.78 \\
\hline Patch Roof & 2433 & 0.14 & 1.51 \\
\hline
\end{tabular}

